\title{
Preference Planning and Unsustainable Desires: A hypothesis toward 'How' contextual and psychological factors influence travel attitudes through qualitative and quantitative measures
}

by

\section{Domenico Betanzo}

A thesis submitted in fulfilment of the requirements for the degree of

\section{Doctor of Philosophy of Architecture}

Victoria University of Wellington. Faculty of Architecture and Design 
Counter to the prevailing view that sees travel attitudes as influencing neighbourhood location decisions, this dissertation sets out to examine if where individuals choose to live has an effect on travel attitudes. To achieve this, both a quantitative and qualitative analysis of the relationship between travel attitudes, place attachment and length of tenure is performed. An association between place attachment and travel attitudes would suggest that travel attitudes, and subsequent travel behaviours, are a result of neighbourhood location considerations rather than an influencing factor on them. This too is the case for an association between length of tenure and travel attitudes. While previous research identifies associations between contextual physical factors or psychological factors and travel behaviour, how these factors exert their influence is relatively undefined. With the proposition of an association between travel attitudes, place attachment and length of tenure, an underlying mechanism to these previous associates is tested. Because place attachment occurs over time and after a decision has been made to reside in a particular neighbourhood, and likewise because length of tenure is time dependent, a connection between either of these factors and travel attitudes supports the hypothesis that travel attitudes may just as likely be a result of residential location choices as they are an influence on them. For this reason, both of these variables are referred to as post-decision reasoning factors and are perceived as the mechanisms through which decisions are justified after they have been made.

While travel behaviour literature is currently focused on the role latent travel attitudes have on residential location choices, housing choice literature consistently finds travel attitudes or neighbourhood factors a distant second to dwelling considerations. ${ }^{1}$ Dwelling size versus price, housing quality, yard and overall house size all have a greater influence on residential location decisions. Even when neighbourhood considerations are made in addition to dwelling characteristic factors, travel attitudes again rank lower than school quality, perceived safety and even the image of the neighbourhood. This dissertation is

\footnotetext{
${ }^{1}$ Dieleman et al., 2000 
placed to add clarity to the discrepancy between travel behaviour and housing choice literature.

An initial pilot study examined the relation between liveability and density and guided this dissertation toward travel behaviour, neighbourhood location decisions and the important role of attitudes to these two domains. Typically travel behaviour is compared between two neighbourhood typologies. These are either conventional or traditional. The former reflects status-quo land development with long winding cul-de-sacs, separated uses, a lack of centeredness and low connectivity. The latter is more akin to neighbourhoods developed before the Second World War and have higher densities, mixed uses, and are generally directed towards pedestrians rather than the automobile. Two traditional and two conventional neighbourhoods from Canada and New Zealand were used as case studies for the main research. Three-hundred households in each of the four case studies received a survey that inquired about residents' preferences toward travel modes and neighbourhood types and included psychological variables used for the prediction of travel behaviour as well as typical socio-demographic variables and the two post-decision reasoning factors of place attachment and length of tenure. This survey was analysed using multiple regression to determine the influence of post-decision reasoning variables. In addition to this quantitative survey, an on-line qualitative survey assessed residents' opinions for what motivates their travel and neighbourhood location decisions. The relative discourse patterns that developed from the qualitative survey provide a context against which the quantitative findings are interpreted. This provides validation to the quantitative findings as well as a theoretically robust method to infer causation.

Findings indicated that attitudes were not correlated to post-decision reasoning variables but that they may still have formed after a neighbourhood selection decision was made and not prior. Here an unanticipated correlation between perceived behavioural control and travel attitudes was observed. Likewise, another unanticipated result suggests a greater mismatch between travel preferences and behaviours than previous studies have found.

While the focus in environmental psychology is on segmenting survey populations into personality cohorts, with the aim of tailoring policy to these subgroups, the findings from the present study suggest a greater concentration should be paid to the context within 
which diverse populations develop. Here, both the qualitative and quantitative results indicate that rather than attitudes informing environmentally supportive behaviours, such as travel behaviour, an individual's social and physical context may afford them opportunities to hold environmentally supportive attitudes instead of the other way around. While the vast majority of research within this field appears satisfied with correlating varying attitudes to positive environmental behaviour rather than explaining why these differences exist, the present study explores a hypothesis toward this rationalization. Here, post-decision reasoning provides a reliable explanation of travel behaviour and this understanding further informs how to more effectively engage with groups and individuals toward increased sustainable behaviour. 


\section{Acknowledgements}

All my life I have wondered what mind-boggling meant. For every answer revealed, another ten questions must be asked. But one certainty remains, those to whom I am thankful and who made this dissertation possible.

I'd like to thank Sinclair Knight Merz (SKM) and Derek McCoy who hired me as an engineer and yet contributed financially to my expressed desire to become an urban designer. Ultimately, I was never able to meet the demands of both a practising professional and budding academic. Suffice to say, academia prevailed.

I don't imagine I'm the cause, however two of the three supervisors I've had during my research both left. One left academia all together and the other left the country. All the same, I'd like to thank Graeme McIndoe, my initial supervisor, for his enthusiastic support, coffees and guidance until his departure. Our often tangential conversations provided much of the context to my early research and added a unique value to my postgraduate experience, something I am grateful for. To Gordon Holden, my second supervisor, I can't decide if I should curse or thank him for recommending that I pursue doctoral research. However, his support in this pursuit is both valued and highly respected, and I expect his new students across the ditch will benefit enormously from his input. I'd also like to thank my third supervisor, Ray Cole. While our contact has been limited, our disciplinary backgrounds diverse and our universities separate, I'm thankful for his recognition of the interdisciplinary nature of my research and his encouragement to pursue this new domain.

My upmost gratitude goes to John Duncan and Building Research. Their financial support has carried through from my Masters to my $\mathrm{PhD}$, and quite literally without them, I simply could not have pursued this life dream.

A big thankyou goes to my mother. Her edits, dinners, leg work and ear all made this experience possible. To my Aunt Ceil, for her data collecting and photos, I am also grateful. The tedium of folding surveys and licking envelopes was shared by my brother 
Diego, and to him I am also grateful. Diego also acted as my agent in New Zealand while I laboured away in my home office in Canada, and without this help I don't know to whom I could have turned. To my other brother Adrian, I am thankful for his mapping help. He provided much of the raw data for the Canadian case studies as an engineer to the City of Victoria and again, without his help I would most likely still be digitizing raster maps. And to my friends in New Zealand, Thomas and Hannah Schikendanz, I am thankful to them for the delivery of my surveys when the emergency of the early birth of my first child in Canada pulled me away from this duty prematurely.

The biggest thanks, however, goes to my loving partner Vanessa. Throughout my life she has been my muse, my peer, my friend, my soundboard, my reasoning and my motivation. She has supported me financially, emotionally and spiritually and is without question the sole reason I have been afforded the privilege of four years university and the opportunity to pursue my interests. She is also the wonderful mother of my wee man Ogden.

Although Ogden was born two months earlier than planned, and at a time when I was fourteen thousand miles away, he is, without question, an endless well of joy and a most pleasant distraction from the grind of research.

This dissertation is dedicated to my father, who's passing, more than anything, was the inspiration to get on with my life and to start doing the things I want. 


\section{Table of $\mathbf{C}_{\text {ontents }}$}

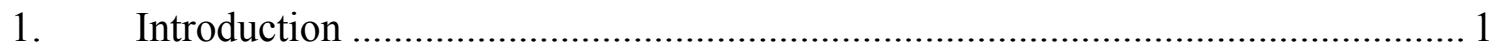

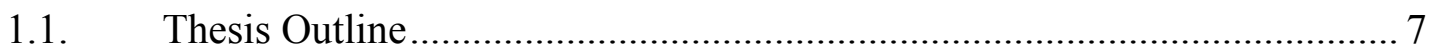

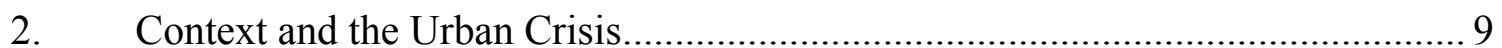

2.1. Environmental Determinism.................................................................. 10

2.2. Demographic Change ……………………………………………..... 17

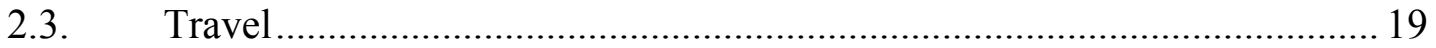

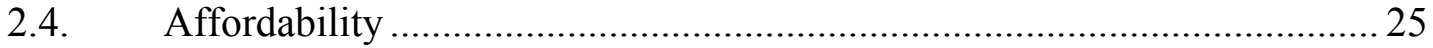

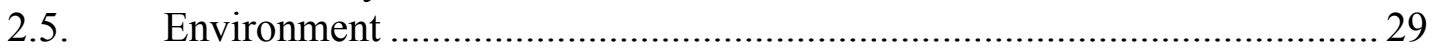

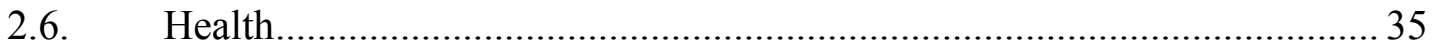

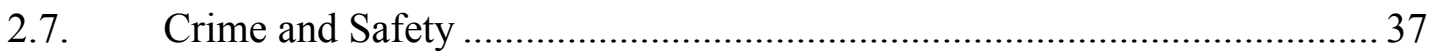

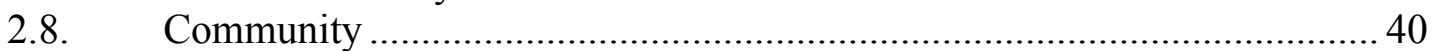

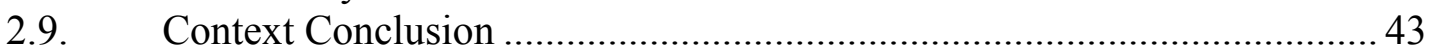

3. Psychological Behaviour Explanations .............................................................. 44

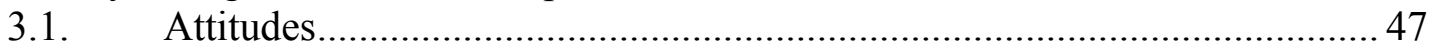

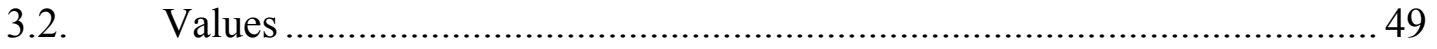

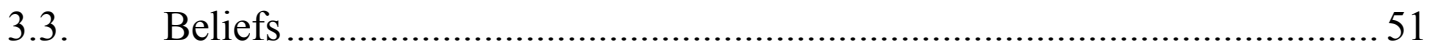

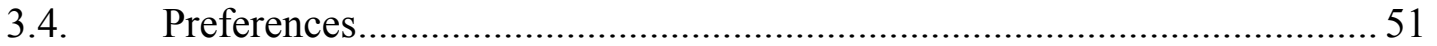

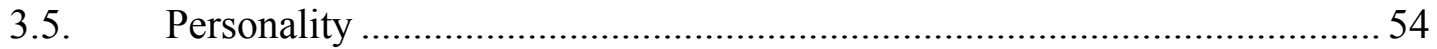

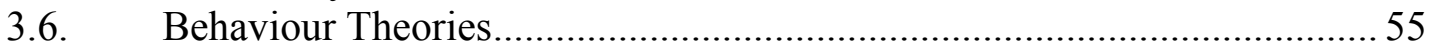

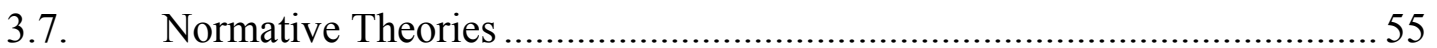

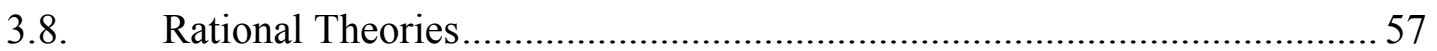

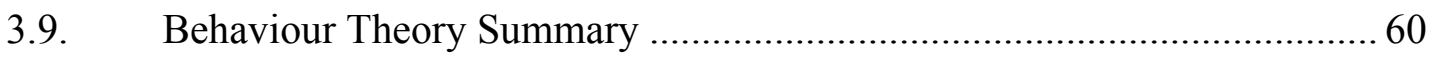

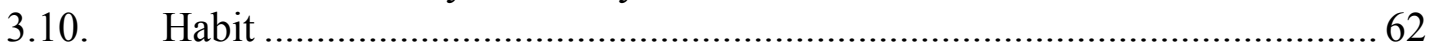

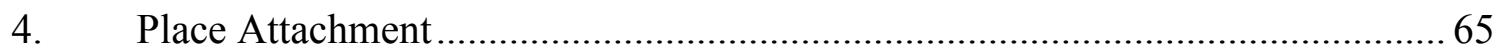

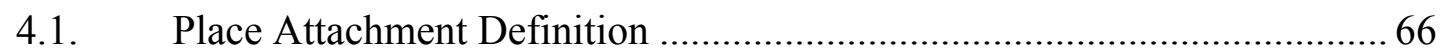

4.2. Place Attachment Limitations ……………………………………….......... 67

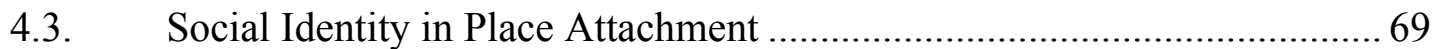

4.4. Conformity in Social Identity ................................................................ 71

4.5. Persuasion and Social Identity................................................................ 72

4.6. Place Attachment and Social Identity Associations ................................. 73

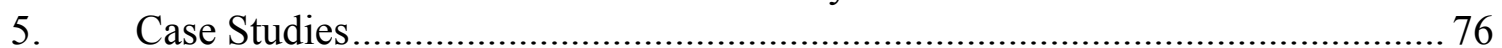

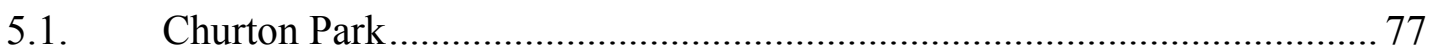

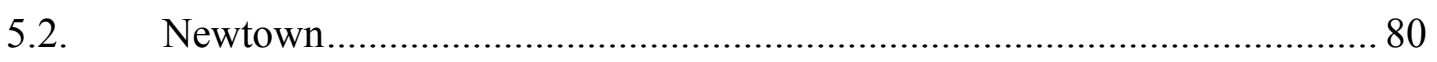

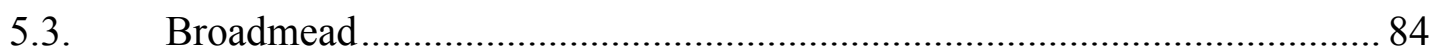

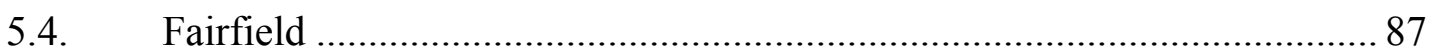

5.5. Physical Attribute Assessment ……………………………………........ 90

5.6. Pilot Study Liveability Survey ………………………………………...... 97

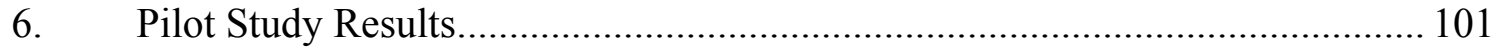

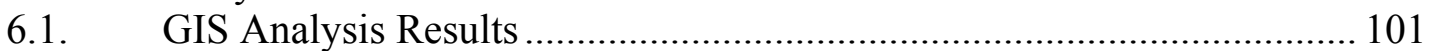

6.2. Pilot Study Liveability Findings......................................................... 109

6.3. Pilot Study Discussion....................................................................... 111

6.4. Pilot Study Conclusion ......................................................................... 117

7. Forming Travel Attitudes -Main Study Methodology ………………………..... 120

7.1. Measuring Moving Targets ………………………………………….... 124

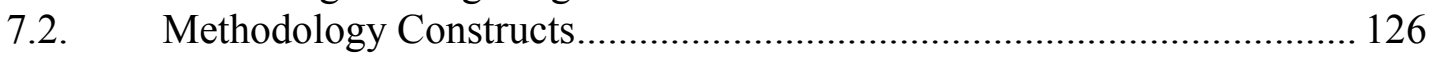


7.3. Stated and Revealed Preferences............................................................ 127

7.4. Conjoint Neighbourhood Preferences .................................................... 129

7.5. Problem Awareness ............................................................................... 132

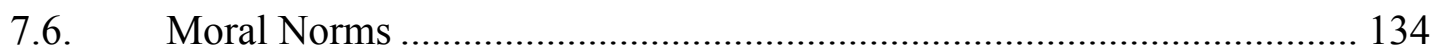

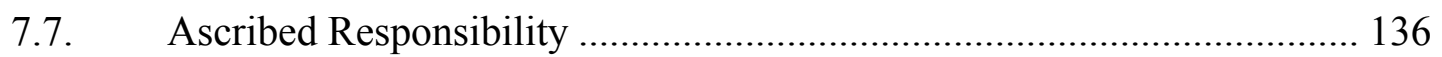

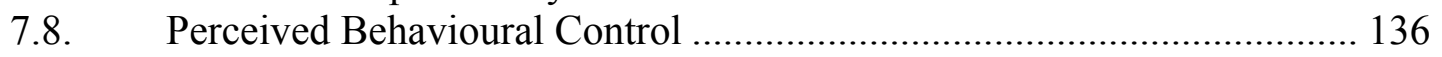

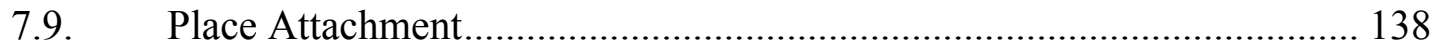

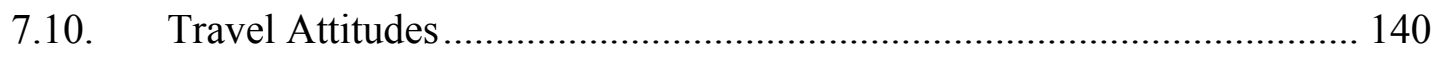

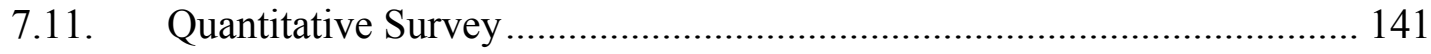

7.12. Quantitative Survey Analysis Methodology …...................................... 141

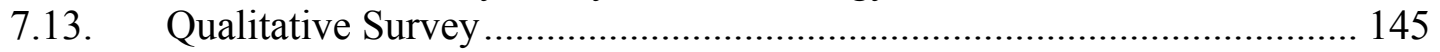

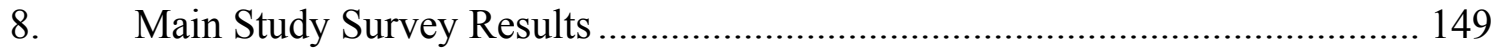

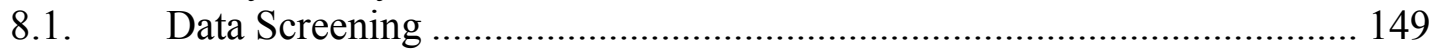

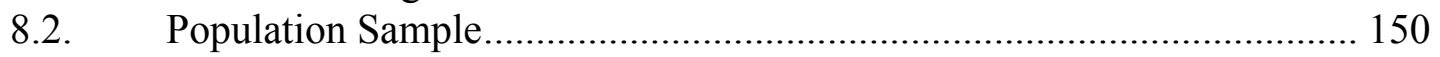

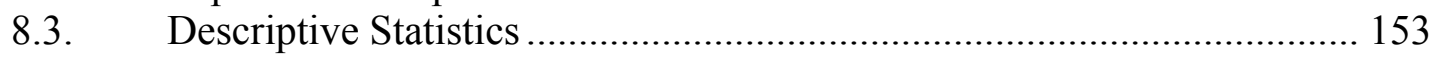

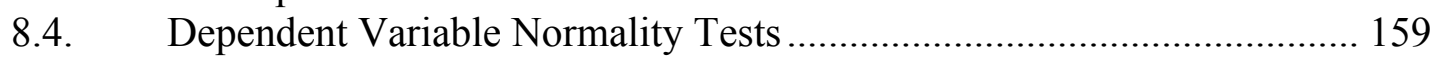

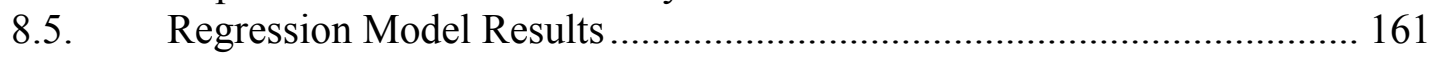

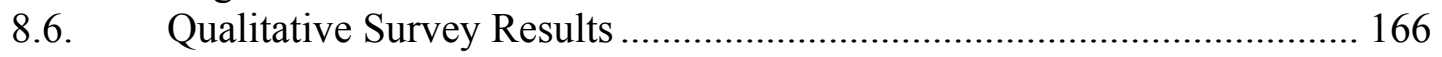

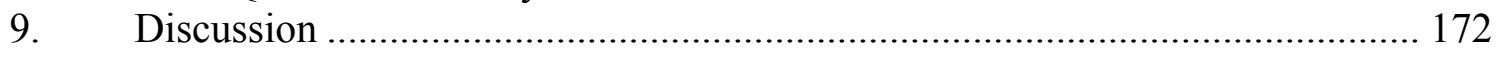

9.1. Post-Decision Reasoning Variables .................................................... 172

9.2. Perceived Behavioural Control ........................................................... 175

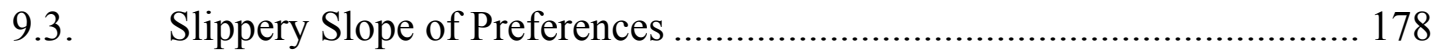

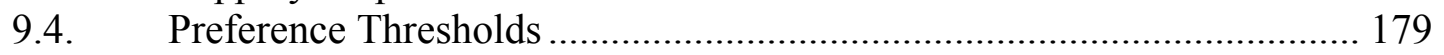

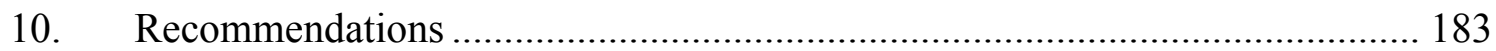

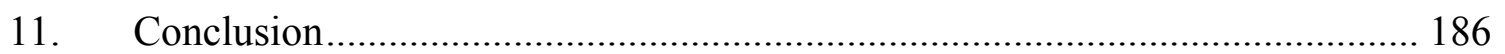

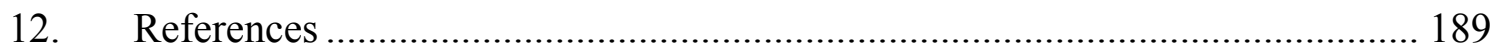

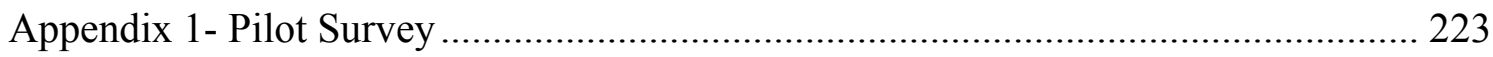

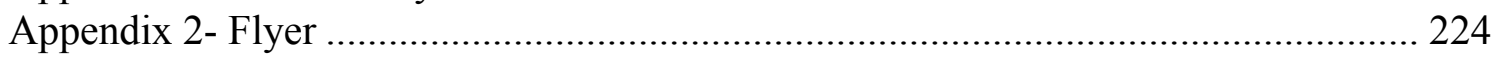

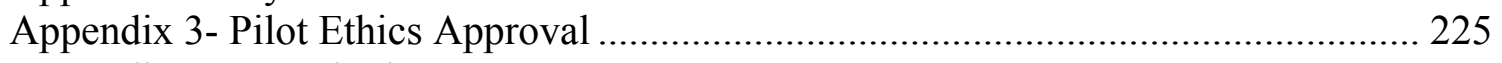

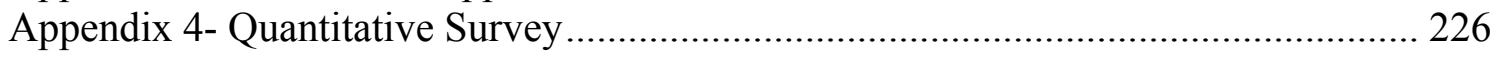

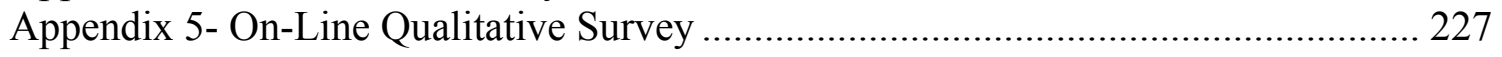

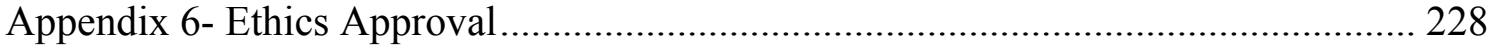




\section{Tables and Figures}

\section{Tables}

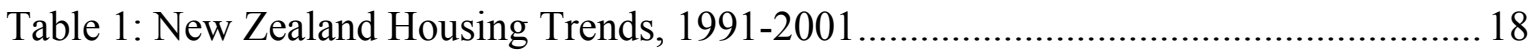

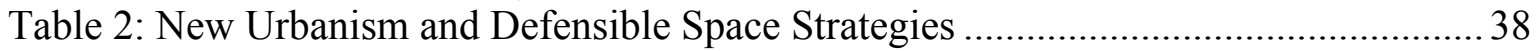

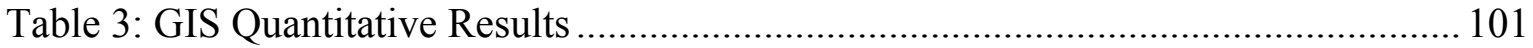

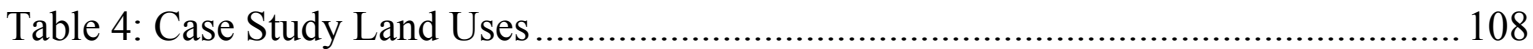

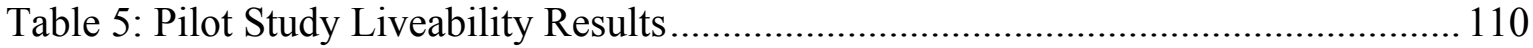

Table 6: Conventional Neighbourhood Socio-demographics ....................................... 150

Table 7: Traditional Neighbourhood Socio-demographics .......................................... 150

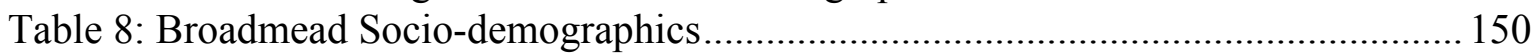

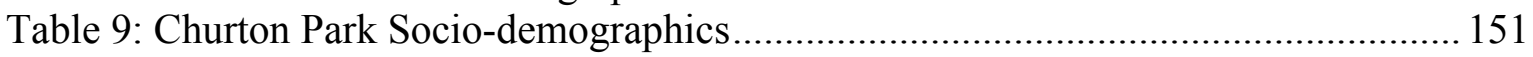

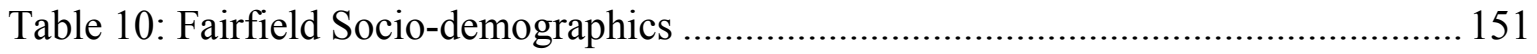

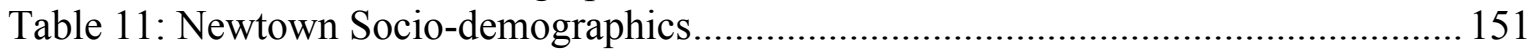

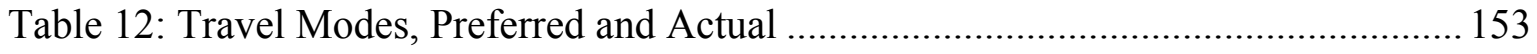

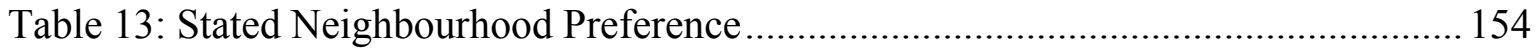

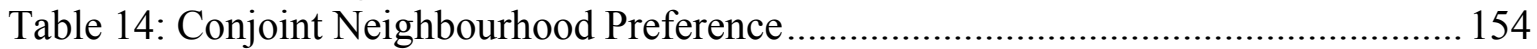

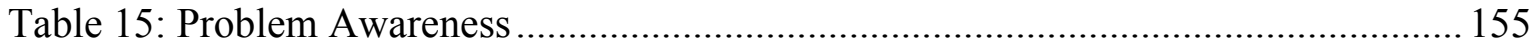

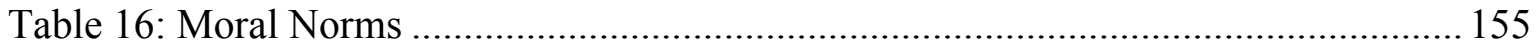

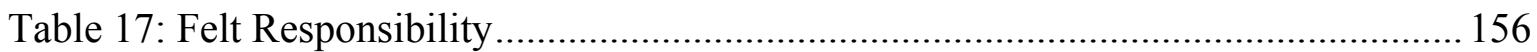

Table 18: Perceived Behavioural Control (private vehicle) .............................................. 156

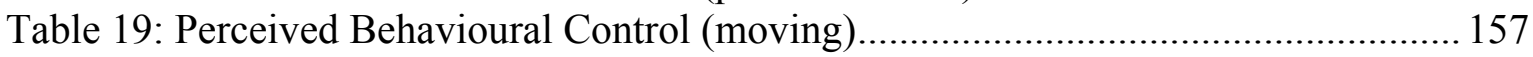

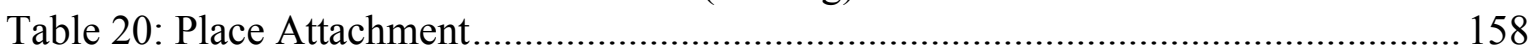

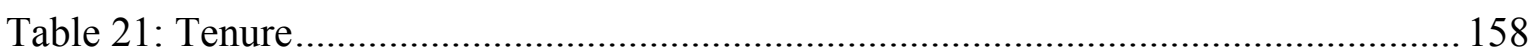

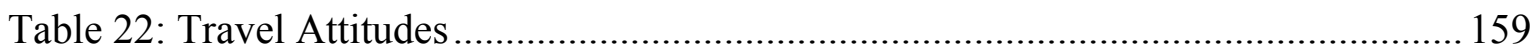

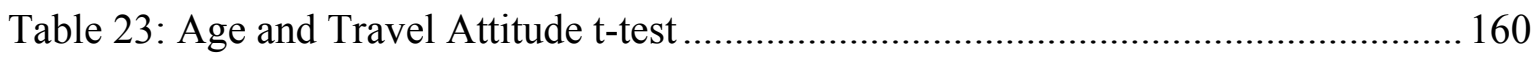

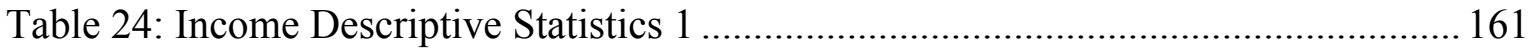

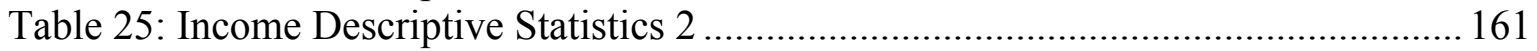

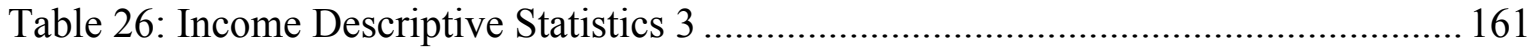

Table 27: Conventional Neighbourhood Travel Attitude Regression .............................. 163

Table 28: Traditional Neighbourhood Travel Attitude Regression................................... 165

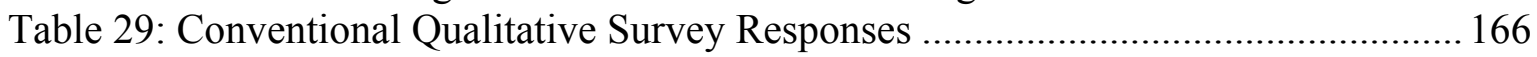

Table 30: Traditional Neighbourhood Qualitative Survey Responses ............................. 167

\section{Figures}

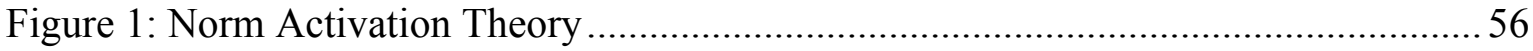

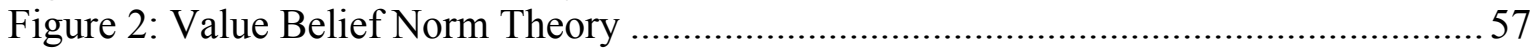

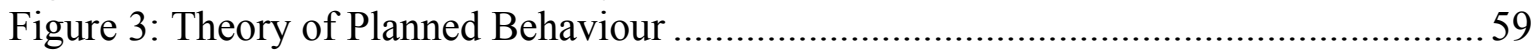

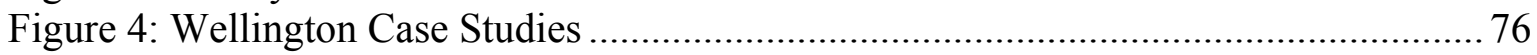

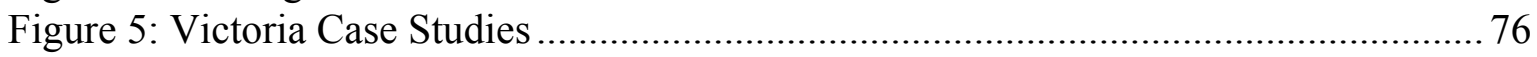

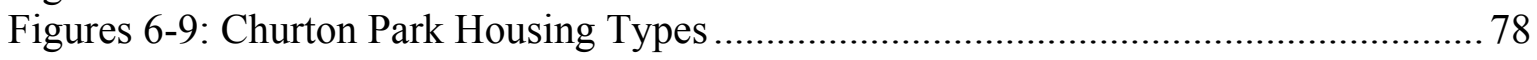

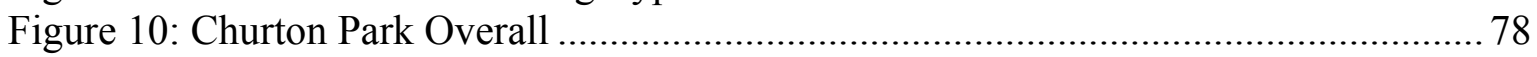

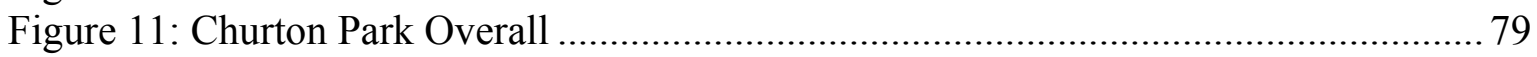

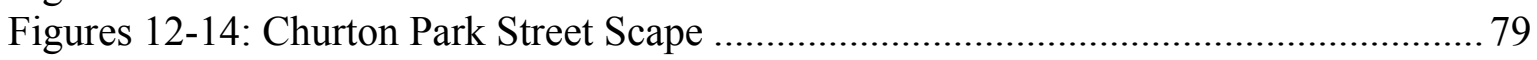

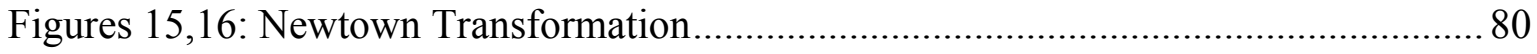




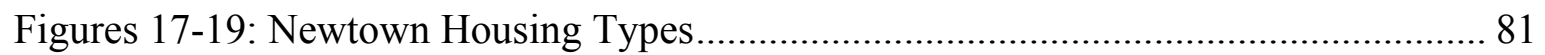

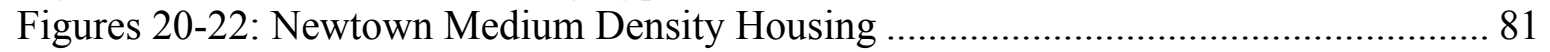

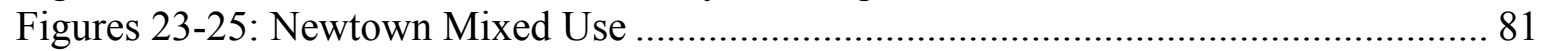

Figure 26: Newtown Samuel Charles Brees Painting .................................................... 82

Figures 27-29: Newtown Council Housing................................................................ 82

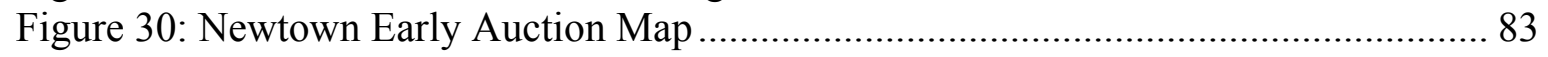

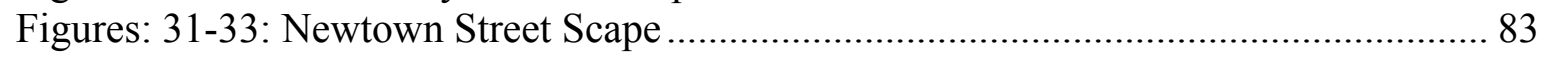

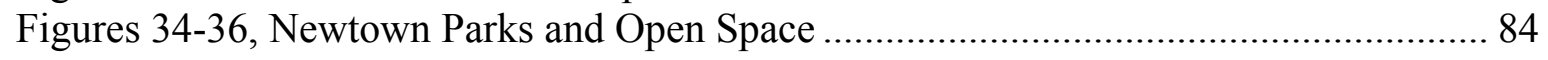

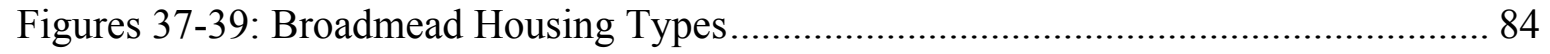

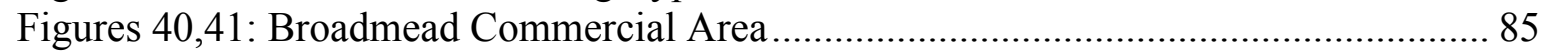

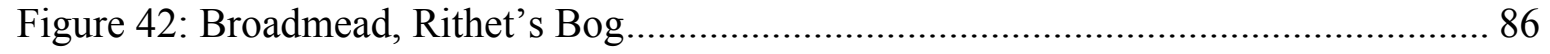

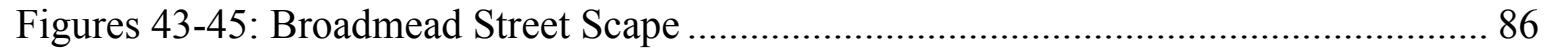

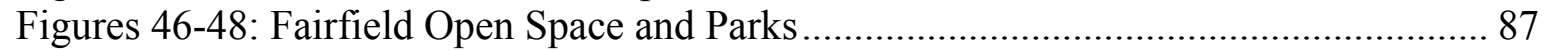

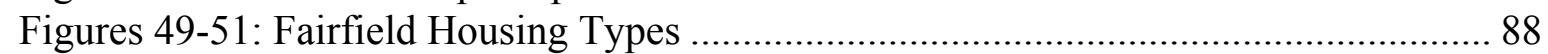

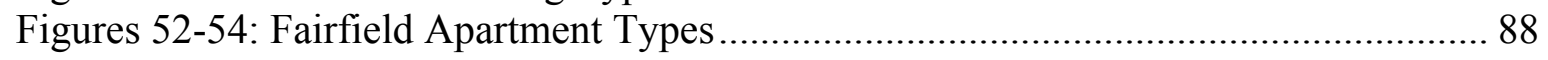

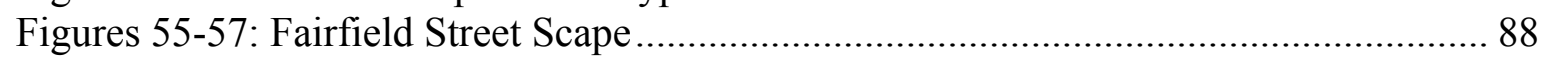

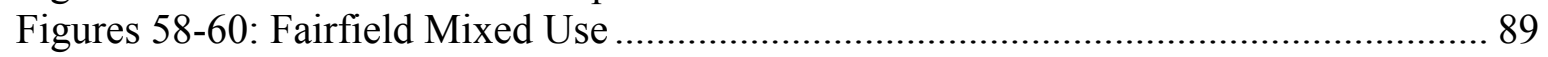

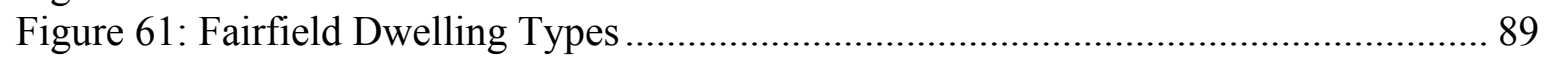

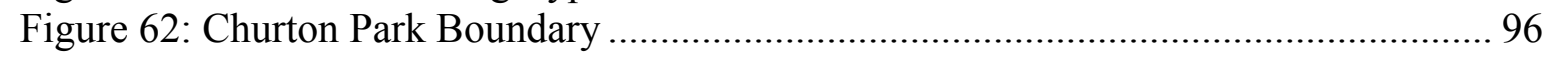

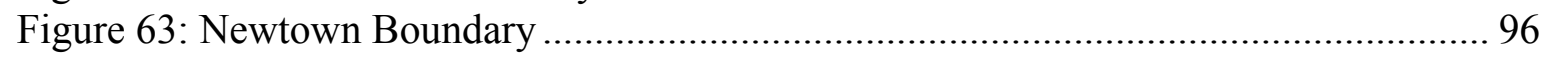

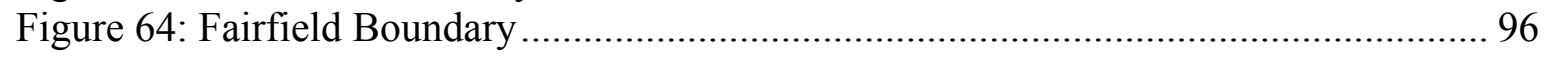

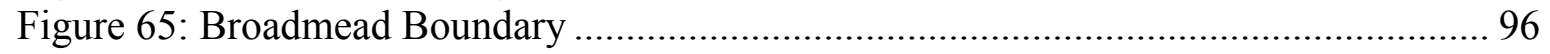

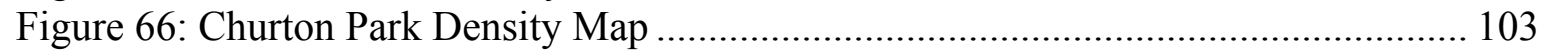

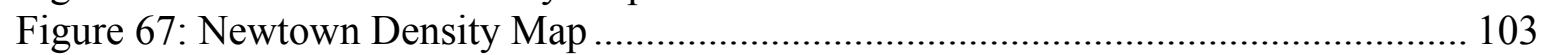

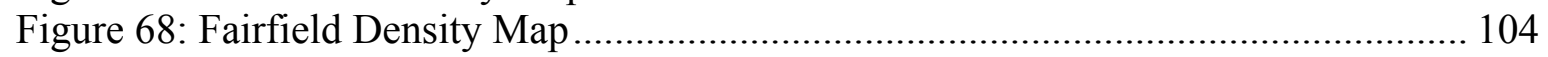

Figure 69: Broadmead Density Map ............................................................................... 104

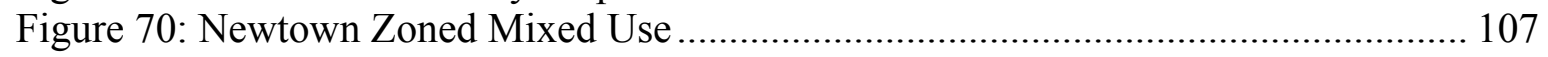

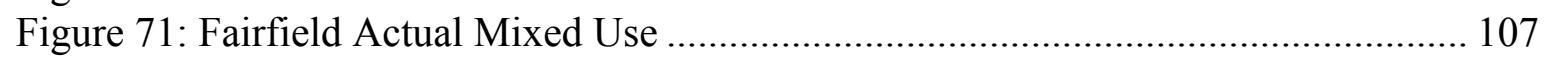

Figure 72: Churton Park Mixed Use ............................................................................ 108

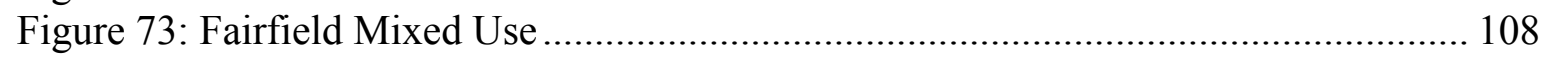

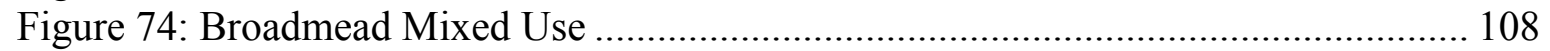

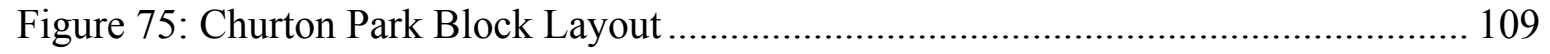

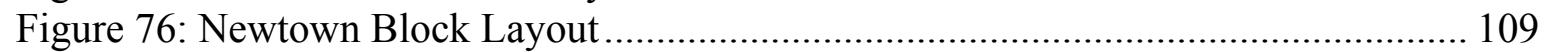

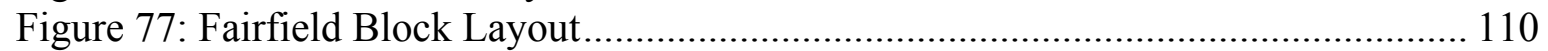

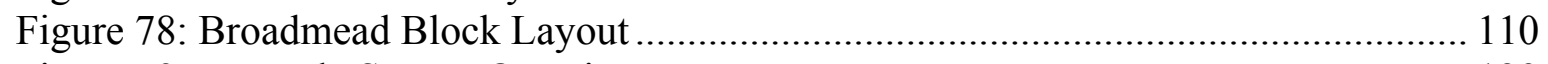

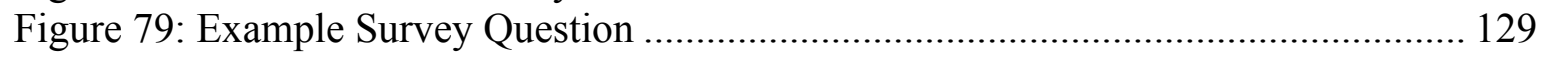




\section{Introduction}

At its very broadest, this dissertation aims to explore the reasons leading to present unsustainable land-use practices, associated negative travel behaviour and the relative inaction toward rectifying this predicament. To move toward answering part of this broad question, an examination of current explanations for travel behaviour reveals a literature deficiency for the potential effect of land use decisions to influence travel preferences. Typically travel preferences are viewed as a precursor to land-use decisions instead of the other way around as this dissertation proposes. The limitation within the literature relates to the difficulty with gaining longitudinal data, and perhaps is in part due to a requisite degree of certainty relative to hypothesized outcomes expected within acedemic research. Because of this limitation, existing travel behaviour literature tends to remain descriptive rather than illuminate causation ${ }^{2}$, and consequently action toward altering conventional land-use and travel patterns is also limited. While there is little evidence that supports a continuation of conventional land-use and travel planning ${ }^{3}$, a relative degree of certainty is maintained, albeit this relies solely on being conventional.

Research in the field of travel behaviour has progressed beyond explanations based solely on sociodemographic factors and now concentrates on two main approaches. These two approaches emphasize either physical context factors or psychological aspects. Context refers to the physical setting and its relation relative to behaviour while the psychological focus views individual choices and personality as the driving force behind behaviours. While each realm is not exclusive to the other, it is rare for studies to simultaneously interpret travel behaviour in both domains. Current research is occupied with disentangling the respective influence either domain has on travel behaviour. This focus is in part due to the importance of agency to the issue of causality. ${ }^{4}$ Because individuals can choose where they live, it's difficult to establish the relative influence a physical setting may have on behaviour. Causality, therefore, is often discussed in terms of self-selection and a number of authors have claimed that where people choose to live (self-selection) is both more important and more influential on travel behaviour than socio-demographic and built environment factors. "They argue that a household with a predisposition toward a certain type of travel "selfselects" a residential location enabling the pursuit of that preferred type of travel." This insight has undermined much of the previous research linking built environment factors to travel behaviour

\footnotetext{
${ }^{2}$ Cao, et al., 2009

${ }^{3}$ Levine, 2006

${ }^{4}$ Handy, 2005

${ }^{5}$ Schwanen \& Mokhtarian, 2005 p84
} 
and has consequently guided research toward examining this relationship after accounting for the influence of self-selection.

Recent self-selection studies have highlighted the important role travel attitudes have on determining travel preferences, subsequent behaviour and even neighbourhood preferences ${ }^{6}$. In these studies, travel attitudes are treated as antecedents to specific travel behaviours. For example, attitudes are often correlated to changes in car use, ${ }^{7}$ walking frequency, ${ }^{8}$ travel mode choices, ${ }^{9}$ trip frequencies by varying modes of transport, ${ }^{10}$ trip distances ${ }^{11}$ and number of private vehicles owned $^{12}$. These self-selection studies, however, are limited to a description of the current attitudinal landscape to be found within the existing, and terminally unsustainable, transportation patterns of the modern city. Often they only reveal a large population with conventional preferences for continued private vehicle reliance and a desire for low-density suburban environments. ${ }^{13}$ What these studies fail to explain is why these preferences exist or if the same array of predispositions would exist if the built environment were something completely different from what it is today. To get at this broader question, the underlying influences to existing preferences need to be explored. Here, previous methods used to explain travel behaviour limit the possibilities of the future by relying on the tendencies of the past if preferences are assumed to exist prior to land-use decisions. The main policy implications of self-selection studies lie in identifying market opportunities for alternative development forms or distinguishing groups of people that may be more responsive to changes from the conventional. The logic in these studies, while sound, seems oddly similar to the prediction of consumer preference of early transport planning.

The historic goal of transport planning was to predict the demand for travel to provide adequate road capacity to meet it. This is known as predict-and-provide transport planning and has resulted in a self-fulfilling prophecy of ever-increasing demand for automobile travel. A better response to consumer views is "not simply to tailor supply directly to it, but to find ways of addressing these preferences, while balancing other pressures," not least that of sustainability. ${ }^{14}$ Self selection studies in this respect may contribute to the same self-fulfilling prophesies as the predict-andprovide methods of early transport planning, and do more to provide evidence justifying

\footnotetext{
${ }^{6}$ Heath and Gifford, 2002; Schwanen and Mokhtarian 2004; Cao et al, 2009; Anable 2005; Nordlund and Garvill, 2003; Levine and Frank, 2007

${ }^{7}$ Hammond, 2005

${ }^{8}$ Clifton and Handy, 2001; Cao, Handy et al., 2006

${ }^{9}$ Cao, Mokhtarian, et al., 2006; Schwanen and Mokhtarian, 2005b; Pinjari et al, 2007; Scheiner and Holz-Rau, 2007;

${ }^{10}$ Cao et al, 2005; Kitamura et al., 1997; Schwanen and Mokhtarian, 2003; Boarnet and Sarmiento, 1998; Greenwald and Boarnet, 2001; Khattak and Rodriguez, 2005

${ }^{11}$ Schwanen and Mokhtarian, 2005b; Vance and Hedel, 2007; Cao, 2008 ; Bagley and Mokhtarian, $2002^{\mathrm{d}}$

${ }^{12}$ Bhat and Guo, 2007; Chen et al., 2008; Cao et al., 2007a

${ }^{13}$ Levine and Frank, 2007

${ }^{14}$ Samuels 2005, p 4. 
conventional land-use practices and travel behaviours. Like transportation planning, once adopted into policy, the assessment of the attitudinal landscape may erroneously be forecast forward, guiding development to accommodate existing unsustainable attitudes. In essence, self-selection studies only add another layer to the picture of travel behaviour but do little to help understand how it was drawn, or more importantly, how to change it.

While self-selection studies have confirmed that the built environment still exerts an influence on travel behaviour after the self sorting of individuals has been accounted for ${ }^{15}$, the premise on which this finding rests may also exacerbate sustainability issues rather than resolve them. Perhaps unwittingly, previous studies have largely resembled the 'cultural war' dichotomy and have pitted the two classes against one another. For travel behaviour these two classes are urbanites and suburbanites, but they could just as easily be rural and urban, conservatives and liberals, right wing and left, or traditional and progressive. In contrast to prior research, this dissertation aims to take a unifying approach to the phenomenon of travel behaviour as its starting point. This approach is best summarized with an analogy of the serenity prayer.

God grant me the serenity to accept the things I cannot change; courage to change the things I can; and wisdom to know the difference. ${ }^{16}$

Instead of a descriptive segmentation of populations into subgroups of attitudes, there is an allowance made to permit the possibility that attitudes are not always antecedent to behaviour. This allowance provides a means to understand why attitudes differ amongst groups. Compared to the broader literature, this form of inquiry is less divisive and provides a more effective way of engaging with individuals toward realizing sustainability objectives. The serenity prayer is analogous to the approach adopted to understand travel behaviour in this dissertation because it allows for psychological adaptation and the constant iteration of attitudes from past decisions and choices. Theories of cognitive dissonance and psychological homeostasis provide the theoretical basis for this study and state that a universal law of human nature, regardless of cultural or ideological leaning, is to maintain equilibrium of mental states. ${ }^{17}$ In order to manifest this equilibrium, people of all walks of life aim to derive satisfaction from the decisions they have made by either accepting the things they cannot change or by having the courage to change the things they can. The implication is that once an individual has selected a neighbourhood to reside in, negative aspects of that decision may be downplayed in order to gain satisfaction from their initial

\footnotetext{
${ }^{15}$ Cao et al., 2009

${ }^{16}$ Reinhold Niebuhr, 1934 quote in Bartlett \& Kaplan, 2002

${ }^{17}$ Festinger, 1957
} 
decision. In order to gain such satisfaction, it may be necessary to be congruent with attitudes that are counter to sustainability but fitting with the choices one has made. For most, the built environment may seem unchangeable, fuelling a general acceptance of it which in turn is reflected in policy directed at maintaining the status quo. This cycle of post-decision reasoning and justification, observed or expressed preference and subsequent policy reproduction leads to the auto-orientated travel behaviour vicious cycle we see today. This dissertation is placed to explore the mechanisms of this cycle by specifically exploring the potential for travel attitudes to follow land-use decisions and not inform them.

The mechanisms of this cycle are understood as how the built form influences travel behaviour. It is hypothesized that one way the built form exerts its influence is through a decision making process where subsequent behaviours associated with choices are internalized as attitudes. While the association between attitudes and behaviours is well established, the time order of this correlation has large ramifications for how travel behaviour is understood. It is assumed that attitudes are antecedent to behaviours, but they may also be a factor of decision making. Within the literature this alternative relationship has been recognized ${ }^{18}$, however, it has not been well studied. This relates to the idea that actions can create and not just reveal preferences ${ }^{19}$. To establish if travel attitudes have formed after a decision, this dissertation quantitatively and qualitatively examines if attitudes can be correlated to place attachment and length of tenure. Both of these factors are referred to as post-decision reasoning factors and employed because the former only occurs after a decision has been made and the latter examines the relationship over time. These factors are indicators of post-decision reasoning and if they can be linked to travel attitudes, it is unlikely that individuals are sorting themselves into neighbourhoods that meet their travel preferences as proposed with self-selection studies. In this respect, it is not the built environment that is shaping attitudes and behaviour directly, but rather the interaction with the built environment through these other factors that inform travel attitudes and subsequent behaviours. Instead of using travel attitudes to explain travel behaviour, a set of variables including post-decision reasoning factors, are used to account for travel attitudes. After accounting for socio-demographic and psychological variables, the post decision reason variables of place attachment and tenure length are anticipated to account for additional variance in travel attitudes beyond what is explained with typical variables. This inquiry contributes to a broader understanding of self-selection dynamics and the influence choice and preferences have on travel behaviour.

\footnotetext{
${ }^{18}$ Pinjari et al., 2007

${ }^{19}$ Airley and Norton, 2008 
The hypothesis posed in this dissertation is arrived at via an initial pilot study. The pilot study focused on the influence built form factors have on behaviour and assessed this relationship by exploring the liveability of neighbourhoods with varying built forms. Three case studies were used for the pilot study, two from Wellington, New Zealand (Newtown and Churton Park) and one from Victoria, British Columbia, Canada (Fairfield). While an international perspective was not critical to the hypothesis posed, the selection of the case studies was based on an early question that initiated the research. This initial question related to the author's admiration of the Canadian neighbourhood Fairfield and a desire to empirically understand how the other neighbourhoods differed. The pilot study employs Geographical Information Systems (GIS) to enable a quantitative analysis of each case study neighbourhoods' physical setting. Here, connectivity, accessibility, mixed use and density in each neighbourhood is measured and quantified. Liveability was assessed with a qualitative survey and the results of this survey are compared against the varying built forms of the case studies. From this analysis, a neighbourhood's density, urban structure, as well as placespecific perceptions of liveability are assessed, and triangulation between a literature review, the qualitative survey and the quantitative built form assessment provide findings that inform the main body of research.

For the main research, a large survey is administered to all three of the case study neighbourhoods, plus an additional case study, asking specific questions about travel behaviour, travel preferences and neighbourhood preferences. The additional neighbourhood is in Victoria, B.C., Canada (Broadmead) and the inclusion of this neighbourhood balances out the types of neighbourhoods used for the case studies, one conventional and one traditional from both Victoria and Wellington. Broadmead's physical layout was also analysed using GIS and the results of this analysis are included with the other case studies. A small scale liveability survey, however, was not administered to Broadmead as its inclusion is for the purposes of the main research only. From all four case studies, the results of the survey are statistically analysed to determine the relative influence post-decision reasoning factors play on travel attitudes. Causation, however, cannot be determined from correlation alone and requires three factors in addition to correlation for a scientifically valid causal claim. ${ }^{20}$ These are briefly, time order, non-spuriousness, and a theoretically robust causal mechanism. While many studies account for the first three criteria, although rarely together, causal mechanisms present an entirely different problem, that of the so called "black box" of social science. ${ }^{21}$ The black box problem refers to the problem of identifying why variables are correlated rather than just the relative degrees of association. Typically causality is inferred from the weight of correctional research instead of by proving a causal process. In this

\footnotetext{
${ }^{20}$ Singleton \& Straits, 1999

${ }^{21}$ Mayntz, 2004
} 
dissertation, however, a qualitative survey is carried out to provide a framework to inform inferences made from the statistical quantitative survey. From the qualitative survey, participants develop their own narrative for the motivations behind their travel and neighbourhood preferences, and this narrative provides insightful data to interpret the statistical correlations.

Instead of a reliance on certainty to inform the expected results of this dissertation, it is clearly exploratory, and aims to expand the literature on travel behaviour an land-use decisions by exploring the time order assumptions associated with attitudes in previous research. It is both an inquiry into a pressing matter, the unsustainable land-use and travel behaviours of modern western culture, and to be a sufficient inquiry, it is also by necessity a wide ranging dissertation. Within an urban design epistemology this dissertation freely adopts a multi-disciplinary research methodology that draws from environmental psychology, transportation engineering, anthropology and geography. It is argued that the plural epistemological nature of this study provides a closer approximation to an accurate description of a travel behaviour reality and from this, a more reasoned approach to influencing more sustainable land-use practices is possible. 


\subsection{Thesis Outline}

Along with introducing the hypothesis, the introduction identified how travel behaviour is typically explained as either a factor of the physical built form (context) or individual personality factors (psychological). Chapter two reviews the literature associated with the influence context plays on travel behaviour and provides the foundation from which the pilot study was conducted. Prior to this review however, the theory of physical determinism is reviewed. This review is a requisite to an understanding of how the physical environment may influence behaviour.

Chapter three explores the psychological perspective on the determinants of travel behaviour. Environmental psychology is often drawn upon in both urban design as well as architecture, and the behavioural theories from this discipline are described in this chapter. Given that the theories used to explain travel behaviour rely on a cognitive evaluation, the role habit plays with travel behaviour is also important to a psychological comprehension of the phenomenon.

Chapter four introduces the idea of place attachment. Place attachment is a seldom included concept within explanations of travel behaviour, and provides the key to the proposed hypothesis by linking the built form to psychological variables. Likewise, how place attachment may form a mechanism through which the built environment and psychological dispositions exert an influence on behaviour is outlined as an important addition to the study of travel behaviour that this dissertation makes.

Chapter five introduces the three case studies used for the pilot study as well as the additional fourth case study added for the benefit of the main research. A general description of each neighbourhood along with some key characteristics is presented. The methodology used to assess the physical attributes of the case studies as well as the methodology used to create the liveability pilot study survey is also outlined.

Chapter six presents the results from the physical form assessments of each neighbourhood as well as the results from the liveability pilot survey. The latter half of this chapter discusses the results from both these forms of inquiry as they relate to the literature, as well as to how they inform the research direction of the main dissertation. 
Chapter seven presents the methodology used to explore the hypothesis that travel attitudes are related to place attachment. The methodology outlines why an association between travel attitudes and place attachment undermines previous self-selection research that relies on stable preferences to inform residential location choices. The quantitative survey is depicted, along with fourteen variables used to predict travel attitudes. Additionally, the strength of this research relies on interpreting the quantitative findings against a qualitative survey rather than simply inferring the meaning of them, and here the qualitative survey methodology is described in this respect.

Chapter eight presents the results from both the quantitative and qualitative surveys. Descriptive statistics for the quantitative survey as well as the multiple regressions to test the hypothesis are both presented. Likewise the results from the qualitative survey are tabulated and shown.

Chapter ten discusses the results for both the qualitative and quantitative surveys. These results are discussed with reference to the direction of planning discussed in chapter four, the relative significance of the results in light of the proposed hypothesis and as a progression of the initial pilot study.

Chapter eleven makes recommendations for future research and chapter twelve presents the broad conclusions made. 


\section{Context and the Urban Crisis}

The literature reviewed in this section informed the pilot study and largely reflects research focused on contextual factors that influence behaviour. While the main body of research is concerned specifically with travel behaviour and neighbourhood preference, this chapter reviews a myriad of contextual factors that research links to travel behaviour but also to a number of issues that affect liveability. These include affordability, environmental condition, health, crime and safety and community development. The question posed at the start of this dissertation, why we build the way we do, is largely in response to the current criticisms directed at conventional land development, and the debate surrounding changes to the status quo guide the literature review. This debate is approached from the perspective of a modern "Urban Crisis" as opposed to the 'urban crisis' of the nineteenth century industrial revolution. The 'Urban Crisis' associated with the industrial revolution was first captured in the writings of Karl Marx and Frederick Engels and was initially known as the 'Social Question' of the day. Unlike Durkheim's assertion that the transition from rural to urban development represented progress ${ }^{22}$, Marx and Engels deplored the conditions early city migrants faced. ${ }^{23}$ Instead of arriving in a thriving modern metropolis as expected, migrant agricultural laborers arrived to teeming cities of uprooted populations, surrounded by decrepit infrastructure and endless rows of tenements. ${ }^{24}$ While the early 'urban crisis' led to formalised planning to mitigate the new phenomenon of over crowded cities ${ }^{25}$, our modern "Urban Crisis" is one of a different nature. This crisis is not so much stimulated by urban blight, but rather a growing concern over the un-sustainable direction society is taking.

While this dissertation terms this crisis 'modern', in fact it stems from the birth of postmodern thought from the early $1970 \mathrm{~s} .{ }^{26}$ The case could be made that the modern urban crisis has a greater focus on the environment rather than a reaction to modernism's positivistic, technocentric and rationalistic leanings, but at the same time the start of the environmental movement marked by Rachel Carson's seminal publication 'Silent Spring' dates from the early 1960's. Indeed the modern urban crisis still laments the belief in linear progress, absolute truths, the rational planning of ideal social orders, and the standardization of production and knowledge as subscribed to within modernism, but clearly global warming, obesity epidemics, demographic changes, aging populations and the threat of running out of oil are the focus of this crisis.

\footnotetext{
${ }^{22}$ Durkheim and Mauss, 1998

${ }^{23}$ Engels, F., 1845

${ }^{24}$ Jenks and Dempsey, 2005

${ }^{25}$ Fishman, 1977

${ }^{26}$ Harvey, 1990
} 
Given that planning and urban design are both responses to this new 'Urban Crisis, ${ }^{27}$, the debates within these disciplines are explored in this chapter. These debates centre on maintaining a business as usual approach to land-use planning versus changes to the conventional. While proponents for changes from the orthodox argue for land-uses more akin to traditional neighbourhoods, common prior to the middle of the twentieth century, arguments for and against traditional and conventional land-uses provide a useful framework for interpreting this debate. This includes the contentious issues surrounding advocacy for increased density and similarly for other land-use patterns such as mixed uses, a more connected street network, and transportation options beyond the private automobile. These characteristics are typical of traditional neighbourhoods and are the context against which improved liveability and sustainability is advocated for in the form of neo-traditional developments.

The urban crisis debate begins by first discussing the view held on physical determinism. Because this section reviews literature that links behaviours to the built environment, be them economic, human or environmental, establishing an understanding of physical determinism is critical. Next the changes in demographics that potentially necessitate a change in land-use patterns are reviewed. The issues that surround transportation and where environmental, economic and social issues strongly relate to transportation are then explored. Next, affordability is addressed as an economic examination less related to transportation. The environmental section aims to review literature that is independent of the transportation debate as well. Health, crime and safety and the effect changes in land-use patterns may have on community formation conclude the chapter.

\subsection{Environmental Determinism}

Design oriented dissertations and the relevant professions they influence (architecture, urban planning and design, industrial design, graphic design etc.) all at some level assume the physical world can influence behaviour. ${ }^{28}$ Without this assumption there would be no point in designing anything nor would there be the need for product differentiation, advertising, or the discipline of environmental psychology. ${ }^{29}$ Accompanying this assumption is the history of the theory of environmental determinism. Environmental determinism makes the claim that all human behaviour is determined by the environment and ignores the influence of culture, politics, and history.

\footnotetext{
${ }^{27}$ Forsyth, 2003

${ }^{28}$ Naess, 2006

${ }^{29}$ Johnson, 1994
} 
Further, environmental determinism proposes that the physical environment, rather than social conditions, determines culture and relative behaviours. From an environmental determinism perspective behaviour is strictly a factor of response to stimulus. The counter proposition follows an ethological approach where cultural and social factors are viewed as a greater determinant of human behaviour. ${ }^{30}$ The physical environment, under the ethological paradigm, is seen more as a condition of culture and social factors rather than a cause of them. ${ }^{31}$ The collective understanding for the influences on behaviour have moved some way since the early popularity of environmental determinism, however, the theory's checkered history continues to haunt environment-behaviour research. ${ }^{32}$ In light of the potential to misinterpret urban design research as resurecting environmentally deterministic claims, this section elaborates on the criticism of the theory and articulates the view this dissertation takes with respect to the influence the built environment can have on behaviour.

The first caveat of this discussion is the assumption, as also held by this research, that human behaviour can be explained. That there are in fact determining factors that can be grasped upon to understand behaviour is an assumption of all research within this vein. An explanation of human behaviour assumes that all human cognition, behaviour, decision and action is causally determined by a series of antecedent occurrences. ${ }^{33}$

Environmental determinism was not a theory, per say, during the classical period of Plato, Hippocrates, Montesquieu and Aristotle, however cause and effect between humans and their environment characterised early understanding of human behaviour. ${ }^{34}$ The climate of discovery in the nineteenth century that saw Wallace's (1855) and Darwin's (1859) theory of evolution take root also produced the early foundations for environmental determinism. Now widely accepted as the origin of modern geographic thought, evolutionary biology set the theoretical stage for environmental determinism. Using the idea of evolutionary biology as analogous to the social conditions of humans, the German geographer Friedrich Ratzel suggested that the capabilities of humans relied solely on the geography that they occupied. ${ }^{35}$ A student of Ratzel, Ellen Semple, is credited with introducing Ratzel's ideas into North American geography and her name appears most attached to environmental determinism. Environmental determinism as a concept soon came to be the social theory explaining the way the world worked rather than just a description of it.

\footnotetext{
${ }^{30}$ Ewing, 2005

${ }^{31}$ Ewing, 2005

32 Judkins et al., 2008; Franck, 1984

${ }^{33}$ Van Inwagen, 1999

${ }^{34}$ Naess, 2006 pp12; Judkins et al., 2008

${ }^{35}$ Peet, 1985
} 
Geography was not alone in viewing the world through a environmental deterministic lens. History, sociology, architecture, and perhaps, most importantly, the political climate of the late nineteenth century also saw the theory as the natural order of the world. Le Corbusier even proclaimed architecture as the liberating alternative to social revolution. ${ }^{36}$ The explanatory appeal of environmental determinism still resonates today. ${ }^{37}$ But alas, early in the twentieth century the limitations of the theory became apparent, both "under the weight of its own contradictions and its growing irrelevancy as a legitimization theory." ${ }^{38}$ Early theories ${ }^{39}$ placed environmental factors as the main determinants of "racial differences, cultural practices, moral values, ingenuity and the ultimate capabilities of any given population". ${ }^{40}$ This line of logic fed into justifying national and racial superiority claims and led into over-generalising the traits of certain people merely based on where they were from. ${ }^{41}$ Taken to the extreme, the expansion of states and countries into other regions was justified under the guise of fulfilling the will of nature, not so unlike claims for globalization today. The first of the clear contradictions the theory failed to prove related to behavioural outcomes from largley similar environments. ${ }^{42}$ Vastley different cultures were observed in near identical environments and environmental determinism offered no explanation for this anomoly. ${ }^{43}$ The way people modified their environments and the misconception that people were merely passive victims to their surroundings were also factors undermining the credibility of the theory. Still, more criticisms include exaggerating the influence of the environment on behaviour while ignoring the influence of other factors, and assuming direct effects on behaviour. ${ }^{44}$

The recent Pulitzer Prize winning publication "Guns Germs and Steel” has fueled a spate literature that reiterates the demise of environmental determinism. ${ }^{45}$ The present popularity of urban design has also attracted fresh accusations and a discourse of this failed theory. ${ }^{46}$ Urban planners and architects have been critisised for typically viewing the built environment as the crucial factor to influencing well being and resource consumption, while at the same time neglecting economic or social influences. ${ }^{47}$ Discussions that attempt to establish the importance the built environment plays on behaviour, even if just through symbolism, still invoke implications of environmental determinism as well as the harsh reactions decades of disciplinary turmoil have resulted in. Within

\footnotetext{
${ }^{36}$ Dovey, 1998

${ }^{37}$ Bale, 2002

${ }^{38}$ Mitchell, 2000

${ }^{39}$ Semple, 1911; Huntington, 1915; Fleure 1919

${ }^{40}$ Judkins et al, 2008, p 20

${ }^{41}$ Peet, 1985

${ }^{42}$ Judkins, 2008; Mitchell, 2000; Franck, 1984

${ }^{43}$ Barnes, 2001

${ }^{44}$ Franck, 1984

45 Jared Diamond's Pulitzer Prize winning Guns Germs and Steel is oft cited as such an example. See Sluyter, 2003

${ }^{46}$ Thompson-Fawcett, M. \& Bond, 2003

${ }^{47}$ Chermayeff, 1992 in Naess, 2006
} 
social science there continues to be a "tradition for denial of the importance of the physical and spatial surroundings to human behaviour". ${ }^{48}$ This denial is likely a reaction to the harmful generalizations that an environmental deterministic view can and has had. Regardless, the literature urban design relies on is largely outside the field, and draws from sources as varied as sociobiology, human geography, environmental psychology and transportation planning, and within these disparate disciplines it is rare to find singularly deterministic claims of behaviour. ${ }^{49}$

A number of theories devoted to explaining human behaviour filled the vacuum left by the demise of environmental determinism, many of which are still developing and are well subscribed to today. Environmental Possiblisism contends that the environment only constrains or enables behaviours rather than determines them. ${ }^{50}$ This view is that held by many architects and urban designers as a soft alternative to the high hopes that were placed on the power of environmental determinism. ${ }^{51}$ Within this theory, culture is viewed as the determining factor for how such limitations or opportunities are dealt with. This ontology for understanding behaviour became popular to many other disciplines and is still held today ${ }^{52}$, known as cultural geography and cultural determinism. In this sense "behaviour does not depend on physical stimuli nor logical necessity, but on acquired habits, which are the culture of the group". 53

Systems theory also contributes to the understanding of human behaviour. ${ }^{54}$ This theory concerns itself more with the relationships between elements in a system, rather than the parts of the system as in a conventional positivist perspective or a classical (Newtonian) approach to science. ${ }^{55} \mathrm{~A}$ benefit of Systems Theory relates to the possibility of unifying the natural and social sciences. The concentration on the links between elements within a system rather than the partitioning and description of elements themselves, allows for the development of similar explanatory concepts to develop with disparate disciplines. ${ }^{56}$ Instead of organising relationships amongst the parts of the whole in a linear relationship, systems theory focuses on the non-linear aspects of relationships. Although the natural sciences have been successful in dismantling large problems into their parts in order to derive the whole, this approach has proved less beneficial in the social sciences. "The systems approach, on the other hand, is based on the assumption that properties of the whole object

\footnotetext{
${ }^{48}$ Naess, 2006, pp30

${ }^{49}$ Wilson, 1998, p181

${ }^{50}$ Sauer, 1925

${ }^{51}$ For example in Dovey, 2008 reference to sociologist Anthony Giddens, 1984

${ }^{52}$ Dovey, 2008; Oscar Newman in Johnson, 1994

${ }^{53}$ Judkins et al., 2008, pp20

${ }^{54}$ Judkins et al., 2008

${ }^{55}$ Van Assche \& Verschraegen, 2008; Payne, 2002

${ }^{56}$ Bausch, 2001
} 
depend not only on the properties of its parts, but also on all possible interactions between them". ${ }^{57}$ Herein may lie a better framework for understanding human behaviour.

Behaviouralism in geography, not to be confused with behaviourism of psychology, is the study of human behaviour within spatial settings. Things like territoriality, place preferences and general spatial reasoning form the hub of this human environment study. ${ }^{58}$ Unlike behaviourism in psychology, behaviouralism in geography is concerned with the cognitive workings of behaviour and not just the observable outputs. That said, behavioural geography is criticized for resembling the theoretically dead Watsonian behaviourism and replicating many of the same mistakes that led to behaviourism's downfall in psychology. ${ }^{59}$ Behaviouralism relies more on the agency of people to explain behaviour than on underlying social laws that determine it. This view is in contrast to systems theory where a more deterministic perspective is held. ${ }^{60}$ The insight Behaviouralism provides relates to "human judgement in resource evaluation". ${ }^{61}$ This revelation, however, has more to do with defining geography as separate to environmental determinism, than to systems theory. The household, rather than the environment, or culture, or state is viewed as the most influential factor in terms of influencing behaviour for those that ascribe to Behaviouralism. With few modifications, human geography today views behaviour in the same fashion as Behaviouralism.

Structuralist theories provide a further perspective to human behaviour. Perhaps the most difficult to understand, structuralism was first used to study the symbology within linguistics. ${ }^{62}$ Structuralism provides a theory to explicate the unconscious cognitive structure behind linguistics which, it posits, creates a way of thinking. In the same way that language has the ability to "contain and constrain individual volitions and to shape the social capacity for communication and [] discourse," ${ }^{63}$ scientific method has the ability to shape the way we think about human behaviour. For this reason, the structuralist ontology expanded to include both criticisms of existing explanations for human behaviour as well as its own theories of it. The structuralist theory of behaviour hypothesises that humans are continually in a state of seeking equilibrium between their mental state and the external world, and as such, seek meaning. From this pursuit, however, a constant state of disequilibrium is maintained in either the external world or an individual's cognitive structure, perpetuating a desire to understand the world ${ }^{64}$ Structuralism further criticises

\footnotetext{
${ }^{57}$ Mesjasz, 1988, p 291

${ }^{58}$ Peet, 1998

${ }^{59}$ Ley, D. 1981, in ED. Cox \& Golledge 1981

${ }^{60}$ Judkins et al., 2008

${ }^{61}$ Ley, D. 1981, in ED. Cox \& Golledge 1981, p210

${ }^{62}$ Solo, 1975

${ }^{63}$ Solo, 1975, p616

${ }^{64}$ Goldmann, 1987 
previous human-environment research for its positivist bias and uncritical view of the role politics, the economy and culture plays on influencing behaviour. ${ }^{65}$

The principle actor within the structuralist ontology is that of larger society. This is in contrast to theories focusing on individual level influences of behaviour and to the more deterministic views of natural laws. Natural laws within Structuralism relate to the structure posited to underlay all meaning. ${ }^{66}$ Here, the environment is perceived as a benign force on behaviour, "serving as a stage for political economic actions and receiving the brunt of impacts originating from collective human systems." ${ }^{\circ 7}$

A goal of science in general has been to partition large problems into their elements. The corollary of this, particularly for social science, has promulgated an array of disciplines focused on their portion of a larger problem. Instead of, however, recognizing the division of a greater issue into its parts with the intention of reformulating the whole, the disparate disciplines tend to expend energy reiterating the importance of their portion and, in some cases, aim to place their discipline at the top of some hierarchy of influence. This may not be the most effective way to understand human behaviour as systems theory posits; nor perhaps are the tools used the most appropriate either, as structuralism contends. Behaviouralism in geography appears transfixed with trying to disassociate the discipline from its early misadventures with environmental determinism, and continues to focus on the false dichotomy between agency and determinism. While Environmental Possiblisism presents perhaps an agnostic view of the dilemma, it remains speculative as well.

Determinism is often erroneously equated with fatalism, which is the true opposite of freewill. Under fatalism, the will is ineffectual, no matter how much it struggles. Establishing causality in terms of behaviour doesn't imply a lack of free will. Free will exists not as freedom from causality but rather freedom from compulsion or restraint. Thus, if will exists, it can exert its influences through causal relations. Causality provides constraints, not a lack of free will. Similar to how gravity limits the conditions under which a person can fly, but it does not prevent flying, the causal sequences by which nerve stimulation results in muscular action give the will the freedom to manifest itself in the world.

\footnotetext{
${ }^{65}$ Judkins et al., 2008

${ }^{66}$ Assiter, 1984

${ }^{67}$ Judkins et al., 2008, p21
} 
Although urban design largely lacks any theoretical underpinnings, ${ }^{68}$ despite some commentators assertions that it, like architecture, relies on environmental determinism, ${ }^{69}$ most research in the field ascribes to a cultural possibilist viewpoint. This dissertation too accepts this theory and sees the environment as either a constraining or enabling factor on behavioural outcomes. Here it is generally assumed that people act on the basis of decisions they make. These decisions are in turn based on appraisals of acquired information, patterns of decisions, and the cultural space within which the decision is made. Thus, "the relationship of the observed action or behaviour to the environment is mediated by psychological processes." $" 70$

In many ways, collectivley, the idea of influencing behaviour, at least on a public level, has been abandoned. Instead a mass subscription to a technological fix, the hope of modernity, has filled this void. Social reform by design is well and truly dead, but what has taken its place? Edited versions of environmental determinism abound, each with a greater or lesser regard to political, cultural, or historical influences on behaviour. The hope is for a theortical approach that recognises and combines each of these influences ${ }^{71}$, but none so far have been as convincing as what technology has offered. Instead of shaping behaviour, technology has afforded the ability to, at least seemingly, predict it. There is a ubiquitous reliance on forcasting models, which for the most part have shapped the built form for the last sixty years. This is particularly true for travel behaviour, and is reflected in how transportation planning operates. However, in light of the current pressures modern society faces, what this chapter calls the "Current Urban Crisis", the hope for a technological fix has faded. And so we return to thinking of a more deterministic sort, and again to the discussion of environmental determinism, right where the debate left off.

\footnotetext{
${ }^{68}$ Arefi \& Triantafillou, 2005

${ }^{69}$ Cuthbert, 2005.pp227.

${ }^{70}$ Garling \& Golledge, 1993, pp7

${ }^{71}$ Judkins et al., 2008, p27-28

16
} 


\subsection{Demographic Change}

Changes to conventional land uses are regarded as a means to address demographic trends and growing populations expected in the $21^{\text {st }}$ century, both internationally and in New Zealand. ${ }^{72}$ Demographic pressures include increased growth through birth rates and immigration, an aging population, a decreasing household size, decreasing housing affordability, more women in the workforce and changes in what people want. ${ }^{73}$

Worldwide populations are abandoning rural lifestyles ${ }^{74}$ to concentrate in cities. ${ }^{75}$ This trend is also apparent in New Zealand, where urban populations represent $85 \%$ of the total population, with this figure expected to grow. ${ }^{76}$ Population migration from rural to urban locations increases the housing pressures on cities and both urban design and planning are tasked with responding to these changes.

The relative aging of the populations in both Canada and New Zealand add to contemporary housing issues. Many developed countries the world over have a greater proportion of older people compared to their younger populations. Statistics New Zealand estimates that the number of New Zealanders over 65 will exceed 1 million people in the late 2020s, following the trend of other developed countries. ${ }^{77}$ Half the total growth in the population will be older than 65 and expected to be predominantly women.

Decreasing household sizes represent one effect of the aging population with older people opting for smaller homes and sometimes shifting to retirement villages. Other factors contributing to this decrease in household size are smaller family sizes, later marriages, lower fertility rates and independent living choices. ${ }^{78}$ Occupancy rates in New Zealand have fallen over the last ten years and one-person households have increased from 20.7\% in 1996 to $23.4 \%$ in $2001 .{ }^{79}$ An Auckland Regional Council report on the demand and supply of housing in Auckland reports some duplication of housing trends. ${ }^{80}$ This report noted that while smaller dwellings are being occupied by larger households, larger dwellings are being occupied by smaller households. Similar

\footnotetext{
${ }^{72}$ Ministry for the Environment, 2005; Ohlin, 2003

${ }^{73}$ Ohlin, 2003; Auckland Regional Growth Forum, 1998; Grimes et al, 2004; Scion, 2006

${ }^{74}$ Although this trend is somewhat skewed by the American 'white flight' phenomenon where inner city populations are decreasing while wealthy, predominantly white, Americans migrate to the suburbs or to what has been termed 'Edge City' locations. Garreau, 1991.

${ }^{75}$ United Nations Population Fund, 2007

${ }^{76}$ Hargreaves \& Davies, 2003; Big Cites, 2003

${ }^{77}$ Statistics NZ, 2007

${ }^{78}$ Big Cities, 2003

${ }^{79}$ Scion, 2006

${ }^{80}$ Auckland Regional Council, 2003
} 
paradoxes are occurring with the fastest growing household size being both large households (those with more than 6 members) and very small households. ${ }^{81}$ Despite these similar trends, some contend that the apparent shift to smaller dwellings phenomenon is based on a flawed interpretation of the data, and a misunderstanding of the social processes that are occurring. ${ }^{82}$ Regardless of shifts in household size and composition, other commentators argue that there has never been a demonstrated demand for smaller dwellings ${ }^{83}$ It's argued that the opposite is true and the trend in consumer preference is for larger dwellings.

A growing rate of women in the workforce also indicates complex relationships about choices, family structure and household size ${ }^{84}$ Changes in household composition are seen as an important factor that influences housing demand. ${ }^{85}$ In New Zealand some key housing structure trends between 1991 and 2001 are shown in Table 4.

Table 1: New Zealand Housing Trends, 1991-2001 ${ }^{86}$

\begin{tabular}{|l|l|l|l|}
\hline Household Composition & Owner- Occupiers & Private- Rented & Housing NZ \\
\hline Couple Only & $-12 \%$ & $+43 \%$ & $-19 \%$ \\
\hline Couple with children & $-16 \%$ & $+82 \%$ & $-22 \%$ \\
\hline 1 Parent + Children & $-4 \%$ & $+147 \%$ & $-58 \%$ \\
\hline One Person & $+20 \%$ & $+57 \%$ & $-9 \%$ \\
\hline
\end{tabular}

A planning shift away from single use zoning and towards what is termed 'life course' zoning is aimed at addressing changing household structures. ${ }^{87}$ Increased density plays a role in this 'life course' zoning by providing the smaller dwellings appropriate for smaller households, and in combination with mixed uses, allows for 'aging in place ${ }^{88}$ or for the changing housing requirements of people throughout their lives. Critics, however, express concern with the "peculiarly mechanistic conception of the family" 89 in this life course planning mandate. They make the argument that a life course is not so simplistic. However, these arguments are not for or against changes from the conventional but rather express scepticism towards the planned policy methods. ${ }^{90}$

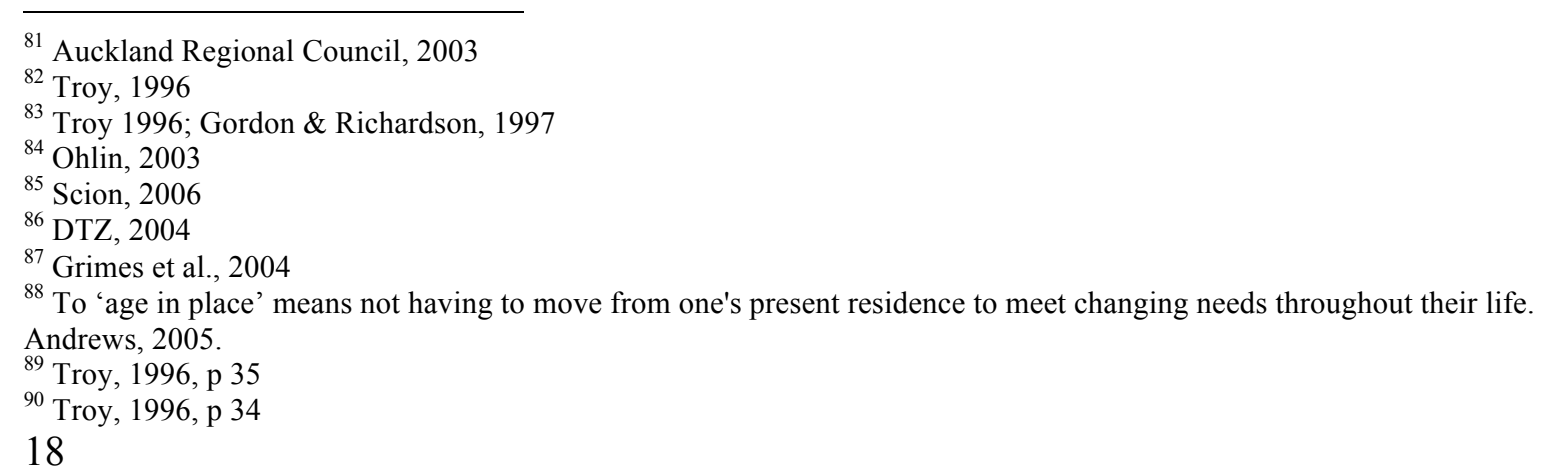


Both New Zealand and Canada are experiencing aging population trends, changing household needs and demographic shifts similar to the rest of the member countries of the Organization for Economic Co-operation and Development (OECD). And like many of the OECD countries, since the majority of the housing stock that will exist in 2030 is already built, the planning and design emphasis is on the need to prepare for these changing trends. ${ }^{91}$

\subsection{Travel}

One aim of changes from conventional land-uses is to target improving liveability by reducing the reliance on the private motor vehicle. Health, environmental, social and economic benefits are anticipated by-products of a reduced reliance. In the past the call for changes to conventional land uses may have been based on an "anti-suburban bias" where today there is distinctively an "antiauto bias". ${ }^{92}$ Concurrent with this anti-auto bias, the contemporary issues of sustainability add urgency to the appeal for changes from the conventional..$^{93}$ Two questions must then be asked about this relationship; first, do changes from conventional land-uses actually reduce the use of the private motor vehicle and second, is this beneficial? The first question can be analysed in terms of mode shift or studies that look at how people are travelling in settlements of varying land-uses. The second question can then be examined in terms of determining what effect alternative land-uses have on emissions, noise and air pollution, economic development, health, safety, the use of space and congestion. This section presents the contextual factors, rather than the psychological, that influence travel behaviour.

At a macro scale, city wide or regional, it is clear that as density increases energy expenditure decreases. ${ }^{94}$ Energy expenditure is the key measurement to determine the effect of transportation on the environment. Newman states that:

... [d] ensity reduces transportation energy through several mechanisms: it shortens distances for all modes and makes transit, bicycling, and walking more viable as alternatives to the car; it also reduces the number of

\footnotetext{
${ }^{91}$ Scion, 2006

92 Jenks \& Dempsey, 2005 p 300

93 Jenks \& Dempsey, 2005

${ }^{94}$ Kenworthy \& Newman 1999, Litman, 2005
} 
journeys, since when transit is used, many journeys are combined-for example, shopping on the way to or from the train. ${ }^{95}$

A study from Holland found limits to the density energy efficiency relation. ${ }^{96}$ This study shows that there were no energy savings between a highly urbanised area compared to a rural area. This lack of energy savings is attributed to lower fuel efficiency at speeds significantly less than or greater than $70 \mathrm{~km} /$ hour, and further inefficiencies due to short trips typical of urban areas. However, other researchers note that even though cars may operate less efficiently in built up or higher density areas, this inefficiency is compensated for by people driving less, less per capita mileage and switching to other modes of travel. ${ }^{97}$

If people do not shift to other modes of travel as a result of living at higher densities, cars may operate less efficiently and congestion may increase. This corollary is the typical finding of the same commentators who believe that urban form has no effect on transportation behaviour and that transportation behaviour is mainly explained by income differences rather than land use differences. ${ }^{98}$ However, many opponents to higher density note that mode shift may occur at higher densities when automobile use is made less appealing. For example, reduced parking amenity may lead to congestion which in turn may lead to mode shifts. This mode shift phenomenon is supported by numerous studies. ${ }^{99}$ In a report prepared for the New Zealand Automobile Association on the benefits of investing in New Zealand infrastructure, it is explicitly stated that investment in roads aimed at creating "travel time savings may result in less fuel consumption and provide commuters with less incentive to use public transportation". ${ }^{100}$ This report highlights the mode shift phenomenon working against public transport by making private automobile use more appealing through investment. Regulating what is viewed as a predominant consumer preference for private automobile use is cited by opponents to changes from the conventional as a loss in personal freedoms. ${ }^{101}$ However, any losses to personal freedoms are compensated for by increases to various other freedoms, such as an increase in travel options and accessibility to mobility as well as greater amenity for non-drivers. ${ }^{102}$ Similarly, the primacy of personal freedoms must be questioned when they are seen to negatively affect others and potentially be terminally elusive. A study published by the NZ Ministry for the Environment on delays to major roading projects

\footnotetext{
${ }^{95}$ Kenworthy \& Newman, 1999, p 26

${ }^{96}$ Van Binebergen et al., 1994. in DeRoo, 2000

${ }^{97}$ Ewing, 1997; Litman, 2004

${ }^{98}$ Lave, 1992

${ }^{99}$ Frank \& Pivo 1994; Kitamura et al., 1995; Cervero, 1995; Owen, 2004; Handy, 2005

${ }^{100}$ Allen Consulting Group, 2004

${ }^{101}$ Gordon \& Richardson, 1997

${ }^{102}$ Litman, 2005 
highlights how no city the world over has ever been able to keep up with demand. ${ }^{103}$ Furthermore, the notion of supplying roads to meet demand has actually been shown to induce demand. ${ }^{104}$

Without the political will to exchange some private freedoms for collective interests, planning and urban design are destined to only provide roads and land to meet demand regardless of what the negative consequences are. This approach is the equivalent of relying on the market to solve a commons dilemma and has been dismissed as wishful thinking. ${ }^{105}$ Critics of this tactic suggest that the option of letting market forces determine the outcome of the built environment would mean that:

\section{...cities would continue to decline, further counter-urbanisation of people and jobs, loss of more country side, and a myriad of physical and social problems"'- and that no one seriously advocates this response. ${ }^{106}$}

However, it must be noted that currently conventional land-use is conventional by virtue of government intervention and policy rather than market forces. ${ }^{107}$ This is a misconception common to this debate and would seem to suggest that market forces would, in fact, deliver land-uses more akin to traditional neighbourhoods.

Opponents to changes from the conventional also argue that regardless of mode shift, the private motor vehicle operates more efficiently, in terms of cost benefit analysis, than rail transit, an intended alternative to car travel. ${ }^{108}$ Litman argues that the cost benefit analysis of rail transit misses and undervalues the benefits of rail travel by focusing on transport objectives only, such as emissions and congestion. ${ }^{109}$ Fouchier notes that it is widely accepted that private automobile travel is far more harmful in terms of pollution per person than public transport and in many cases it is this damage to the environment that is hard to assess in any cost benefit analysis. ${ }^{110}$

A further argument on the effect density has on transportation focuses on consumer preference, which is meant to be a greater determinant of travel behaviour. ${ }^{111}$ The consumer preference argument contends that people who prefer to travel by public transport choose locations to live

\footnotetext{
${ }^{103}$ Minsitry for the Environment, 2003

104 Thill \& Kim, 2005; Cervero \& Duncan, 2002

${ }^{105}$ Perkins et al,, 1998; Breheny, in Echenique, 2001

${ }^{106}$ Breheny, in Echenique, 2001, p 49

${ }^{107}$ Levine \& Frank, 2007

${ }^{108}$ Cox, 2004

${ }^{109}$ Litman, 2004

${ }^{110}$ Fouchier, in De Roo, 2003. p 245

111 Boarnet \& Crane 2001; Cervero \& Duncan, 2002
} 
where public transport is supported, and people who prefer to travel by private automobile choose locations that support their preferred mode of travel. While numerous studies have confirmed this theory, these studies have also established an association between travel behaviour and land-uses after controlling for the effects of self-selection. ${ }^{112}$ Similarly, the role of self-selection may be less important than previously thought. Instead of viewing the issue of self-selection as undermining the association between the built environment and behaviour, some authors contend that this proves that the built environment enables households to self select. ${ }^{113}$ Without alternative land-use patterns, alternative travel patterns would also not be available.

It is argued that increases to mobility will subsequently increase economic development. ${ }^{114}$ This is achieved through a number of mechanisms including; increases to the catchments of people able to access places of employment, increases to the catchments of employees and increases to productivity through reducing transportation costs. ${ }^{115}$ Echenique argues that the more mobile a person is, the greater the gross domestic product per person will be. ${ }^{116}$ Echenique assumes that the relationship with mobility and increases in personal income are a cause of mobility rather than a result. ${ }^{117}$ However, Litman argues that this rationale confuses cause and effect. ${ }^{118}$ He states that:

\begin{abstract}
...many countries experience their greatest economic growth when per capita automobile use is relatively low and economic growth rates decline as households become wealthy enough to afford more consumer goods such as private cars. ${ }^{119}$
\end{abstract}

The association between greater wealth and mobility also is not entirely that accurate. Instead of more mobility being demanded as individuals accumulate more wealth, what they may be actually demanding is more amenities. Koorey, however, cites the 1999 Standing Advisory Committee on Trunk Road Appraisal (SACTRA) study from the UK that found strong correlations between economic growth and transportation improvements. However, he notes that direct empirical evidence in the SACTRA study was weak and that transportation improvements include speed reduction and traffic restriction methods. ${ }^{120}$ A method for increasing market, employee and employment catchments that is not readily discussed in transportation literature is that of increasing

\footnotetext{
${ }^{112}$ Cao, et al., 2009

${ }^{113}$ Naess, 2005; Ewing et al, 2007

${ }^{114}$ Allen Consulting Group, 2004; Echenique, 2001

${ }^{115}$ Allen Consulting Group, 2004

${ }^{116}$ Echenique, 2001

${ }^{117}$ Echenique, 2001

${ }^{118}$ Litman, 2003

${ }^{119}$ Litman, 2004, p 32

${ }^{120}$ Koorey, 2003 
density. Although literature from proponents for high density discuss the economic benefits of large catchments of employees and employers within walking distance to amenities, there is a disjoint between this literature and transportation literature which emphasises the same economic benefits but on the grounds of increased auto mobility.

External benefits associated with less private automobile travel, beyond pollution, reinforce the arguments for other modes of travel. Even if the private automobile was a non-polluting mode of travel, congestion and loss of productivity through time spent travelling are still real detriments. ${ }^{121}$ Koorey highlights cost savings due to less auto provision, less parking, fewer accidents, health related savings, environmental related savings and in the pocket savings for everyday people not requiring a car or a second car, as some of these external benefits. ${ }^{122}$

Frumkin considers the obesity epidemic to be one of the externalities of auto-dependency which harms people's health, but also economic development as a burden to the health care system. ${ }^{123}$ Ewing found that people living in countries where low density sprawl is typical, walk less and weigh more than people who live in areas typified by compact development. ${ }^{124}$ These findings associating low density development with diminished walking and increased car-dependency compared to more densely developed communities are echoed in a number of studies. ${ }^{125}$ There is "now ample evidence that more compact cities encourage physical activity, both walking and cycling". 126

One of the greatest causes of environmental noise pollution is traffic. ${ }^{127}$ Here, the relationship shifts back to the forms of land use associated with greater levels of traffic and mode shift. However, like many land use and liveability relationships, the issues associated with certain land use patterns generally extend beyond the borders of the particular land use pattern, shifting problems to other areas. In terms of noise pollution and its relation to land use patterns, the potential cumulative effects of car dependent suburbs travelling through inner residential areas has not been reviewed in the literature.

Several arguments strongly relate safety to mode change and how this liveability indicator integrates with transportation. If mode change doesn't occur at higher densities, pedestrian safety is

\footnotetext{
${ }^{121}$ Ewing, 2002

${ }^{122}$ Koorey, 2003

${ }^{123}$ Frumkin et al., 2004

${ }^{124}$ Ewing et al., 2003

${ }^{125}$ Frank \& Pivo, 1995; Ewing , 2005; Dieleman \& Wegener, 2004

${ }^{126}$ Chapman, 2005

${ }^{127}$ Ministry for the Environment, 1999
} 
diminished. However, if mode change occurs, the subsequent reduction in traffic and higher use of public transportation can increase pedestrian safety. ${ }^{128}$ Both the proponents and opponents of higher density claim that more traffic is prevalent compared to their preferred land use pattern, and ignore the arguments around mode shift. Both sides back their claims with statistics that show that more people die from traffic accidents each year than from any other source. ${ }^{129}$

As to what the effect transportation has on a sense of community, a major attribute of liveability, the arguments centre around the time spent in cars, the divisive effects of large roads with high traffic volumes and missed community interaction through long commutes. ${ }^{130}$ Putnam argues that each ten additional minutes in daily commuting time cuts involvement in community affairs by $10 \%{ }^{131}$ Support for Putnam's contention has been found in empirical studies, and findings indicate that sprawling suburbs contribute to diminished participation in community activities. ${ }^{132}$ Likewise, recent findings indicate a correlation between longer commutes and less access to social capital. ${ }^{133}$ Opponents to higher density claim that citing transportation infrastructure as having an effect on social mechanisms such as community formation, harks back to the days of environmental determinism. ${ }^{134}$ Syme, however, believes research in this area is still inconclusive. ${ }^{135}$

In New Zealand regional and local transport strategies, a continued dominance of motor vehicles is seen as inevitable and that continued road building is also required, on a scale far greater than alternatives. ${ }^{136}$ This acceptance of transportation trends seems to point to a lack of understanding of the mechanisms (both social and political) in place that have favoured a transport reality dominated by the private automobile. Although, Koorey notes that it seems...

...like a chicken and egg question as to which of these two outcomes (more motor vehicles or more roads) originally steered the other into the vicious cycle we see today. ${ }^{137}$

\footnotetext{
${ }^{128}$ Auckland Regional Growth Forum, 1998

${ }^{129}$ Auckland Regional Growth Forum, 1998

${ }^{130}$ Frank et al., 2004

${ }^{131}$ Putnam, 2000

${ }^{132}$ Naess, 2005; Hougen, 1998 in Naess 2005

${ }^{133}$ Besser et al., 2008

${ }^{134}$ Crane \& Crepeau, 1998

${ }^{135}$ Syme et al, 2005

${ }^{136}$ Koorey, 2003. p 1

${ }^{137}$ Korrey, 2003 p 1 


\subsection{Affordability}

Affordable housing has worsened in the last decade in both New Zealand and Canada. ${ }^{138}$ This is true for both Wellington and Victoria, the cities where the case studies of the present research is focused. Changes to conventional land-uses, specifically increasing land-use mix, is an environmental factor that is aimed at improving affordability.

It is generally accepted that housing is affordable if no more than thirty percent of a household's income goes towards it. ${ }^{139}$ However, there is some debate as to what affordable housing means. ${ }^{140}$ The subjectivity of affordability and a set of agreed upon values which define it are at the centre of this lack of definition. Stone succinctly observes;

There is no such thing as housing "affordability". Housing, in and of itself, is neither affordable nor unaffordable. Affordability is not an inherent characteristic of housing, but a relationship among housing cost, household income, and a standard of affordability. The term "affordable housing" is at best meaningless and at worst misleading, for it ignores or obscures the central question of who can and cannot afford housing. ${ }^{141}$

Proponents of alternative land-use patterns claim that affordability increases with rises in housing density. ${ }^{142}$ An increase in affordability is meant to be realised through increased choice, tenure variety, personal and public expenditure savings on infrastructure investment and maintenance, health and environmental external cost savings and greater efficiencies in infrastructure use. Further to these cost savings, increases in density are also meant to promote economic development through providing the critical mass of people to support businesses and public services.

A policy mechanism aimed at encouraging alternative land-uses is to implement urban growth boundaries. Critics of these growth boundaries, however, assert that limiting the supply of land available for development will in turn increase the cost of housing. ${ }^{143}$ This view is based on resource price theory where the productivity of the land is positively related to its value. ${ }^{144} \mathrm{In}$

\footnotetext{
${ }^{138}$ CRD, 2007; CHRANZ, 2006

${ }^{139}$ HNZC, 2005

${ }^{140}$ DTZ, 2004

${ }^{141}$ Stone, 1994

${ }^{142}$ Burton, 2002; Duany, 2000; Calthorpe, 1993; Rogers, 1999

${ }^{143}$ Pozdena, 2003; McShane, 2003

${ }^{144}$ Sanderson, 2005
} 
residential housing affordability, the productivity of land can be assumed to be relative to the amount of people that can be housed per hectare of land, or the density. However, what this supplydemand line of thought neglects is that the ability to afford a house is not solely based on land price or even the material costs for construction.

The demand-supply argument over simplifies the issue. As densities increase, so too does the value of land but the density increase is generally greater than the land value increase, making land prices per person lower. ${ }^{145}$ With increases in density, the range and income potential of employment opportunities also increases, which results in both higher labour participation and higher incomes. ${ }^{146}$ Savings in reticulated infrastructure required per person and the shift to active travel modes, such as walking and bicycling, also offset higher land costs. ${ }^{147}$ In a comprehensive review of the literature on growth management and affordable housing, findings indicate that market demand rather than land constraints are the main determinant of housing prices. ${ }^{148}$ Further, conventional land use regulations tend to take a 'laissez-faire' approach for the provision of affordable housing, and this excludes low income households disproportionately. ${ }^{149}$ The zoning out of low income households in turn causes urban fringe development, where land prices are cheapest and mobility options most expensive. ${ }^{150}$

In terms of public capital costs and the effect alternative land-uses have on them, both proponents and opponents generally agree that as density increases, these costs decrease. ${ }^{151}$ However, some contend that the capital infrastructure cost savings are overstated and that social costs such as the provision of schools, policing, fire services, traffic management, and waste collection are more expensive to provide in higher density areas. ${ }^{152}$

Beyond affordability, capital and social cost issues, the effect alternative land-uses are meant to have on the economy is that of a catalyst. The Auckland Regional Council's urban growth forum states that:

Opportunities will exist within higher density centres for a mix of commercial and residential developments. This will increase the opportunity for people to work closer to where they live. This approach has the potential to create economically

\footnotetext{
${ }^{145}$ Sanderson, 2005

${ }^{146}$ Litman, 2004

${ }^{147}$ Litman, 2004; Burchell \& Listokin, 1995; Carruthers, 2003

${ }^{148}$ Nelson et al., 2002

${ }^{149}$ Nelson et al., 2002

${ }^{150}$ Nelson et al., 2002

${ }^{151}$ Najafi et al., 2006; Speir \& Stephenson, 2002; Litman, 2004. Shoup, 2005; Vision 2020, 2005.

${ }^{152}$ Ladd 1992 in Troy 1997 
active communities which support a range of functions. This in turn, creates

opportunities for niche businesses and jobs to service the local business community

e.g. security, deliveries and cleaning. ${ }^{153}$

In advanced economies, knowledge-based output is seen as more significant than natural resources, or mass production, for economic growth. ${ }^{154}$ Young adults with university degrees, talent and discerning lifestyle requirements form, what has been termed, "the creative class", and it is these individuals who provide the engine to the knowledge economy. ${ }^{155}$ A city's ability to attract these people is a key to its economic growth and competitiveness. Crucial to attracting these people is providing vibrant, mixed use high amenity areas where density plays a key role. ${ }^{156}$

Economic benefits from increases to density may also be non-linear. ${ }^{157}$ Some suggest that only when a certain critical mass of people is achieved will external benefits be realised, including viable transit and soft travel modes and until then the cost benefit analysis may favour conventional land-uses. An empirical study that looked at the economic viability of local amenities suggests populations levels required to support particular amenities. This study recommends median populations of 2140 for a bakery, 1736 for a grocery store and 2894 for a corner store. ${ }^{158}$ Before arriving at these required population levels however, tensions may exist while existing modes of travel become less feasible and public or alternative modes of travel remain undersubscribed.

However, Vancouver's recent experience demonstrates the difficulties associated with waiting for sufficient population to warrant implementing travel mode changes. The additional costs in both capital expenditure and loss of business involved in retro-fitting an existing auto-orientated landuse pattern instead of directing land-uses around a transit orientated travel network compound this dilemma. $^{159}$

A common fear of intensification is that property values will decrease. ${ }^{160}$ However, Syme cites two American studies that found property prices actually increased as an effect of being either located near or as part of higher density developments. ${ }^{161}$ Von Hoffman has found similar positive relationships between higher densities and increased land values in a number of studies. ${ }^{162}$

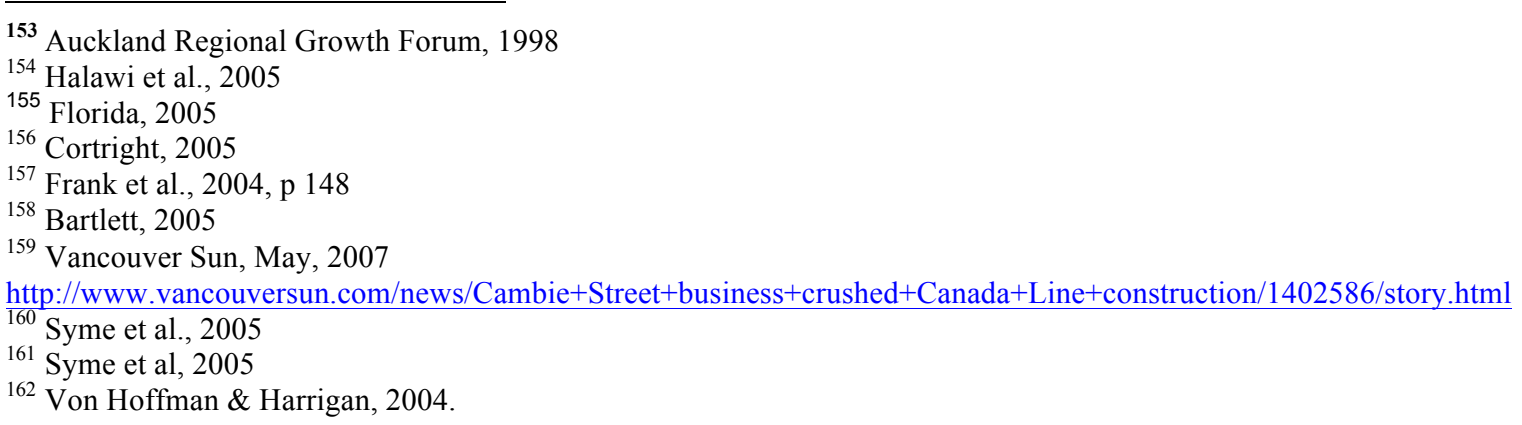


Although one population's concern for property value decreases may be unfounded, property value increases can lead to another population's problem. Gentrification as a result of increased property values has been suggested as exacerbating the predicament of the poor and leading to their displacement. ${ }^{163}$ However, new research suggests that poor residents in gentrifying neighbourhoods are no more likely to lose their homes than poor residents of other neighbourhoods. ${ }^{164}$

In New Zealand, subsidized housing, that often takes the form of higher density dwellings, did not have an effect on property values in a review of 15 case studies. ${ }^{165}$ Instead of high density or mixed uses, proximity to attractive amenities, particularly green spaces, has been found to have the greatest effect on property values. ${ }^{166}$ The relative density of neighbourhoods had less effect on property values because both high and low densities exhibit varying accessibility and proximity to open spaces. This finding suggests that the form of neighbourhoods is more important than the actual densities on influencing property values.

Many of the potential economic benefits of alternative land-uses are difficult to quantify. They span a divergent group of stakeholders and are not reflected on one balance sheet. ${ }^{167}$ Consumers may save on housing costs only to later spend more on travel, taxes or health care. Similarly, developers may spend less on developments only to have city councils struggle to afford maintenance costs. Who gains any economic benefits or pays for negative externalities is generally wide ranging. Any change from conventional land-use patterns is hindered by a vague idea of how the changes will be received, a lack of experience with alternative building forms, and because of the uncertainty surrounding the relative costs involved. As economic models expand to include many of the externalities of relative building types and settlement patterns, alternative land-uses appear to be more affordable than business as usual. ${ }^{168}$

\footnotetext{
163 Podenza, 2003

164 Atkinson 2002; Chamberlain, 2004; Newman \& Wyly, 2006

165 Auckland Regional Growth Forum, 1998

166 Kaplan et al, 2004, p 300

${ }^{167}$ McIndoe et al, 2005

168 Vision 2020, 2005 


\subsection{Environment}

Both the advocacy for and the mandate of planning and urban design is motivated by a concern for sustainable development and to protect the environment. While this is a general interpretation of these disciplines' roles, it neglects the interrelated economic, health and well being aspects of sustainability, which are also concerns of planning and urban design.

Sustainability as a planning concept was born out of the negative environmental side effects associated with the post WWII global economic boom. ${ }^{169}$ Sustainable development was a response to this economic growth versus environmental protection conflict, and was pitched onto the world stage with the Bruntland Report (1987). The Bruntland Report outlined a framework for achieving growth in an environmentally benign way by reconciling the ideological differences between environmentalism and neo-liberalism. ${ }^{170}$ It provides the most often quoted definition of sustainable development as "meet[ing] the needs of the present without compromising the ability of future generations to meet their own needs". ${ }^{171}$

However, despite the widespread adoption of sustainable development concepts, there is equally widespread criticism of the concept. ${ }^{172}$ Critics highlight the competing and sometimes contradictory aims of economic growth, environmental protection and social equity. ${ }^{173}$ Growth and sustainability seem to be at odds, where if one is achieved the other cannot be. To deal with this paradox, a focus on improvements to quality-of-life rather than economic growth, are suggested. ${ }^{174}$ Further reconciliations replace economic considerations of sustainability with developmental considerations. Here the difference between growth and development is stressed with the former being a quantitative term referring to the expansion of a system and the latter being a qualitative term referring to improvement and progress. ${ }^{175}$

In the context of urban planning, the usefulness of sustainability is questioned because of its primary focus on environmental aspects. ${ }^{176}$ The environmental focus assumes that cities are part of a natural system which ignores the complex social and political systems that maintain and create

\footnotetext{
${ }^{169}$ Davidson, 2005

${ }^{170}$ Davidson, 2005

${ }^{171}$ United Nations World Commission on Environment and Development, 1987, p 43

172 Perkins \& Thorns, 1998

${ }^{173}$ Davidson, 2005

${ }^{174}$ Porritt, 2006

${ }^{175}$ Snellen et al, 1996, in DeRoo, 2000, p 56

${ }^{176}$ Perkins and Thorns, 1998
} 
them. ${ }^{177}$ This also often elicits solely technical responses, useful for environmental problems, but cosmetic to social and political issues. ${ }^{178}$ For example, because the general ecological cycles of tree growth are understood- sustainable development offers useful guidance in the development of forest plantations. However, because the actions and behaviours of humans are less predictable, and knowledge of both social and environmental systems is uncertain, the idea of sustainable development for our cities must be weighed against this uncertainty. ${ }^{179}$

A major concern of sustainable develop today relates to planning current land-uses to mitigate the effects of global warming. The Intergovernmental Panel on Climate Change (IPCC) 2007 report provides consensus within the scientific community on the cause and existence of global warming. The report advises that global warming is 'very likely' to be caused by human activity. The 'very likely' represents $90 \%$ certainty ${ }^{180}$ and human activity in the report relates to current resource consumption, which in turn is related to land-use patterns.

The threat of peak oil, the point when the rate of oil production enters terminal decline, has also raised concern regarding the trend toward increased private automobile dependency associated with conventional land-use patterns. ${ }^{181}$ Some contend the peak has already been reached while others believe the world's oil reserves are larger than anticipated and concern is premature. ${ }^{182}$ Unconventional oil reserves are typically included in critics of Peak Oil world oil reserve figures, and unconventional oil includes synthetic oil derived from shale or tar sands. ${ }^{183}$ The refining process for un-conventional oil produces far more greenhouse gases than for conventional oil and this must be considered within the argument. ${ }^{184}$ Once oil reserves are depleted, contentious energy sources such as nuclear power may receive more attention as well. If new technologies have not been invented, and if demand does not abate, a return to coal and the exploitation of an unconventional oil supply will inevitably increase the dangers of global warming. ${ }^{185}$ Changes to conventional land-uses, as a means to reduce the reliance on fossil-fuels through reduced autodependence, may become not only desirable, but also a necessity.

A large portion of the environmental debate concerning changes to conventional land-uses relates to the relationship density has with the private automobile. This association was discussed

\footnotetext{
${ }^{177}$ Perkins and Thorns 1, 1998

${ }^{178}$ Perkins and Thorns, 1998

${ }^{179}$ Perkins and Thorns, 1998

${ }^{180}$ Intergovernmental Pannell on Climate Change, 2007

${ }^{181}$ Hubbert, K. 1949

${ }^{182}$ Williams, 2005; CERA, 2006

${ }^{183}$ Farrell \& Brandt, 2006

${ }^{184}$ Farrell \& Brandt, 2006

${ }^{185}$ Kunstler, 1994; Farrell \& Brandt, 2006 
previously in the transportation section and relates mainly to automobile energy use and auto space provision. The environmental concerns outside of transportation considerations include the impact land-use changes have on land preservation and non-transport related pollutants. The non-transport related pollutants covered in this section concern energy use in buildings, in terms of embodied energy in the building's construction, and lifecycle energy use in the building's operation. How urban land use patterns affect the concentration or dilution of pollutants is also discussed. Land preservation covers three areas, productive land infringement/ conversion, green-space provision and the subsequent amounts of paved areas and the associated run- off quantities.

Aside from environmental benefits land-use changes may lead to, how these benefits are achieved is under debate. Some contend that there are a number of potential negative consequences en-route to achieving the goals set out for alternative land-uses that haven't been accounted for. ${ }^{186}$ Additionally, opponents to changes from the conventional argue that new technology or man made advancements have not been allowed for, which may render problems solved or redundant. Changing land-use patterns is viewed by opponents and critics alike as an inefficient method to address environmental concerns. ${ }^{187}$

Energy consumption by various housing and building forms typical of either conventional or alternative land-uses is yet another environmental concern within the debate. The energy usage of varying building forms is the main source of carbon dioxide in the housing industry- carbon dioxide being the culprit of global warming. ${ }^{188}$ The Australian Bureau of Statistics (1992) states that energy expenditure is higher for detached single family dwellings than for multi unit dwellings or apartments. ${ }^{189}$ Critics, however, point out that when the number of people is factored in, to represent the figures as energy expenditure per person, apartments and multi family dwellings have a greater energy expenditure. ${ }^{190}$ This, however, may be attributed to the addition of single person households and the greater frequency of smaller household sizes in apartments. These calculations may represent a value statement prioritizing one form of living arrangement (single family dwellings) over another (single parent families). Counter to the Australian bureau of statistics energy expenditure figures, is the argument that while low density development may experience greater heat losses and consume more energy than medium density housing, the energy used is more likely to come from renewable sources and there are potential solar energy gains not available

\footnotetext{
186 Troy, 1996

${ }^{187}$ Gordon \& Richardson, 1997

${ }^{188}$ Newton et al., in Williams et al, 2000

${ }^{189}$ Troy, 1996

${ }^{190}$ Troy, 1996
} 
to higher density developments. ${ }^{191}$ One opportunity for renewable energy, potentially exclusive to single family detached dwellings, is wood burning. However, as experience in Christchurch, New Zealand has made apparent, this fuel use cannot occur in all geographical locations. Some contend that greater solar gain is achievable from any solar designed building, which can be either a single family detached dwelling or a multi family dwelling and apartment. ${ }^{192}$ Empirical findings demonstrate that energy savings can be best met by "simultaneously increasing the compactness whilst maintaining a limited building depth of 10-12 metres and where possible, achieving a solar orientation". ${ }^{193}$

Despite alternative land-use proponents' focus on getting people out of their cars to realise energy and pollution savings, buildings account for a large amount of energy use and as such also produce greenhouse emissions. ${ }^{194}$ This mainly occurs through artificial air conditioning, elevators and lighting. However, there is the potential for buildings to reduce their energy use once their external environments are improved. Removing or reducing automobile use may go some way to improving the external environment and thus reducing the need for buildings to use artificial air conditioning. ${ }^{195}$ Transportation policies will also have a greater immediate effect on energy expenditure because of the relative short life of vehicles compared to buildings. ${ }^{196}$ Despite the two to one ratio of building energy use over auto energy use, cars also have accidents, fatalities, and social and physical health erosion characteristics, which emphasise their lack of sustainability over buildings. ${ }^{197}$

Embodied energy comprises all the energy inputs that are needed to manufacture the elements of a house, such as flooring, glazing, roofing, fittings, and fixtures" as well as the "energy associated with extracting the natural resources, energy used in making the manufacturing equipment and in transporting raw materials and finished products. ${ }^{198}$

Proponents of conventional land-uses claim that timber framed houses are less environmentally stressful than the brick or steel dwellings required to build at higher densities. ${ }^{199}$ In a study looking at various housing forms in Australia's three largest cities, Melbourne, Sydney and Brisbane,

\footnotetext{
${ }^{191}$ Troy, 1996

192 Steemers in De Roo, 2000

${ }^{193}$ Steemers in De Roo, 2000, p 119

${ }^{194}$ Steemers in Echenique, 2001

${ }^{195}$ Steemers in Echenique, 2001

${ }^{196}$ Steemers in Echenique, 2001

${ }^{197}$ Litman, 2005

${ }^{198}$ Newton et al., in Williams et al, 2000, p 76

${ }^{199}$ Holland \& Holland (1991) in Troy, 1996
} 
lifecycle energy expenditure and embodied energy varied from location to location depending on climatic conditions. ${ }^{200}$ The overall conclusion of this study was that the annual lifecycle energy use and embodied energy were very similar for both housing forms, apartments and houses. However, this study also found, when considering energy use per person, the life cycle energy usage for apartments was significantly less than for single family dwellings.

Outside of retaining productive land reserves to maintain economic output, the preservation of open space and productive land is, for the most part, a subjective, value based concern. Beyond agricultural and food production, the value of open space to other economic factors such as tourism and health are hard to quantify. The general view simply sees more open space as a positive quality. Not surprisingly then, both proponents on either side of the debate claim that more open space is preserved with their advocated land-use pattern. ${ }^{201}$

Recent international literature emphasises a serious food supply problem and the highest ever recorded numbers of malnutrition. ${ }^{202}$ This is more of a concern in the developing world, and is not a food production concern but rather one of low incomes, inequitable restrictions on import tariffs, inadequate distribution of food, conflict, and economic insecurity. ${ }^{203}$ A reliance on increased yields is meant to abate the concern of productive land conversion. ${ }^{204}$ However, because of declining yield rates, aquifer depletion, failure of crop varieties to respond to additional fertilizers and that the easy gains in technology breakthroughs for food production are behind us, relying on continued increased yields must be treated with caution. ${ }^{205}$ That caution is amplified by the widely accepted view that much of the world's productive land is in use, with little room for expansion. ${ }^{206}$

Chapter 14 of Agenda 21, on sustainable agriculture and rural development, notes that, by the year 2025,83 per cent of the expected global population of 8.5 billion will be living in developing countries. Yet the capacity of available resources and technologies to satisfy the demands of this growing population for food and other agricultural commodities remains uncertain. Agriculture must meet this challenge, mainly by increasing production on land already in use and by avoiding further encroachment on land that is only marginally suitable for cultivation. Critics believe, however, that the need for agricultural land is declining and is only made viable in developed

\footnotetext{
200 Newton et al., in Williams et al, 2000

201 Ewing, 1997; Gordon \& Richardson, 1997

202 Rosenweig et al., 1993; Pimentel et al., 1996

203 Rosenweig et al., 1993; Pimentel et al., 1996

${ }^{204}$ Rosenweig et al, 1993; Pimentel et al., 1996.

205 Ewing, 1997; Diamond, 2005

${ }^{206}$ Rosenweig et al., 1993; Pimentel et al., 1996
} 
countries through government subsidies, to the detriment of developing nations. ${ }^{207}$ They conclude that the loss of open space and productive land is more of an aesthetic concern than a security one.

Urban expansion has been occurring in New Zealand at an estimated rate of 4\%-5\% per year. ${ }^{208}$ Similar to international trends, agricultural productivity in New Zealand has increased at a rate of 2\% per annum between 1972 and 1992, slowing in the last two decades. ${ }^{209}$ Granting that New Zealand will not be able to rely on technological innovation as its productivity slows in line with international trends, the threat to its productive lands from urban expansion is only seen as minor. ${ }^{210}$ However, rather than any threats of starvation, the loss of green space may prove more damaging to New Zealand's tourism industry and populations' health. ${ }^{211}$

The benefits of green spaces to health are widely accepted. ${ }^{212}$ Which pattern of urban development increases the amount of green space is contentious. Both local and regional evaluations must be made. Here, the amount of paved areas required to support the automobile take precedence, however the interesting dilemma of increased exposure to pollutants is raised. ${ }^{213}$ Some warn that although increased density is necessary for accessibility, the potential for reduced environmental quality exists if waste is not handled properly. ${ }^{214}$ Increased densities are seen to have the potential to impact negatively on air, water, noise and soil, which can affect a community's health. ${ }^{215}$ This relates back to the mode shift argument in the transportation section, where if mode shift doesn't occur, human exposure to excessive traffic, noise and pollutants may.

Without any threat to New Zealand's productive land base and the exposure to nuisances focused on transportation there is still the issue of a lack of available developable land near New Zealand's major centres. ${ }^{216}$ Many territorial authorities are addressing this issue through growth strategies which aim to intensify inner city regions while controlling leap-frog development. Increasing urban densities may be the most efficient means of dealing with this shortage.

\footnotetext{
${ }^{207}$ Echenique, 2001

${ }^{208}$ Ministry of Agriculture and Forestry, 2006

${ }^{209}$ Ministry of Agriculture and Forestry, 2006

${ }^{210}$ Ministry of Agriculture and Forestry, 2006

${ }^{211}$ Kaplan, 2001

212 Jolanda Maas et al., 2006; Morris, 2003

${ }^{213}$ Fouchier, in De Roo, 2000

${ }^{214}$ White, 2002

${ }^{215}$ Auckland Regional Growth Forum, 1998, p 20

${ }^{216}$ Grimes et al., 2004
} 


\subsection{Health}

Despite advancements in medical science, over the last few decades a world wide health epidemic is predicted. ${ }^{217}$ Concern is mainly focused on increased rates of obesity, asthma, depression, anxiety, inattentiveness and hyper-activity in children, the ageing population with its associated health issues, and vehicular accidents. ${ }^{218}$ The overwhelming concern focuses on obesity; or in other words obesity takes the cake. ${ }^{219}$ Many factors have contributed to increasing obesity rates, however, the focus in the context of this research, is on poor lifestyle habits and inactivity associated with conventional land-use patterns. ${ }^{220} \mathrm{New}$ Zealand is no exception to this rising obesity trend, with obesity rates doubling over the last twenty five years. ${ }^{221}$ Canada is in a comparable dire situation. ${ }^{222}$ Similar to how a health concern resulting from demographic shifts during the industrial revolution instigated the start of modern urban planning, again a health concern may be the catalyst for dramatic changes to current land-use patterns and the disciplines tasked with this change.

One argument suggests that people are willing to trade an increase in their weight for a cheaper house, or for more house for their dollar. ${ }^{223}$ This implies that there is a conscious trade-off, a choice made to be less active or to gain weight in exchange for increased value. Opponents to changes from conventional land-use patterns use similar logic when they cite studies highlighting the role that preference plays in dispersed settlement patterns. In terms of gaining weight, this trend seems unlikely. Another theory is that individuals are throwing caution to the wind in terms of their waistlines and health, instead relying on technological innovations in the future to reverse the effects of their current harmful decisions. ${ }^{224}$ This too, however, seems a little far-fetched.

In New Zealand the obesity epidemic is being taken seriously. The New Zealand Ministry of Health has published a programme to improve the nations' health, which includes urban pattern improvements. ${ }^{225}$ Similarly, Sport and Recreation New Zealand is following this trend by promoting community design that encourages activity, termed 'active living by design'. ${ }^{226}$ The

\footnotetext{
${ }^{217}$ Frumkin et al., 2004

${ }^{218}$ Frumkin et al., 2004

${ }^{219}$ Frank, 2004

${ }^{220}$ Frumkin et al., 2004

${ }^{221}$ Ministry of Health, 2004

222 Statistics Canada, 2005

${ }^{223}$ Plantinga \& Bernell, 2005

${ }^{224}$ Landsburg, 2001

${ }^{225}$ Ministry of Health, 2004

${ }^{226}$ SPARC, 2007
} 
benefits exercise has on health are not disputed and these links are well supported. ${ }^{227}$ How landuses relate to this trend, however, has received debate and this debate focuses on the role density has with health outcomes.

The potential health benefits arising from the relationship between higher density and transportation are as significant as the environmental benefits to which higher density may contribute. Well-being and liveability indicators that are related to health mainly come from the effect increasing density has on private automobile use. Frumkin summarises the debatable relationship:

Land use and transportation interact to affect many aspects of human activity, wellbeing, and health. Heavy reliance on the automobile for transportation results in more air pollution, which contributes to respiratory and cardiovascular disease. Driving more also means less physical activity, contributing to a national epidemic of overweight and associated diseases. More time on the roads means a greater risk of collisions with other cars and with pedestrians, with associated injuries and deaths. Sprawling cities threaten the quality of drinking water sources and the availability of green spaces. Even mental health and the network of social interactions and trust known as "social capital" may be affected. ${ }^{228}$

Non-transport related studies on the effects of density on health are somewhat lacking in the literature. However, a recent study on the health impacts of residential intensification in Auckland found that regardless of housing type, health and well-being may be negatively affected, but this effect differs between housing types. ${ }^{229}$ This study found that "noise, indoor living area and size of outdoor living space all have the potential to affect the quality-of-life and wellbeing of occupants of high and medium density homes. ${ }^{230}$ On the other hand, stand alone dwellings may affect wellbeing and health through environmental factors such as condensation, mould and mildew as well as stress factors associated with long commutes. ${ }^{231}$ In terms of medium and high density dwellings, recent moves by Auckland City Council have imposed design standards to control noise nuisances and minimum space requirements. ${ }^{232}$ However in New Zealand, living at higher densities is still

\footnotetext{
${ }^{227}$ Ewing et al., 2003

${ }^{228}$ Frumkin et al., 2004, p 2

${ }^{229}$ Lyne, 2004

${ }^{230}$ Lyne, 2004, p 5

${ }^{231}$ Lyne, 2004

${ }^{232}$ Syme et al., 2005 
largely regarded as a compromise to living in single family detached dwellings, with accepting increased noise and reductions in space as imperative. ${ }^{233}$

Frumkin argues that increased mixed use provides increased access to health facilities and this additional amenity in turn relies on increased average densities to remain viable. ${ }^{234}$ The Auckland Regional Councils' (ARC) Urban Growth Forum also suggests that one of the best ways to improve health is by improved access to health facilities. Here the ARC stated;

Health services will tend to be more accessible with greater levels of intensification, particularly with improved public transport systems. Also, population concentrations can facilitate the efficient use of facilities. ${ }^{235}$

Regardless of both access to health facilities and opportunities for soft modes of travel, Wilson suggests residents' perceptions of their neighbourhoods have the largest effect on health in terms of self health assessments. ${ }^{236}$ This implies that regardless of the actual form of neighbourhoods, how residents feel about where they live is more important than actual location and conditions.

However, Wilson concludes that the physical nature of residents' environments is the main factor that informs their perceptions. ${ }^{237}$

\subsection{Crime and Safety}

A tendency to blame cities as the cause of many social ills has long held sway. ${ }^{238}$ Given that proposed changes to conventional land-uses reflect urban rather than suburban characteristics, some expect that perceived urban problems will accompany these changes. Based on empirical evidence, the 2005 National Guidelines for Crime Prevention through Environmental Design in New Zealand suggests that crime prevention can be assisted through proper design and effective use of the built environment. ${ }^{239}$ However, there is debate on what design strategies will reduce crime and improve safety.

\footnotetext{
${ }^{233}$ Morrison \& McMurray, 1999; Turner et al., 2004; Syme et al., 2005

${ }^{234}$ Frumkin et al., 2004

${ }^{235}$ Auckland Regional Growth Forum, 1998, p 20

${ }^{236}$ Wilson et al., 2004

${ }^{237}$ Wilson et al., 2004

${ }^{238}$ Glaeser \& Sacerdote, 1999

${ }^{239}$ Ministry of Justice, 2005
} 
The two schools of thought on urban form and its relation to crime can be divided into either a Safescape (New Urbanist) or a Defensible Space camp. ${ }^{240}$ The different strategies for designing cities to minimize crime between the two camps are outlined in Table 5 .

Table 2: New Urbanism and Defensible Space Strategies ${ }^{241}$

\begin{tabular}{|l|l|l|}
\hline & \multicolumn{1}{|c|}{ Safescape } & \multicolumn{1}{c|}{ Defensible Space } \\
\hline $\begin{array}{l}\text { Public vs. } \\
\text { Private }\end{array}$ & $\begin{array}{l}\text { Maximise commons to promote } \\
\text { interaction and a sense of community }\end{array}$ & $\begin{array}{l}\text { Maximise private areas to create defensible space; } \\
\text { create a sense of community through smaller } \\
\text { development with fewer strangers }\end{array}$ \\
\hline Uses & $\begin{array}{l}\text { Mix uses to provide activity and } \\
\text { increase eyes on the street }\end{array}$ & $\begin{array}{l}\text { Mixed uses reduces residential control and therefore } \\
\text { increases crime }\end{array}$ \\
\hline $\begin{array}{l}\text { Streets and } \\
\text { Footpaths }\end{array}$ & $\begin{array}{l}\text { Encourage walking and cycling, } \\
\text { increase surveillance through a grid } \\
\text { street pattern }\end{array}$ & $\begin{array}{l}\text { Limit access and escape opportunities to provide } \\
\text { more privacy and increase residential control }\end{array}$ \\
\hline Alleys & $\begin{array}{l}\text { Face buildings to alleys to provide } \\
\text { eyes on the alley }\end{array}$ & $\begin{array}{l}\text { Eliminate or gate alleys as they increase burglary } \\
\text { and are dangerous for pedestrians }\end{array}$ \\
\hline Autos & $\begin{array}{l}\text { Build homes close to the street, } \\
\text { forcing parking to be on the street or } \\
\text { in rear courtyards }\end{array}$ & $\begin{array}{l}\text { Autos are safest in garages or visible in front of the } \\
\text { house; rear courtyards facilitate burglary }\end{array}$ \\
\hline Density & $\begin{array}{l}\text { High density to promote activity, } \\
\text { sustain public transit and reduce } \\
\text { sprawl }\end{array}$ & $\begin{array}{l}\text { Density increases vulnerability when it increases } \\
\text { common areas or unsafe parking }\end{array}$ \\
\hline
\end{tabular}

In one of the largest empirical studies of its kind, a spatial crime analysis of a London borough found that some of the design strategies and criticism for the dangers of courtyard parking, alleys and footpaths within the defensible space camp is justified. ${ }^{242}$ These design features are commonly advocated for by proponents for changes from conventional land-uses. However, the authors argue that the main issues of grid versus tree-like road layouts, public versus private space, developmental scale, permeability, mixed use and residential density seem to favour a return to traditional land-use patterns as well as higher densities. ${ }^{243}$

In an American study looking at crime in cities, some suggest that density increases the proximity between wealthy potential victims and poor potential criminals. ${ }^{244}$ This study notes how it is ironic that the same advantages of lower transport costs, faster information flows and the scale of economies that make cities more productive also make crime more productive. Density can make crime more productive by providing more potential victims at a greater rate, making criminals more informed about a wider range of victims and a greater sophistication in criminal activity, and by providing anonymity within a larger pool of people. ${ }^{245}$ On the other hand, because density

\footnotetext{
${ }^{240}$ Hillier \& Sahbaz, 2005; O’Toole, 2005

241 Town \& O’Toole, 2005 in Hillier, 2004

${ }^{242}$ Hillier, 2004

${ }^{243}$ Hiller \& Shu, 2000

244 Glaeser \& Sacerdote, 1999

${ }^{245}$ Glaeser \& Sacerdote, 1999
} 
interacts strongly with other variables, conclusive connections to crime are difficult to determine. ${ }^{246}$ However, in many space syntax studies, as density increases both robberies and burglaries decrease. ${ }^{247}$ The correspondence between mixed uses and crime are context sensitive and research shows that having a greater proportion of residential to non-residential development is the key to crime reduction. ${ }^{248}$ In terms of permeability, these same studies show alleys and footpaths to be crime hazards and street connectivity and accessibility not to be. The critical factor is getting the correct block size; too small with too few dwellings per street segment increases crime, as does blocks that are too large or long.

Mixed use and connectivity have been found to play a greater role than density in terms of positively affecting safety, however, sufficient populations are required to make mixed uses viable. ${ }^{249}$ Contrary to 'Defensible Space' theory, land-use segregation and private communities may shift crime to other neighbourhoods and reduce "people's willingness and capacity to deal with it". ${ }^{250}$ A recent report by the New Zealand Ministry of Justice suggests that 'eyes-on-thestreet' are one of the best defences against crime. ${ }^{251}$ This follows the findings of a large empirical study on the sense of security, which found that a social network or neighbours' acquaintance is the most important factor leading to a resident's sense of safety and security. ${ }^{252}$ Mixed uses and higher density both increase the frequency of eyes on the street and the proportion of them.

Building types that are associated with alternative land-uses are also commonly associated with crime. ${ }^{253}$ These include apartments and multi-family dwellings. Some feel that the more frequent turnover of tenants in apartments as compared to single family detached dwellings leads to a lack of cohesion in the neighbourhood and a greater threat from strangers. ${ }^{254}$ Another view is that the higher and more frequent social interaction in apartments leads to more crime. ${ }^{255}$ However, a large empirical study in Canada found that the association of crime and apartments has more to do with the lower relative costs of apartments and hence the higher proportion of low income tenants. ${ }^{256}$ This study found that crime and safety problems are more associated with socio-economic, rather

\footnotetext{
${ }^{246}$ Hillier, 2004

${ }^{247}$ Hillier, 2004

${ }^{248}$ Hillier, 2004

${ }^{249}$ McIndoe et al, 2005

${ }^{250}$ Dover (2000) in McIndoe et al, 2005, p 12 and p 30

${ }^{251}$ Ministry of Justice, 2005

${ }^{252}$ Greene and Greene, 2003

${ }^{253}$ Syme et al., 2005

${ }^{254}$ Peters, 2002

${ }^{255}$ Glaeser \& Sacerdote, 1999

${ }^{256}$ Kitchen, 2006
} 
than spatial factors. Additionally, apartment living has often been cited as providing a sense of security derived from both safety in numbers and the reduced access typical of such dwellings. ${ }^{257}$

In general, crime rates per person are higher in urban areas. That is not to say, however, that high density land-use is intimately associated with high crime rates. This correlation has been empirically disproved. ${ }^{258}$ Crime rates are better explained by socio-economic factors, and the high proportion of people at the lower end of the socio-economic spectrum in high density areas attests to the affordability of this form of living. Greater concern should be targeted to levels of mixed use in terms of the positive effect that diluting deprivation can have. The importance of quality design, mixed uses, permeability and connectivity play a major role along with high density to reduce opportunities for crime. Despite the relatively conclusive evidence however, New Zealand public opinion still associates alternative land-uses and higher density housing with poverty and high crime rates. ${ }^{259}$ And this association fuels the perception that changes from conventional land-uses results in diminished safety and security. ${ }^{260}$

\subsection{Community}

Many lament the perceived decline in both community values and a sense of community. While it is also widely accepted that a sense of community is essential to an individual's well being, the effect land-use changes may have on influencing it is widely debated. Little agreement exists on community assessment tools and these tools differ between disciplines. ${ }^{261}$ Likewise, isolating the effect of built form characteristics on community is also a challenge. The studies that examine the role land-uses may have on community development tend to focus on neo-traditional developments. These developments typically share characteristics akin to traditional land-uses and fall under names such as New Urbanist, Smart Growth or Compact development. ${ }^{262}$

In a study of Seaside Florida, a renowned New Urbanist development, findings indicated that residents felt a greater sense of community and a distinctive community experience. ${ }^{263}$ The density in Seaside is 25 dwellings per hectare gross and 50 dwellings per hectare net, with commercial areas over $3 \%$ of its total land area. Seaside has a typical traditional block pattern of a grid

\footnotetext{
${ }^{257}$ Guzman \& Bhatia, 2005

${ }^{258}$ Hillier \& Sahbaz, 2005; Harries, 2006

${ }^{259}$ Syme et al., 2005

${ }^{260}$ Morrison \& McMurray, 1999; Syme et al., 2005; Turner et al., 2004

${ }^{261}$ Kekäle, 2002

${ }^{262}$ Talen, 2001; Thompson-Fawcett \& Bond, 2003; Plas \& Lewis, 1996; Kim \& Kaplan, 2004

${ }^{263}$ Plas \& Lewis, 1996
} 
radiating out from a semi-circle of commercial use. However, the marketing of Seaside as a community focused neighbourhood may have biased the results, and the fact that only 14 of the 125 residents surveyed were both owners and year round residents limits the validity of this study. ${ }^{264}$ Further studies have produced mixed results, showing in some cases conventional neighbourhoods to have a greater sense of community, and in other cases, neighbourhoods associated with New Urbanist designs to demonstrate a greater sense of community. ${ }^{265}$

One built form aspect that is thought to increase a sense of community is casual neighbour interaction. ${ }^{266}$ In a Toronto study, casual neighbour interaction was more frequent in a neighbourhood with mixed uses, high permeability and concentrated land uses. ${ }^{267}$ In another New Urbanist development in Oregon, residents reported having increased opportunities to get to know their neighbours and a high level of social cohesion within the community was found. ${ }^{268}$ Contrary to this finding, though, residents on cul-de-sacs in a conventional neighbourhood were found to experience higher levels of neighbourliness compared to residents in neighbourhoods with through streets and higher densities in yet another study. ${ }^{269}$ However, like self-selection studies, community minded individuals may sort themselves into neighbourhoods that they perceive as more community orientated rather than the built-form exerting any influence on community development. ${ }^{270}$

A U.S. study that tested eleven community indicators in varying neighbourhoods found that in mixed use neighbourhoods, a greater sense of community existed. ${ }^{271}$ This same study compared apartment buildings (one with a public courtyard and another with an interior corridor only), and found the apartment with the courtyard exhibited a greater sense of community, emphasising the value of shared common space in community building.

Neighbourliness is often included within the broader term social capital. ${ }^{272}$ Although an agreed definition of social capital does not currently exist, it too is advocated as a positive neighbourhood quality that may be influenced by land-use changes. ${ }^{273}$ The similarities and differences between social capital and sense of community are apparent in the definition below.

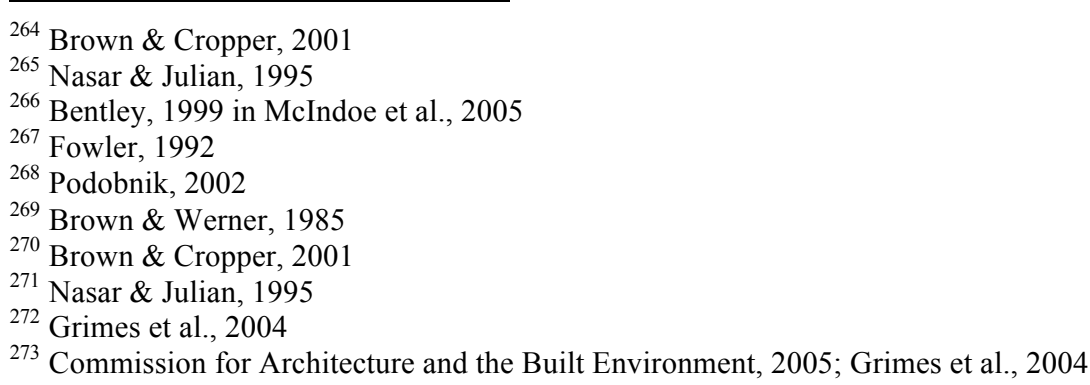


Social capital is defined as the social, political, and economic networks and interactions that inspire trust and reciprocity among citizens (Putman, 2000). Other definitions have emphasized the importance of the common good, mutual obligation and "horizontal trust" (that is between those in similar social situations). The erosion of social capital reduces trust and exchange among citizens. In other words, less civic engagement leads to the loss of a sense of community. ${ }^{274}$

The design of buildings and the space between them has the potential to affect social capital. ${ }^{275}$ Some suggest that residents who live in apartments are more likely to socialize with their neighbours and develop relationships that could lead to the development of community. However, apartment residents are more likely to rent and social capital has been found to be higher among home owners due to their lower mobility. ${ }^{276}$

Syme concludes that in New Zealand there are divergent views on the effect of land-use patterns on community. ${ }^{277}$ She states:

Some residents of intensive housing developments do not want to interact with their neighbours - some even expressing concerns about the mix of people in their neighbourhoods. However many residents of intensive developments consider the sense of community and diversity of residents as one of the main attractions of their neighbourhood. ${ }^{278}$

While a lack of consensus and inconclusive evidence generally typifies the relationship land-use patterns may have on community development ${ }^{279}$, the provision for opportunities of social interaction remains a laudable design objective. Whether or not individuals choose to take advantage of these opportunities, however, is difficult to predict. ${ }^{280}$

\footnotetext{
${ }^{274}$ Bray et al, 2005

${ }^{275}$ Glasear and Sacerdote, 2000

${ }^{276}$ Glaeser and Sacerdote, 2000

${ }^{277}$ Syme et al., 2005

${ }^{278}$ Syme et al., 2005, p 3

${ }^{279}$ Syme et al., 2005

${ }^{280}$ Tiesdell, 2004
} 


\subsection{Context Conclusion}

Comparatively, the issues and trends of this modern era crisis seem more threatening than those of the industrial revolution. Although the relative conditions of the $19^{\text {th }}$ century were perhaps worse than what is now the developed world, it is likely that these negative conditions have only been shifted rather than remedied. This chapter identified a number of associations between certain land-use patterns and the behaviour of not just an individual's travel but also the market, the environment, an individual's health, crime and safety and community formation behaviour. These associations are further examined in the pilot study.

There is a tremendous pressure to accept and conform to the inevitabilities of globalization, autodomination, obesity, sprawling suburbia, global warming, diminished communities and a negligible public realm. ${ }^{281}$ But rather than being passive to these forces, this chapter has demonstrated that changes from status-quo land-use practices appear both effective and well warranted. To reverse the unsustainable direction the developed world is pursuing, it seems as though a complete change from current western norms in lifestyle is required, and many interpret this as a change for the worse. However, this is clearly not the case. The literature identifies improved quality of life as the basis for changes to current land-use patterns. The most effective, and least drastic of these changes, can come from revolutionizing current travel behaviour.

While this chapter has identified a number of positive and negative outcomes associated with different land-uses, these associations fail to establish causation because of the spurious issue of agency. Past research, whether be it quantitative, statistical or qualitative has established a body of evidence that links neo-traditional land uses to positive sustainability outcomes, however, all of these associations may be a result of personal dispositions rather than a factor of changes to conventional land-use patterns. For this reason, travel behaviour research has moved to consider psychological factors alongside contextual ones, and the following chapter reviews this perspective.

${ }^{281}$ Saul, 1999 


\section{Psychological Behaviour Explanations}

The way individuals travel is most recently explained as a function of personality factors rather than socio-demographic or contextual built form factors. Given that the best predictors of travel behaviour are psychological in nature, then if it is accepted that current travel behaviour is unsustainable, the route to alter this is through behavioural change. ${ }^{282}$ This is similarly the approach adopted for other emergent environmental issues and concepts such as climate change ${ }^{283}$, air pollution ${ }^{284}$, environmental citizenship ${ }^{285}$, and sustainable communities ${ }^{286}$. Changes in human behaviour are believed to be needed because technical efficiency gains tend to be overtaken by consumption growth.

It is widely regarded that the relationship society has with the environment ultimately affects its' well-being, health, economy, and competitiveness ${ }^{287}$, however, meaningful action on this knowledge has yet to occur. ${ }^{288}$ This discrepancy has often been referred to as the "gap" between sustainability knowledge and the action directed to address it. Given that barriers to sustainable action appear to be psychological in nature, the value a psychological perspective has on this dilemma is apparent. Often discussed in terms of pro-environmental behaviour, psychology has provided an avenue to explore this lack of action. Pro-environmental behaviour (PEB) is a focus for a variety of disciplines that aim to understand behaviour related to environmental preservation, increased environmental awareness and action toward protecting the environment. If environmental behaviour is defined broadly as all types of behaviour that change the availability of materials or energy from the environment or alter the structure and dynamics of ecosystems or the biosphere, then pro-environmental behaviour relates to positive change. This can include recycling, preserving resources, consuming less, re-using, not polluting, adopting new environmentally friendly technologies, and a greater awareness or willingness for environmental concern.

A number of realms or types of causal variables provide the framework within psychology for the determination of pro-environmental behaviour. Stern (2000) classifies these as personal capabilities, external or contextual factors, attitudinal factors and habit or routine. ${ }^{289}$ Similarly, Garling and Garvill (1993) offer "external circumstances (situations, opportunities, constraints, and

\footnotetext{
${ }^{282}$ Suzuki, 2004; Potworowski, 2009

${ }^{283}$ Slocum, 2004

${ }^{284}$ Bickerstaff and Walker 20012002

${ }^{285}$ Burgess et al. 1998

${ }^{286}$ Smith et al. 1999

${ }^{287}$ Porritt, 2006

${ }^{288}$ Huddart, 2009

${ }^{289}$ Stern, 2000
} 
consequences), personality traits and abilities, motivational states (needs, drives, and goals), and information processing (judgements, evaluations, and decisions)," as further elaboration of these realms. ${ }^{290}$ Gifford and Heath (2002) suggest, more specifically, that in psychology travel behaviour is understood through factors like social value orientation, trust in others, environmental concern and awareness of environmental problems. ${ }^{291}$ With these causal variables comes the acknowledgement that a determination of human behaviour is highly complex, and gathering all the variables that may influence it is generally untenable. ${ }^{292}$

Personal capabilities used to explain pro-environmental behaviour are often measured as sociodemographic factors. ${ }^{293}$ These factors typically include age, gender, income, race and educational attainment. For example, many assume that as income rises, so too does the consumption of mobility. This is reflected in numerous studies and is often held up as an argument against curtailing private-automobile travel. ${ }^{294}$ However, others suggest that the link between rising living standards and rising demands for private space and car use misinterprets the association, and should not be accepted as inevitable. ${ }^{295}$ Instead of an association between increased wealth and mobility reflecting a greater demand for mobility, it may simply reveal the reduced accessibility and mixed use of current land-use patterns. Other associations between socio-demographics and travel behaviour include the finding that women tend to travel shorter distances and for less duration than men but make more trips. ${ }^{296}$ Females also appear to be more willing to reduce their car use. ${ }^{297}$ The most obvious assessment of personal capabilities is measured with automobile ownership and this factor has been shown to greatly influence travel behaviour. ${ }^{298}$ Sociodemographic factors have even been used to explain other-socio-demographic relationships with travel behaviour, such as explaining gender differences in travel with race, income and age variables. $^{299}$

Contextual factors that influence pro-environmental behaviour include physical, social, economic and political variables. In one respect this is the social or cultural landscape that promotes behaviours and relates to a macro-level from an ethological deterministic approach, and in another it is the influence of the environment on behaviours. So far, monetary incentives, the price of gas, high occupancy vehicle lanes, tolls and policy influences on travel behaviour have been the

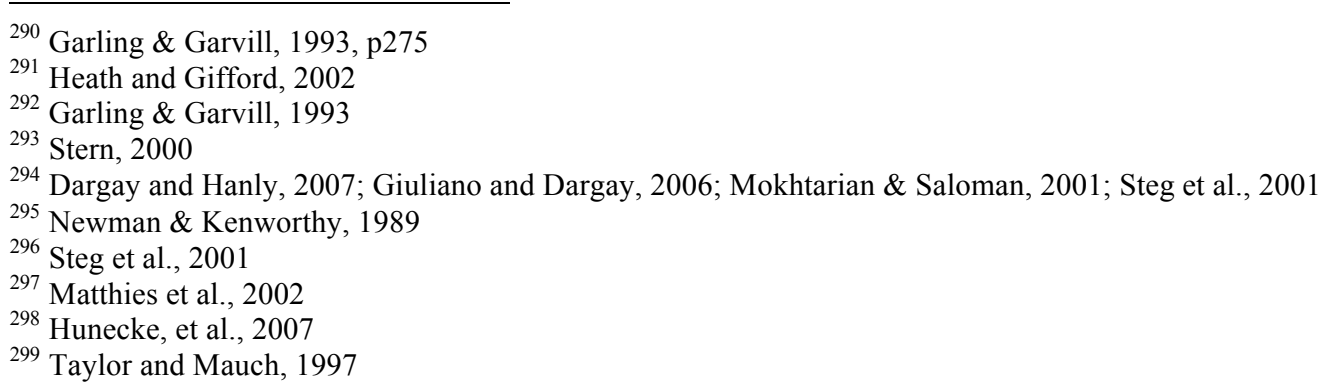


preferred option to physical land-use changes. Although the efficacy of these mechanisms suffers the same causal deficiencies as environment-behaviour associations, they remain the concentration of policy objectives to reduce private-vehicle use. Many studies demonstrate changes in travel behaviour as a result of one or another pricing control. Tolls have been touted as a solution to congestion along with an array of other monetary disincentives. ${ }^{300}$ Similarly, monetary incentives for other modes of travel have been shown to be positively associated with changes in travel behaviour. $^{301}$

The other realm of contextual factors that influences pro-environmental behaviours is that of the environment. Just as it is difficult to recycle if recycling facilities do not exist, it is also difficult to take alternatives to the private automobile if those alternatives are unavailable. Here, again, several studies, as discussed in chapter two, demonstrate a link between the built form and travel behaviour. As opposed to social contextual factors receiving the majority of policy reflection, environmental contextual factors have received the majority of academic attention. The main claims within this realm of human-environment relations pertains to the positive influence environmental attributes, such as higher densities, mixed uses, greater transportation connectivity, and increased accessibility, have on reducing private-automobile use. However, as discussed in the introduction, the concept of self-selection, at least in part, undermines the associations between built form factors and behavioural outcomes.

This section outlines the determinants of both pro-environmental and travel behaviours from a psychological perspective. A discussion of the key theories used to explore pro-environmental behaviour follows. These include the theory of planned behaviour, the norm activation theory and the value belief norm theory. While these three theories either assume a rational or normative causation of behaviour the latter half of this section discuses the role habits play on behaviour. Habits tend to be neither rational nor normative. Pro-environmental behaviour has increasingly been examined with these three theoretical domains, and travel behaviour has been included in this assessment. The goal of these theories has been not only to predict behaviours from attitudes "but also to explain the process through which the two are linked". ${ }^{302}$ Therefore a discussion of the key terms that surround the issue of attitudes is presented prior to the explication of the theories.

\footnotetext{
${ }^{300}$ Bonsall et al., 2007; Henshar \& Puckett, 2007; Saleh, 2005

${ }^{301}$ Heath \& Gifford, 2002

${ }^{302}$ Oreg \& Katz-Gerro, 2006 


\section{1. $\quad$ Attitudes}

The general consensus among researchers is that attitudinal variables are much better predictors of consumers' propensity to engage in positive environmental behaviour than demographic variables. ${ }^{303}$ As such, at the core of psychology's approach to understanding travel behaviour is the relationship between attitudes and behaviour. Attitudes are generally defined as "a psychological tendency expressed by evaluating a particular entity with some degree of favour or disfavour." 304 As the disciplinary lines blur to solve the social dilemma of travel behaviour, literature that addresses the influence of attitudes on it often lacks the theoretical background associated with attitudes in psychology. A variety of terms appear interchangeable with attitudes. These include values, beliefs, stated preferences, revealed preferences, core preferences, personality and predispositions. Attitudes within the theories used to explain pro-environmental behaviour are understood as the net result of the multitude of interactions with the world that an individual makes. These interactions inform the values and beliefs an individual holds which translate into attitudes that are later expressed as preferences. These preferences lead to further interactions with the world that again lead to and maintain certain values and beliefs that are continually refined as an individual's perception of the workings of the world. ${ }^{305}$ The way in which values, beliefs, stated preferences, revealed preferences, core preferences, personality, and predispositions inform and relate to attitudes is presented in this section along with some clarification of each of these terms.

Attitudes are generally considered to be relatively stable regardless of context. ${ }^{306}$ This is the finding self-selection studies rely on to make the assumption that causality flows from innate preferences to the self sorting of households into neighbourhoods that match their preferences instead of the other way around. This view of attitudes stems from the classical economics tradition. However, research within the emerging literature on constructive attitudes suggests that context plays a key role in determining both preferences and attitudes. ${ }^{307}$ Here, whatever immediate contextual information available is relied on to make a choice rather than a latent attitude toward a certain decision. These previous choices potentially inform the evaluation of future decisions to be congruent with and support past choices. This combination of insulating a decision trajectory doesn't rely on latent values or beliefs, but rather tends to form beliefs and values from a contextual perspective. Life-

\footnotetext{
${ }^{303}$ Roberts, 1996; Straughan and Roberts, 1999

${ }^{304}$ Eagly and Chaiken, 1991, pp1

${ }^{305}$ Mayntz, 2004, pp242

${ }^{306}$ Eagly and Chaiken, 1993

${ }^{307}$ Hoeffler and Ariely 1999; Simon et al., 2004
} 
stage has also been shown to affect attitudes. Attitudes are more flexible at the beginning and end of an individual's life as compared to the years in between. ${ }^{308}$ Similarly, self esteem affects attitudes where low self esteem is associated with unstable attitudes. ${ }^{309}$ Framing also has been shown to have an effect on attitudes, framing being the context within which attitudes are expressed. ${ }^{310}$ It must also be considered that not all activities that a person engages in are associated with well formed opinions of those activities beforehand. When individuals have ambivalent attitudes toward certain decisions, their attitudes have also been associated with a measure of variability. $^{311}$

Even when attitudes are well established and stable there is not a direct link between them and behaviour. ${ }^{312}$ It is viewed as a naïve assumption that behaviour can be predicted from attitudes alone and research has categorically demonstrated this. ${ }^{313}$ Many studies show that often individuals express a concern for the environment and claim to hold high environmental values but at the same time engage in environmentally harmful activities. ${ }^{314}$ These inconsistencies between attitudes and behaviours have been referred to by some authors as errors of omission and errors of commission. ${ }^{315}$ Individuals may express positive attitudes for some behaviour but may not act on those attitudes. This is known as an error of commission. An error of omission then, is to carry out a behaviour without a previous positive attitude toward it. Response bias is a common example of an inconsistency between attitudes and behaviours. Typical of the social sciences, individual preferences and attitudes are often gauged in questionnaires, and attempts to appear socially responsible can taint the results from survey instruments, known as response bias. As opposed to the view that attitudes are stable regardless of context, some authors claim that attitudinal and behavioural factors are strongly related to predicting travel behaviour only when contextual factors are neutral. ${ }^{316}$ In this sense linking attitudes in favour of alternatives to the automobile to actual use of alternatives is contingent on those alternatives being physically available. In fact the relationship between attitude and behaviour is suggested to be stronger the more facilitating the physical context is. $^{317}$

The distinction between attitudes towards the environment and attitudes about pro-environmental behaviour has been suggested as one of the factors responsible for the disconnect between attitudes

\footnotetext{
${ }^{308}$ Visser and Krosnick, 1998

${ }^{309}$ Campbell, 1999

${ }^{310}$ Craig et al., 2005

311 Hodson et al., 2001

312 Eagly and Kulesa, 1997

313 Eagley and Kulesa, 1997; Hayes, 1996

314 Ampt, 2003

315 Fujii and Garling, 2003

${ }^{316}$ Guagnano et al., 1995

${ }^{317}$ Diekmann \& Preisendorfer, 2003
} 
and behaviours. ${ }^{318}$ In either case the focuses of the attitudes vary; the former being on the relative importance of the environment, and the latter on beliefs certain consumption behaviours have. The important attitudes to environmental stewardship are those related to beliefs about consumption impacts. $^{319}$

\subsection{Values}

Values are important to the study of pro-environmental behaviour, travel behaviour being one such behaviour, for a number of reasons. First, values have been empirically shown to predict behavioural antecedents and are theoretically linked to explaining certain behaviours. ${ }^{320}$ Second, values as opposed to attitudes or beliefs are a relatively parsimonious tool for explaining behaviour. ${ }^{321}$ Generally values have been reduced to two opposing value types (self-transcendent or self-enhancement values) ${ }^{322}$ and sometimes three (egoistic, social-altruistic, and biospheric). ${ }^{323}$ Value orientations are regarded as "a stable preference for patterns of outcomes for oneself and others". ${ }^{324}$ Value orientations can be situated within in a cooperative realm where collective interest comes first (social-altruistic), in a competitive domain where self interest is paramount and concern for the collective is limited (egoistic), or in an arena where the interest of the ecosystem and biosphere as a whole is the priority (biospheric). ${ }^{325}$ The two opposing value types are represented as a combination of universalism and benevolence, or a combination of power and achievement for self-transcendent or self-enhancement values, respectively. ${ }^{326}$ The usefulness of having three value orientations rather than just two has not been empirically demonstrated until recently. ${ }^{327}$ Most studies fail to distinguish self-transcendence values from biospheric values. Social-altruistic and biospheric value orientations are both closely linked to self-transcendence values and to each other. One clear distinction between the two value orientations, however, is that biospheric values tend to ascribe more personal responsibility for environmental damage and proenvironmental behaviour. ${ }^{328}$ The triple value distinction is particularly evident when altruistic and biospheric behavioural intentions conflict. This is the case in terms of some pro-environmental behaviour such as donating to certain causes.

\footnotetext{
${ }^{318}$ Kaiser et al. 1999; Bamberg et al, 2003

${ }^{319}$ Axelrod and Lehman 1993; Kaiser et al. 1999; Kaiser and Gutsche 2003

${ }^{320}$ de Groot \& Steg, 2008

${ }^{321}$ Karp, 1996

${ }^{322}$ Stern et al.,1999; Nordlund \& Garvill, 2003

${ }^{323}$ Stern \& Dietz, 1994; Stern et al.,1993

${ }^{324}$ Bonaiuto et al., 2008, p952

${ }^{325}$ Bonaiuto et al., 2008

${ }^{326}$ Howes \& Gifford, 2008

${ }^{327}$ de Groot \& Steg, 2008

328 de Groot \& Steg, 2008
} 
Schwartz (1992) defines a value as: "a desirable trans-situational goal varying in importance, which serves as a guiding principle in the life of a person or other social entity". ${ }^{329}$ This definition highlights the hierarchical nature of values as well as the role values play as a guiding principle for evaluating behaviour, people and events. Similarly, values have been defined as a way individuals determine the desirability of a certain objective which is in turn expressed as a preference. Values are also abstract and, in this sense, not specific to certain situations.

Given that a causal mechanism is critical to the determination of causation, the term closest to what could be considered a causal mechanism is values. Values are often represented as stable cognitive structures with clear affective links ${ }^{330}$ and tend to be seen only within the agent based realm of causal mechanisms. Causal mechanisms are viewed as being agent based (originating from the individual on the micro-scale), functional (socially influenced on the meso-scale), or structural (politically influenced from the macro-scale).

Despite the view that values are stable, new research demonstrates that values do change when situational factors change. ${ }^{331}$ For example, self-enhancement values may be prioritized above selftranscendent values in terms of travel behaviour. When the negative environmental factors of travel behaviour can be demonstrated as more immediate, as opposed to in the distant future, selftranscendence values may replace self-enhancement values in the hierarchy. This, however, holds true more for self-enhancement value change than for self-transcendence value change where a shift from a self to a collective interest is more likely than the other way around. In terms of travel behaviour and self-selection studies, this finding suggests that even individuals who have a preference for auto-orientated neighbourhoods and land-use patterns may reconsider their positions. However, like attitudes, values alone do not have direct effects on behaviour and instead beliefs mediate the relationship between values and behaviour. ${ }^{332}$

\footnotetext{
${ }^{329}$ Schwartz , 1992, pp21

${ }^{330}$ Rohan, 2000

${ }^{331}$ Howes \& Gifford, 2008

332 de Groot \& Steg, 2008 


\subsection{Beliefs}

As opposed to attitudes, beliefs go beyond expressing disfavour or favour toward something and touch on an individual's reasoning for taking such attitudinal positions. ${ }^{333}$ Within attitude theory, attitudes are perceived to be determined by beliefs and beliefs are more closely tied to values. A belief resembles a personal cognitive theory for causal mechanisms. ${ }^{334}$ For example, an individual may believe that frequent private automobile use negatively affects the environment. Depending on their value orientation, this belief would influence their behaviour. This follows the theoretical proposition that values precede beliefs in a behavioural causal chain. ${ }^{335}$ The result is that certain beliefs are unlikely to form if they are incongruent with corresponding value orientations. A value orientation geared toward self-enhancement rather than self-transcendence would more likely result in beliefs that view frequent private automobile use as benign on the environment and vice versa for self-transcendence values. This belief then would translate into certain attitudes that are expressed as preferences both stated and revealed. Like attitudes, an individual may have many beliefs, and because of the contingent nature of attitudes and beliefs they are often used interchangeably. However, beliefs mainly provide an indication of attitudes rather than a specific attitude. ${ }^{336}$ Likewise, while beliefs evaluate the relative likelihood of certain situational outcomes or a perceived plausibility of them, attitudes reflect whether or not such outcomes are considered desirable for an individual.

\subsection{Preferences}

Not to be confused with attitudes, preferences are expressed choices based on the cumulative values, then beliefs, then attitudes held by an individual. A preference may contain two distinct parts: a core preference component and a component that depends on context. ${ }^{337}$ Core preferences are considered to be the preference component, and contextual preferences to be a contingent preference. The main difference between core preferences and contingent preferences is that core preferences are considered to be stable and invariant over time, and across situations. The focus of the majority of preference studies, including travel behaviour research and related residential location preferences, targets only core preferences.

\footnotetext{
${ }^{333}$ Eagly \& Kulesa, 1997

${ }^{334}$ Oreg \& Katz-Gerro, 2006

${ }^{335}$ Stern, 2000

${ }^{336}$ Baron et al., 1998

${ }^{337}$ Fujii and Garling, 2003
} 
Core preferences are the canon of micro-economics, and are typically understood with an invariant utility function (an unchanging mathematical equation that quantifies a unit of satisfaction derived from a unit of effort). Measuring preferences relies on survey instruments which elicit preferences based on hypothetical choices (stated preference) or by observing and quantifying choices after they have been made in the real world, ( revealed preferences). ${ }^{338}$ "Inconsistencies between stated preferences and preferences revealed by actual choices are well documented in the literature on travel demand analysis (Bates, 1988; Ben-Akiva et al., 1989; Morikawa et al., in press; Wardman, 1988)."339

Proponents for changes to conventional land-uses argue that along with demographic changes in household composition, housing preferences have shifted from predominantly single family detached dwellings to a more varied housing market. The desirability of suburban living has significantly diminished and alternatives are being sought to meet changing housing needs. Do suburbs or a business as usual approach to housing developments represent what people want, or are they a function of uneven government subsidies and interventions? Do people unrealistically want the benefits of both high and low densities without any of the drawbacks? This section looks at the literature to determine the drivers of choice in both international as well as New Zealand housing markets.

In New Zealand the dominant housing preference is for detached housing although, alternative housing forms have seen an increase in demand in recent years. ${ }^{340}$ More people are choosing to live in alternative housing forms because of the proximity to employment and social facilities as well as the increased convenience and affordability they offer. ${ }^{341}$ Some contend however, that the increased popularity of alternative housing forms actually represents the realization of an existing housing demand by people who already prefer other forms of living rather than a change in preferences from single family dwellings. ${ }^{342}$ A study conducted for the Centre for Housing Research in New Zealand concluded that there will be continued growth in demand for both homes and apartments. ${ }^{343}$ This study found that the "majority of 18-40 year old participants aspired to live in larger dwellings (villas rather than units) on large sections". ${ }^{344}$ However, this study also found that low maintenance homes were a desire shared by all age groups and that higher density

\footnotetext{
${ }^{338}$ Timmermans \& Noortwijk 1994

${ }^{339}$ Fujii \& Garling, 2003 pp390-391

${ }^{340}$ Big Cities, 2003

${ }^{341}$ Big Cities, 2003

${ }^{342}$ Morrison and McMurray, 1999

${ }^{343}$ DTZ, 2005

${ }^{344}$ DTZ, 2005, p 2
} 
dwellings acted as "substitutes for those unable or unwilling to enter the single-unit dwelling owner-occupied market." 345 Another significant finding of this study demonstrated a willingness to trade typical single family dwelling characteristics for proximity to schools and places of employment. ${ }^{346}$ This was highly evident in Auckland due, mainly, to traffic congestion.

The proximity to schools is a desire echoed in a study on consumer preference carried out by the Commission for Architecture and the Built Environment (CABE) in the United Kingdon. ${ }^{347}$ This study found an overall preference for single family homes for both families with children and for older couples. However, the study noted that this preference doesn't imply an associated preference for the common land form (sprawl) linked to this housing choice. Instead the findings suggest a preference for attractive areas with public surveillance, ample accessibility and proximity to schools, quality public transport, and a variety of facilities over business as usual developments. Younger people also showed a greater preference for alternatives from the conventional. Overall the study found that "house type preferences are strongly influenced by family circumstance and life stage, and of course, by affordability." ${ }^{348}$ In the U.S., Americans appear to dislike both density and sprawl which brings up an interesting dilemma. ${ }^{349}$ Despite a desire for conventional lowdensity land-uses and high amenity, this form of development may be untenable. ${ }^{350}$ The conflicting goals of exclusivity and public amenity suggest that simply meeting demand does little for sustainability objectives or realistic housing initiatives.

Opponents to changes from the orthodox contend that conventional settlements are the overwhelming choice for residential living because of preferential tax treatment to home mortgage interest, and biased, uneven subsidies between highway and public transport funding. ${ }^{351}$ It is stressed, however, that current regulations in America are not preventing developers from building alternative developments, but rather that developers are savvy and do not see a demand in the market that they should supply for. However, during high demand periods of growth the market is unlikely to reveal actual consumer preferences. ${ }^{352}$ Instead, consumer choice is not only limited by affordability but also by geography, regulations, and an un-competitive market which in turn limits choice. Although many consumer preference studies suggest a preference for the single detached

\footnotetext{
${ }^{345}$ DTZ, 2005, p 2

${ }^{346}$ DTZ, 2005, p 2

${ }^{347}$ Samuels, 2005

${ }^{348}$ Samuels, 2005, p 14

${ }^{349}$ Danielson et al., 1999

350 Samuels, 2005

${ }^{351}$ Gordon \& Richardson, 1997

${ }^{352}$ Samuels, 2005
} 
family dwelling, they also consistently rank suburbs lower than small towns, rural, or villageresidential settings. ${ }^{353}$

How one views the potential for future economic growth provides insight into how the consumer preference debate is viewed. If, on the one hand, it is believed that economic growth can continue at its current rate and be sustainable, then directing consumer preference seems overly regulatory. If, on the other hand, it is believed that changes to the current rate of economic growth are required to be sustainable, then promoting alternatives to the current apparent housing preferences appears justified. Even accepting a continuous growth economic model, the sector where growth occurs further informs consumer preferences. Now that more sustainable options are available, consumer preference is convoluted with market coercion and lobbied government preference. Instead of viewing consumer preference as sacrosanct, it may now be time to balance these desires against environmental limiting factors. ${ }^{354}$

\subsection{Personality}

Personality factors have been used by some authors, mostly outside of psychology, in an effort to further explain travel behaviour variance. ${ }^{355}$ Survey respondents are typically asked to select from a list of statements which best describe themselves, and are subsequently organised into categories such as adventure seekers, organizers or loners. These factors appear neither related to attitudinal variables about specific behaviours nor to beliefs about the mechanisms and externalities certain behaviours are associated with. Personality factors relate more to general individual dispositions which lack a theoretical framework or an historical association to travel behaviour, or to the more empirically established factors that influence pro-environmental behaviour. The corollary of this has shown personality factors to have little relevance to travel behaviour or associated residential location choices. ${ }^{356}$ Predispositions, similarly, are rarely equated with actual variables tested in a regression model. Instead, when speaking of self-selection the term 'predisposition' generally refers to attitude or belief factors or even psychological factors as a whole.

To a researcher unacquainted with the vast theoretical morass of the science of psychology, the differences between values, beliefs, attitudes, preferences and personality seem somewhat

\footnotetext{
${ }^{353}$ Ewing, 1997

${ }^{354}$ Samuels, 2005a

${ }^{355}$ CF Cao et al., 2006; Schwanen \& Mokhtarian, 2007

${ }^{356}$ CF Cao et al., 2006; Schwanen \& Mokhtarian, 2007
} 
indiscernible and even trivial. However, the differences are critical, and are the result of a long history of theoretical iterations, experimental research and real world case studies. The preceding account may be accurate in terms of partitioning behaviour into its' distinct components, however, the relation between each part may not be. The structural equations that are outlined in the succeeding section both aim to test the relationship amongst the parts of behaviour as well as provide behavioural theories.

\subsection{Behaviour Theories}

While attitudes are a factor of values and beliefs expressed as preferences and further associated with behaviour, this relationship tends to be weak without a number of contingent factors. ${ }^{357}$ This is despite attitudes often demonstrating a stronger relationship with behaviours than sociodemographic or built form factors. ${ }^{358}$ Three theories that help to link attitudes to behaviour include preconditions that must be satisfied in order to accurately predict behaviours from attitudes. These three theories are the Theory of Planned Behaviour (TPB ${ }^{359}$, the Norm Activation Theory $(\mathrm{NAT})^{360}$ and the Value Belief Norm Theory (VBN-Theory) as an extension of the NAT. Depending on which theory is employed, preconditions include social and personal norms, value orientations, perceived behavioural control and behavioural intent. ${ }^{361}$ These theories are the most widely used theories to explain pro-environmental behaviour, and consequently have increasingly been employed to examine travel behaviour. ${ }^{362}$ What differentiates these theories beyond the constructs used to predict behaviour are the underlying causal mechanisms assumed to govern behaviour. These are either altruistic moral motivations (NAT) or self interested utilitarian aspects (TPB).

\subsection{Normative Theories}

Schwatz's (1977) Norm Activation Theory (NAT) is commonly used in psychology to understand behaviour. Initially the NAT was developed to explain altruistic behaviour performed for the

\footnotetext{
${ }^{357}$ Fishbein \& Ajzen, 1975

358 Oreg \& Katz-Gerro, 2006

359 Ajzen, 1991

360 Swartz, 1977

361 Ajzen, 1991

${ }^{362}$ Bechtel \& Churchman, 2002
} 
benefit of others as compared to the widely held perception of human behaviour as self-serving. ${ }^{363}$ The underlying causal mechanism embedded within NAT is that people tend to behave according to what they perceive to be the moral right course of action. Norm activation theory holds that people act based on their perceived moral obligation to do so, and therefore behaviour is influenced by what people think they ought to do. A number of criteria are stipulated to activate this moral course of action. The first is a general awareness of the problem at hand. The second is an awareness of actions that could be helpful, and the third criteria required to activate moral norms is the perception that an individual is actually able to help. The final criterion is that responsibility to act is ascribed to oneself. ${ }^{364}$ Behaviour is assessed in relation to these four criterion and from this the decision to act or not is taken. Figure 1 outlines the norm activation theory.

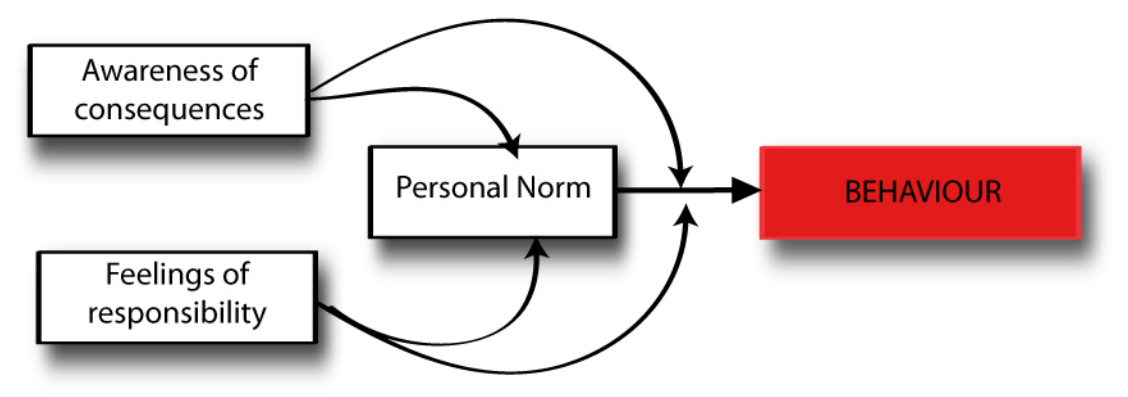

Figure 1: Norm Activation Theory

Although NAT typically aims to explain behaviour that places the interest of others first, it has also been used, within environmental behaviour research, to explain holding the interest of the environment paramount. ${ }^{365}$ The extension of the NAT into the environmental domain is articulated with the value-belief-norm theory $(\mathrm{VBN})^{366}$. The VBN theory combines the NAT with the Theory of Values ${ }^{367}$ and the New Environmental Paradigm (NEP) ${ }^{368}$. Within the VBN-theory the three value orientations (biospheric, altruistic and egoistic) inform a position on the NEP. The NEP represents a scale that taps into ideas about limitations of continued growth, the delicate balance of nature and the rejection of anthropocentrism. A NEP view holds that "human actions have substantial adverse effects on a fragile biosphere." ${ }^{369}$ Widely used, this scale typically employs fifteen measures to assess a general "planet earth" perspective. ${ }^{370}$ A positive score on the NEP scale along with an appreciation of the consequences of certain behaviours, a perceived ability to reduce

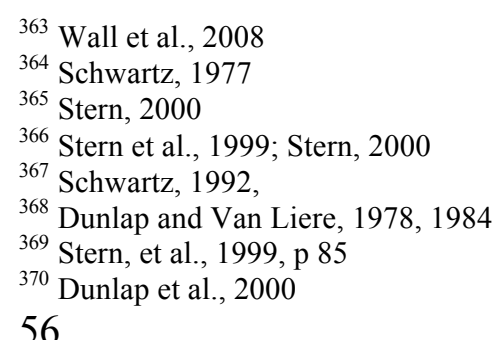


an environmental threat and a sense of obligation to act will in turn motivate pro-environmental behaviour. ${ }^{371}$ Figure 2 outlines the VBN-theory.

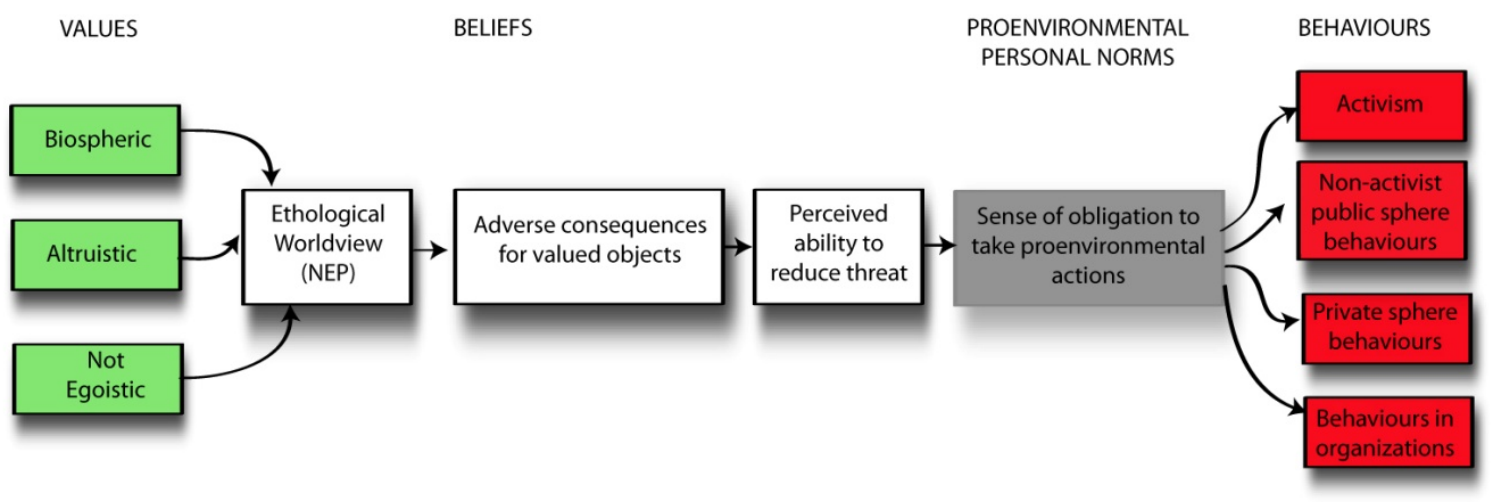

Figure 2: Value Belief Norm Theory

The normative approach to explaining behaviour has also been used to account for travel behaviour. Personal norms have predicted general car use ${ }^{372}$, the use of alternatives to private automobiles $^{373}$ and the acceptability of travel demand management policy measures ${ }^{374}$. However, norms appear more capable of predicting low-level pro-environmental behaviour as compared to situations where high behavioural costs are involved. ${ }^{375}$ Common low-level pro-environmental behaviour relates to behaviours that require less effort and commitment to carry out. These include a general willingness to change behaviour, political behaviour, environmental citizenship and policy acceptability. Behaviours that are more difficult to change, such as travel behaviour, are less predictable from a normative perspective. ${ }^{376}$

For behaviours that are constrained within contextual issues, such as travel behaviour, the theory of planned behaviour appears to offer a more appropriate tool.

\subsection{Rational Theories}

In an attempt to understand the discrepancy between attitudes and behaviour, the theory of reasoned action (TRA) was formed. ${ }^{377}$ The theory posited that attitudes together with the influence of an individual's social environment would predict his intention to perform a given behaviour. The

\footnotetext{
${ }^{371}$ Gifford, 2007

372 Bamberg \& Schmidt, 2003

${ }^{373}$ Matthies et al.,, 2002; Nordlund and Garvill, 2003

${ }^{374}$ Harland et al.,1999; Matthies et al., 2006; Steg and Vlek, 1997

375 Steg \& Vlek, 2009

${ }^{376}$ Steg \& Vlek, 2009

377 Ajzen \& Fishbein, 1980; Fishbein \& Ajzen, 1975
} 
influence of the social environment is considered the subjective norm and includes the attitudes of people important to the individual making the decision toward certain behaviours. As such, the perceived norm about the behaviour of a typical group member is used to assess subjective norms. ${ }^{378}$ Additionally, the most important factor in terms of predicting behaviour in the theory is behavioural intention. "A behavioural intention entails a commitment to act in addition to a desire to act. ${ }{ }^{379}$ The greater the intention to perform a behaviour, the more likely it is that the behaviour is performed ${ }^{380}$ However, not all behaviours are under an individual's volition. Although one may act as he chooses, this depends on opportunities, skills, money, time and cooperative people being available. ${ }^{381}$ This caveat led to the addition of an individual's perceived behavioural control (PBC). With the inclusion of this variable, the theory of reasoned action came to be known as the theory of planned behaviour (TPB). ${ }^{382}$

The theory of planned behaviour has been widely adopted to explain a number of behaviours from alcohol abuse ${ }^{383}$ to safe sex ${ }^{384}$ to pro-environmental behaviour. ${ }^{385}$ More importantly for the purposes of this dissertation, the ТPB has been used to explain travel behaviour. Certain travel behaviours like car use in general ${ }^{386}$, restricting car use ${ }^{387}$, changing travel modes ${ }^{388}$ and the acceptability of alternative transport policies ${ }^{389}$ have all been empirically accounted for with the TPB. Attitudes in the TPB are understood as the attitude toward the behaviour or the individual's appraisal of the expected outcomes of a certain behaviour. Subjective norms concern the social environment in which the person acts and the social pressures to perform certain behaviours. PBC is the perceived possibilities to perform a given behaviour, i.e. how easy or difficult the behaviour is perceived to be and to what extent the actor has control over the behaviour. Lastly, a behavioural intention is interpreted as per the TRA, and again includes both a desire and commitment to particular behaviour or action. ${ }^{390}$ The four components to the TPB are shown in Figure 3.

\footnotetext{
${ }^{378}$ Huchting et al., 2008

${ }^{379}$ Fujii \& Garling, 2003, pp 392

${ }^{380}$ Chen et al., 2004

381 Garling \& Garvill, 1993

${ }^{382}$ Ajzen, 1985

${ }^{383}$ Schlegel et al., 1992; Huchting et al., 2008

${ }^{384}$ Cha et al., 2008

${ }^{385}$ Laudenslager \& Holt, 2004

${ }^{386}$ Bamberg \& Schmidt, 2003

${ }^{387}$ Kaiser \& Gutscher, 2003

${ }^{388}$ Bamberg, 2006; Heath \& Gifford, 2002

${ }^{389}$ Garling \& Schuitema, 2007

${ }^{390}$ Fujii \& Garling, 2003, p 392 


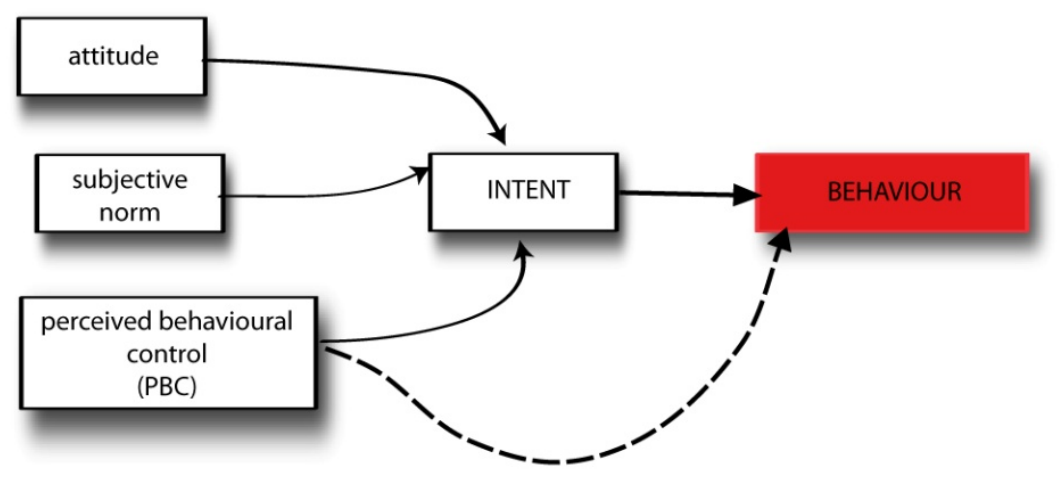

Figure 3: Theory of Planned Behaviour

Although actual control over one's behaviour can have a direct link to actual behaviour, this factor is difficult to measure. ${ }^{391}$ In this respect, perceived behavioural control is used as the closest estimation of actual control to the extent that people's perceptions of control are accurate. In transportation modelling, perceptions of control are further estimated with socio-demographic factors. ${ }^{392}$ In many respects, perceived control is more important to the enacting of behaviours as an initial understanding of an individual's volition. ${ }^{393}$ While actual behavioural control may have a greater influence over behaviour, changes in perceived behavioural control can still result in changes in behavioural intention. ${ }^{394}$

The theory of planned behaviour follows a causal mechanism closely linked to rational choice or self interested utilitarian aspects and is considered within a reasoned decision framework. ${ }^{395}$ Under this framework, the decision maker is assumed rational and is aware of all available options to them as well as the relative benefits and costs for each of these options. ${ }^{396}$ The decision maker is then guided by his desire to maximize his utility, and selects whichever option best achieves this goal.

Because of the rational decision making and utility maximization causal mechanism assumed as part of the TPB, the theory receives many of the same criticisms directed at these mechanisms. Foremost, these are that individuals are not rational and nor is all behaviour guided by a desire to maximize utility. ${ }^{397}$ Similarly, travel behaviour is assumed to be a market phenomenon, which it may very well not be, and as such, maximizing utility as a causal mechanism of travel behaviour is limited in its explanatory application. A greater emphasis should be placed on determining the

\footnotetext{
${ }^{391}$ Kraft et al., 2005

${ }^{392}$ Chen et al., 2004

${ }^{393}$ Chen et al., 2004

${ }^{394}$ Sutton, 1998

${ }^{395}$ Ajzen, 1985

${ }^{396}$ Chen et al, 2004

${ }^{397}$ Bechtel \& Churchman, 2002; Ariely, 2008
} 
limits of using a theory of utility maximization to understand behaviour in non-market activities. ${ }^{398}$ Instead of weighing up the costs and benefits of every decision, individuals are more inclined to develop algorithms or shortcuts to navigate a world with seemingly endless choices. ${ }^{399}$ Habits are one such shortcut that minimizes the cognitive effort to cope with the array of choices available. ${ }^{400}$ The addition of a habit factor within the TPB has, in fact, been shown to make the theory a more powerful predictor of behaviour. ${ }^{401}$ However, habit has also been shown to prevent people from forming behavioural intentions for behaviour change. ${ }^{402}$ Other criticisms include the emphasis the TPB places on behaviour being a solely cognitive process. It is suggested that instead of behaviour being an internal deliberation based on external information, behaviour is more akin to being deliberated within a social context, or not solely internal. The inclusion of social aspects in the TPB from this perspective is viewed as limited to the internalising of an individual's perception of a social context rather than an engagement with the social realm as part of the deliberation involved in behaviour. ${ }^{403}$

\subsection{Behaviour Theory Summary}

While both normative and rational theories of behaviour have demonstrable predictive associations with behaviour, a case has been made for the combination of both models. ${ }^{404}$ By combining both approaches, norms are accounted for that originate both from the individual and from the larger social context. This is in contrast to the focus on internal norms within NAT and external norms in TPB. Additional benefits of combining both models relate to the inclusion of duel behavioural causal mechanisms, rational-choice theory, where self interest guides behaviour and altruism as the guiding force behind pro-environmental behaviours.

Even with combined theories, a limited regard for context is still apparent. This includes physical contextual factors as well as cultural. The social context beyond the individual is stressed as important because behaviours are better understood "by considering the social structure within which individuals are embedded". ${ }^{405}$ Similarly the limited consideration for physical context is quite odd considering these theories come from an environmental psychology epistemology, where

\footnotetext{
${ }^{398}$ Sippel, 1997 in Keen 2003, p109.

${ }^{399}$ Keen, 2003. p1 10

${ }^{400}$ Keen, 2003. p110

${ }^{401}$ Bamberg \& Schmidt, 2003

${ }^{402}$ Taniguchi \& Fujii, 2007

${ }^{403}$ Timmins et al., 2003

${ }^{404}$ Harland et al., 1999; Wall et al, 2007.

${ }^{405}$ Oreg \& Katz-Gerro, 2006. p465

60
} 
the focus of the discipline is on transactions between humans and their environment. ${ }^{406}$ While the theory of planned behaviour accounts for the environmental context in terms of the perceptions individuals have of it, a greater account of context is required. Some suggest that there are a number of different ways context can influence behaviour. ${ }^{407}$ This can be directly through the provision of services, i.e. in order to use alternatives to the private vehicle, those alternatives must be available. Contextual factors may also mediate the relationship between attitudes' effect on personal norms and behaviour. For example, if public transit options were available and they were also an equitable alternative to private vehicle travel, individuals may have more positive attitudes toward public transit and as a result also use it more often. Contextual factors may also influence what motivates certain behaviours. If alternative travel options are normally used by a majority of people, these norms may influence further use. If on the other hand alternative travel modes are unavailable, behaviours may be motivated by more self serving factors. ${ }^{408}$

Either theory alone has been criticised for biases that can arise due to the sample populations the theories are used to study. Depending on the population sample either NAT or TPB has shown a greater capacity to explain travel behaviour. Where populations are more educated and more ideological NAT proves effective as compared to the TPB which is better at predicting behaviour from a wider cross section of society. ${ }^{409}$ Depending on the sample used, altruism or self interest will vary in their influence. Both theories together (NAT \& TBP) were found to better explain the overall influences on car-use compared to either theory alone. ${ }^{410}$ However, NAT better explained certain aspects of intentions to reduce car use compared to TPB.

As suggested earlier, the TPB or rational behaviour models improve their behavioural predictive power with the inclusion of habit factors. The same can be said for normative behavioural models. Much behaviour is guided by "automated cognitive processes, rather than being preceded by elaborate reasoning." habits are formed. ${ }^{412}$ It's even been suggested that behaviours that do not agree with proenvironmental attitudes receive little deliberation and end up being relegated to habitual behaviour.

\footnotetext{
${ }^{406}$ Steg, 2009

${ }^{407}$ Steg, 2009

${ }^{408}$ Guagnano et al., 1995

${ }^{409}$ Wall et al., 2007

${ }^{410}$ Wall et al., 2007

${ }^{411}$ Steg \& Vlek, 2009, p312

${ }^{412}$ Verplanken and Aarts, 1999
} 
While normative and rational theories of behaviour are successful at predicting behaviour that is deliberated on, these theories proves less beneficial to behaviour that is habitual. The majority of day to day behaviour is often hypothesised as habitual ${ }^{413}$ and more importantly to this dissertation, travel behaviour, to a large degree, is also considered habitual. ${ }^{414}$

Habit is defined as a behaviour resulting from repeated previous behaviour ${ }^{415}$ where little or no deliberation is required. ${ }^{416}$ Habits are often used as a heuristic to minimize cognitive effort involved in the multitude of decisions an individual is faced with on a day to day basis. ${ }^{417}$ Habit is used in this way to "simplify decision making and is a highly sensible way to cope with effectively unlimited choice". ${ }^{418}$ A number of studies have demonstrated a statistical correlation between past behaviour and predicted future behaviour. ${ }^{419}$ This suggests a pattern of behaviour or a habit. While some authors view habits as goal orientated ${ }^{420}$ others see them as unintentional ${ }^{421}$. A slightly different view of habit is that it is like a behavioural script held in memory and the habitual choice may then be retrieved with minimal effort. ${ }^{422}$ Within the goal orientated habit perspective, the more a goal is achieved through a habitual behaviour, the stronger the habit becomes. ${ }^{423}$ Hence habits develop as a stable reward for certain behaviours. ${ }^{424}$

While an initial decision may receive a conscious evaluation that weighs up the benefits and drawbacks, similar decisions that follow may receive less and less consideration. The initial decision may well be suited to an explanation with the TPB or the NAT, but the persistent repetition of similar decisions start to resemble a habit. ${ }^{425}$ Some argue that so long as the context of similar decisions doesn't drastically change, initial decisions will be relied on and habit can be claimed. ${ }^{426}$ Determinants at both the start and throughout the stages of habit forming may also be different. $^{427}$

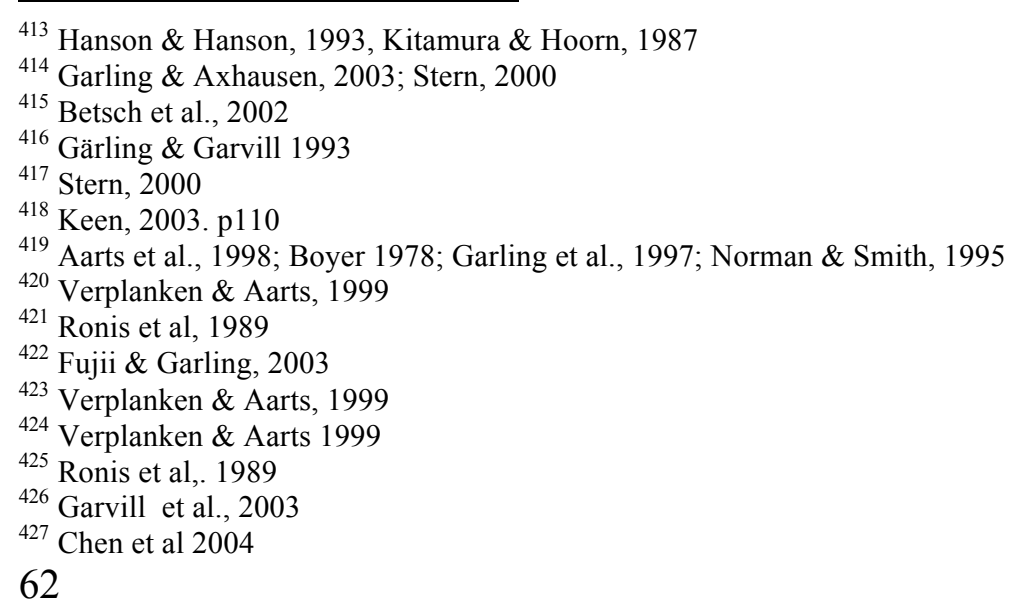


Habits are also particularly difficult to alter. Once a habit is formed, new information that might affect the habit if it were deliberated on is ignored. ${ }^{428}$ This results from a sort of cognitive frugality, where once a certain behaviour has been evaluated, individuals are reluctant to expend energy reevaluating what they have already considered. Habits are generally characterised with efficiency, lack of awareness and functional as well as situational constancy. ${ }^{429}$ In this sense, habits become automatic behaviours. It is postulated that the costs, uncertainty and effort involved in seeking out alternatives to originally deliberated behaviour is too great to trigger a shift in behaviour. ${ }^{430}$

Habit is regarded as important to travel behaviour research because of its bearing on travel demand management strategies. ${ }^{431}$ "A choice that is non-deliberate may in fact be difficult to influence with rational arguments (e.g., increased costs), since the person making the choice tends to discount relevant information." ${ }^{432}$ This has particular bearing on travel forecasting. Travel forecasting is premised on the assumption that what individuals do in terms of their travel behaviour represents their expressed preferences, and is consequently accommodated within forecasting models. When in fact what transportation modellers may be observing is habits rather than deliberate choices, and as a result end up perpetuating bad habits by planning to accommodate them. However, given the links between travel behaviour, particularly the work-commute, and residential location choices, attributing where individuals choose to live as habitual seems unlikely. However, that line of reasoning relies on the presumption that individuals make the connection between travel behaviour and neighbourhood location choices. Similarly, the timing of residential location choices may have a bearing on the relative value placed on travel preferences. Not until recently have global warming concerns been reflected to any degree in policy nor have sustainability issues received much consideration from the general public. Likewise, the cultural desirability of certain built form representations has not been questioned. This issue relates to the measuring of habits as well. Instead of assessing a habit, the physical constraints that led to the habit may be evaluated. If choices for alternative travel modes to the private automobile are limited then private automobile use may not be a preference, nor a habit but instead an assessment of repetitive constraining physical factors. ${ }^{433}$

The focus of many studies is on finding solutions to the habit of excessive private-automobile travel. These studies have found that habits rely on stability, and in situations where individuals

\footnotetext{
${ }^{428}$ Garvill et al., 2003

${ }^{429}$ Verplanken \& Aarts 1999

${ }^{430}$ Garling \& Axhausen, 2003

${ }^{431}$ Garling \& Axhausen, 2003

${ }^{432}$ Garling \& Axhausen, 2003, p1

${ }^{433}$ Garling \& Axhausen, 2003
} 
reconsider their travel options, such as when moving or under forced experimental conditions ${ }^{434}$, the influence of habit is weaker compared to normative or rational influences on behaviour. ${ }^{435}$ This is as opposed to when habit is found to be a strong predictor of behaviour. In these cases, intentions, norms and attitudes were less influential. Changing conditions have been highlighted as policy opportunities to alter poor travel habits. However, in some instances the uptake of alternative travel modes is short-lived after intervention experiments. ${ }^{436}$ Other intervention studies expose participants to information on alternatives to the private automobile and have found that awareness of alternatives to the car corresponded to a decrease in car use for people with a strong car habit but this was not so for people with a weak habit. ${ }^{437}$ Although in a new context such as residential relocation it appears that habit can be broken, the rescheduling of travel activities or trips appears not to abide by this rule. Instead activity rescheduling was found to be habitual. ${ }^{438}$ Activity rescheduling refers to individuals revising the original schedule in case of unexpected events.

Habit has additionally been found to prevent individuals from forming behavioural intentions for travel behaviour modification. ${ }^{439}$ Other associations between habits and travel behaviour include the prediction of travel modes ${ }^{440}$, the selection of travel routes ${ }^{441}$ and the predilection for destinations individuals travel to. ${ }^{442}$ Some studies, however, are critical of the role habit plays in travel behaviour. A study observing the travel behaviour of recently relocating individuals showed no difference in travel behaviour between a control group and a group given new information on travel alternatives, regardless of past travel behaviour. ${ }^{443}$

Together, norms, rational evaluations and habits form a framework for understanding travel behaviour within an environmental psychological perspective. Many of the findings from this field are adopted, relied on, and built upon in other disciplines and from an interdisciplinary approach, perhaps, the gap between good intentions and poor behaviours can be closed. Environmental problems, travel behaviour being one such issue, are not entirely psychological, they are also ecological, technological and socio-cultural and as such an interdisciplinary approach is required for their solution.

\footnotetext{
${ }^{434}$ Fujii et al., 2001

${ }^{435}$ Verplanken et al., 2008

${ }^{436}$ Davidov, 2007

${ }^{437}$ Garvill et al., 2003

${ }^{438}$ Chen et al, 2004

${ }^{439}$ Ronis et al., 1989

${ }^{440}$ Bamberg, Ajzen et al., 2003

${ }^{441}$ Bogers et al., 2005

${ }^{442}$ Handy, 2005

${ }^{443}$ Bamberg, Rölle et al.,2003

64
} 


\section{Place Attachment}

Strengthen relationship between 3 and ch 4

With few exceptions, the relationship between place attachment and travel attitudes is unexplored. This chapter introduces the concept to the study of travel behaviour as a key factor to help explain how the built environment combined with psychological factors exerts an influence on travel attitudes. An association between an attachment to a place and the act of people leaving a place, at first, seems counter intuitive. However, this is not the case. The place specific focus of place attachment provides the link between the built environment and psychological variables commonly used to explain travel behaviour. ${ }^{444}$ While self-selection studies aim to establish the influence the built environment has on travel behaviour after accounting for the influence of psychological variables, utilising place attachment variables may explain why there is an influence between the built form and travel behaviour at all. Similarly, where the main use of psychological variables in environmental psychology studies of travel behaviour is to segment sample populations into clusters of like psychological dispositions, again place attachment provides that important link to the built environment. There are causal mechanisms or demonstrable attitude changes associated with the development of place attachment and these mechanisms of attitude change can be inferred to explain travel behaviour if a link between place attachment and travel attitudes is established. Likewise, place attachment is more likely to occur after an individual has resided in a neighbourhood for an extended period of time. Hence, links between place attachment and travel attitudes undermine the assumption of existing attitudes informing individuals to selfsort into neighbourhoods that match their preferences as in self-selection studies.

This section first discusses the various definitions and ways of interpreting place attachment. Next, the limitations of place attachment are discussed, specifically the individual focus of the concept. Much of the criticism of place attachment stems from theories common to social identity theory and, as such, this theory is briefly outlined. Social identity theory also provides both theoretical and empirical evidence of attitude change mechanisms and these are outlined in detail as they provide the theoretical importance of linking travel attitudes to place attachment. This section ends with some of the findings that are common to place attachment studies and emphasises the theoretical underpinnings that suggest place attachment is a post decision factor.

$\overline{{ }^{444} \text { Patterson and Williams, 2005; Sack, } 1997}$ 


\subsection{Place Attachment Definition}

Place attachment is a widely researched concept and also widely divergent. ${ }^{445}$ It is typically defined as "the idea that people develop special bonds with certain settings that have deep meaning for them ${ }^{446}$ but agreement on its definition is far from being reached. ${ }^{447}$ Current understanding of the concept sees two main types of place attachment; place identity and place dependence. Some authors position place attachment, place identity and place dependence under the umbrella of sense of place. ${ }^{448}$ However, other authors avoid sense of place definitions because they view the field as too large and chaotic, essentially diluting the focus needed to make the term useful. ${ }^{449}$ Further definitions rest place identity in the larger concept of self, ${ }^{450}$ place attachment as the meanings certain places hold ${ }^{451}$, and place dependency as the functional attachment to a place in terms of the place meeting the needs of an individual or group. ${ }^{452}$ Still more authors suggest viewing place attachment concepts in terms of psychology's attitude theory, using cognitive, affective and conative facets. ${ }^{453}$ This approach recognizes place attachment as multidimensional and helps to identify linkages between place attachment and particular behaviours. ${ }^{454}$ The cognitive aspect of place attachment refers to beliefs and perceptions, the conative aspect refers to behavioural intentions and commitments and the affective aspect relates to feelings and emotions. In this respect place identity is cognitive, place attachment is affective and place dependence is conative. $^{455}$

Place attachment should not be confused with a sense of community. Typical to urban design, an increased sense of community is often touted as one of the positive effects resulting from reduced private automobile use. ${ }^{456}$ This generally results from increased neighbour interaction, ${ }^{457}$ less time spent driving and a greater prevalence of mixed uses ${ }^{458}$. Although this may be the case, a sense of community is defined as:

\footnotetext{
445 Jorgensen \& Stedman 2006; Altman \& Low, 1992

${ }^{446}$ Gifford, 2007

${ }^{447}$ Altman \& Low, 1992

${ }^{448}$ Shamai, 1991

${ }^{449}$ Stedman, 2002

${ }^{450}$ Proshansky et al.,1983; Proshansky, 1978

${ }^{451}$ Altman \& Low, 1992; Stedman, 2002

${ }^{452}$ Shumaker \& Taylor, 1983

${ }^{453}$ Jorgensen \& Stedman, 2006

${ }^{454}$ Jorgensen \& Stedman, 2006

${ }^{455}$ Jorgensen \& Stedman, 2006

${ }^{456}$ Putnam, 2000

${ }^{457}$ Bentley, 1999 in McIndoe et al., 2005

${ }^{458}$ Fowler, 1992 


\section{A feeling that members have of belonging, a feeling that members matter to one another and to the group, and shared faith that members' needs will be met through their commitment to be together. ${ }^{459}$}

From this perspective, a sense of community appears far broader than place attachment and, perhaps as a result, lacks the established means of measurement. ${ }^{460}$

The varying definitions of place attachment help to highlight the specific nature of attachment under study. This is important because different types of place attachment have been associated with different behaviours or outcomes. Place identity and place dependence seem to differ in their relation to pro-environmental behaviour. Generally people who identify with natural environments tend to exhibit a greater environmental concern than people who depend on natural environments or exhibit place dependency. ${ }^{461}$ Place attachment associated with where one lives inevitably must be associated with both place identity and place dependency aspects.

Place attachment can also develop for specific physical settings as well as for social settings. ${ }^{462}$ Given this caveat, the definitions of place attachment could be further divided into categories focusing on physical or social elements that individuals may become attached to. While place is clearly a spatial concept and community is a social construct the psychology associated with attachment is congruent. The various objects, settings or situations individuals become attached to also reflect different aspects of attachment. Highly visible and expensive objects that reflect an individuals' role or accomplishments in society, such as automobiles and dwellings, are argued to reflect a self identity concept of attachment. ${ }^{463}$ Given that travel behaviour is linked to both autoownership and residential location choice, the relevance of the role place attachment may have on travel behaviour is apparent.

\subsection{Place Attachment Limitations}

Early studies on place attachment tend to focus on the individual experience of attachment. ${ }^{464}$ This is similar to the vast majority of social psychological literature on attitudes that almost wholly view

\footnotetext{
${ }^{459}$ Bray et al, 2005

${ }^{460}$ Kekäle, 2002

${ }^{461}$ Kyle et al., 2004

462 Williams et al., 1992

${ }^{463}$ Ball \& Taski, 1992

${ }^{464}$ Brown \& Raymond, 2007
} 
attitudes as individual cognitive representations. ${ }^{465}$ The current focus on self-selection within travel behaviour research recognizes the importance of attitudes but also limits the understanding of attitudes to the individual. ${ }^{466}$ Place attachment studies have been criticized for focusing on the individual dimensions of place and not looking beyond to the "collective nature of relations between people, identities, and their environments." 467 This criticism can extend to travel behaviour research as well. Because attitudes are viewed to totally reside within individuals, the findings from self-selection studies are limited to sample segmentation. Again, despite the value of this, little is achieved in so far as determining how certain attitudes form, how to change them and how this relates to the built environment.

Place attachment has also largely concentrated on only positive outcomes of attachment. The same can be said for urban design's focus on only positive sense of community aspects. While a sense of community can have positive qualities it can also serve negative ends. ${ }^{468}$ The exclusion of individuals from communities, increased homogenisation, and the insulating effect of being part of a community that limits responsibilities to a wider range of issues and to other communities, are among the negative effects a sense of community can create. ${ }^{469}$ These negative associations to a sense of community may also be true for place attachment, and this may be particularly true for negative environmental spin-offs. A potential negative result of place attachment is the desire to protect places that individuals are attached to. While place protection by attached individuals is linked to positive environmental aspects, ${ }^{470}$ it may also manifest negative behaviours. By maintaining certain behaviours (such as, predominantly driving) individuals may believe that they are also maintaining the exclusiveness of their place. Travel behaviour in this sense can be interpreted as actively attempting to protect a place by maintaining its' separation from other places. Similarly place attachment invokes strategies to prevent being separated from places individuals are attached to, ${ }^{471}$ and this may result in discouraging or opposing any changes to a particular place.

As outlined previously an attachment to a place is not always associated with environmental concern for it. ${ }^{472}$ Presumably one can be attached to and identify with their place of work, which may be an open-pit mine, or to a secluded lake. Maintaining their attachment to either such place requires entirely different environmental attitudes. Common in social identity theory is the view

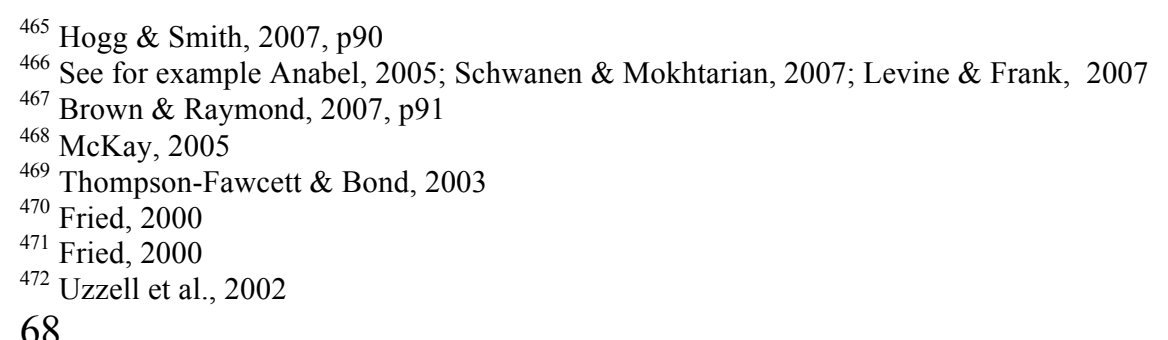


that people can hold a number of different identities at the same time. ${ }^{473}$ The tendency is to express one identity at a time; however, people strive to be coherent with an integrated self-concept. ${ }^{474}$ Generally the more attached a person is to a place the more likely they will see less wrong with it and inferentially less wrong with the attitudes and behaviours normative of the place. ${ }^{475}$

\subsection{Social Identity in Place Attachment}

Social identity theory provides an avenue that can help understand the casual mechanisms leading to the development of place attachment. Social identity refers to an individual's self-concept that is derived from a perceived membership within a social group. ${ }^{476}$ A self concept is formed from an individual's beliefs and knowledge about themselves ${ }^{477}$ and increasingly individual self concepts have been inextricably linked to notions of place. ${ }^{478}$ Identity is defined very broadly to include all attributes that constitute the self-concept, individual and group attributes that are possessed as well as those that are aspired to. Presumably social groups can also possess location specific aspects, namely groups associated with neighbourhoods and an individual's immediate surroundings. Given the well documented connections between dwelling location choices and travel behaviour, the significance of social identity theory to this phenomenon is evident.

Social identity theory originated with Tajfel (1981) and Tajfel and Turner (1979) and focused on the way in which groups and group members amplified their differences to other groups or individuals and accentuated similarities among group members. ${ }^{479}$ As opposed to this metacontrasting, Turner et al., 1987 developed a self-categorization theory that recognized both the cognitive and motivational factors of the earlier social identity theory but instead concentrated on how individuals came to identify with groups. ${ }^{480}$ Self categorization is the key insight of social identification theory, and highlights a process of attitude change. Categorization can apply to individuals as well as to groups, and it is posited that through the process of categorization and related social mechanisms, real attitude change occurs. Related social mechanisms include conformity, persuasion and influence, and each of these follow from a self-categorization effect. Illuminating the underlying mechanisms to attitude change is the focus of this dissertation and here,

\footnotetext{
${ }^{473}$ Hogg \& Smith, 2007

${ }^{474}$ Baumeister, 1998

${ }^{475}$ Lalli, 1992; Stedman, 2003; Kaltenbjorn \& Bjerke, 2002

${ }^{476}$ Hogg \& Vaughan, 2008

${ }^{477}$ Baron et al., 1998

${ }^{478}$ Dixon \& Durrheim, 2000

${ }^{479}$ Hogg \& Hains, 1996

${ }^{480}$ Huddy, 2001
} 
categorization expressed as a factor of place attachment provides an indicator of attitude change employed for this purpose.

Categorization refers to classifying people as either in-group or out-group members, as well as the perception an individual has as to which group they belong to. The classification of individuals into groups relies on identifying typical characteristics of the group as a whole, including attitudes, and attributing these characteristics to every member of the group. In this sense individuals are not seen as unique, but in a sort of cognitive simplification attempt to understand the multitude of people an individual encounters; individuals are reduced to a prototypical example of a group. Not only then are group norm characteristics and behaviours attributed to all group members, but also these norms are expected for group members. In a process of self-categorization, individuals transform their own self concept to reflect the group norm. This includes a shift of "one's perceptions, attitudes, feelings, and conduct to conform to the category prototype". ${ }^{481}$ In the same way that categorization of in-group and out-group members minimizes an idiosyncratic view of individuals, self-categorization depersonalises individual attitudes to conform to the group norm or group prototype the individual wishes to identify with. ${ }^{482}$ While depersonalization can result in positive outcomes, such as a greater concern for a community's goals rather than individual ends, it can also result in negative effects. This is particularly true when the group norm is to travel exclusively in private automobiles, use them as a status symbol and partake in other normative but unsustainable behaviour.

The place identity aspect of place attachment relates to self-categorization and highlights the role identifying with a larger community can play with travel behaviour. Communities are very often a localised group ${ }^{483}$ making neighbourhood group identification an important avenue for understanding travel behaviour. Viewing group identification through the lens of a commons dilemma, it is known that group identification leads to enhanced cooperation among group members. ${ }^{484}$ In order to be a contributing member of a community a person wishes to identify with, they may exhibit concern and even action toward some form of environmental preservation or resource conservation. ${ }^{485}$ This must also then be true for the exploitation of particular resources as well. Although more likely viewed as a normative behaviour to downplay the importance of preserving some resources, travel behaviour or attitudes towards travel may be negatively influenced by the larger neighbourhood one resides in. In the same vein as the negative effects a

\footnotetext{
${ }^{481}$ Hogg, 2007, p96

${ }^{482}$ Hogg, 2007

${ }^{483}$ Bonaiuto et al., 2008

${ }^{484}$ Turner, 1987

${ }^{485}$ Bonaiuto et al, 2008 
sense of community can result in, when the needs of an immediate community are actually detrimental to the larger community, the environment or to other communities, identifying with certain place specific groups may be unsustainable. ${ }^{486}$ While travel behaviour may be influenced by the constraints that residing in particular neighbourhoods presents, travel attitudes are more likely influenced by the extent to which individuals identify with their neighbourhood. The shift from a self to a collective interested behaviour has in fact been identified as a factor of the extent to which people identify with their local community. ${ }^{487}$ This must also then be true for the inverse of such a relationship, from a collective to a self interested individual behaviour, if this is the group norm. This raises the interesting question of whether or not land use patterns can influence value orientations, which hitherto have been considered an unchanging human characteristic.

\subsection{Conformity in Social Identity}

Conformity relates to self-categorization through a process of individuals internalizing "group prototypical attitudes as their own". ${ }^{488}$ The internalization of these group norms, stereotypes, attitudes and other attributes "become subjectively interchangeable with personal norms, stereotypes, and attitudes, influencing thought and guiding action". ${ }^{489}$ It is argued that this process is not superficial compliance but rather represents real attitude change. This theoretical perspective outlines a process of conformity that relates to self-categorization beyond that of the social psychologists' claim that individuals conform in order to curry favour from a group ${ }^{490}$. Instead of simply conforming to gain approval from others, as typical views of conformity posit ${ }^{491}$, the selfcategorization of individuals as members of a group suggests attitude transformation. In this sense conformity is a voluntary behaviour.

Individuals may also conform to group norms as a more reactive rather than proactive ambition. Conformity in many cases results from unwanted external pressures that force individuals to comply with the behaviour of the majority. For instance there is a tremendous pressure to accept and to conform to the inevitabilities of globalization, auto-domination, obesity, sprawling suburbia, global warming and privatization. ${ }^{492}$ Similarly, personal behaviours may be forced to "yield under

\footnotetext{
486 Van Vugt, 2001

${ }^{487}$ Bonaiuto et al, 2008, p 951

${ }^{488}$ Hogg, 2007, p97

${ }^{489}$ Hogg, 2007, p97

${ }^{490}$ Deutsch \& Gerard, 1955

491 Parks \& Sanna, 1999

492 Saul, 1999
} 
the threat of rejection or the promise of reward". ${ }^{493}$ That said, however, conformity under a selfcategorization precept relies on positive factors influencing the desire to conform. Oftentimes individuals conform to gain advantage. This may be to take advantage of others' efforts (like purchasing a similar vehicle to one's friends after they have researched the market) or likewise, because they believe others may know something they do not. ${ }^{494}$ The important factor to remember in terms of travel behaviour and neighbourhood selection is that when individuals place an attachment on their neighbourhood, and part of this attachment is in the form of place identity, selfcategorization along with depersonalization enhances conformity to group norms. ${ }^{495}$

\subsection{Persuasion and Social Identity}

Persuasion is aimed at providing an appealing message rather than a coercive tactic. It is theorized to occur via two "different processes, reflecting different amounts of cognitive effort". ${ }^{496}$ The first influences attitude change by presenting a message that is interesting, important or personally relevant and relies on the message recipient to evaluate the message without any prior knowledge or distraction, which would prevent careful consideration. The second form of persuasion is through what is termed the peripheral route. Persuasion by this route attempts to influence attitude change through eliciting positive feelings by associating the message with a desirable messenger or framing the message in a desirable context. This route to persuasion relies on a less critical analysis of the message compared to appealing to the logic of the intended message recipients. Selfcategorization relies on the latter form of persuasion.

When individuals aim to identify with a particular group they are more likely to be persuaded by group members who most typify the salient attributes of the group. In this sense prototypical group attributes are more readily subsumed as personal attributes through a process of identification, persuasion and then actual attitude change. Identifiers discredit out-group and accept in-group arguments not because of logical evaluations but rather because it is easier to simply agree with sources that individuals already identify with. ${ }^{497}$

\footnotetext{
${ }^{493}$ Goldstone et al., 2006, p612

${ }^{494}$ Goldstone et al., 2006

${ }^{495}$ Postmes et al., 2001; Spears et al., 1990

${ }^{496}$ Baron et al., 1998

${ }^{497}$ Fleming \& Petty, 2000
} 


\subsection{Place Attachment and Social Identity Associations}

While many authors theorize how place attachment develops, by places serving basic human needs for safety, security, a sense of belonging and to meet basic physiological needs, ${ }^{498}$ or through places supporting the attainment of one's goals, ${ }^{499}$ there are a number of associations that have been empirically linked to the concept. Place attachment and its other components of place identity and place dependence are known to be associated with life-stage, length of residence, form of tenure, religiosity ${ }^{500}$, gender, homogeneity, appeal and safety. ${ }^{501}$ An initial gender association demonstrates that both females and older people tend to exhibit a greater attachment to place. ${ }^{502}$ Similarly, both females and older people tend to drive less, or are less mobile, than their median aged male counterparts. ${ }^{503}$ In one of the few studies examining the effects of place attachment on travel behaviour, greater mobility or car use in general, is associated with diminished place attachment. $^{504}$

Studies that investigate the relationship between the built form and place attachment show mixed results. Some researchers' findings suggest that there is not a correlation between place attachment and the built form at all, ${ }^{505}$ while others have found numerous links, either direct or indirect through symbolic meanings. ${ }^{506}$ Of the studies that demonstrate links, some argue that individuals do not actually become directly attached to the physical features of a place, but rather, to the meaning that those features represent. ${ }^{507}$ This is referred to as the mediated model of place attachment and empirical evidence shows how a developed area may symbolize community, or an underdeveloped area may symbolize wilderness. ${ }^{508}$ The physical aspects constrain the possible meanings a place may adopt, and therefore, physically based place attachment rests in these symbolic meanings.

Individuals tend to become attached to places that are desirable to identify with. This includes places of high environmental quality ${ }^{509}$ and also high quality built form. ${ }^{510}$ Access to natural

\footnotetext{
${ }^{498}$ Chavis \& Pretty, 1999; Turnbull, 1987

${ }^{499}$ Kyle, Mowan, et al., 2004; Moore \& Graefe, 1994

${ }^{500}$ Casakin \& Billig, 2009

${ }^{501}$ Shumaker \& Taylor, 1983; Giuliani \& Feldman, 1993

502 Brown, 1987; Varady, 1986; Brown \& Perkins, 1996

503 Giuliano and Dargay, 2006; Hunecke et al., 2007; Mokhtarian \& Salomon, 2001; Steg et al., 2001

${ }^{504}$ Hagihara \& Fujii, 2005

505 Aguiliar, 2002

506 Stedman, 2003

507 Stedman, 2003

508 Stedman, 2003

${ }^{509}$ Uzzell et al., 2002

${ }^{510}$ Gary et al., 2002
} 
areas $^{511}$, residing in cul-de-sacs ${ }^{512}$ and village type residential settings ${ }^{513}$ all demonstrate empirical associations between these built form factors and place attachment. Similarly, place attachment has been shown to be greater in New Urbanist communities or neighbourhoods where traditional landuse patterns have been created, compared to conventional neighbourhoods. ${ }^{514}$ Changes to existing neighbourhood physical features have also been associated with place attachment through invoking NIMBYism (not in my backyard) responses. ${ }^{515}$ Here, the desire to protect one's neighbourhood from threat is the result of place attachment attitudes. Negative associations between place attachment and the physical environment include attachments to places that actually pose risks to individuals' health. Place attachment surprisingly even exists for these places where negative environmental qualities dissuade new residents while existing residents downplay such factors, even to the extent that their own health is at risk. ${ }^{516}$ However, place attachment has also been shown to exist for places even after the entire physical structure has been obliterated to make way for urban renewal or new infrastructure. ${ }^{517}$ Some authors contend that counter to the physical environment influencing attachment, it is the experiences in a place that forms attachment bonds and in turn, creates meaning. ${ }^{518}$

Important to the aim of this dissertation, place attachment is associated with length of residency. ${ }^{519}$ The longer individuals reside in a particular place the more likely it is that they "have developed significant relationships with other residents as well as with physical attributes of the place". ${ }^{520} \mathrm{~A}$ familiarity with and an organizing knowledge of the physical elements of a place is viewed as the cognitive component of place attachment, and these factors can only develop over time through an intimate cohabitation with a place. ${ }^{521}$ Likewise, as individuals personalise their places, an attachment to place develops. ${ }^{522}$ However, while there is evidence that supports the view that place attachment is related to length of residence, there is also evidence that shows no association. ${ }^{523}$ Instead, form of tenure, rented or owned, is posited as more influential. Property ownership encourages place attachment because of a hypothesized return on time and monetary investments. ${ }^{524}$ Home ownership correspondingly shows an association with greater place

\footnotetext{
${ }^{511}$ Catrill, 1998

512 Brown \& Werner, 1985

${ }^{513}$ Kim \& Kaplan, 2004

${ }^{514}$ Kim \& Kaplan, 2004

${ }^{515}$ Wall et al., 2008

${ }^{516}$ Hunter, 1998

${ }^{517}$ Bonaiuto et al., 1999

518 Manzo, 2005

519 Tuan, 1977; Relph, 1976

${ }^{520}$ Hernández et al., 2007

521 Fullilove, 1996

522 Williams et al., 1992

523 Stedman, 2002

524 Motloch, 2000
} 
attachment and also acts as a buffer toward perceived as well as actual neighbourhood incivilities. ${ }^{525}$ However, regardless of whether or not place attachment develops over time or is more a factor of ownership, the critical concept is that place attachment is a post decision factor. In this sense, place attachment is more contingent on the choices individuals have made rather than pre-existing or innate preferences. Although criticized, place attachment has almost wholly been researched as a factor of residential settings and living arrangements. ${ }^{526}$ Rather than viewing place attachment as an emotion motivating individuals to select places that confer with their preferences, this focus on residential settings implies that place attachment develops as a response to an existing association with a place not likely to form prior to moving to a particular neighbourhood. In terms of residential location choices, an individual would not likely be attached to a place until they live there. If this is the case, then should attitudes, specifically travel attitudes, be associated with place attachment, the idea that travel attitudes influence where individuals decide to reside, as in selfselection studies, is questionable. A recent study supports this view and found that regardless of predispositions, place attachment can influence behaviour both in-line with and counter to existing preferences. ${ }^{527}$ Here, an individual's sense of themselves as a group member may shape their attitudes and, more specifically, their attitudes toward their travel behaviour. ${ }^{528}$

The unique contribution of place attachment to the study of travel behaviour employs the concept as an indictor of attitude change. Rather than using a longitudinal study to measure before and after travel attitudes during residential relocations, an association between place attachment and travel attitudes indicates that travel attitudes are contingent on previous decisions instead of antecedents to them. The evidentiary background of the place attachment concept adds weight to the theoretical proposition that an individual's attitude cannot be viewed separate to the previous decisions they have made.

\footnotetext{
${ }^{525}$ Barbara et al.,2004

${ }^{526}$ Manzo, 2003

${ }^{527}$ Bonaiuto et al, 2008

${ }^{528}$ Hogg \& Smith, 2007, p91
} 


\section{Case Studies}

This chapter introduces the four case study neighbourhoods of this research and discuses the criteria for their selection. Figures and maps are presented for each neighbourhood to give an indication of the relative layouts, built form and housing types. The methodology used for each case study's physical assessment is described in detail along with the pilot study methodology employed to survey residents' opinions about the liveability in their neighbourhoods.

Each neighbourhood reflects typical characteristics of either traditional or conventional neighbourhoods and was selected on this basis. These neighbourhoods can be seen in the context of their relevant cities in Figures 4 and 5 and are set to a one kilometre grid.
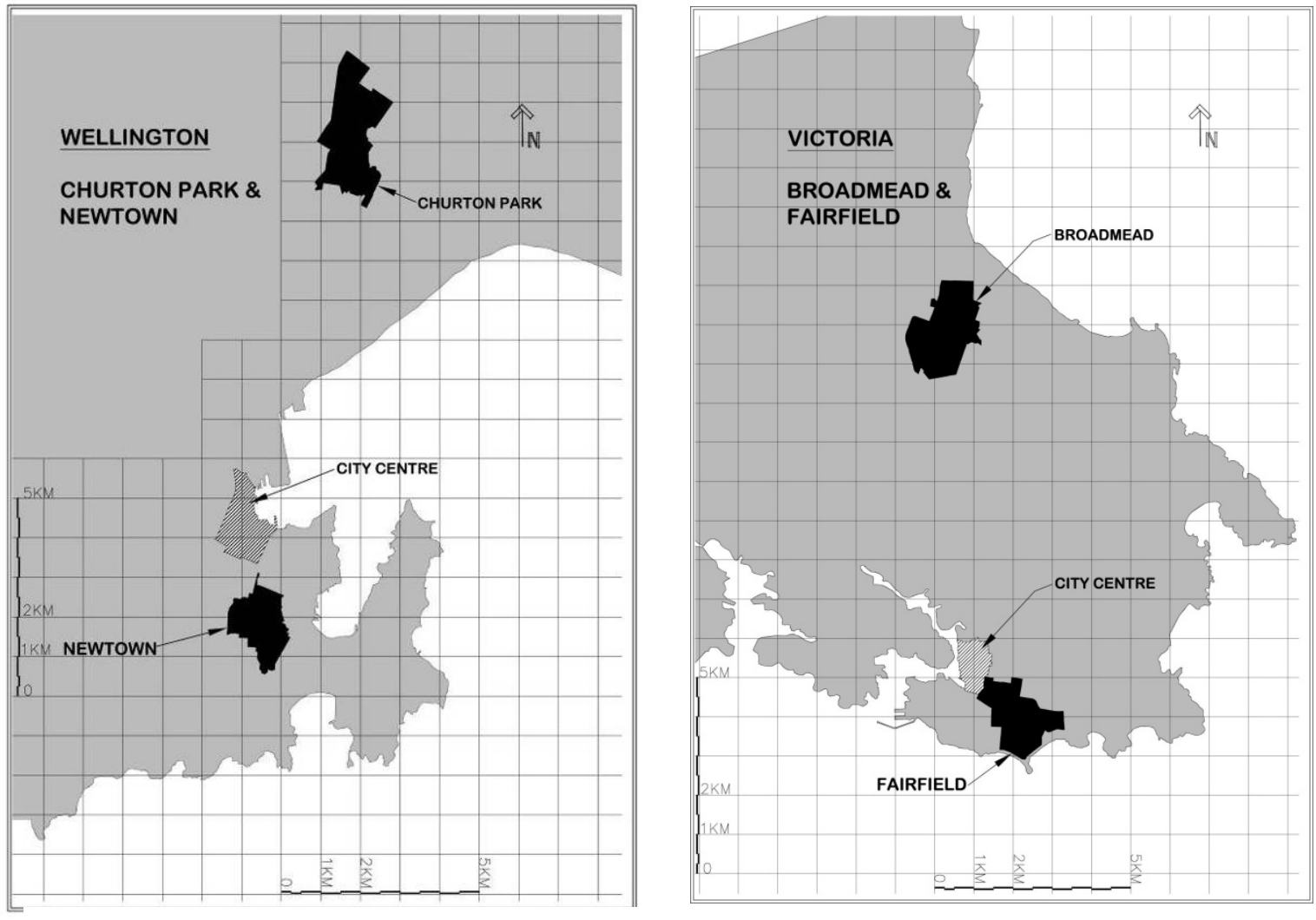

Both Victoria and Wellington are coastal cities with relatively equal populations. ${ }^{529}$ Both cities are also capital cities, Wellington, a national capital and Victoria, a provincial capital. Where Newtown and Fairfield are both relatively the same age and are both traditional neighbourhoods, Churton Park and Broadmead are both much younger and also considered to be conventional neighbourhoods. Similar to conventional neighbourhood land-use patterns in the literature, Churton

\footnotetext{
${ }^{529}$ Statistics NZ, 2001; City of Victoria, 2001 
Park and Broadmead typify conventionality with their relatively low density, single use zoning, curvilinear streets, long winding cul-de-sacs and limited connections to adjoining areas. ${ }^{530}$

Newtown and Fairfield both exhibit traditional neighbourhood characteristics with their pre-WWII age, heritage buildings and dwellings, grid street layout and central locations relative to the city centres of each neighbourhood respectively. Other characteristics that are common in traditional neighbourhoods include higher than average densities, a high proportion of mixed land uses and a large degree of connectivity with adjoining areas. ${ }^{531}$

\subsection{Churton Park}

Churton Park is a relatively new subdivision located $1.5 \mathrm{~km}$ out of Johnsonville in Wellington, New Zealand. Development started in the 1960's and continues today, expanding toward the northern valleys. The majority of residents own their homes, are of European descent (78\%) and have a higher than average household income compared to the New Zealand average. ${ }^{532}$ Asians represent $21 \%$ of the population as the only other Non-European ethnicity over ten percent. ${ }^{53}$ Churton Park's urban pattern is typical of both its city fringe location and era of development. This pattern is characterised by curvilinear streets, long winding cul-de-sacs and limited connections to adjoining areas. Churton Park is largely a dormitory suburb of Wellington City, mainly orientated toward families and retirees, and is generally a quiet peaceful neighbourhood that offers the benefits of newer homes and large lots.

Single family dwellings are the dominant building type in Churton Park. Generally, the majority of houses are two storeys high and have garages. Figures 7 to 9 demonstrate typical dwelling types of varying ages.

\footnotetext{
${ }^{530}$ Schwanen \& Mokhtarian, 2005; Levine \& Frank, 2007

${ }^{531}$ Song \& Knapp, 2004

${ }^{532}$ Statistics NZ, 2001

${ }^{533}$ Statistics NZ, 2001
} 

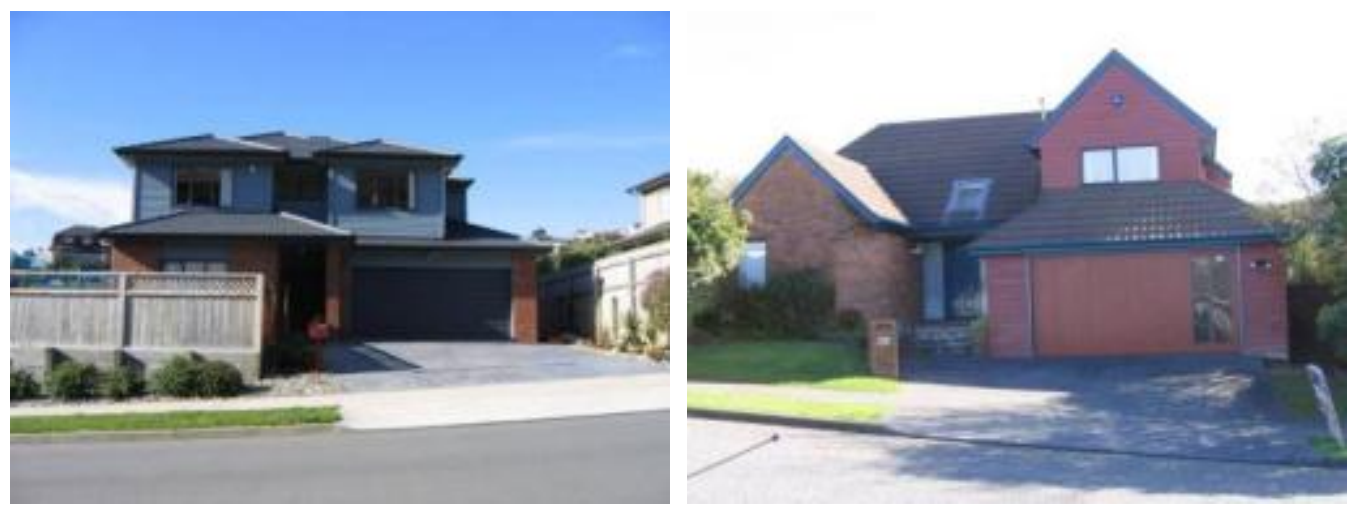

Figure 6, 7: Churton Park Housing Types
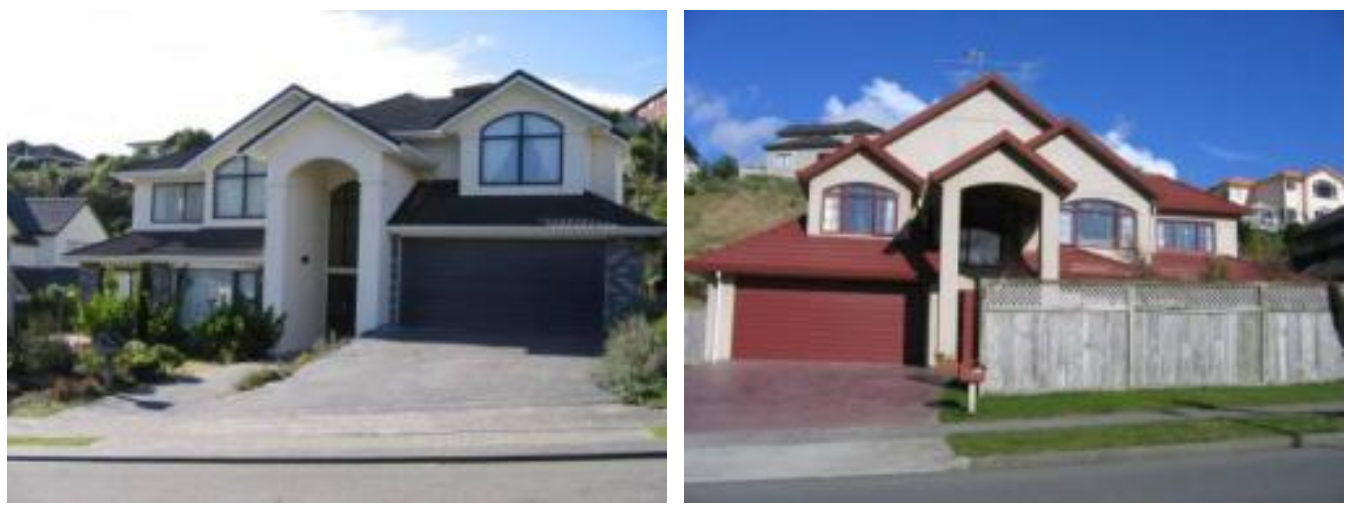

Figure 8, 9: Churton Park Housing Types

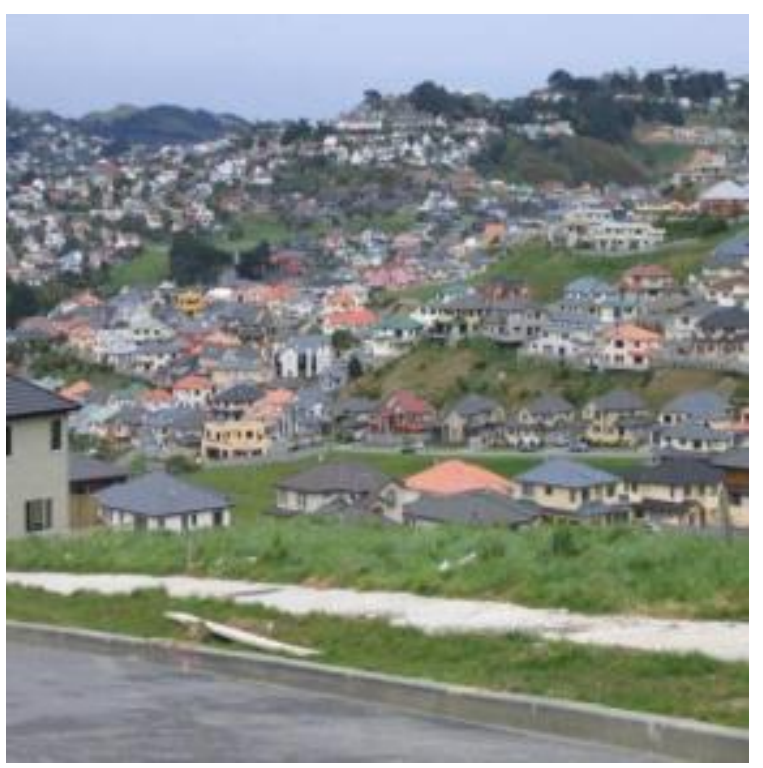

Figure 10: Churton Park Overall

The large proportion of residential land use and residential zoning is apparent in Figure 10, with the only other significant land use being either parks or open space.

The city fringe location of Churton Park ensures views of open spaces toward the pastoral hills at the undeveloped boundaries of the neighbourhood. However, as development expands these views are diminished. Parks, reserves and green spaces are dotted throughout the neighbourhood and in some cases are linked as a connected walkway. 
As is typical with developments of this age, most power and telephone cabling is underground.

Generally the topography of the area can be described as a large open bowl of rolling hills within a valley surrounded by undulating rural lands. Figure 11 shows the main Park in Churton Park which is located centrally in the neighbourhood and has amenities mainly geared toward children.

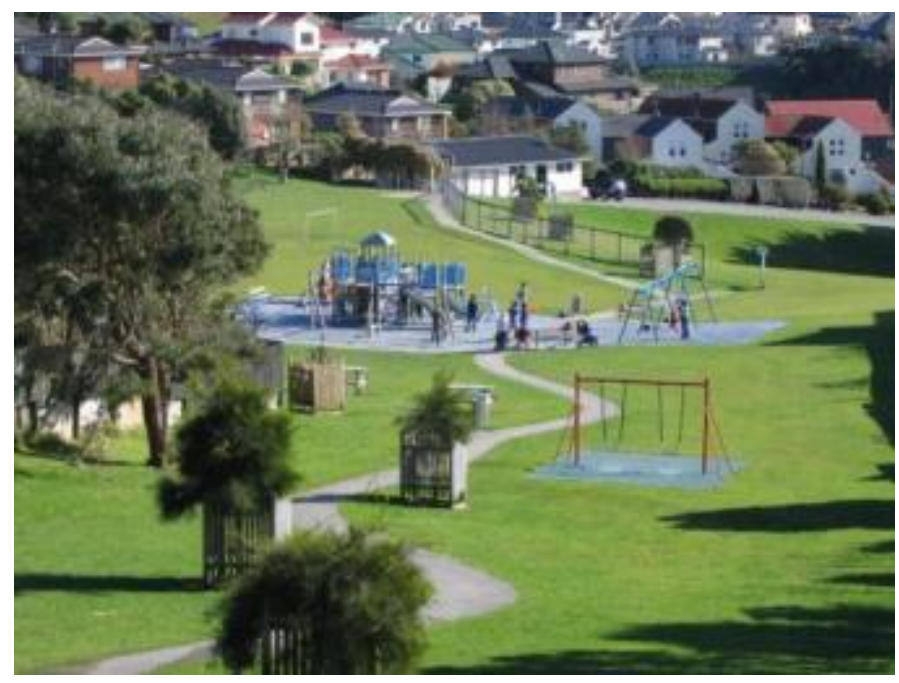

Figure 11: Churton Park Central Park

Figures 12 to 14 give an indication of the street-scape and the overall look of Churton Park. A distinctive characteristic of the neighbourhood is the lack of trees. The streets in Churton Park are generally wide with few cars parked along them during the day, are in a tree-like pattern with many cul-de-sacs and there are few intersections interrupting the flow of traffic. Foot paths are common and in many cases are on both sides of the road and include a small grass verge.
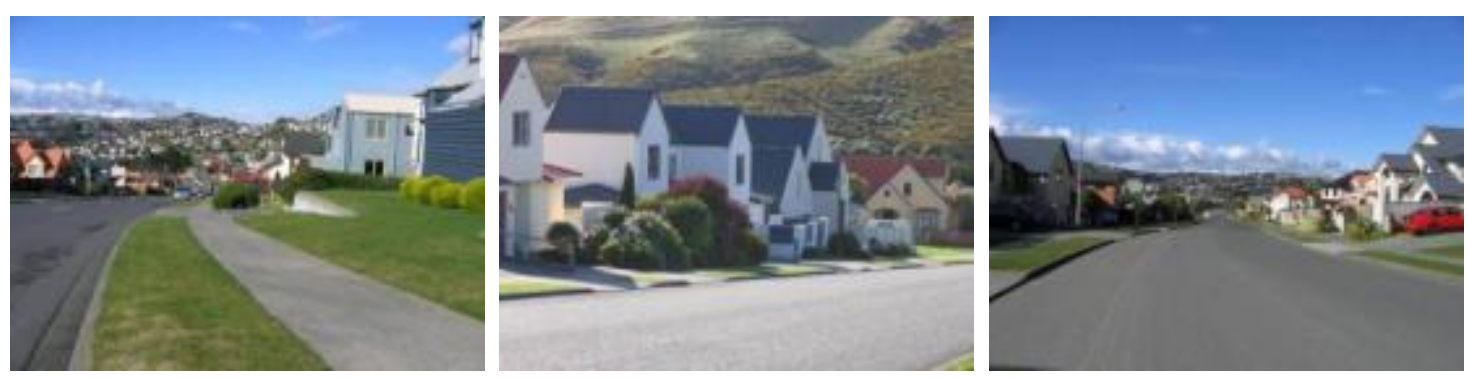

Figure 12,13,14: Churton Park Street Scape

Most dwellings in Churton Park have generous yards and reserves and open spaces are plentiful and intertwined between pods of single family dwellings. The area is zoned predominantly outer residential with most existing lots ranging in size from $500 \mathrm{~m}^{2}$ to $700 \mathrm{~m}^{2}$ and some as large as a quarter acre. The site coverage in the area is regulated to thirty five percent, which ensures the continued predominance of open space. The other zoned land uses in Churton Park include open 
spaces ' $A$ ' and 'B', which differ in their provision of man-made recreational facilities; open space 'A' having man made facilities and open space 'B' left largely in a natural state. Lastly, the school in Churton Park is in an educational zone.

\subsection{Newtown}

Newtown is one of Wellington, New Zealand's earliest neighbourhoods located not far from the city centre and the first to be lit by electricity. ${ }^{534}$ The majority of development in this area took place in the early 1900's. ${ }^{535}$ Initially developed by Walter Turnbull in the late 1880 's, the transformation of the area can be seen in Figures 15 and 16.
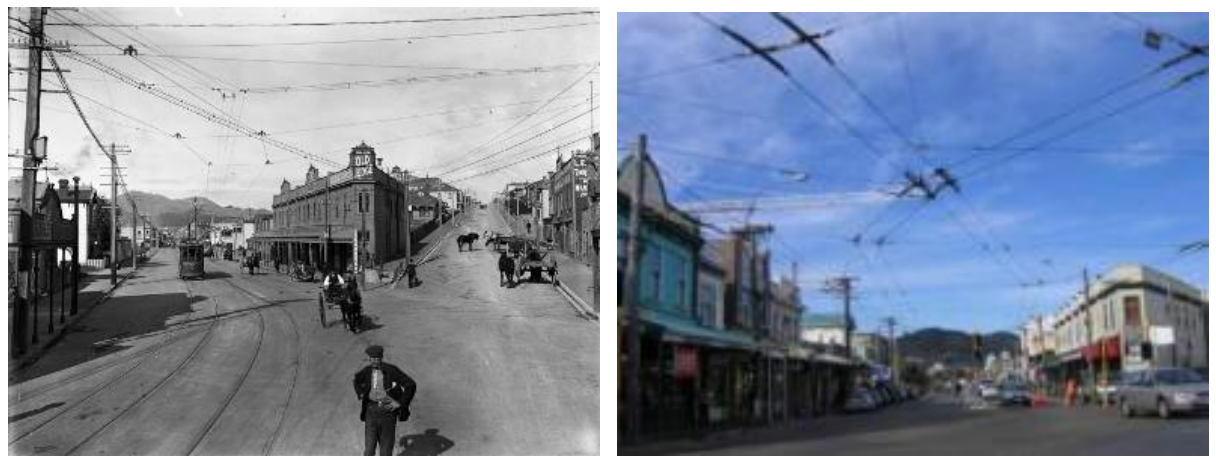

Figure 15, 16: Newtown Transformation

Unlike some of Wellington's other early neighbourhoods, single storey cottages and villas are the predominant building form, rather than the more substantial residences and two storey buildings of Thorndon and Mt. Victoria. ${ }^{536}$ Two storey buildings represent a third of all buildings in Newtown, and only a few buildings in the area are taller. ${ }^{537}$ The sections or lots in Newtown are on average relatively small, between $200 \mathrm{~m}^{2}$ and $400 \mathrm{~m}^{2}$, however there is the odd section over $1000 \mathrm{~m}^{2}$ and below $200 \mathrm{~m}^{2} \cdot{ }^{538}$ Newtown is predominantly zoned inner residential, and the site coverage for this zone is fifty percent. Figures 17 to 19 give an indication of the typical dwellings within the neighbourhood. As can be seen in this figure, the single family detached dwellings in Newtown are predominantly quite old. However, Figures 20 to 22 show some of the more recent developments in Newtown, which are generally multi-family and considered medium density.

\footnotetext{
${ }^{534}$ Hudson, 2005

${ }^{535}$ McIndoe \& Popova, 1999

${ }^{536}$ McIndoe \& Popova, 1999

${ }^{537}$ McIndoe \& Popova, 1999

${ }^{538}$ McIndoe \& Popova, 1999 

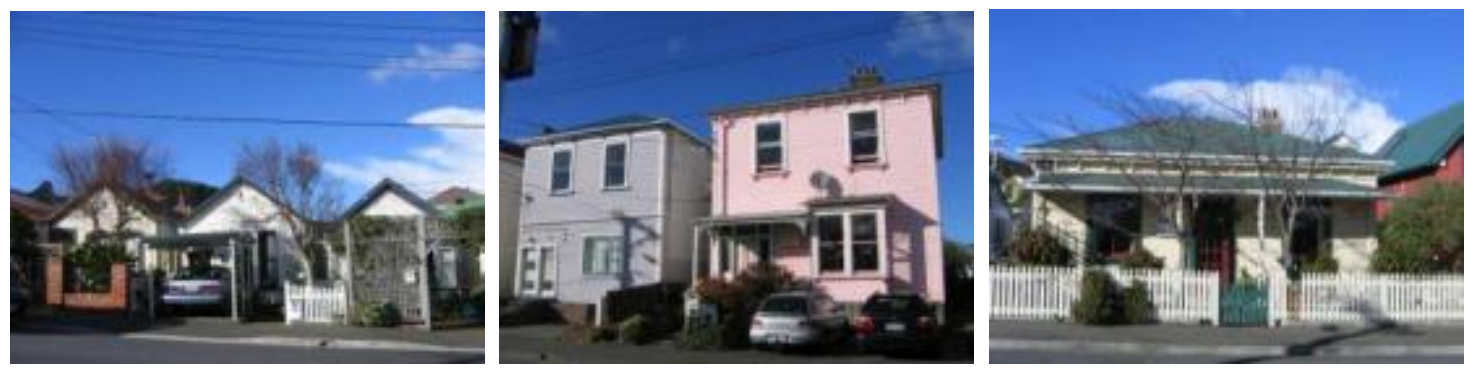

Figure 17, 18, 19: Newtown Housing Types
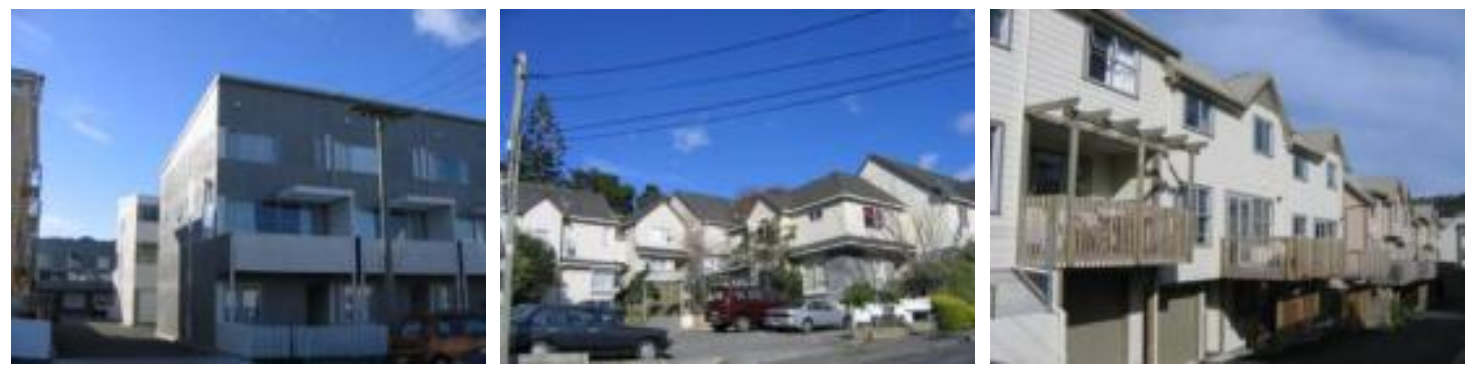

Figure 20, 21, 22: Newtown Medium Density Housing

With Newtown's rich history, the neighbourhood is also home to a few distinctive developments that have influenced its evolution. These include the hospital, the zoo and the town green belt.

Newtown is characterised by a commercial strip that cuts through the middle of the neighbourhood, running north to south. Grocery stores, florists, bakers, butchers, antique dealers, clothing stores, cafes and pubs line this strip, and the commercial area acts as both a commercial hub outside the city centre and as a neighbourhood amenity. The mix of land uses in the area is both horizontal, changing from site to site, and vertical, with dwellings above shops. Figures 23 to 25 show typical mix of land uses in Newtown, which in some areas of the neighbourhood range from commercial and institutional to industrial.
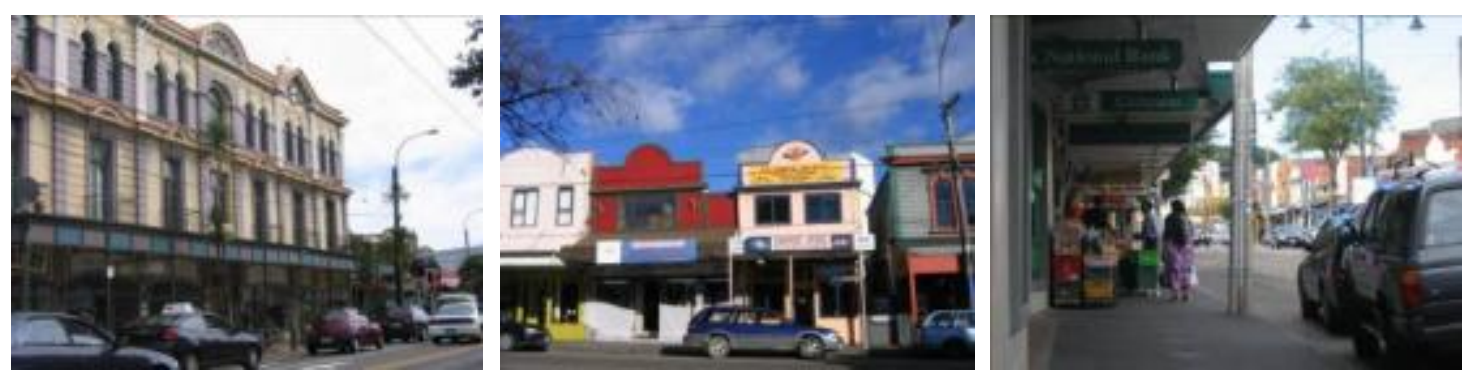

Figure 23, 24, 25: Newtown Mixed Use

Newtown is relatively flat and forms a valley between Mt. Victoria to its east, Mount Cook to the west and the town greenbelt hills to both its west and south. An early painting of Newtown (Figure 26) gives an indication of the topography in the area. 


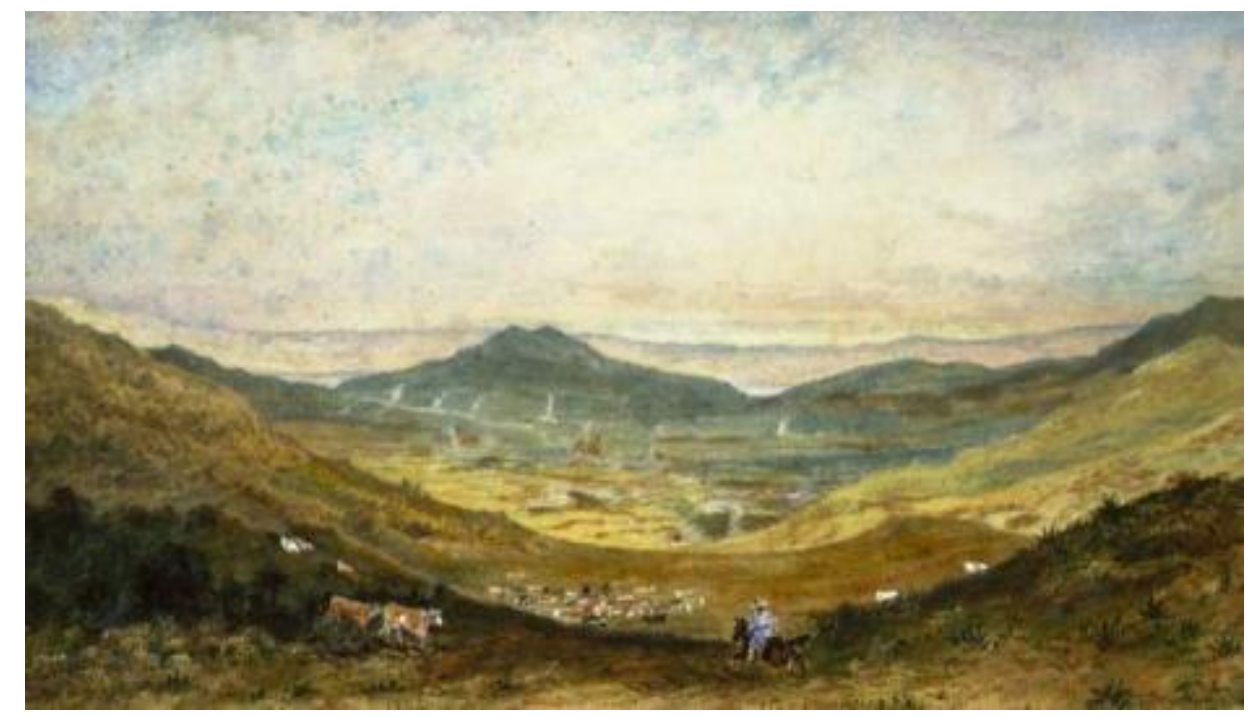

Figure 26: Newtown Samuel Charles Brees Painting

Turnbull [Brees, Samuel Charles] 1810-1865:[Looking towards Mt Victoria across the present site of Newtown from below Kingston. ca 1843]

The majority of residents are of European descent (71\%) with Maori (12.5\%), Pacific Peoples (10.9\%), and Asians (10.2\%) making up the rest of the population. ${ }^{539}$ The median 2001 income in Newtown was below the national average, and correspondingly just over a third of dwellings in Newtown were owned with or without a mortgage. ${ }^{540}$ Newtown also has a large proportion of council housing which takes a variety of forms, from large apartment blocks and condominiums to attached and single family dwellings. Figures 27 to 29 show some typical council housing types.
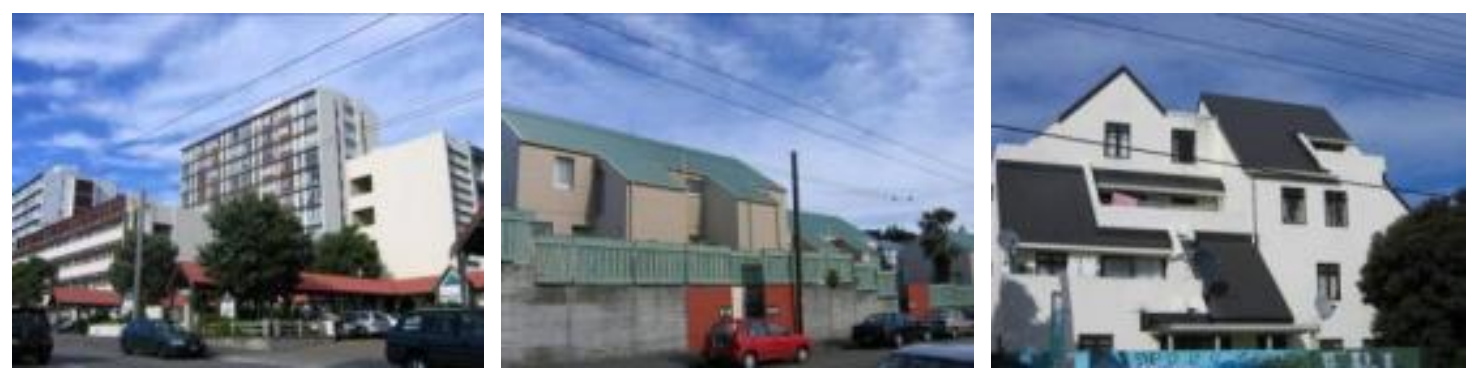

Figure 27, 28, 29. Newtown Council Housing

\footnotetext{
${ }^{539}$ Statistics NZ, 2001

${ }^{540}$ Statistics NZ, 2001

82
} 


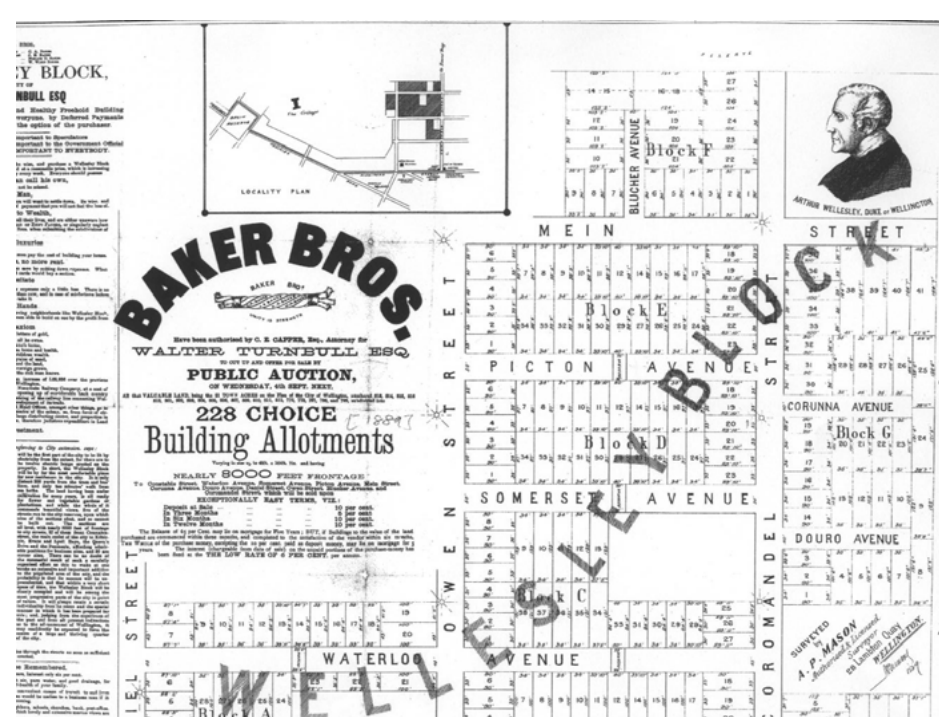

Figure 30: Newtown Early Auction Map ${ }^{541}$
A grid-like street pattern typifies the neighbourhood, which is a characteristic of its age. The blocks in Newtown vary in width and depth with some being over $150 \mathrm{~m}$ in both directions. An early plan in Figure 30 shows the grid layout and section sizes around Owen Street in one of the earliest auctions for sections in the neighbourhood.

The street-scape in Newtown is defined by the older commercial buildings of the neighbourhood. The height of buildings frame the street and give the area a distinctive character that is of heritage value in New Zealand. In the residential areas, the streets appear to be dominated by parked vehicles. The prevalent lack of garages with historic houses seems to be the main contributing factor to the predominance of parked vehicles. Figures 31 to 33 give an indication of the streetscape.
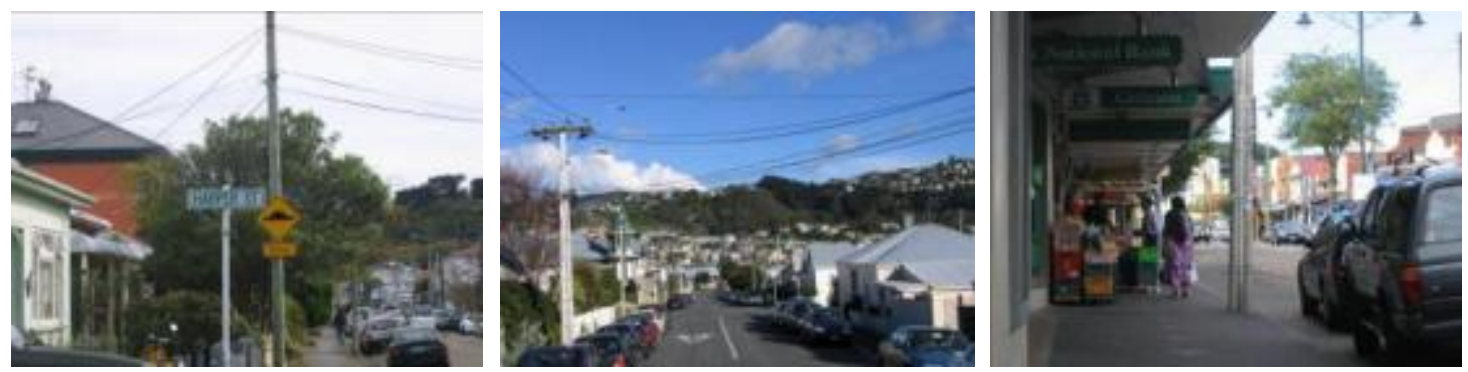

Figure 31, 32, 33: Newtown Street Scape

The main open spaces in Newtown are located around the boundaries in the town green belt, with a few smaller parks located centrally. Figures 34 to 36 show typical parks and open spaces.

${ }^{541}$ Hudson, 2002 

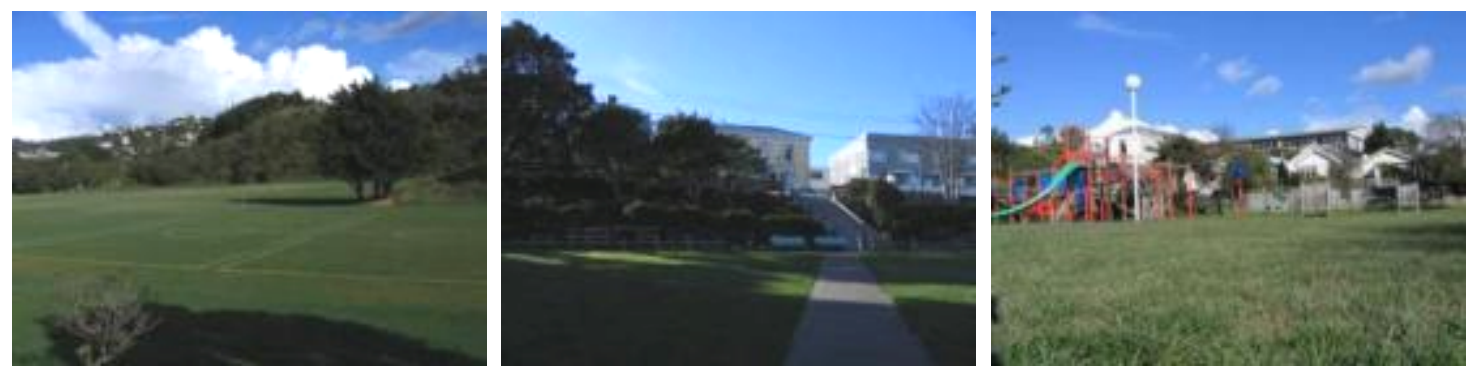

Figure 34, 35, 36: Newtown Parks and Open Space

\subsection{Broadmead}

Broadmead occupies over three hundred hectares in the municipality of Saanich in the Greater Victoria area of British Columbia, Canada. Broadmead Farms Limited commenced this development starting in 1965 and contrary to what the developer's name suggests, this area was largely treed, and was not productive farmland at the time of development. Prior to that, the area had been cleared to grow grain and raise chickens and also, interestingly, to breed prize horses. Most of the trees seen today are second growth Douglas fir and oak and remnants of any farming history are near invisible.

Broadmead census data divides the population into "mother tongue" groups rather than ethnic entities, and $83 \%$ of the population identifies as English, with the only other significant populations being Chinese and Punjabi at 2.6\% and 2.1\% respectively. The average household income is above that for the Greater Victoria region, and the majority of the population is aged between twenty five and forty four years, $26.5 \%$. The next significant age bracket is for those aged between forty five and fifty four, $16 \%$.

Broadmead's built form is characterised by large homes and yards, long winding streets and a number of private multi-family units gated off from the rest of the neighbourhood. Typical housing types can be seen in Figures 37 to 39.
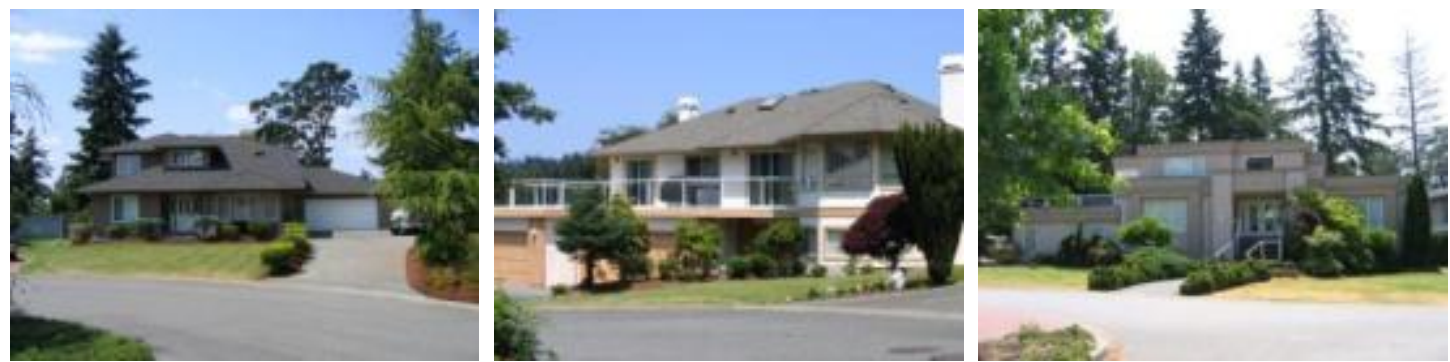

Figure 37, 38, 39: Broadmead Housing Types 
Broadmead is also defined by a large commercial "plaza" area at the western boundary of the neighbourhood. This plaza is anchored by a large grocery store but also offers many other amenities such as restaurants, clothing stores, a bakery, a café, and an auto-repair/ home hardware store. Figures 40 and 41 show this commercial area.
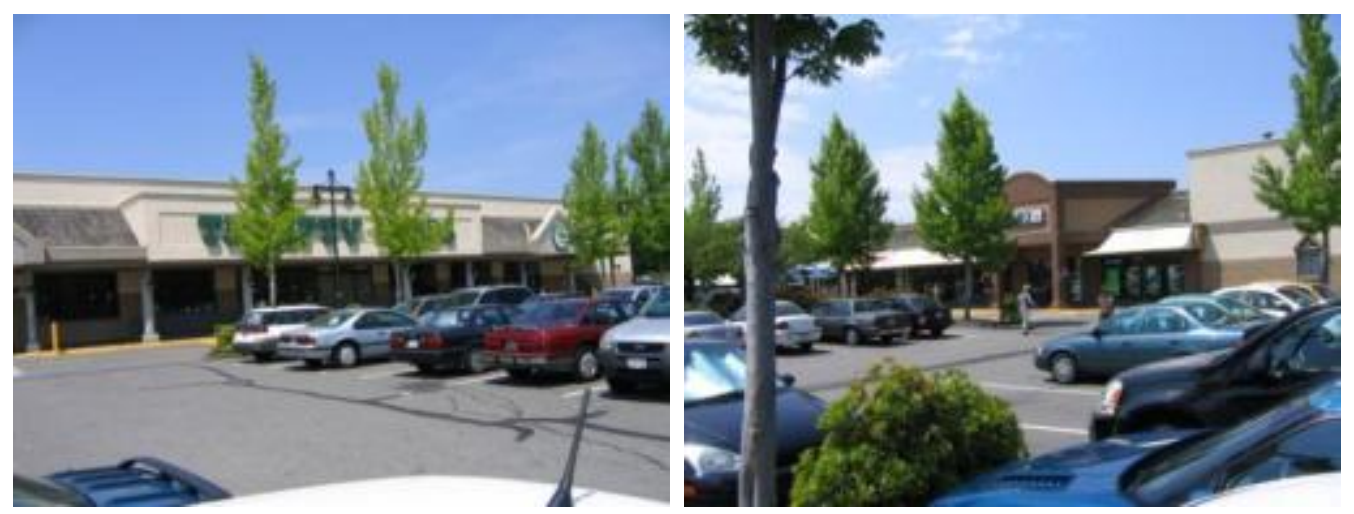

Figure 40, 41 Broadmead Commercial Area

Another commercial area exists along the southern entry way to the neighbourhood which houses professional office park services such as a chiropractic office, an engineering firm, law offices and a real estate agency. There is also a large 225 -bed multilevel care facility for veterans and seniors.

The natural features of Broadmead that distinguish the neighbourhood are the large coniferous trees throughout. It's more recent age reflects the change in attitudes to retain the natural tree cover rather than to clear and replace it with European trees. As per the local topography, the neighbourhood also features a number of rocky outcroppings which have been well preserved, giving the area a distinctive feel. More than twenty percent of the area remains as green space open to the public and much of this is connected via winding walking paths. Another unique natural aspect of this neighbourhood is the large bog at the centre of it. Rithet's Bog (Figure 42) is a natural wetland area that hosts many unique wetland plant species and is over forty two hectares in size. 


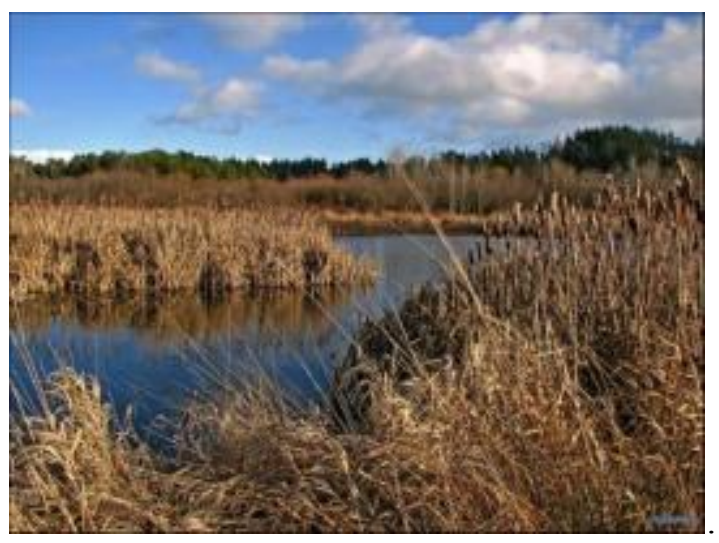

Figure 42: Broadmead Rithet's Bog

The gated multi-family units are unique to Broadmead and not encountered in any of the other case studies. In these areas, dwellings tend to be smaller and closer together, and many cater only to retirees.

There are six zones in Broadmead which include two dwelling and multi-family areas, parks, commercial and institutional areas, and single family dwelling areas. Despite these six zones, the neighbourhood is clearly dominated by single family dwellings. Site coverage ranges from 30 to $40 \%$ and the majority of dwelling are on lots greater than $750 \mathrm{~m}^{2}$. The street-scape in Broadmead is generally defined by wide roads with few cars on them plus a boulevard through the middle of the neighbourhood lined with trees, and winding roads throughout the neighbourhood also lined with trees ( Figures 43 to 45 ).
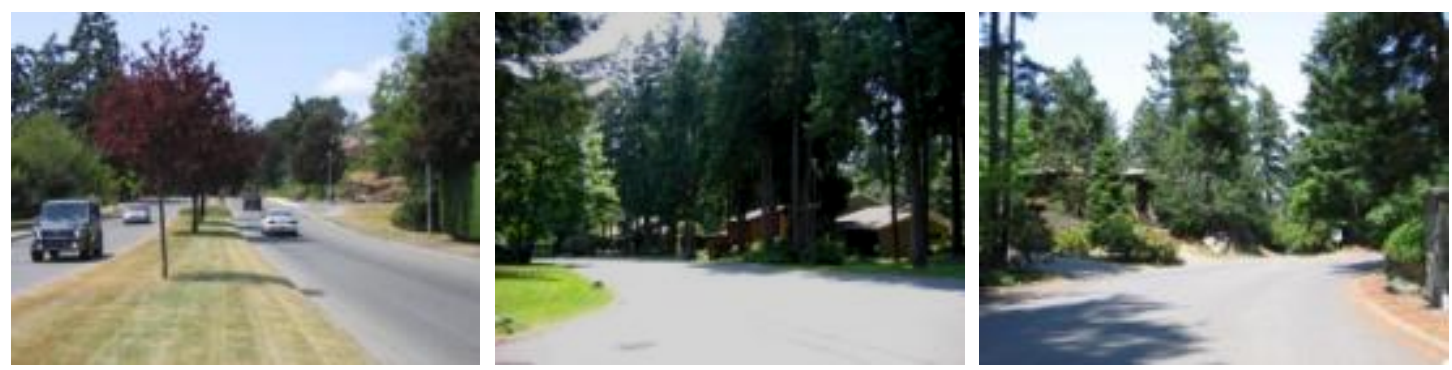

Figure 43, 44, 45: Broadmead Street Scape 


\subsection{Fairfield}

Fairfield is an historic inner city neighbourhood located in Victoria, British Columbia Canada. Its development occurred around the same time as Newtown but rather than being a large new development of relatively small lots, it started out as large private holdings that were later divided into smaller sections. ${ }^{542}$

The majority of the residents in Fairfield are of European descent (95\%) with a distinctive demographic of older couples with no children at home $(60 \%) .{ }^{543}$ The average income is slightly above the city average and has been steadily climbing since the early 1990's. Fairfield's built form is typified by heritage homes, few dwellings constructed after 1950, and both late and early apartment developments. The prevalent grid street network is typical for the age of this development, and again provides a traditional urban form that higher density proponents support.

The distinctive features of Fairfield that define its edges and make up the main open spaces in the neighbourhood are the waterfront to the south, Beacon Hill, the main city park to the west and Ross Bay Cemetery to its east. These open spaces can be seen in Figures 46 to 48 below.
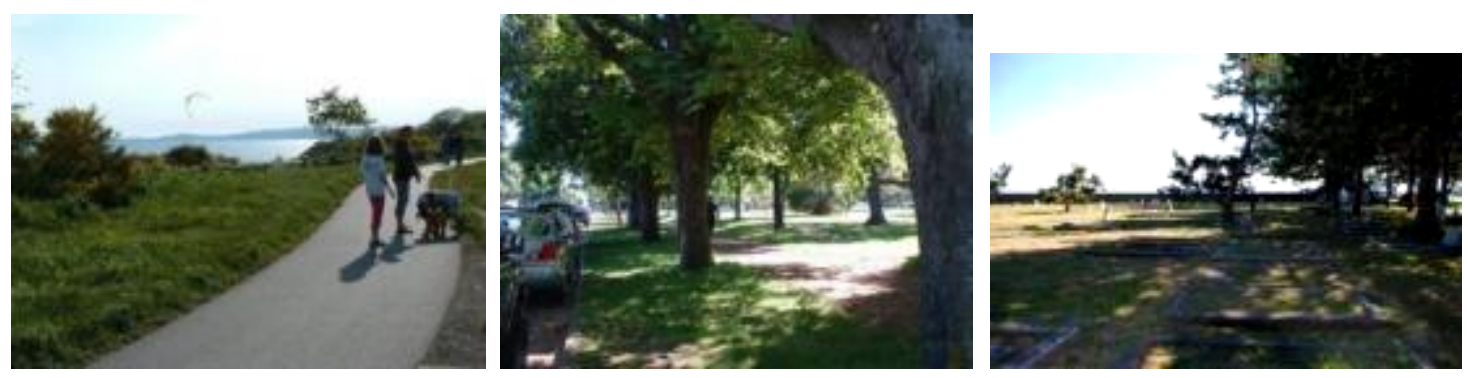

Figure 46, 47, 48: Fairfield Open Space and Parks

The neighbourhood borders downtown Victoria to its Northwest where its' building form transitions to compact apartments. Small shopping facilities within walking distance, and low rise, low maintenance apartments typify the neighbourhood. This came about from the popularity of Fairfield amongst the retirement community. Victoria boasts the best weather in Canada, rarely receiving snow, unlike the rest of the country. The favourable weather in Victoria has led to its nickname, 'the place for the 'nearly dead and newly wed'. A distinguishing feature of the neighbourhood is its large retention of heritage homes (pre WWII) that have been maintained as

\footnotetext{
${ }^{542}$ Roueche, 2005

${ }^{543}$ City of Victoria 2001
} 
both single family dwellings and also divided into multi family dwellings. Examples of these can be seen in Figures 49 to 51.
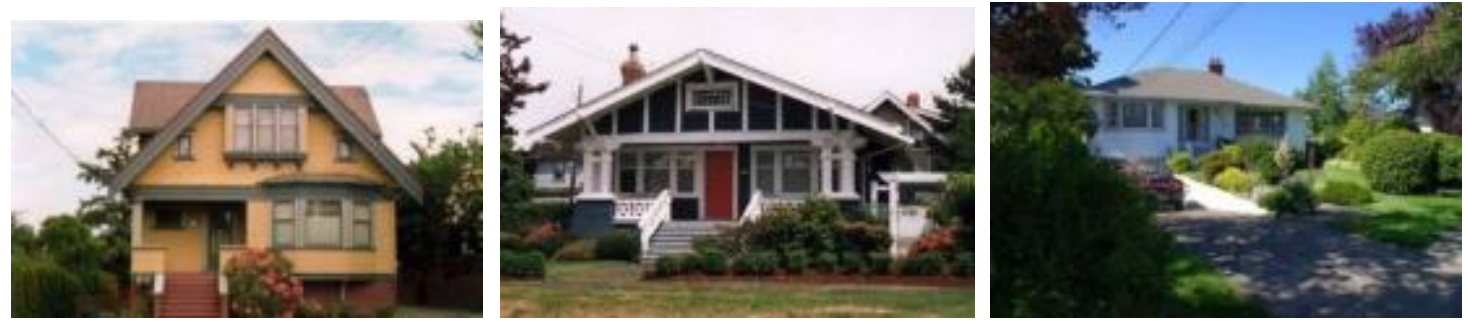

Figure 49, 50, 51: Typical Housing Types in Fairfield

Apartment development in Fairfield took off in the late 1960's. The relatively high density of the neighbourhood is largely accommodated in these apartments. For a breakdown of dwelling types in Fairfield, see Figure 61 (page 90). Typical apartment types can be seen in Figures 52 to 54 below.
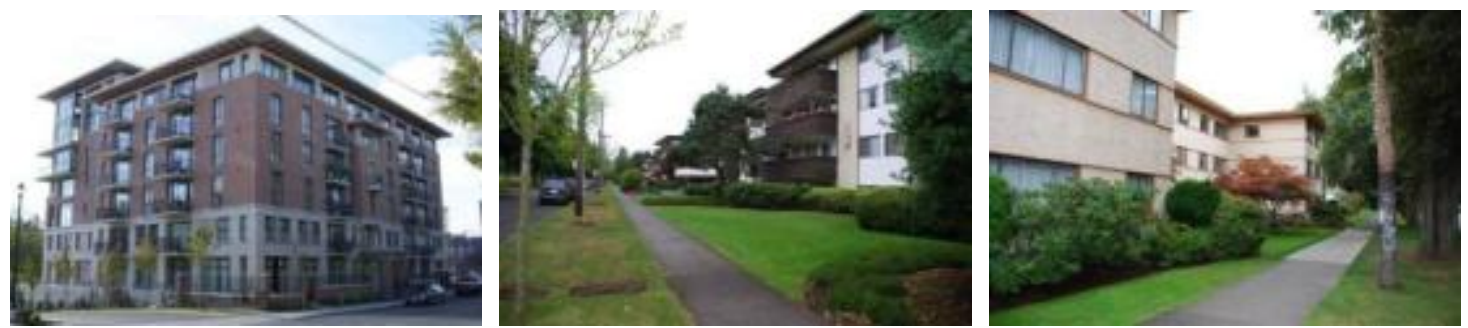

Figure 52, 53, 54: Typical Apartment Types in Fairfield

The topography is defined by the waterfront cliff at the southern limit of the neighbourhood and the successive table top plateaus that climb north in large flat areas, interrupted by gentle hills gaining elevation away from the water. Fairfield enjoys a southerly aspect facing the Juan De Fuca Strait which divides Vancouver Island from The United States of America.

One of the most distinctive features in Fairfield is the amount of large trees lining the streets. These trees characterise the street-scape in the area and can be seen in Figures 55 to 57.
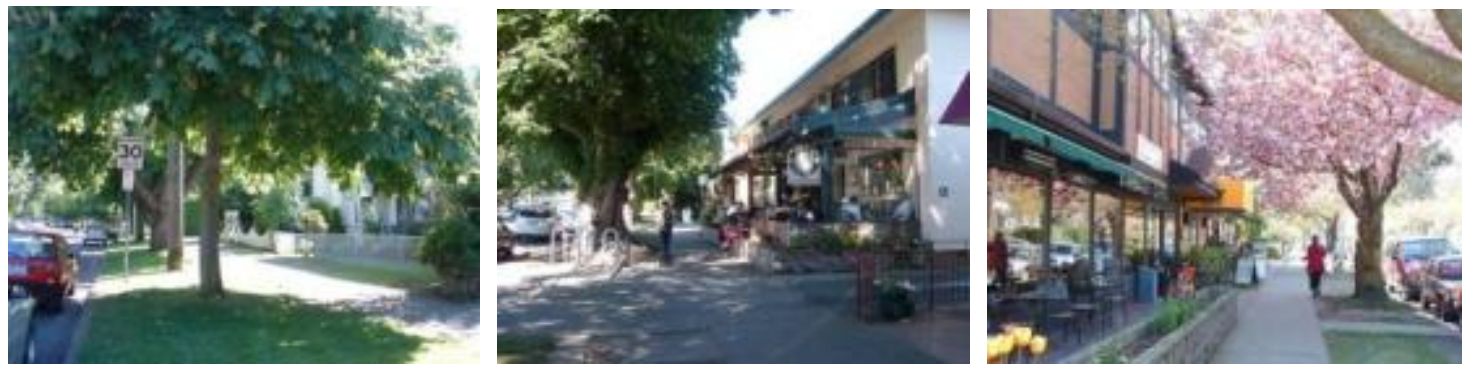

Figure 55, 56, 57: Fairfield Street Scape 
Along with a mix of single family dwellings, multi family dwellings and apartments, there is also a mix of commercial amenities in Fairfield. Two distinct areas contain the majority of these commercial areas; Cook Street Village and the Thrifty Foods shopping complex at both the western and eastern edges of the neighbourhood. However, dairies, or corner stores as they're known in Canada, are frequent throughout the neighbourhood and located at main intersections. Figures 58 to 60 give and indication of a typical mix of uses in Fairfield.
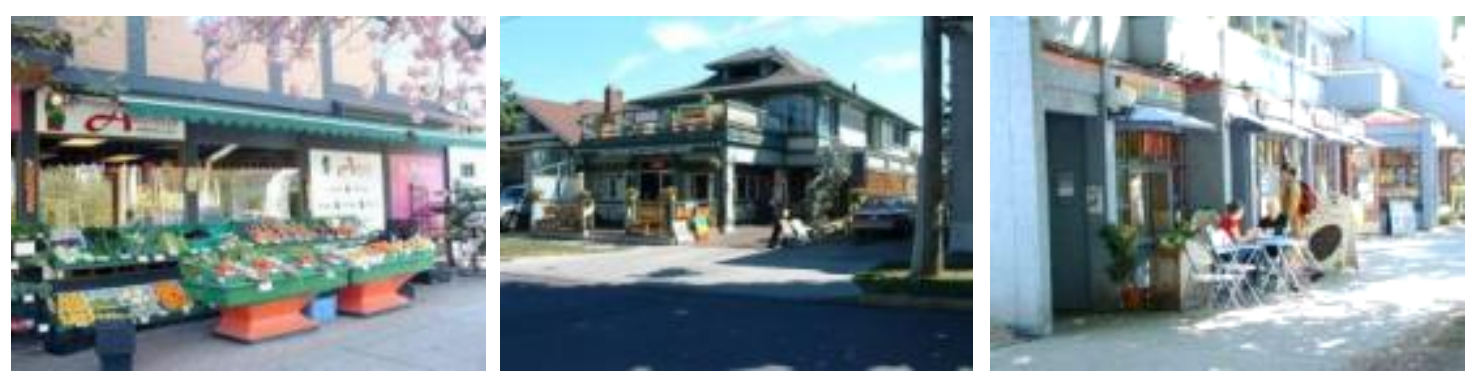

Figure 58, 59, 60: Typical Mixed Use in Fairfield

Type of Dwelling 2001

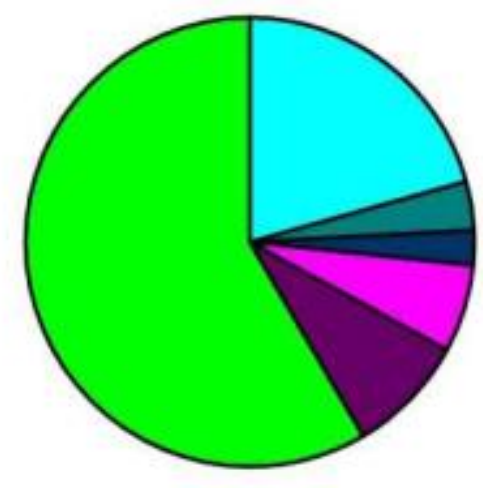

\author{
a Single-detached \\ house \\ 口Semi-detached \\ house \\ ERow house \\ 口Apartment- \\ detached duplex \\ apartment, with 5 \\ or more storeys \\ 口Apartment, fewer \\ than 5 storeys
}

Figure 61: Types of Dwellings in Fairfield ${ }^{544}$

Fairfield has over 40 different zones. These range from single family dwelling zones and commercial zones to site specific zones which refer to the exact use of the buildings on the land. Examples of these site specific zones include, Cook and Oxford Street Pub zone, Mears Bed and Breakfast zone and Fairfield Road Apartment zone. Many of the zones are road specific where individual roads have a certain type of zoning.

${ }^{544}$ City of Victoria, 2001 


\subsection{Physical Attribute Assessment}

The physical form measurement carried out for each case study was initially used to validate the neighbourhoods as either traditional or conventional. The classification of a neighbourhood as traditional or conventional relates to the current shift in land-use planning toward land-uses that resembled those of a pre-automobile era. As opposed to conventional neighbourhoods, the controlling theme within a traditional neighbourhood prioritizes pedestrian movement over the automobile. This auto-centrism by and large defines conventional neighbourhoods built form. Traditional neighbourhoods mix land uses, create densities where public transport and mixed amenities are viable, and link developments together with efficient public transport. ${ }^{545}$ Likewise they are defined by a grid street pattern and a scale more appropriate to the pedestrian.

Conventional neighbourhoods are typified by low density, single use zoning, curvilinear streets, long winding cul-de-sacs, limited connections to adjoining areas, and a clear priority for the automobile.

Following the neighbourhood validation, came relating neighbourhood factors that the pilot study survey participants' highlighted as affecting their liveability to actual neighbourhood measures. Accurate and robust physical form measures are important to the case study definitions, both to help ensure consistency across studies, ${ }^{546}$ and also to provide a reference to data generated by other means. While in either the pilot study or the main research, physical attribute measures cannot be statistically correlated with other variables, they do provide a reference to the subjective and quantitative data generated from the survey participants.

The main objective of the quantitative assessment is to measure and describe each case study neighbourhood. However, standardized metrics to achieve this are somewhat lacking. The concepts within urban design suffer from a general lack of applicability precisely because quantifying them has proved difficult. ${ }^{547}$ This is true for sprawl, and what is considered to be desirable urban form as well. ${ }^{548}$ With neither a clear definition for what's wrong with the built environment nor how to fix it, perpetuating the status quo is unremarkable.

In many regards the conventional neighbourhood, and the derogatory term "sprawl," meant to describe the result of an over supply of conventional neighbourhoods, has received greater input

\footnotetext{
545 Jabareen, 2006.

${ }^{546}$ Bauman et al., 2002 in Handy, 2005

547 Talen, 2003

${ }^{548}$ Forsyth, 2003. 
than traditional neighbourhoods toward the metrics that define the term. A number of urban form measures are common throughout the many definitions of sprawl and these relate to density, continuity, concentration, clustering, centrality, nuclearity, mixed uses, and proximity. ${ }^{549}$ From these measures, sprawl is defined as low density, leapfrog, commercial strip development that lacks continuity, is haphazard and decentralized. ${ }^{550}$ Desirable urban form, then, is defined as dense, continuous, planned, highly mixed, proximal, and clustered or polycentric. Other aspects of desirable urban form include, centrality, nuclearity ${ }^{551}$ diversity, and ecological integration. ${ }^{552}$ However, these terms have been criticized for only providing interesting information rather than being policy relevant. ${ }^{553}$ The same critique is applicable to Ecological Footprint techniques developed by Wackernagel and Rees (1996) for defining sustainable urban forms. While this technique is widely used ${ }^{554}$, it lacks the micro-level descriptions necessary to inform design beyond simply aiming to provide more green space per capita.

The relative availability of data also informs the extent of measures used. For example, in many cases gross density information is the easiest to obtain, which explains its prolific use but not the reliance placed on studies using it. ${ }^{555}$ Other studies rely on proximity to central business districts, ${ }^{556}$ distance from dwellings to various amenities ${ }^{557}$, and number of retail or service industry jobs within a specified distance to dwellings ${ }^{558}$ as their built form measures. Previous studies have also employed more subjective urban form measures and simply classify case studies as either high medium or low density, street patterns as either grid, fragmented or radiating, and sidewalks are estimated as continuous, fragmented or non-existent. ${ }^{559}$ There is a general recognition, however, that no one best approach exists for measuring urban form, and instead different situations demand different measures. ${ }^{560}$

A widely accepted set of measures have been developed by Eliot Allen. ${ }^{561}$ These measures go beyond providing only "interesting information about metropolitan form" such as "gross measures of density, nuclearity, and centrality", and include "measures of transportation options, residential

\footnotetext{
${ }^{549}$ Ewing and Chen. 2002; Frenkel, 2004; Galster et al., 2001; Fina and Siedentop. 2008; Song and Knaap. 2004; Tsai, 2005

${ }^{550}$ Ewing, 1997; Weitz and Moore, 1998; Galster et al., 2001; Hess et al., 2001; Malpezzi and Guo, 2001

551 Galster et al., 2001

552 Wheeler, 2003

553 Song \& Knapp, 2004

554 Ghosh et al., 2007

555 Burton et al, 2002.

${ }^{556}$ Cervero and Duncan 2006

${ }^{557}$ Naess, 2005; Kitamura et al., 1997, 2000

${ }^{558}$ Clifton \& Handy 2001

559 Schwanen and Mokhtarian 2005

${ }^{560}$ Handy and Niemeier, 1997

${ }^{561}$ Song \& Knapp, 2004
} 
proximity to retail and industrial uses, and accessibility of parks shops, and transit [which] is of direct concern to citizens and policy makers". ${ }^{562}$ Another increasingly standardized set of measures is the sprawl index developed by Ewing et al. (2002). These measures combine six sets of variables that assess residential density, land use mix, development concentration and street network patterns to compute an overall measure of sprawl. This index provides parameters that policy makers and urban designers have an influence on, and as such the sprawl index has recently been adopted as part of the criteria for Leadership in Energy and Environmental Design Neighbourhood Design (LEED ND) certification. LEED ND is the only neighborhood development rating system that provides "independent, third-party verification that a development's location and design meet accepted high levels of environmentally responsible, sustainable development". 563

The urban form measures used in this dissertation were adopted from Yan Song and Gerrit-Jan Knaap (2004). These measures are largely in line with those developed by Ewing et al. (2002); however they also include some modifications to suit the neighbourhood level of their study. These measures were deemed the most appropriate for this study because they provide the most comprehensive set of measures and are at an appropriate scale for the case studies selected. These measures also correspond well with LEED ND which makes the case studies and this research highly applicable for cross validation with other studies in the future. For each case study elements of the urban form are measured, quantified and expressed as a ratio for comparison between studies. Some modifications to the Yan Song and Gerrit-Jan Knaap (2004) measures are made for this research and are outlined below.

\section{Density}

Measures of density used in this study vary from the Song and Knapp (2004) study by not including lot sizes and floor space. Lot sizes and floor space are not included because the Song and Knapp study suggests that smaller lot sizes and less floor space go hand in hand with higher density, however, this is not the case and would be misleading. Available floor space can actually increase with higher density as more space is available with more storeys. Similarly, measuring smaller lot sizes and including that measure in the study suggests a reduction in lot sizes across the board is implicit in accepting higher densities, which is also misleading. The focus in the pilot study is to determine what contributes to neighbourhood liveability, and as such, both gross and net measures of density suffice.

\footnotetext{
${ }^{562}$ Song \& Knapp, 2004, p 213

${ }^{563} \mathrm{http}: / /$ www.usgbc.org/DisplayPage.aspx?CMSPageID $=148$ 
The density measures include:

- Gross Density- the number of dwelling units in the neighbourhood divided by the total neighbourhood area; the higher the ratio, the higher the density. The total neighbourhood area is defined by the relevant boundaries as shown in figure 1, 2 and 3 (page 14).

- Net Density- the number of dwelling units divided by the area of zoned residential land.

\section{Connectivity}

Adopted measures of connectivity include the number of nodes and intersections, the distance between points of access into the neighbourhood, the number and lengths of blocks, and the lengths of cul-de-sacs. Four of these measures assess connectivity within each neighbourhood and one measure assesses connectivity between neighbourhoods.

Connectivity measures include:

- Internal Connectivity - number of street intersections divided by the sum of the number of intersections and the number of cul-de-sacs; the higher the ratio, the greater the internal connectivity.

- Perimeter of Blocks - median perimeter of blocks; the smaller the perimeter, the greater the internal connectivity.

- Number of Blocks - number of blocks divided by number of dwelling units; the higher the ratio, the greater the internal connectivity.

- Lengths of Cul-De-Sacs - median length of cul-de-sacs; the shorter the cul-de-sacs, the greater the internal connectivity.

- External Connectivity - median distance between Ingress/Egress (access) points); the shorter the distance, the greater the external connectivity.

\section{Land Use Mix}

This study measures both the zoned land use mix as well as the actual land use mix. Because council zoning definitions varied between the case studies, all zones are divided into five main zones to make comparisons. These comprised residential only, commercial only, institutional only, parks and open space and mixed use.

- Mix-Actual - hectares of commercial, institutional, and mixed uses in the neighbourhood divided by the number of housing units; the higher the ratio, the greater the land use mix. 
- $\quad$ Mix-Zoned - hectares of land zoned for commercial, institutional and mixed land uses in the neighbourhood divided by the number of housing units; the higher the ratio, the greater the mix.

\section{Accessibility}

Measures of accessibility differed from the Song and Knaap study. ${ }^{564}$ Three measures of accessibility are employed; network distance to a commercial area, network distance to a bus stop and network distance to a park for all dwelling units. Network distances are calculated using a pedestrian shed measurement where distances are measured along walkable routes only, rather than as the crow flies. All dwellings outside of the pedestrian shed are considered to not have access to the relevant facility. These measures included:

- Commercial Distance - percentage of dwellings outside of a $400 \mathrm{~m}$ pedestrian shed; the larger the percentage, the less access.

- $\quad$ Bus Distance - percentage of dwellings outside of a $400 \mathrm{~m}$ pedestrian shed; the larger the percentage, the less access.

- $\quad$ Park Distance - percentage of dwellings outside of a $400 \mathrm{~m}$ pedestrian shed; the larger the percentage, the less access.

The accessibility measures consider neighbourhood attributes that are outside of the neighbourhood as well. If the nearest bus stop, commercial facility or park is located outside of the neighbourhood boundary but within the $400 \mathrm{~m}$ pedestrian shed, the respective dwellings are considered to have access to these attributes.

Although neighbourhoods are regarded as building blocks of urban form, what defines a neighbourhood has been disputed. ${ }^{565}$ The definitions of the neighbourhoods chosen for this study rely on both the availability of data and a large proportion of primary data collection. The limits or boundaries of each neighbourhood have a strong influence on the quantitative data results. What is included and what is left out can tip the density measures dramatically, particularly when open space is considered. For these case studies, council neighbourhood maps were found to misrepresent the actual boundaries of each neighbourhood and as such, boundary adjustments were made for each case study.

\footnotetext{
${ }^{564}$ Song and Knaap (2004) measured median distances from the centroid of all dwellings to the centroid of all other land uses. The software used in this research could not calculate this measure.

${ }^{565}$ Song \& Knapp, 2004

94
} 
In the case of Churton Park, being a relatively new subdivision, a large proportion of undeveloped land is included in the council neighbourhood boundary that is intended for future development. Similarly, Churton Park borders open paddocks, and paper roads ${ }^{566}$ that again are included in the council boundary. These areas would have misrepresented the actual density of the neighbourhood and are excluded from this study.

In Newtown, the zoo and the town greenbelt are included within the council boundary. These inclusions misrepresent the amount of open space that Newtown residents have access to and have been excluded from this study.

In the case of Fairfield, the cemetery, the waterfront, and the major city park that borders the neighbourhood are all not included within the council boundary. In all cases these bordering amenities are both accessible to the neighbourhood residents and frequently used. As such, these areas are included in this study.

Broadmead's council boundary excluded an area of dwellings at the eastern edge of the neighbourhood that bordered rural land. This cluster of houses was not connected to an adjoining neighbourhood and formed an island within the Broadmead boundary. A steep heavily wooded open area was also included within the council boundary that was gated off from Broadmead residents and inaccessible. Both of these areas were excluded from the boundary definition used in the present research.

For the use of this research an adjusted boundary is adopted to define the edges of each neighbourhood where council defined boundaries were inappropriate. Boundaries are based on the amount of open space reasonably accessible to residents and, when large open spaces create the boundary between two neighbourhoods, half of the open space is included within the neighbourhood boundary. The differences in neighbourhood council boundaries versus the boundary definitions used in this study are presented in Figures 62 to 65.

\footnotetext{
${ }^{566}$ A legal designation for a future road.
} 


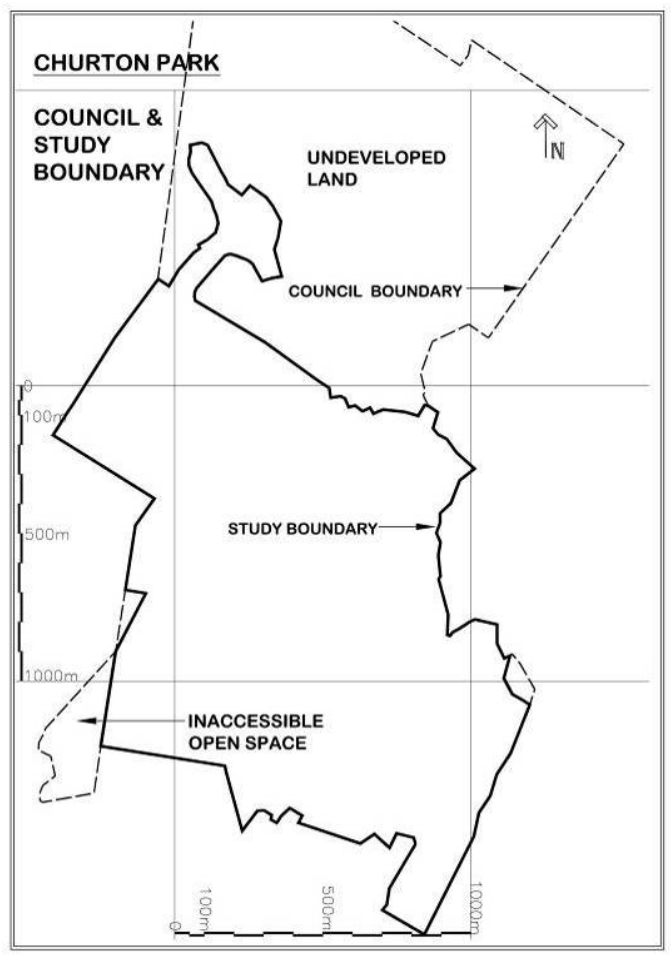

Figure 62: Churton Park Boundary

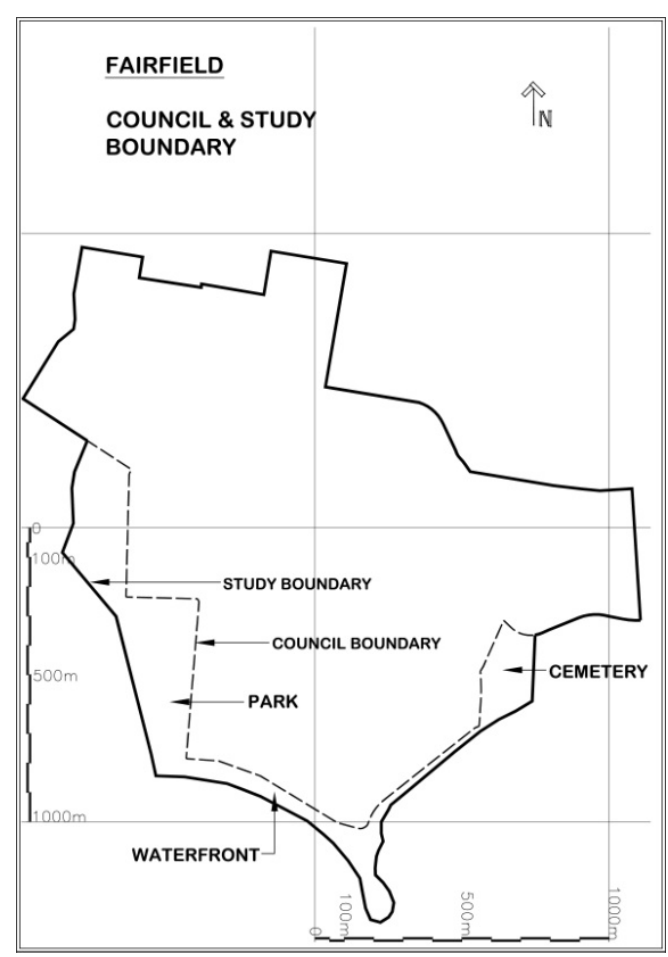

Figure 64: Fairfield Boundary

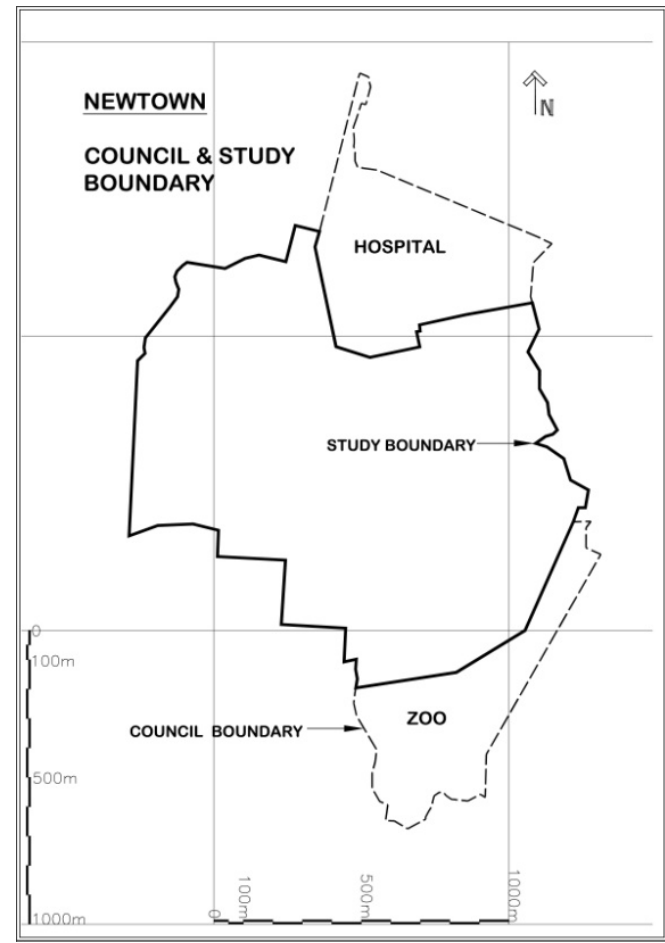

Figure 63: Newtown Boundary

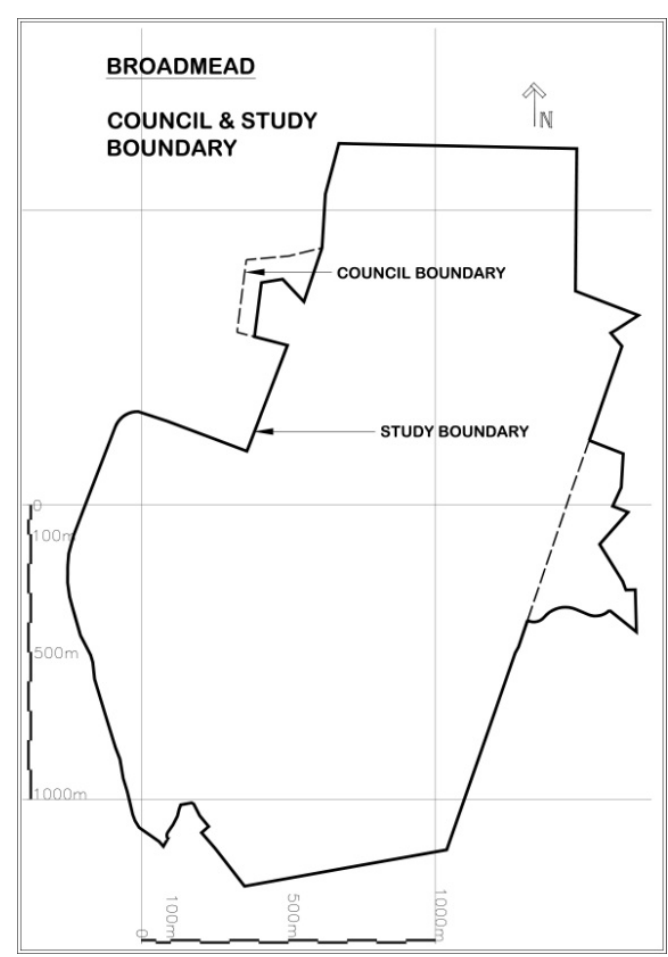

Figure 65: Broadmead Boundary 
Because the results of this study depend on the precision and comparability of external data, a large effort was devoted to ensuring data accuracy. Council maps that show legal boundaries and the associated zoning were digitised for each of the relevant case studies. This involved translating hard copy data (paper data) to digital data. Although, both Wellington City Council and Victoria City have a large proportion of their hard copy data in digital format, they were unable to provide this data in the large format required for this study. Geographical information systems (GIS) aid in the analysis of the maps to count the individual land parcels and measure the urban form. Where the numbers of dwellings are unclear from the zoning and cadastral maps, an on-the-ground confirmation was carried out. This typically involved counting addresses at apartments and mixed use properties.

In the case of Fairfield, the numbers of dwellings are compared to the population records published by the city council. Broadmead neighbourhood association publishes population and dwelling data and this information was compared against the GIS analysis. In Newtown and Churton Park the number of dwellings, after the GIS analysis and the on-the-ground confirmation, are compared against records provided by Quotable Value Limited. ${ }^{567}$ In all three cases, the numbers of dwellings calculated by these two methods correspond well with each other with the greatest inaccuracy representing an $8 \%$ difference between results. In Newtown the vertical mixed uses are difficult to assess. Independent zones that demarcate where dwellings are located above commercial uses do not exist. Therefore, an on the ground confirmation of the vertical mix is carried out, although this method lacks a cross check confirmation like the methods described above. Hence the accuracy of the vertical mixed use in Newtown is unknown, although it is anticipated that the rigorous on-theground assessment is the most accurate record available.

\subsection{Pilot Study Liveability Survey}

The liveability survey of the pilot study assesses the success of each neighbourhood in terms of its liveability as experienced by its residents. To assess liveability, previous studies are used as a benchmark to compare and validate the findings of the qualitative case study appraisals. ${ }^{568}$ The qualitative analysis evaluates liveability by seeking patterns within the survey responses. Such pattern recognition from seemingly random information can provide an accurate snapshot of a

\footnotetext{
${ }^{567}$ A property information company responsible for publishing official property values and rate information.

${ }^{568}$ For example: Burton in Williams et al, 2000; Nieboer, 2005; Gray, 2001
} 
larger phenomenon. ${ }^{569}$ Major patterns and concepts within the pilot study survey sample are identified and the results are coded by concepts. ${ }^{570}$

The pilot study survey asked residents their opinions on certain factors of their neighbourhood that contribute to their liveability. The surveys also included a section on travel behaviour in each neighbourhood. Residents were asked to select which mode of travel they use most often to access a variety of destinations from their home, and then were asked which mode of travel they would prefer to use for the same destinations. A copy of the pilot survey is included in Appendix 1.

The pilot survey was developed with reference to examples from a variety of sources. ${ }^{571}$ Most questions are open ended to allow the respondents to develop their own theme for how their built environment affects the liveability of their neighbourhood. Questions range from considering liveability experiences within economic, environmental and social realms, yet remain general to allow respondents to generate a complex narrative and to elicit un-prompted responses. The general nature of this survey provides results that are both insightful and an accurate representation of the way residents feel about their neighbourhoods' liveability.

This liveability assessment avoids specific indicators and survey strategies aimed at making statistically accurate generalizations about the case study populations. Instead, the pilot survey seeks to develop place-specific themes of liveability that are related to the physical environment and that can also be used to develop tightly defined questions to explore in greater depth.

Two hundred pre-paid envelopes and pilot survey flyers were hand delivered to selected households in both Churton Park and Newtown. The survey was initially only available on-line, recruiting participants through a flyer drop. However, preliminary response to this form of recruitment was not substantial. Consequently, a pre-paid envelope drop to both Newtown and Churton Park was required. See Appendix 2 for a copy of the flyer. Flyers and surveys were delivered to a representative sample of dwelling types for each neighbourhood. However, once the surveys were returned it was impossible to determine what type of dwelling the survey was from because the survey's only control for dwelling type regarded the tenure of the dwelling, rented or owned.

\footnotetext{
${ }^{569}$ Boyatziz, 1998

570 Jabareen, 2005, p 39

${ }^{571}$ Ministry for the Environment, 2002; Big Cities, 2003; Thompson-Fawcett \& Bond, 2003; Ministry for the Environment, 2000 
A breakdown of dwelling types is provided by Victoria City for Fairfield and although, this may be beneficial to this study for the other two neighbourhoods, such an assessment was beyond the scope of this research. Similarly, demographic differences, such as income, family situation, education, and marital status were not controlled for and neither was it deemed necessary to achieve a representative population sample. Generalizing to a larger population is an aside from the main aim of the pilot study, which is to explore density and liveability relations and provide a clear research question through a qualitative evaluation. ${ }^{572}$ The qualitative aspect of the pilot study provides a significant insight into the density-liveability relationship for these specific case studies. Although the techniques of this research, if applied on a much larger scale, may be useful for broader generalizations, the focus here is clearly on exploring the phenomenon of liveability under varying densities to establish qualitative relationships for the three case studies.

The case study neighbourhood in Victoria, Canada- Fairfield proved more difficult to elicit survey responses from. Initially the Victoria City Council was approached to help with this task by circulating the survey to staff that resided in or that had a professional interest in Fairfield. The Fairfield Residents Association was also approached to provide survey feedback from their members. A small response rate was achieved through both methods and hence the survey was registered on a 'Blog' where Victoria development issues are discussed on-line. Sufficient responses came from this method. ${ }^{573}$ The results from the quantitative and qualitative analysis of the case studies are presented in chapter six.

With any qualitative study, both the researchers' and the survey respondents' interpretations and opinions reflect their "historical and cultural background, audience and genre, standing and agenda, the contemporary social context, and are constrained by an intellectual framework and use of language. $" 574$ Fundamentally, qualitative research is interpretive and this includes the interpretation of data and the drawing of conclusions. ${ }^{575}$ The validity of qualitative research is improved upon by comparing the findings against similar studies, which this pilot study does.

The pilot study methodology is considered experimental but generally follows that of logical argumentation as described by Groat and Wang. ${ }^{576}$ Their description follows that logical argumentation forms a system where an issue is framed and components within the issue are

\footnotetext{
572 Yin in Groat \& Wang, 2002, p. 354

573 A world wide web based discussion forum where people post and reply to messages and news articles published on the site. http://www.vibrantvictoria.ca/

574 Duncan, 1990, p 12

575 Groat \& Wang, 2002

${ }^{576}$ Groat \& Wang, 2002
} 
related to one another such that behaviours for actors within the system can be explained. ${ }^{577}$ Previous quantitative studies that measured urban form in terms of density, accessibility, connectivity and mixed use are well founded and can suggest patterns of urban form to achieve sustainability goals. The pilot study aims to seek out patterns of perceived liveability to complement such quantitative studies and further explore physical and temporal relationships of urban form. The culmination of environmental and psychological assessments in this study, form a system to relate the findings to meaningful success indicators ${ }^{578}$ and inform the main research of this dissertation.

Triangulation between qualitative surveys and quantitative urban form assessments for each of the three case study neighbourhoods, together with a literature review were used to explore and validate density-liveability relationships. A "triangulated method combine[d] the strengths of [this] research strategy while neutralizing [its'] weaknesses". ${ }^{579}$ Similarly, triangulation has become an important evaluation tool to mitigate bias and produce valid scientific propositions. ${ }^{580}$ Geographical information systems (GIS) were used to measure and tabulate density, connectivity, mixed use, and accessibility attributes while the survey canvassed residents' opinions about the liveability of their neighbourhoods. Both forms of inquiry were analysed to identify relative patterns that agreed with the literature review findings.

Similar studies such as Sherry Ahrentzen's study on home offices, which have combined quantitative and qualitative approaches, have been described as a 'bricolage' ${ }^{581}$ Her study sought to understand the socio-spatial consequences of home-office arrangements and weaved together surveys, interviews, sketches, and a physical inventory of the workspace to gain this understanding. The pilot study aims to replicate this 'bricolage' by weaving together multiple research strategies to understand the intricate patterns and relationships in our urban tapestry.

\footnotetext{
${ }^{577}$ Groat \& Wang, 2002

${ }^{578}$ Wish, 1986

${ }^{579}$ Groat \& Wang, 2002, p 362

${ }^{580}$ Mathison, 1998, p 13

${ }^{581}$ Groat \& Wang, 2002

100
} 


\section{Pilot Study Results}

The pilot study aimed to examine the relationship between density and liveability and also to inform the research questions of the main dissertation. This chapter details the results of the pilot study. First, the case study physical analysis results are presented. These include measurements for Broadmead which was included for the main research, but do provide insight in terms of comparison. An assessment of liveability indicators for Broadmead is not detailed because of its inclusion for the purposes of the main research only. Responses to the pilot study liveability survey for the other three neighbourhoods are then communicated along with a discussion of these results. The chapter concludes with the relevant findings from both forms of analysis and provides a synopsis of density-liveability relationships as well as findings for further investigation.

\subsection{GIS Analysis Results}

The following table presents the geographical information systems analysis results.

Table 3: GIS Quantitative Results

\begin{tabular}{|c|c|c|c|c|c|}
\hline Quantitative Measurement Summary & (as $\mathrm{p}$ & represen & ative boun & aries) & \\
\hline Measurement & 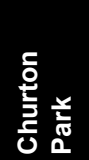 & 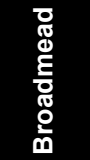 & $\begin{array}{l}5 \\
\frac{5}{0} \\
\frac{3}{2} \\
2\end{array}$ & 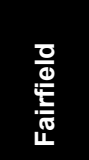 & Quantitative Measures \\
\hline Density & & & & & \\
\hline Density (Dwelling Units per hectare gross) & 9.24 & 5.79 & 14.93 & 26.57 & higher ratio $=$ greater density \\
\hline Density (Dwelling Units per hectare res net) & 11.59 & 7.72 & 24.26 & 34.97 & higher ratio $=$ greater density \\
\hline Total Area (hec) & 199.16 & 327.53 & 149.13 & 243.91 & \\
\hline Area of Residential zone (hec) & 158.83 & 245.80 & 91.77 & 185.32 & \\
\hline Number of dwelling units & 1841 & 1897 & 2226 & 6480 & \\
\hline Park Area (hec) & 40.08 & 63.57 & 33.31 & 32.91 & \\
\hline Park Area (hec) as \% of dwelling units & $2.18 \%$ & $3.35 \%$ & $1.50 \%$ & $0.51 \%$ & \\
\hline Park Area (hec) as \% of total area & $20.12 \%$ & $19.41 \%$ & $22.34 \%$ & $13.49 \%$ & \\
\hline Connectivity & & & & & \\
\hline No. of intersections divided by sum of \# ints' + \# cul-de-sacs & $25.33 \%$ & $42.16 \%$ & $63.16 \%$ & $94.48 \%$ & higher $\%=$ greater internal connectivity \\
\hline No Blocks divided by no. dwelling units & $0.38 \%$ & $0.90 \%$ & $1.03 \%$ & $1.39 \%$ & higher $\%=$ greater internal connectivity \\
\hline Median Length of cul de Sacs (m) & 115 & 82 & 86 & 104 & shorter cul-de-sac = greater int connectivity \\
\hline Median Perimeter of Blocks $(\mathrm{m})$ & 1639 & 1280 & 693 & 623 & smaller perimeter $=$ greater int connectivity \\
\hline Median Distance between ingress and Egress $(\mathrm{m})$ & 275 & 622 & 398 & 223 & shorter distance = greater ext connectivity \\
\hline Accessibility & & & & & \\
\hline$\%$ Dwellings outside $400 \mathrm{~m}$ Network Park Access & $4.67 \%$ & $7.33 \%$ & $7.19 \%$ & $5.77 \%$ & higher $\%=$ less access \\
\hline$\%$ Dwellings outside $400 \mathrm{~m}$ Network Commercial Access & $94.30 \%$ & $84.03 \%$ & $1.62 \%$ & $7.16 \%$ & higher $\%=$ less access \\
\hline$\%$ Dwellings outside $400 \mathrm{~m}$ Network Bus stop Access & $8.75 \%$ & $33.26 \%$ & $0.90 \%$ & $0.00 \%$ & higher $\%=$ less access \\
\hline Land Use Mix & & & & & \\
\hline Mix Actual & $0.10 \%$ & $1.04 \%$ & $1.33 \%$ & $0.40 \%$ & higher $\%=$ greater the mix \\
\hline Mix Zoned & $0.10 \%$ & $1.04 \%$ & $1.06 \%$ & $0.40 \%$ & higher $\%=$ greater the mix \\
\hline
\end{tabular}




\section{Density}

The density measures show Fairfield to have the highest gross and net densities at 27 and 35 dwellings per hectare respectively. Newtown has the second highest gross and net densities at 15 and 24 dwellings per hectare. Churton Park has the second lowest gross and net densities at 9 and 12 dwellings per hectare respectively, and Broadmead has the lowest gross and net densities at 6 and 8 dwellings per hectare respectively.

The relative density of each neighbourhood is expressed in Figures 66 to 69 . Each dot in the figures represents a dwelling. These figures demonstrate the zoned dwelling densities only.

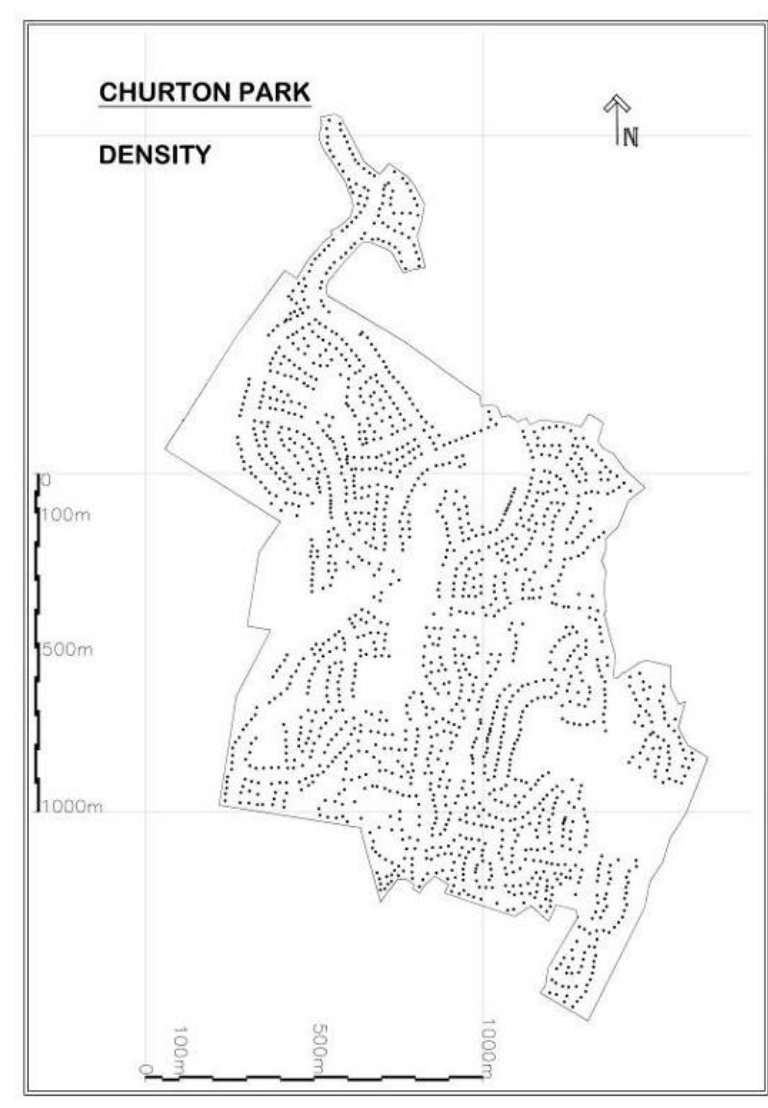

Figure 66: Churton Park Density Map

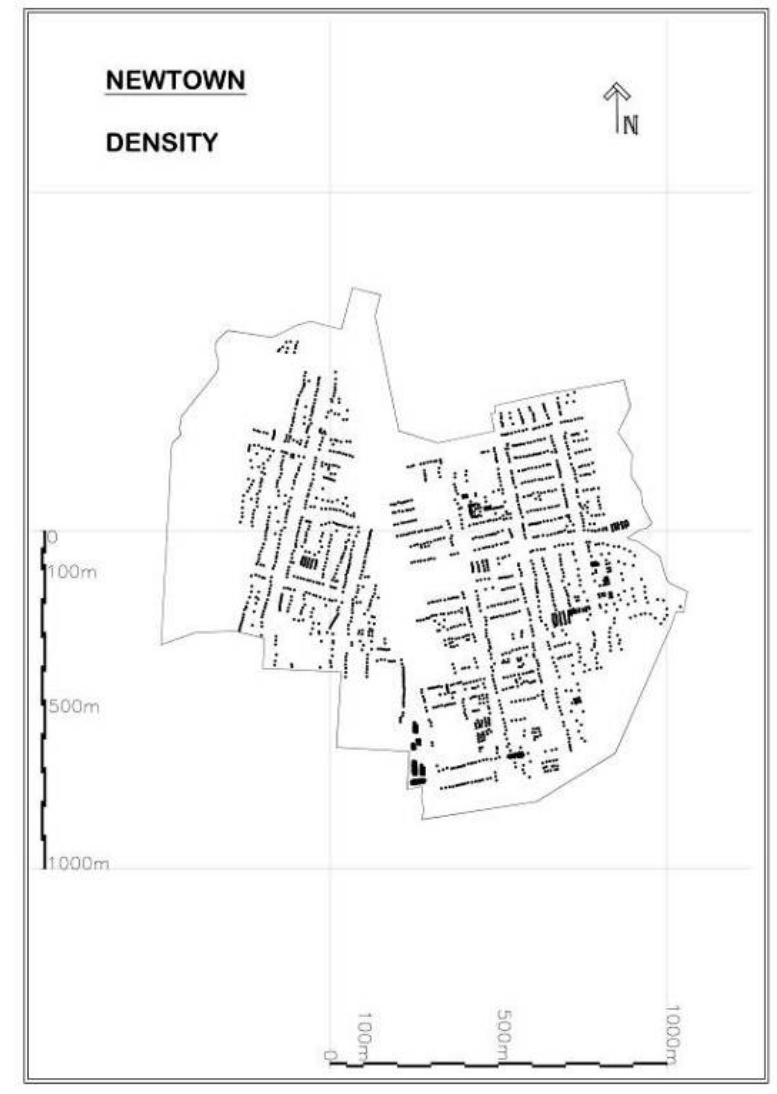

Figure 67: Newtown Density Map

The uniform spacing of dwellings and equal density throughout Churton Park gives an indication of the single use zoning and regulated design templates that have contributed to the development of this neighbourhood. Newtown's density is characterised by the smaller lots and by council housing developments which generally have more than two storeys and are of higher density. Some of the newer multi-family dwelling developments also show a higher density with a clustering of dwellings. 
In Fairfield, the greater frequency of apartments can be seen in the density map (Figure 65). Here the transition from the neighbourhood proper to Downtown Victoria is visible. Higher densities occur at the waterfront as well where, again, apartments house the majority of the dwellings. The lack of dwellings in the uppermost northwest corner of the neighbourhood is due to the sole commercial use of this area. Similarly the school and its associated playing fields can be seen in the middle of the neighbourhood where again there are no dwellings.

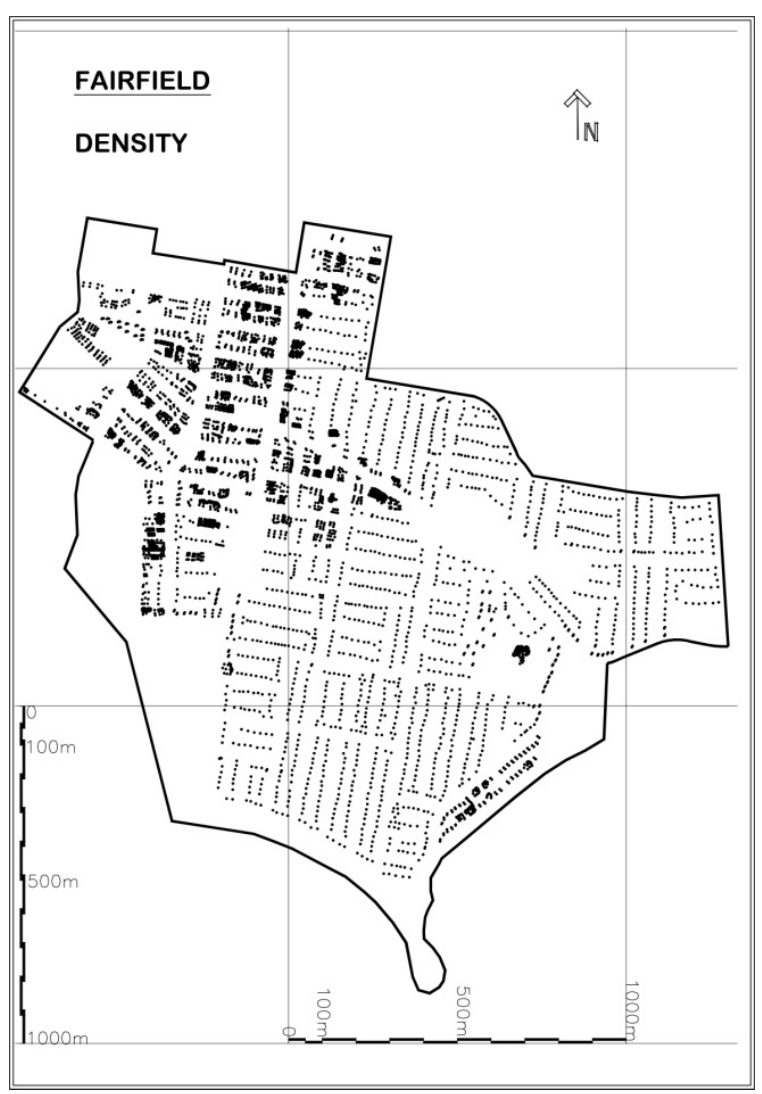

Figure 68: Fairfield density Map

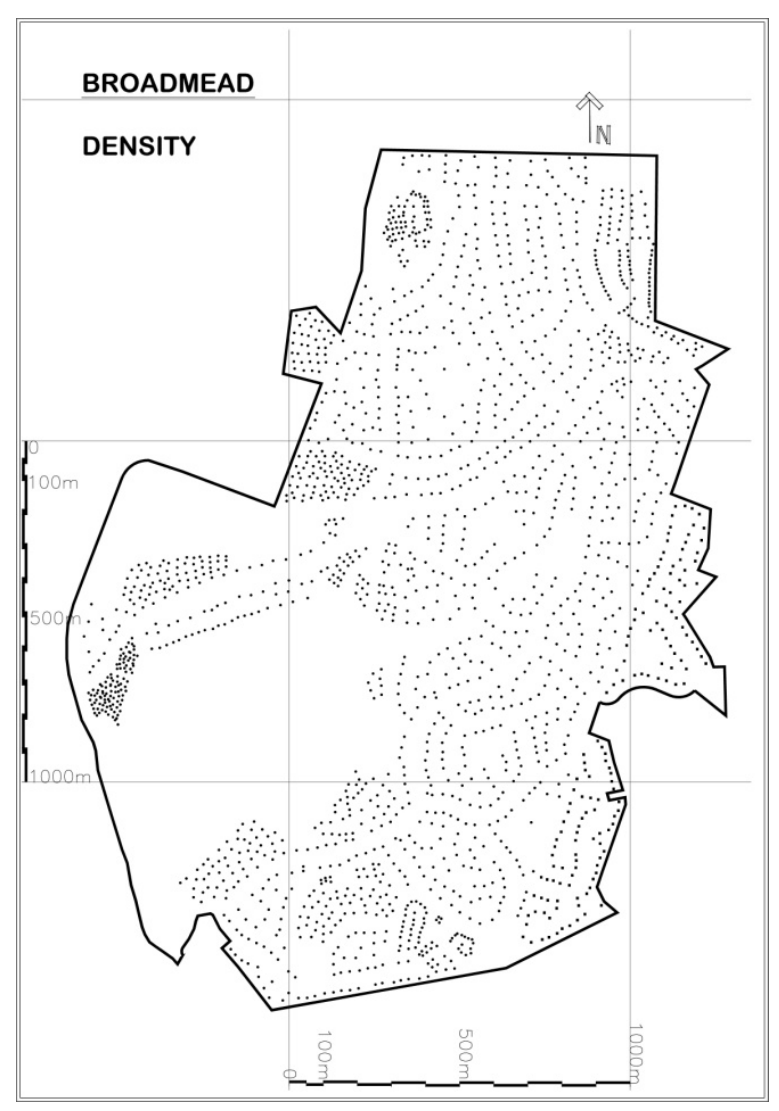

Figure 69: Broadmead density Map

Broadmead's density is regular throughout the areas dominated by single family dwellings but where multi-family units are located, which are typically gated off, the density is evidently higher. The large open area in the middle of the neighbourhood is where Rithet's Bog is located and the area in the middle northwest corner is the location of the commercial plaza.

Newtown has the greatest proportion of land devoted to parks and open spaces as a percentage of the total neighbourhood area. However, Churton Park has a greater proportion of park area per dwelling. Broadmead has the highest proportion of park area per dwelling but less park area per the total neighbourhood area than Newtown and Churton Park. Fairfield has the lowest percentage of 
land devoted to parks or open spaces and also the lowest percentage of open space and parks per dwellings.

\section{Connectivity}

The greatest internal connectivity is in Fairfield, then Newtown and then Broadmead, leaving Churton Park with the least internal connectivity. All three measures for internal connectivity confirm this finding. The most dramatic difference in connectivity is identified with the median perimeter of blocks measure. The median perimeter of blocks in Fairfield is $623 \mathrm{~m} ; 693 \mathrm{~m}$ in Newtown; nearly double in Broadmead at 1280m; and 1639m in Churton Park. The measure for median lengths of cul-de-sacs doesn't define the built form well in the case studies. The actual numbers of cul-de-sacs provide a better indication of the built form along with Figures 72-75 (page 49-50). There are sixty-three cul-de-sacs in Broadmead, fifty-six in Churton Park, twenty-nine in Newtown and nine in Fairfield. Fairfield also has the greatest external connectivity, or connectivity to the areas that surround the neighbourhood. However, Churton Park has the second greatest external connectivity, Newtown has second lowest and Broadmead has the least external connectivity. This finding may be influenced by the boundary definition for Churton Park. Where the boundary was drawn split Churton Park from its bordering neighbourhood across winding roads that went in and out of either neighbourhood but did not actually go anywhere or connect to anything. Consequently there appears to be more ingress and egress points from the measurement used than there actually are. Typically, Churton Park has the least external connectivity because there are only two ways in and out of the neighborhood, compared to Newtown which has six main routes in and out, and even Broadmead which has five.

\section{Accessibility}

All four neighbourhoods have relatively equal access to parks and open spaces. Churton Park has the greatest access to parks with just over 95 percent of all dwellings within $400 \mathrm{~m}$ walking distance. Fairfield has the second greatest access with slightly over 94 percent of all dwellings within the $400 \mathrm{~m}$ pedestrian shed. Newtown has the second least access to parks and open spaces with 93 percent of all dwellings within 400m walking distance and surprisingly Broadmead has the least with under $93 \%$. The 1 percent difference in access to parks and open spaces between each of the case studies represents, at most, an additional 65 dwellings that are outside the $400 \mathrm{~m}$ pedestrian shed.

A far greater difference in access to commercial facilities between the four case studies is observed. Newtown and Fairfield have similar proportions of dwellings within a $400 \mathrm{~m}$ network distance to 
commercial amenities with 98 and 93 percent respectively. Broaead has the second least access to commercial areas with $84 \%$ of its dwellings outside of a $400 \mathrm{~m}$ network distance. Churton Park has the least commercial access with fewer than 6 percent of dwellings within walking range. In the case of Churton Park, the commercial amenities are located outside of the neighbourhood and consist of two cafes, a garden centre, a warehouse and a construction depot.

The percentages of dwellings in each case study, with the exception of Broadmead, have a similarly high proportion of their dwellings within the $400 \mathrm{~m}$ pedestrian shed around bus stops. Just over 91 percent of dwellings in Churton Park, 99 percent of dwellings in Newtown and 100 percent of dwellings in Fairfield have walking access within $400 \mathrm{~m}$ of a bus stop. In Broadmead, only $67 \%$ of dwellings are within $400 \mathrm{~m}$ walking distance to a bus stop. In all cases however, it is important to remember that having a bus stop within walking distance is only one measure of public transport accessibility. Perhaps more importantly, frequency of buses plays a greater role in terms of public transit accessibility. This measure was not included; however, future research should consider it.

\section{Mixed Use}

Mixed use is expressed as a percentage of land area devoted to commercial divided by the total area of each case study. Newtown has the greatest proportion of mixed uses of all four case studies and the only difference between zoned and actual mixed land uses. The difference between zoned and actual land use mix in Newtown can be seen in Figures 70 and 71. Commercial uses are frequent in areas zoned inner-residential in Newtown. These include uses ranging from manufacturing, to gas stations and dairies. It is worth noting that there are a number of religious buildings and churches in Newtown that were not accounted for in the land use mix maps. 


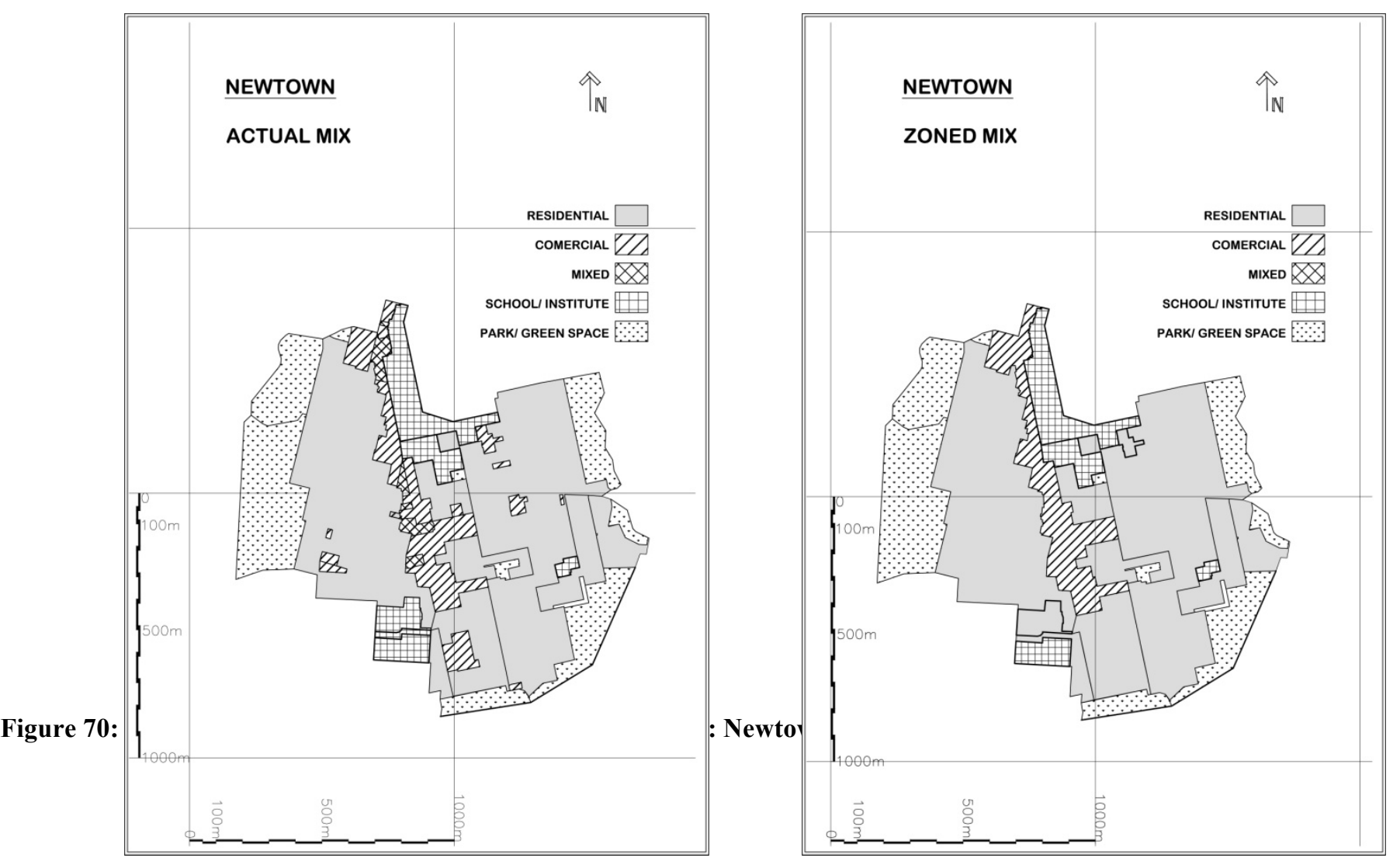

Vertical land use mixing is common throughout the central commercial strip in Newtown.

Typically, commercial uses are located on ground floors with dwellings located above.

Generally, buildings are only two stories high where the majority of vertical mixed use occurs and in commercially zoned areas.

There are no differences between the actual versus zoned land use mix in Churton Park, Broadmead or Fairfield. The zoned mix of land uses in Churton Park, Broadmead and Fairfield can be seen in Figures 72 to 73 on the following page. 


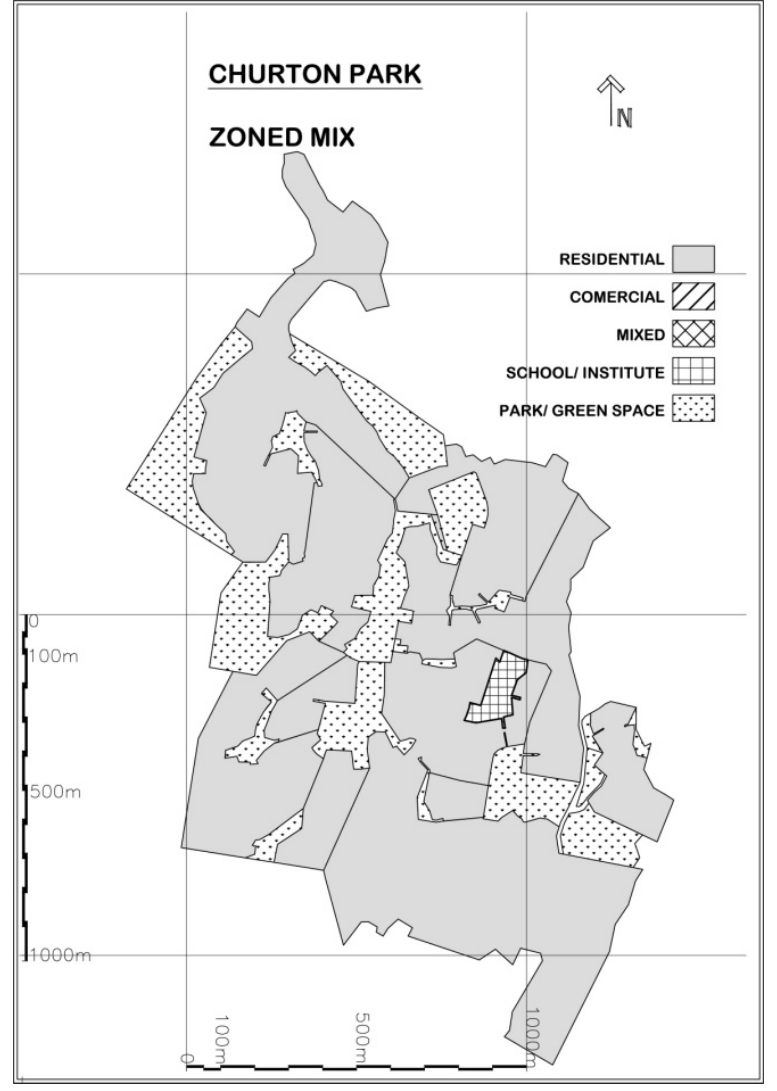

Figure 72: Churton Park Actual Mix

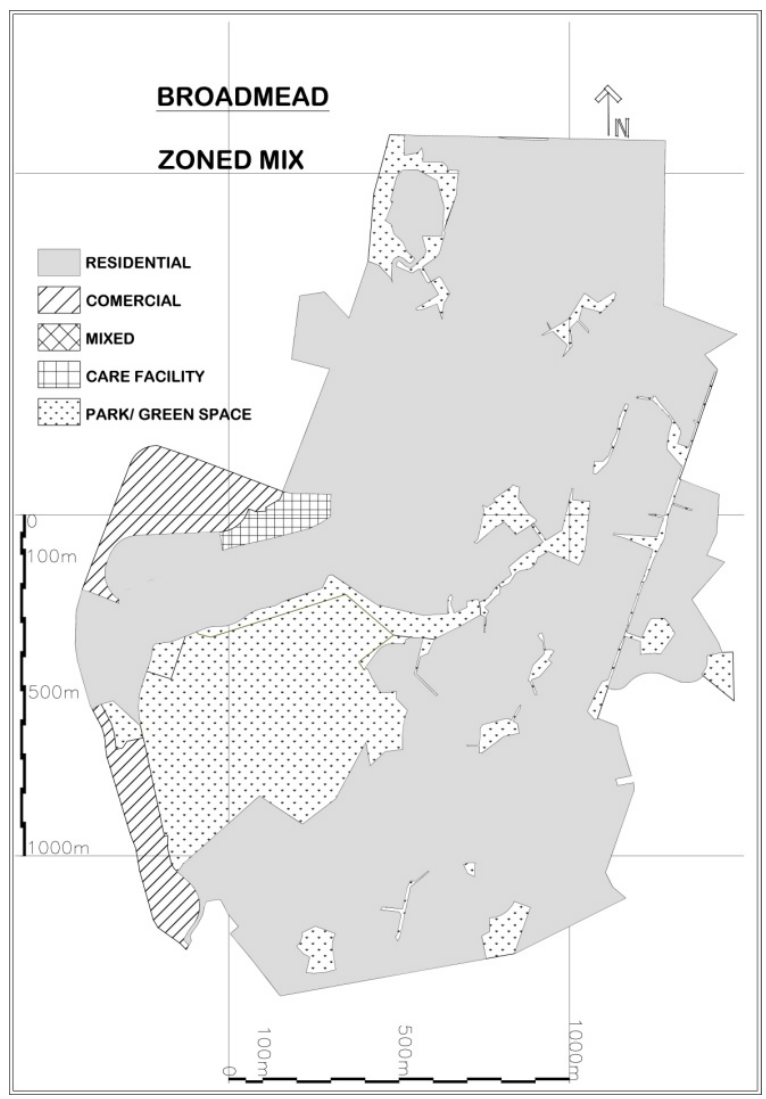

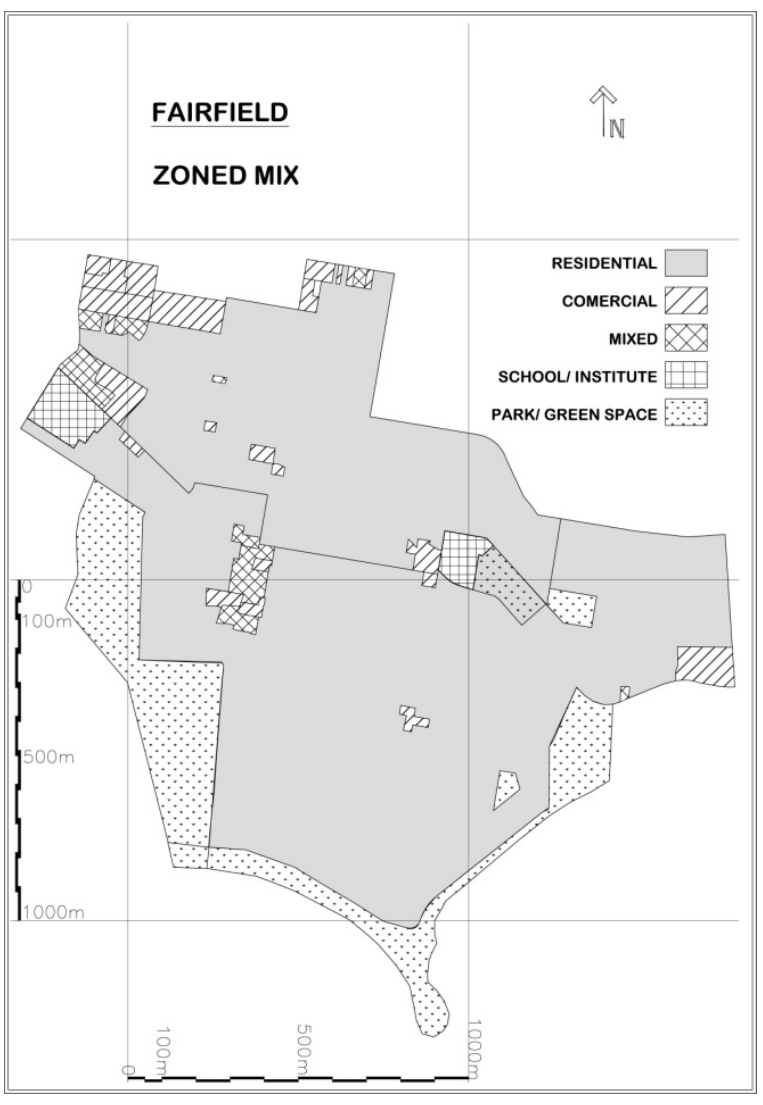

Figure 73: Fairfield Actual Mix

Figure 74: Broadmead Actual Mix

Broadmead, surprisingly, had a higher mixed use than Fairfield; however, of note is the location of that mixed use which is clustered at the edges of the neighbourhood and at some distance to many of the dwellings. Likewise, the mixed use measure doesn't include mixed residential as in the mix of apartments, town homes, condominiums and duplexes.

The total area for land uses as a percentage of the total area for each case study is shown in Table 2 . 
Table 4: Case Study Land Uses

\begin{tabular}{|l|c|c|c|c|}
\hline $\begin{array}{l}\text { Parks and open space as a percentage of total } \\
\text { area }\end{array}$ & $19.4 \%$ & $20.1 \%$ & $22.3 \%$ & $13.5 \%$ \\
\hline Residential area as a percentage of total area & $75.0 \%$ & $79.0 \%$ & $58.0 \%$ & $76.0 \%$ \\
\hline $\begin{array}{l}\text { Commercial, mixed and institutional areas as } \\
\text { a percentage of total area }\end{array}$ & $5.6 \%$ & $1.0 \%$ & $20.0 \%$ & $10.5 \%$ \\
\hline
\end{tabular}

The school in Churton Park represents the one percent land use mix seen in Table 2. A greater land use mix is present in Newtown, and would have appeared in the urban form measures if the hospital and zoo had been included.

The level and the layout of connectivity and accessibility for each case study is evident in the block layout Figures 75 to 78 . These figures show blocks in black and roads in white, and are set against a thousand square metre grid. Proponents of increased density stress the importance of block sizes and layouts, and although the block perimeter lengths are accounted for in the urban measurements, the actual block dimensions are better compared in these figures.
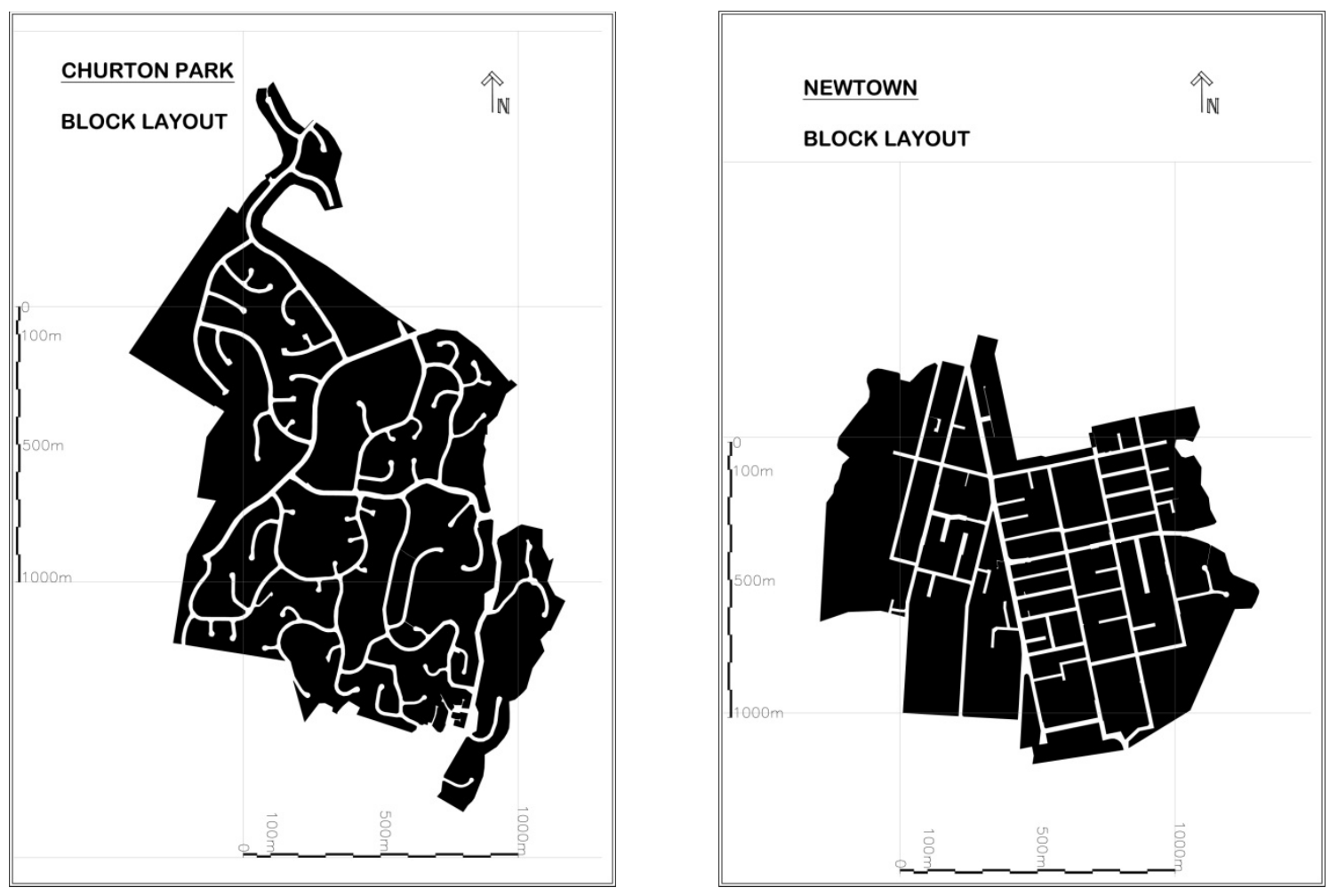

Figure 75: Churton Park Block Layout 

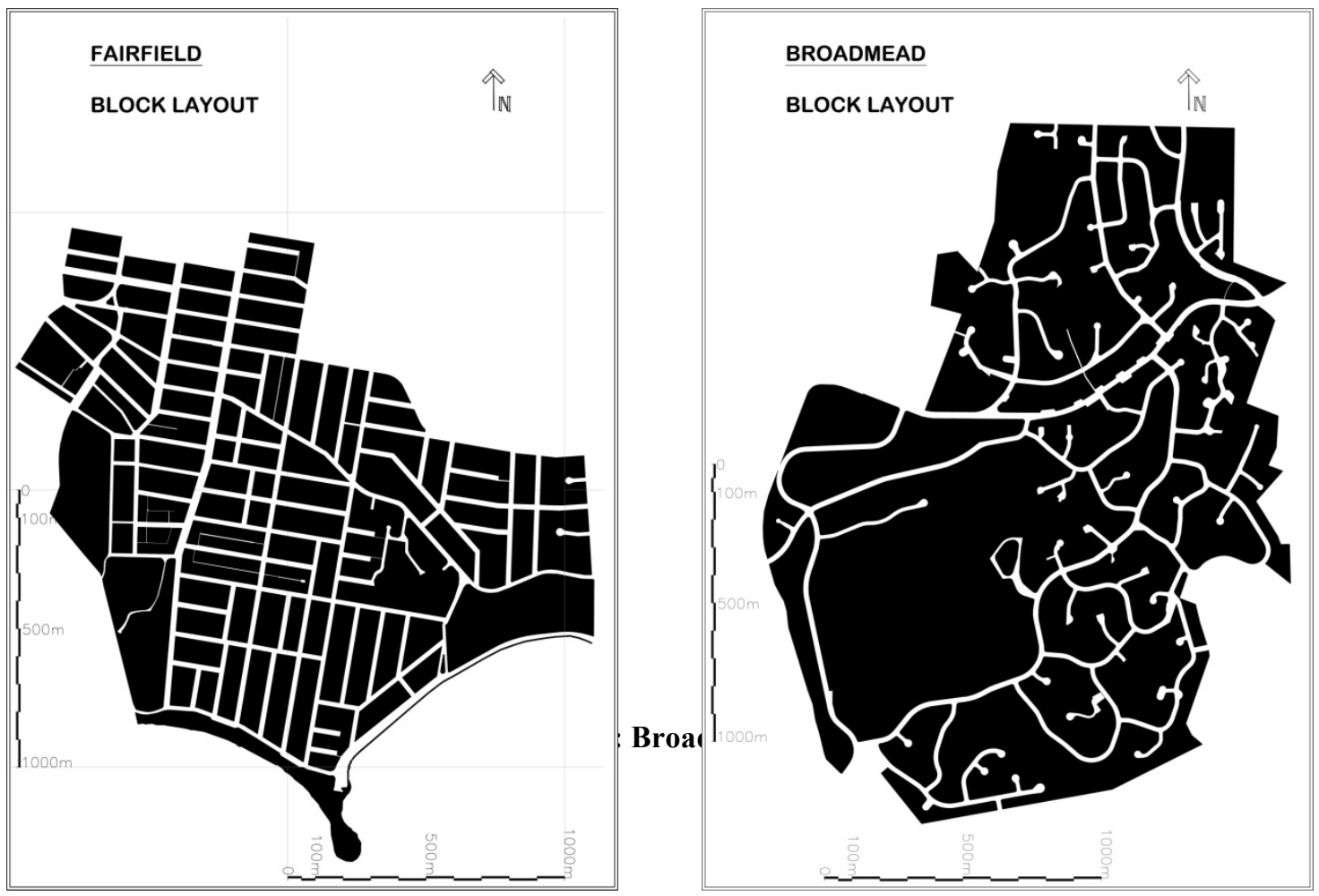

Figure 77: Fairfield Block Layout

\subsection{Pilot Study Liveability Findings}

A total of 47 responses were gathered from the three initial neighborhoods combined (Churton Park-20, Newtown-13, Fairfield-14). The overwhelming consensus from all survey respondents was that they felt their neighborhoods were liveable. That is not to say, however, that residents were entirely happy with every aspect of their neighborhood, and the results reflect clear trends for both liveability satisfaction and dissatisfaction in each case study.

The most common negative responses cited that detracted from survey respondents' assessment of liveability included the lack of local amenity in Churton Park, the excessive traffic in Newtown and the gentrification in Fairfield. Local amenities are the most cited positive liveability aspects for both Newtown and Fairfield, and the presence of parks is the most common liveability aspect in Churton Park. Other salient trends included those for transportation. Churton Park residents both own and use private automobiles more often than the other two case studies; and Fairfield survey respondents report the least car ownership and use. Significantly, however, most respondents report a preference for walking over automobile travel as the main mode of travel. The major themes from the pilot study qualitative survey are summarized and presented in Table 3 . 


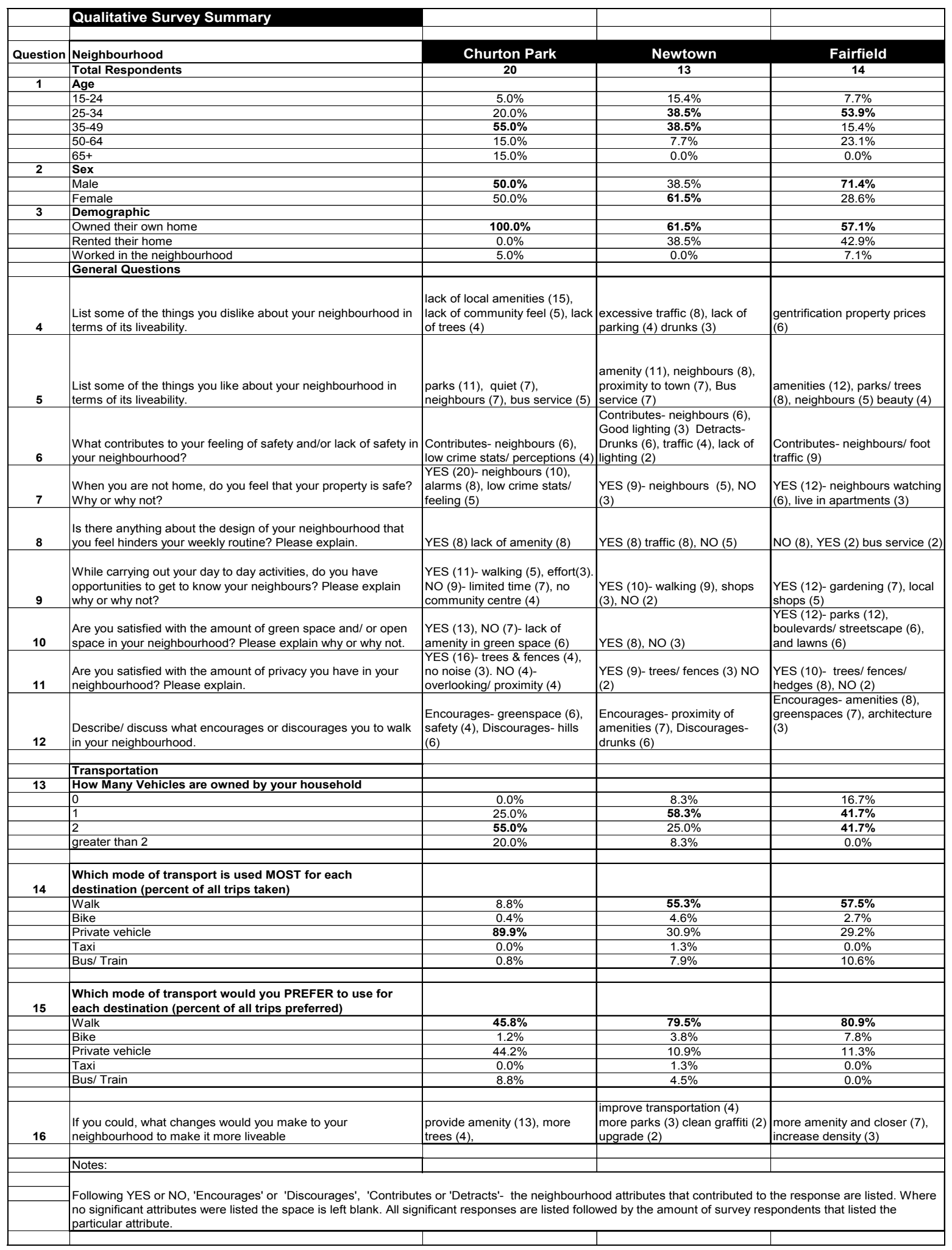




\subsection{Pilot Study Discussion}

A divergent demographic from each neighbourhood returned the liveability surveys. In some cases the survey respondents were relatively representative of their neighbourhood populations. In Churton Park the survey sample male to female ratio and the age profile match the actual population of the neighbourhood. However home ownership rates are reported at $15 \%$ higher than the actual $85 \%$. In Newtown the age profile is representative, but a greater proportion of females replied to the survey compared to the actual neighbourhood proportion. Similarly, home ownership rates among survey respondents are reported as $20 \%$ more than actual rates in Newtown. The high proportion of people over the age of 65 in Fairfield are not represented in the survey, with the majority of responses coming from the middle age group, 25-64. This is most likely due to the method of survey which was mostly conducted on-line. Men in Fairfield were $20 \%$ more representative than the actual population and women equally less representative. Home ownership rates in Fairfield from the survey are exactly the inverse of actual home ownership rates. Forty percent of the population in Fairfield are owner occupiers compared to the survey responses showing $60 \%$ owner occupiers.

Churton Park survey participants are satisfied with the liveability in their neighborhood. However, similar to the findings of a recent report by Wellington City Council (2006), they express a clear desire for increased amenity in the area. Shops, a community centre and a café are commonly suggested amenity improvements. Frequently cited characteristics contributing positively to the neighbourhoods' liveability are the parks and open spaces in Churton Park. Newtown survey respondents, like Churton Park, are satisfied with the liveability of their neighborhood and cite their neighbours as an important contributing factor to its liveability. However, unlike Churton Park, amenity is also a common factor that contributes to the neighbourhood's liveability. Traffic and the associated traffic issues, such as a lack of parking, safety, noise and congestion are often reported in Newtown, and are the largest contributing factor to diminished liveability. Similar to Newtown, Fairfield respondents list local amenities as the greatest contributing factor to the neighbourhood's liveability. The least liveable trend in Fairfield is reported as being the high property prices.

Liveability aspects are not always sustainable. A fondness for neighbours was reported in all neighbourhoods and extends beyond just making the neighbourhoods liveable, but also makes residents feel safe. However, this finding doesn't reveal the characteristics of the relative neighbours that the survey respondents are fond of. These may include similarity to themselves, a middle class status, a set of shared values or any of the potentially negative aspects a sense of 
community may contribute to. ${ }^{582}$ Similarly, parks and open spaces are commonly viewed as a positive liveability aspect, and this is supported in the case studies. However, the quantity of these features may be less important than their design and access to them. This caveat is often overlooked. Some may consider vast open spaces as a liveable feature, but such a benefit may come at the expense of an unsustainable land-use.

The findings from the pilot study suggest that the most useful density measure is gross density measured in conjunction with accessibility and at a neighbourhood scale. Because some neighbourhood boundaries include areas that are inaccessible to residents or include areas that are set aside for future development, an explicit boundary definition allows for an equal comparison between case studies and for future studies. The debate surrounding which form of density measurement is more useful, net or gross, (Jenks and Dempsey, 2005) is less important compared to using precise and consistent measures, as in this study. At the city scale, many measures include large areas of un-developed land or open space within their boundaries which misrepresent their actual densities. Similarly, at a neighbourhood scale, often odd areas are added to the neighbourhood boundary, only to make the boundaries coincide with adjacent areas which may be largely undeveloped. Net density measures restrict the understanding of an area under consideration and exclude mixed uses and the balance of land uses associated with liveable neighbourhoods. Gross densities, on the other hand, consider an area as a whole, the same way as the residents of any neighbourhood would, and go some way to informing liveability aspects within a neighbourhood to permit future comparisons.

\section{Consumer Preference}

In all three case studies a clear preference for dwellings located close to amenities is demonstrated. In both Newtown and Fairfield, one of the most cited 'likes' is the proximity to local amenities and in Churton Park the lack of amenities is a salient 'dislike'. This finding corresponds well with housing aspirations in New Zealand (DTZ, 2005). However, rather than this finding signalling a preference for higher density living, it suggests a preference for the benefits of higher density living without any of the perceived drawbacks. Particularly for Churton Park, this seems to be the case with the stated dislike for higher density building types in a study conducted by the Wellington City Council (2006). This line of reasoning generally follows that of the literature ${ }^{583}$, particularly Samuels's (2005) arguments from the United Kingdom, where he highlights the untenable position of achieving the benefits of higher density while at the same time realising the advantages of a large private lot and unencumbered auto freedom.

\footnotetext{
${ }^{582}$ Thompson-Fawcett \& Bond, 2003

${ }^{583}$ Danielson et al, 1999; Molin et al., 2001
}

112 


\section{Transportation}

Churton Park survey respondents both own more cars and travel via them more often than either of the other case studies. Although private vehicles are the main mode of travel in Churton Park, a preference for walking is reported. Newtown fell in between Churton Park and Fairfield for car ownership with the majority of survey respondents owning just one vehicle. Walking is the most common mode of travel at $55.3 \%$, with even more people (at nearly $80 \%$ or survey respondents) expressing a preference to walk. In Fairfield, a substantial number of survey respondents do not own a car with one saying that they have been car-free as a lifestyle choice. Walking is the main transportation mode in Fairfield, and walking, again, is also the preferred mode of travel.

This reported preference for walking is a significant finding. Within the literature, the case was put forward that auto-orientated neighborhoods are self selected by people who prefer that mode of travel. ${ }^{584}$ While the phenomenon of individuals self-sorting into neighbourhoods that meet their preferences account for a portion of travel behaviour, the built form still exerts an influence even after self-sorting factors are accounted for. ${ }^{585}$ This finding is congruent with the case studies, where a mismatch between travel preferences and travel behaviors was reported.

With the increased time spent in cars reported by Churton Park residents, they appear to be more susceptible to missed opportunities for community interaction, which is one of the side effects of auto-orientated neighbourhoods. ${ }^{586}$ Although, time spent commuting is not specifically referred to in Churton Park, the survey responses suggest a trend toward having less time available compared to the other case studies. Both Fairfield and Newtown report more opportunities to get to know their neighbours, and they cite these opportunities as resulting from foot traffic, the provision of local amenities, and on their walking commutes to and from work.

The reports of traffic issues in Newtown correspond well with the increased density opponents views that higher density increases traffic congestion. ${ }^{587}$ The traffic issues in Newtown include noise pollution and safety, which surveyed residents frequently cite as detracting from their liveability. Fairfield, however, provides an example of a positive relation between higher densities and liveability, without the negative transport externalities reported in Newtown. The high proportion of mixed uses in Newtown as compared to Fairfield may be the greater causal factor. Perhaps there are limits to both the type and distribution of mixed uses that require further exploration and quantification in conjunction with precisely noted locations of main transportation

\footnotetext{
${ }^{584}$ Boarnet \& Crane 2001; Cervero \& Duncan, 2002

${ }^{585}$ Cao et al., 2009

${ }^{586}$ Wilson et. al., 2004; Putnam, 2000

${ }^{587}$ Gordon \& Richardson, 1997
} 
routes. The dominance of the private motor vehicle for the majority of travel in Churton Park corresponds well with the literature, given its built form measurements. ${ }^{588}$ The clear trend toward a preference for walking, however, was a more significant finding.

\section{Affordability}

Higher density proponents claim that higher densities increase affordability through providing, among other savings, more choice which leads to a variety of tenure types. ${ }^{589}$ Here, the findings from the case studies agree with the literature. An equal proportion of Fairfield and Newtown survey respondents list renting as their tenure type compared to $100 \%$ ownership in Churton Park.

It is suggested that a certain number of people are required to support various local amenities. ${ }^{590} \mathrm{By}$ these estimates, there are enough residents to support a small grocery store in Churton Park. However, the quantitative analysis revealed no commercial or mixed uses in the neighborhood.

An estimation of minimum population requirements to support local amenities indicates an over abundance of amenities in Newtown given its population. ${ }^{591}$ Newtown appears to be supporting facilities and amenities far beyond the minimum required population levels. This may indicate that Newtown is attracting users from outside the neighborhood which in turn may be affecting the survey respondents' reports of traffic concerns.

A Fairfield respondent specifically noted the density of their neighborhood in an unprompted survey question, that in their opinion was meeting the density requirements to support a vibrant village centre. He states that " $[t]$ here is sufficient density around Cook Street Village to provide sufficient people with seemingly adequate buying power to maintain a viable 'village'.” Two thirds of all dwellings in Fairfield are apartments which may explain how this sufficient density is achieved.

\section{Environment/ Green Space}

Both proponents and opponents of high density claim that more space is available with their preferred settlement pattern. ${ }^{592}$ The findings in the three case studies show mixed results. Fairfield has the highest density and least amount of open space; Newtown has the second highest density and the greatest amount of open space; Churton Park has the second lowest density and the second

\footnotetext{
${ }^{588}$ Williams et al., 2000; Calthorpe, 1993; Jenks \& Dempsey, 2005

${ }^{589}$ Burton, 2002; Duany, 2000; Calthorpe, 1993; Rogers, 1999

${ }^{590}$ Bartlett, 2005

${ }^{591}$ Bartlett, 2005

${ }^{592}$ Ewing, 1997; Gordon \& Richardson, 1997

114
} 
greatest amount of open space; and Broadmead has the lowest density and third greatest amount of open space. The qualitative findings, however, suggest that it is not the quantity of open space that improves liveability, but rather the quality of it and accessibility to it. Survey respondents for both Newtown and Churton Park are not totally satisfied with their open spaces. Fairfield survey respondents, on the other hand, are overwhelmingly positive about their open space. This is particularly interesting when the quantitative analysis revealed that Fairfield has the least amount of open space of all three case studies. However, Fairfield open space does include the waterfront. Newtown respondents express a desire for a greater quantity of open space while Churton Park respondents want more amenities within their open spaces. Access to Newtown's parks is the worst of all three case studies, which may explain this paradox. Access to Churton Park's open spaces is the greatest of all three case studies; this may point to a quality issue being the source of dissatisfaction.

The findings for the overall densities of each neighbourhood show empirically larger numbers of people living on less land and the survey responses relate this experience to positive perceptions of liveability. This supports the literature that relates increased density to less land consumption as a positive result of higher density land-use patterns. ${ }^{593}$

\section{Health}

The main health related liveability aspect surveyed was for neighborhood walkability. The green spaces and parks, as well as the relative safety in Churton Park, are mentioned most often in terms of neighborhood features that encourage walking. The proximity of local amenities is the most salient neighborhood feature that encouraged walking in Newtown. The presence of undesirables discourages walking in Newtown; however this is only reported for walking at night. This finding may relate to the type of land use mix in the neighborhood where there is a large proportion of social housing present. Walking in Fairfield is generally encouraged by the same factors that contribute to the overall liveability of the neighborhood. These include the local amenities, parks and open spaces.

Noise also relates to liveability and health, and some authors portray higher density developments as a compromise to the single family dwelling, rather than the exercise of some preferences over others in this respect. ${ }^{594}$ In Fairfield however, survey respondents did not raise any noise related problems; but in Newtown, respondents list noise problems that are related to traffic and construction. Within the literature, higher densities are associated with a potential for negative

\footnotetext{
${ }^{593}$ Kunstler, 1994

${ }^{594}$ Morrison \& McMurray,1999; Syme et al., 2005; Turner et al., 2004
} 
noise related issues ${ }^{595}$, however, Fairfield provides a contrary example. There still may exist certain thresholds of density beyond which noise becomes a problem but the findings in the case studies suggest that noise is more related to accessibility, connectivity and mixed uses. On the other hand, Churton Park survey respondents consistently cite the quiet nature of their neighborhood as a positive liveability aspect. A number of factors have a greater influence on the ambient noise levels within a dwelling that may be more related to construction materials, accessibility and mixed-uses as opposed to levels of urban density.

\section{Crime and Safety}

One of the staples of defensible space theory, which is reflected in conventional subdivision design, advocates maximising privacy. In all three case studies however, the presence of neighbours and their eyes on the street is cited as the most salient factor contributing to a sense of safety. This finding reflects the literature which supports increases to density to increase safety. ${ }^{596}$

Neighbors are the main factor contributing to the perceived safety of both properties and residents in Churton Park. Survey participants feel that both the presence and homogeneity of residents in the neighborhood ensured their safety. Churton Park is also, interestingly, the only neighborhood where people cite having an alarm as contributing to their sense of safety.

The presence of undesirables ('drunks' and 'weirdos') is commonly cited as detracting from liveability in terms of safety, discouraging walking at night, and as a general dislike in Newtown. Newtown is also the only case study where respondents reported feeling that their property is not safe when they are not at home. The survey results also show that living in an apartment adds to a sense of safety in both Fairfield and Newtown.

As in Churton Park, Fairfield residents find their neighbors contributed to their sense of safety. They reported that knowing their neighbors were home or out and about provided surveillance, which in turn improved their sense of safety.

Newtown survey responses suggested disquiet with safety in their neighbourhood. Although both Newtown and Fairfield have traditional physical urban patterns similar to the New Urbanist ideal, the relative mix of land uses may be of greater significance to the actual and perceived safety of surveyed residents. Hillier and Sahbaz (2005) suggest that having a greater proportion of residential to non-residential development is the key to crime reduction. A relatively high proportion of land is

\footnotetext{
${ }^{595}$ Lyne, 2004

${ }^{596}$ Greene \& Greene, 2003
}

116 
devoted to council housing in Newtown, which is often housing of a last resort and is associated with many of the problems common to socio-economic disadvantage. A high proportion of this type of housing in the neighbourhood both concentrates disadvantage and increases the exposure of other residents to it.

\section{Community}

In Churton Park there is an almost 50-50 split between residents who feel they have opportunities to get to know their neighbors and those that do not. This finding represents the most infrequent report of opportunities to get to know neighbors compared to both Fairfield and Newtown which report more opportunities. In all three case studies, walking facilitates the majority of opportunities to get to know neighbors. Local amenities are commonly cited as also providing civic opportunities and the lack of such facilities is reported in Churton Park as detracting from these opportunities.

Issues regarding community development relate to the effect mixed uses have on providing a setting for community interaction. ${ }^{597}$ The case studies conform with the notion that mixed uses, higher connectivity, increased accessibility and higher density contribute to a sense of community, through increased opportunities for social interaction. Both Newtown and Fairfield residents report proportionally more opportunities to get to know their neighbors while carrying out their day to day activities, than those in Churton Park. Local amenities are one of the main factors contributing to their increased neighborly interactions, and in Churton Park the lack of such amenities is specifically cited as detracting from their opportunities.

\subsection{Pilot Study Conclusion}

The findings from the pilot study illustrate both positive and negative density-liveability relationships in three case studies. Further, these results reflect the extant literature, and add evidence to the arguments for changes to current land-use practices. Liveability outcomes are found to be both positive and negative at all levels of density; high, medium and low. Understanding the built form and the liveability correlatives can be better achieved by combining, rather than isolating, explanatory measurable variables. Accumulative relationships amongst many variables may inform how to achieve positive liveability outcomes. In this regard, the pilot study methodology shows merit. With similar studies on a greater scale, applicable thresholds could

\footnotetext{
${ }^{597}$ Bentley et al., 1999 in McIndoe et. al. 2005; CABE, 2005
} 
emerge for levels of mixed use, connectivity, accessibility and density to facilitate opportunities for improved liveability.

The age of the case study neighborhoods influenced their proximity to city centers and also their layouts. Although this may have affected the findings, the important factor remains that many of the issues fringe suburbs face relate to their location. The potential for neighborhoods to be located near city centers or commercial hubs decreases with low density urban forms. Comparing liveability outcomes between these differing urban forms, when proximity to commercial centers plays an important role in determining both mode choice and amenity possibilities, may at first appear questionable. However, this misses the point. The aim was to explore liveability amongst different land-use patterns where proximity is included as an explanatory element.

While carrying out this research, the relation various physical attributes had with each other and the neighborhood as a whole were not entirely illustrated by the quantitative measures. This was particularly true for the presence of traffic issues in Newtown and lack of them in Fairfield. Although Fairfield had a greater density, reports of traffic nuisance was less than for Newtown or Churton Park. A numerical expression, that captures where mixed uses and traffic generating uses are located in relation to the rest of the neighborhood, would both better inform policy, and avoid subjective assessments. In Fairfield, the majority of commercial activities are located on the edges of the neighborhood, compared to through the middle, as in Newtown. This layout may contribute to the relative lack of traffic noise in the neighbourhood centre, with the majority of traffic directed around it. This view is somewhat at odds with contemporary urban design and Transit Orientated Development, where nodes of commercial use occupy the centre of neighborhoods. Research towards identifying limits to mixed uses, where they are distributed, how they are accessed and how they are connected may prove beneficial.

A move toward a higher density urban form appears warranted in the context of the pilot study. However, caution must be exercised in terms of how higher densities are achieved, where intensification is located, what and where land use mixes are integrated and where improved access and connectivity is targeted.

An expressed travel preference toward alternatives from the car was also found in all three case studies. This finding is significant, and guides the main research toward further exploring the determinants of travel behaviour. Instead of people self-selecting neighbourhoods that met their 
travel preferences, as self-selection explanations of travel behaviour would suggest ${ }^{598}$, the pilot study found that regardless of the type of neighbourhood the respondents resided in, the majority of survey participants preferred alternatives to private auto-mobile travel. This preference extends beyond that found in previous studies, where approximately a quarter of residents' preferences are not matched to the type of neighbourhood they reside in. ${ }^{599}$ This finding raises the question of whether or not residents are self-selecting themselves into neighbourhoods that meet their travel preferences and if this would be the case with a larger sample capable of generalizing to the greater population. However, a number of studies appear to be relatively conclusive on this inquiry.

Generally, about a quarter of residents in both traditional and conventional neighbourhoods are mismatched in terms of their travel preferences and actual travel behaviours. ${ }^{600}$ In these studies, psychological and personality variables are used to explain this mismatch. Personality characteristics such as being an adventure seeker, organizer, loner, or calm ${ }^{601}$ are used to segment sample populations, and from this, certain characteristics appear highly correlated to actual travel behaviours. Similarly, psychological attributes like being a status seeker, workaholic, family or community orientated and frustrated are commonly correlated to travel behaviour and used to account for it. Even more elaborate population classifications result in groups such as malcontented motorists, complacent car addicts, die hard drivers, aspiring environmentalists, car-less crusaders, and reluctant riders. ${ }^{602}$ Although actual travel behaviours can be related to and correlate well with a psycho-graphically segmented sample population, this classification still does little toward understanding the mechanisms underlying these psychological dispositions. Therefore a preceding question generated from the mismatch between survey respondents' travel preferences and their actual travel behaviours in the pilot study concerns how travel behaviour is influenced rather than focusing on what factors are correlated to it. The following chapters outline the important role attitudes play in determining an individual's behaviour and from this, the main research question looks to identify how travel attitudes are formed.

\footnotetext{
${ }^{598}$ Boarnet \& Crane 2001; Cervero \& Duncan, 2002

${ }^{599}$ Schwanen \& Moktarian, 2005

${ }^{600}$ Schwanen \& Mokhtarian, 2007; Schwanen \& Mokhtarian, 2004; Redmond, 2000; Levine \& Frank, 2007.

${ }^{601}$ Schwanen \& Mokhtarian, 2007; Redmond, 2000

${ }^{602}$ Anabel, 2005
} 


\section{Forming Travel Attitudes -Main Study Methodology}

A strong link between travel attitudes and travel behaviours is well established. Attitudes have also been convincingly correlated to neighbourhood preferences. However, why there is an association or more importantly, how the built environment and psychological dispositions influence this connection is largely unexplored. Instead of viewing attitudes as antecedent to behaviours, this dissertation proposes the hypothesis of post-decision reasoning to explore the possibility of travel attitudes as subsequent to neighbourhood location decisions. The three case studies that were the subject of the pilot study described earlier (Churton Park, Newtown, and Fairfield), with the addition of another conventional neighbourhood, are also used as the subject of the main research. The fourth neighbourhood, Broadmead, balances the types of neighbourhoods examined. With its inclusion there is a traditional and a conventional neighbourhood in each country that the present study is concerned with, New Zealand and Canada.

This chapter begins by further elaborating on the idea behind post-decision reasoning and the relative similarities between it and cognitive dissonance. Following this introduction, the difficulties around the reflection problem and self selection problem commmon to studies that examine the effect of neighbourhoods on behaviour is discussed. An introduction to the constructs used for the quantitative survey is then presented. Subsequent to this, the methodology used to analyse this survey is depicted. The theoretical underpinnings of the qualitative survey, as well as the elements and questions of this second survey end out the chapter.

It is proposed that preferences are a factor of attitudes which are governed not by innate moral compasses but instead by the previous choices and decisions an individual has taken. The term used to describe this process within the current dissertation is post-decision reasoning. It is argued that the choices an individual makes have a reverberating effect not only on future decisions but also on the way in which decisions are made in general, and further affect even the values and beliefs individuals hold. This process continually refines the schema used by individuals to understand the world. Values, beliefs and subsequent attitudes are then informed by this process and expressed as preferences. In a sense it is argued that individuals' values and beliefs are partly the sum of their decisions and choices.

Post-decision reasoning is akin to escalated commitment, cognitive dissonance and even habit. Escalated commitment usually refers to only negative situations where an individual justifies initial 
decisions in the face of mounting negative consequences. ${ }^{603}$ However, post-decision reasoning better reflects obtaining justification for previous judgements and reasoning based on them regardless of negative or positive objective or subjective perceived consequences. The difference between escalated commitment and post-decision reasoning is similar to habit formation. Habits form within a stable context where certain behaviours result in certain outcomes. If the outcomes are positive, or at least perceived to be more positive than negative on balance, then habits form. However, if a behaviour results in a negative outcome then it is unlikely for that behaviour to become habitual. Cognitive dissonance best captures the idea behind post-decision reasoning. Cognitive dissonance is perhaps one of the most pivotal theories in social psychology and also one of the most widely debated. ${ }^{604}$ The theory of cognitive dissonance suggests that individuals need consistency among their attitudes and behaviours and any inconsistency between them provokes a state of imbalance or 'dissonance' that motivates behavioural or attitudinal change to increase consistency. ${ }^{605}$

In terms of travel behaviour, the implication is that once an individual has selected a neighbourhood to reside in, negative aspects of that decision may be downplayed in order to gain satisfaction from his initial decision. Due to the relation between travel behaviour and neighbourhood selection, travel behaviour may be one of the negative aspects of choosing where to reside. To foster satisfaction from a decision, it may be necessary to form or change some beliefs and attitudes that are counter to sustainability but congruent with the choices one has made. This relationship can go both ways, where individuals in traditional neighbourhoods may under-report negative aspects of their neighbourhoods (such as privacy issues, ageing housing or traffic and space constraints) and individuals in conventional neighbourhoods may under-report negative aspects of their neighbourhoods (such as a reliance on the private automobile, extensive and expensive yard-work, or expensive energy requirements). Similarly, positive aspects of neighbourhoods may also be subsumed as pre-existing preferences. Initially an individual may not have considered environmental issues in their decision to locate in a certain neighbourhood. However, in retrospect they may determine an ability to afford to hold environmental values without contradicting their previous choices, and as such misremember their initial motivating factors for locating in a particular neighbourhood to include environmental considerations. If an individual's context affords them the opportunity to affiliate themselves with positive aspects of whatever that context may be, they most likely will, knowingly or not. The focus for this dissertation, however, is clearly on the travel related aspects of residential location choices. Beyond

\footnotetext{
${ }^{603}$ Brockner \& Rubin, 1985; Staw \& Ross, 1989

${ }^{604}$ Harmon-Jones and Mills, 1999

${ }^{605}$ Festinger, 1957
} 
simply the under-reporting of negative aspects of an individual's decisions, this process is posited as contributing to the reasoning apparatus used by individuals to interpret the world at large. This interpretation may even extend to subjects such as belief in global warming, beliefs about the effects of excessive car use, political affiliations, attitudes toward privatization and value positions on self-interest to placing the interests of the community or the environment first.

There are two key problems fundamental to research involving estimating the effect of neighbourhoods on behaviour. These are referred to as the reflection problem and the self-selection problem. ${ }^{606}$ The difficulty these problems pose relates to the challenge of identifying what exactly is influencing the effect under consideration (travel attitudes in this case) within a neighbourhood setting.

The reflection problem relates to distinguishing between endogenous and contextual effects that are together referred to as neighbourhood effects. ${ }^{607}$ Broadly neighbourhood effects relate to:

"a social interaction that influences the behavior or socioeconomic outcome of an individual. Neighborhood effect research includes, but is not restricted to, models of endogenous preference effects, peer effects, and compositional effects. Neighborhood effects also include influences on individual behavior or outcomes due to the characteristics of an individuals' neighbors and neighborhood." 608

An endogenous effect refers to the propensity of an individual to behave in some way that varies with the average behaviour of the group. For example if an individual's travel behaviour is correlated to the average travel behaviour in the neighbourhood. If the average travel behaviour in the neighbourhood changed, the individuals travel behaviour would then also change. A contextual effect relates to the propensity of an individual to behave in some way that varies with the average background characteristics of the group. For example if an individual's travel behaviour changed as the average income in his neighbourhood changed. It is important to know the difference between these two effects in order to effectively target policy. It is also argued that it is impossible to establish the degree of influence endogenous effects or contextual effects have on behaviour within a neighbourhood setting without prior knowledge of the reference group characteristics. ${ }^{609}$

\footnotetext{
${ }^{606}$ Manski,1993

${ }^{607}$ Dietz, 2002

${ }^{608}$ Dietz, 2002 p 540

${ }^{609}$ Manski, 1993
} 
While the proposition of peer influence or normative influence as it is known in environmental psychology is suggested within the current research to influence travel attitudes, no attempt has been made to establish this. The focus is clearly on determining the influence a neighbourhood may have on travel attitudes while accounting for the various other variables that may also influence them. This dissertation ignores questions relating to the distinction of underlying mechanisms through which neighbourhood effects operate (for example the distinction between endogenous and contextual effects). While distinguishing Manski's endogenous and contextual effects would clearly be of interest, solving the self-selection issue is considered a precondition, leaving the identification of particular mechanisms for future research.

The second issue with neighbourhood effect research is that of the self-selection problem. The self selection problem relates to distinguishing what effects are acting on the outcome under consideration (travel attitudes) between neighbourhood effects (endogenous effects and contextual effects taken together) and correlated effects. Correlated effects refer to unobserved similarities in residents that influence them to locate within certain neighbourhoods. Correlated effects arise because individuals are not randomly distributed across different neighbourhoods and instead sort themselves into neighbourhoods on the basis of their personal and family background characteristics (for example, income, ethnicity). Some of these characteristics may influence the effect under consideration.

The problem of self-selection arises because the statistical estimation of such a proposition requires observed explanatory variables to be uncorrelated with unobserved explanatory variables. ${ }^{610}$ In other words, this problem will occur if relevant attitudes are unmeasured and if they also influence residential location, in effect influencing what environmental characteristics the individual experiences. This is related to determining the direction of causality. The neighbourhood an individual resides in may influence travel attitudes, or alternatively the travel attitudes an individual holds may influence what neighbourhood they decide to reside in. Standard econometric methods are unable to distinguish between two-way causality and may consequently yield biased results. ${ }^{611}$ That said a number of studies within transportation research readily separate out the influence of correlated measures. This is true for travel behaviours like car use in general ${ }^{612}$, restricting car use $^{613}$, changing travel modes ${ }^{614}$ and the acceptability of alternative transport policies ${ }^{615}$. The assumption within these studies is that the method of statistical control includes the factors known

\footnotetext{
${ }^{610}$ Cao et al, 2009

${ }^{611}$ Blume and Durlauf, 2006

${ }^{612}$ Bamberg \& Schmidt, 2003

${ }^{613}$ Kaiser \& Gutscher, 2003

${ }^{614}$ Bamberg, 2006; Heath \& Gifford, 2002

${ }^{615}$ Garling \& Schuitema, 2007
} 
to influence residential location decisions (socio-demographics) and "explicitly accounts for the influences of attitudinal factors in analyzing travel behaviour, by measuring them and including them in the statistical equation (thereby moving them from unobserved to observed)". ${ }^{616}$ The research design within this dissertation uses these same attitudinal factors to help control for unobserved variables.

The research design adopted further aims to circumnavigate the statistical self-selection problem of disentangling endogenous effects from correlated effects by correlating travel attitudes to effects that clearly cannot be associated with an individual prior to his residence in a neighbourhood, these being place attachment and length of tenure.

\subsection{Measuring Moving Targets}

The ubiquity of studies that rely on the assumption of stable preferences and attitudes may be a factor of the difficulty involved in measuring them. This difficulty relates to the problems associated with assessing attitude change and measuring cognitive dissonance, as well as the type of complex research designs required and available data sets.

A thorough assessment of attitude change ideally would use longitudinal instead of cross sectional data. ${ }^{617}$ Here within subject measures could evaluate attitude change over time instead of either retrospectively or between subjects, as in data obtained at one point in time. While longitudinal data would be ideal, obtaining and assessing these data was beyond the scope and budget of this dissertation. Similarly, structural equation models have been stressed as important to the study of attitude change. Structural models present the ability to test qualitatively established theory and, perhaps more importantly to the issue of causality, can statistically test the direction of correlations. ${ }^{618}$ Although difficult to apply to the study of social phenomenon in the "real world", experimental studies would also go some way to measuring attitude change. ${ }^{619}$

Many of the issues that the study of travel attitude change has faced have also been present in research on cognitive dissonance. An important issue to the study of cognitive dissonance is the timing of measurement. Attitudes must be assessed prior to and after certain decisions have been

\footnotetext{
${ }^{616}$ Cao et al., 2009

${ }^{617}$ Schwanen \& Mokhtarian, 2007

${ }^{618}$ Hoyle, 1995

${ }^{619}$ Handy et al., 2005
}

124 
made, and data here is lacking. ${ }^{620}$ Similarly, when survey subjects are cognizant of data given prior to a choice, their evaluation and subsequent responses post choice may be influenced. Almost ironically, this may be an effect of cognitive dissonance where survey participants' aim to minimize the discrepancy between original and post attitudes. An individual may initially indicate a preference for a certain choice and then after the choice has been taken, may dislike the result but still indicate favourable attitudes toward the choice to appear congruent with their initial evaluations. Some authors have even suggested that this is done without the knowledge of the subject. ${ }^{621}$ Similarly a retrospective evaluation of attitudes will give little indication of actual attitudes, especially after a decision has been taken based on those attitudes. In fact measuring cognitive dissonance has been largely abandoned and replaced with consumer preference studies. This change has more to do with the difficulty of measurement than a loss of interest or a disproving of the theory. As such, there is no established scale to assess cognitive dissonance.

Despite the difficulty in measuring cognitive dissonance, a review of numerous studies established that choice plays an important role in eliciting dissonant mitigation techniques. ${ }^{622}$ This is particularly important to the theory of post-decision reasoning introduced in the present study, because for every preference study conducted, all data yielded is influenced by the participants' actual neighbourhood location choices. From this perspective, it is impossible to establish what the effects of future land-use patterns or policy interventions will have on individuals simply because there is no tabula rasa, which all previous studies assume. In this sense, we cannot limit the possibilities of the future based solely on the tendencies of the past.

Some argue that the data required to properly assess attitude change and hence establish travel behaviour causation is untenable. ${ }^{623}$ The fact that the data required would need to account for countless exogenous factors also poses many problems. Travel attitudes may be influenced by land use policies, transportation investments, national identities, political forces and may also be a factor of present land-use patterns. ${ }^{64}$ For these reasons some authors conclude that at present, "reliable predictions of the impacts of new transportation investments on land development patterns or land use and design strategies on travel behaviour will themselves remain elusive. ${ }^{.625}$

\footnotetext{
${ }^{620}$ Montgomery \& Barnes, 1993

621 Chen, 2008

${ }^{622}$ McElrath, 2004

${ }^{623}$ Schwanen \& Mokhtarian, 2007

${ }^{624}$ Handy et al., 2005

${ }^{625}$ Handy, 2005, p 167
} 


\subsection{Methodology Constructs}

While psychological measures are replacing socio-demographic factors for the prediction of travel behaviour, typically they are used as correlatives to behaviour only. The use of psychological variables, particularly attitudinal variables, are commonly used in self-selection studies to demonstrate an array of attitudes that are then correlated to changes in car use, ${ }^{626}$ walking frequency, ${ }^{627}$ travel mode choices, ${ }^{628}$ trip frequencies by varying modes of transport, ${ }^{629}$ trip distances ${ }^{630}$ and number of private vehicles owned ${ }^{631}$. Most existing studies use attitudes to predict certain behaviours. The aim of many of these studies is to address the spuriousness issue due to the insight of agency that has undermined previous correlations between the built environment and travel behaviour. In this regard these studies have successfully established a remaining correlation between the built environment and travel behaviour while accounting for self selection. ${ }^{632}$ However, how the built environment influences travel behaviour is still largely ill defined. In many cases a causal inference is not even made. To examine how the built environment may be affecting travel behaviour this dissertation looks to predict travel attitudes from variables that have theoretical links to the built environment, namely place attachment and length of tenure as indicators of post-decision reasoning. The remaining constructs employed to understand travel behaviour were adopted from a number of studies and include typical socio-demographic variables, travel mode preferences, both stated and conjoint neighbourhood preferences, problem awareness, perceived behavioural control, moral norms, personal responsibility, and the dependent variable of travel attitudes.

Personality factors are largely not included with the constructs presently used. Although they are prevalent in many previous travel behaviour studies ${ }^{633}$ they are without the theoretical background to attribute them any explanatory value to how the built environment influences travel behaviour, beyond distinguishing groups of people that may be more receptive to changes from the conventional. Whether or not some individuals may be gas guzzling, die-hard driving, environmental plundering status seekers, or eco-friendly, environmental crusading, self actualized walkers appears less important to closing the attitude-behaviour gap that may be a result of the

\footnotetext{
${ }^{626}$ Hammond, 2005

${ }^{627}$ Clifton \& Handy, 2001; Cao, Handy, et al., 2006

${ }^{628}$ Cao, Mokhtarian, et al., 2006; Schwanen \& Mokhtarian, 2005b; Pinjari et al., 2007; Scheiner \& Holz-Rau, 2007;

${ }^{629}$ Cao et al, 2005; Kitamura et al., 1997; Schwanen \& Mokhtarian, 2003; Boarnet \& Sarmiento, 1998; Greenwald \& Boarnet, 2001; Khattak \& Rodriguez, 2005

${ }^{630}$ Schwanen \& Mokhtarian, 2005b; Vance \& Hedel, 2007; Cao, 2008; Bagley \& Mokhtarian, 2002

${ }^{631}$ Bhat and Guo, 2007; Chen et al., 2008Cao et al., 2007a

${ }^{632}$ Cao et al., 2009

${ }^{633}$ Anabel, 2005; Steg, 2005; Joireman et al., 2004

126
} 
limiting influence the built form plays on positive environmental behaviour. This segmentation of personality types typically is used within marketing strategies to tailor consumer messages, or in the case of travel behaviour, to tailor policy, which better addresses the varying motivations and behaviour drivers different groups of people may have. This line of research may prove valuable to informing policy but does little toward understanding how the built environment may be influencing attitudes and subsequent behaviour.

\subsection{Stated and Revealed Preferences}

The specific travel and neighbourhood preferences of each case study participant provide an initial construct for this dissertation's survey. Stated neighbourhood preferences used in this survey were adopted from a study conducted by Schwanen and Mokhtarian (2007). This study used thirty two attitudinal statements that were factor analysed with oblique rotation into six main attitudinal groups. Factor analysis is used to determine the internal consistency of a number of factors aimed at measuring a particular attribute. ${ }^{634}$ From these attitudinal groups their sample population was segmented into individuals who were in favour of suburban housing, in favour of higher density housing, in favour of environmental solutions, in favour of highway travel, believed their commute provided them with some benefit, and individuals who expressed a desire to not restrict their travel freedom. In each grouping, two or three survey questions established membership within the group. However, many of these attitudinal statements better resemble stated preferences rather than attitudes, and as such only the pro-suburban housing and the pro-high density questions were garnered for the purposes of the stated neighbourhood preference construct. These survey questions are presented below and employ a five-point Likert-type scale ranging from strongly agreeing to strongly disagreeing.

\section{Stated Neighbourhood Preference questions:}

1. Pro-suburban housing

a. I like to have a large yard at my home

b. Living in a multi-family unit wouldn't give me enough privacy

2. Pro-High Density

a. I like living in a neighborhood where there is a lot going on

b. Having shops and services within walking distance of my home is important to me

Assessing travel mode preferences is established with a simple two part stated preference question. The first question asks what mode of travel is typically used to access places important to the

${ }^{634}$ Field, 2005 
survey participant on a weekly basis. The second question asks which mode of travel they would prefer to take. A variety of travel modes are presented and include private-automobile, bus, train, walking, cycling, taxi, or other.

There are, however, a number of problems with stated preference questions. The first is that stated preference questions are hypothetical. In this sense, an individual is free to express whatever preference he may wish to convey without experiencing the repercussions that an actual choice would entail. ${ }^{635}$ In a more theoretical sense, stated preference questions also assume rationality consistent with utility theory. ${ }^{636}$ Utility theory assumes that preferences are stable and aimed at increasing personal utility. As discussed previously, this may not be the case. Often when situations occur with which a decision maker has no previous experience, he may construct his preferences then and there, from whatever information is available and, most importantly, may not be rational or utility seeking in this construction. ${ }^{637}$ Despite these problems, within transportation forecasting, stated preference surveys are frequently relied on to assess the impact of transport policies on travel demand. ${ }^{638}$ Revealed preferences, on the other hand, are the assumption of the execution of preferences and are the observed choices individuals make. While observing the choices individuals make may on the surface appear to better reflect actual preferences, revealed preferences may only indicate constraints on actual preferences. ${ }^{639}$ The numerous studies that indicate discrepancies between stated and revealed preferences ${ }^{640}$ can be interpreted either way. One can infer that revealed preferences are more accurate of actual preferences or that stated preferences are more accurate of them, and revealed preferences only indicate the barriers to actual preferences.

To avoid some of the difficulties with stated preferences some authors have suggested using both stated as well as revealed preferences together. ${ }^{641}$ In transportation studies as well as health studies this has proved beneficial and correlations exist between both types of preferences, indicating a close approximation to actual preferences. ${ }^{642}$ Revealed preferences are interpreted as where survey participants currently reside and stated preferences are assessed through the constructs described. The literature recommends a careful consideration of surveys designed to elicit preference, ${ }^{643}$ and

\footnotetext{
${ }^{635}$ McFadden, 1999

${ }^{636}$ Ryan et al., 2008

${ }^{637}$ Gigerenzer and Todd, 1999; Payne et al., 1999

${ }^{638}$ Fujii \& Garling, 2003

${ }^{639}$ Garling \& Auxhausen, 2003

${ }^{640}$ Bates, 1988; Ben-Akiva et al., 1989

${ }^{641}$ Louviere et al., 2000

${ }^{642}$ Mark \& Swait, 2003; Hensher \& Bradley, 1993; Sakano \& Benjamin, 2008

${ }^{643}$ Baron, 1997; McFadden, 1998, 1999; Smith, 1992 
as such, a tertiary examination of preferences is gained through a set of conjoint neighbourhood preference questions.

\subsection{Conjoint Neighbourhood Preferences}

Conjoint preference analysis is similar to stated preferences in that it too is based on a hypothetical situation and also relies on a utility maximization theory. ${ }^{644}$ Where it differs is in how stated preferences are elicited. Instead of choosing one option over another or ranking one option higher than the other, conjoint analysis recognizes that most real world decisions rely on certain compromises. ${ }^{645}$ This aspect of conjoint analysis is said to be well suited to model actual travel choices because it provides an understanding of what type of physical features consumers are willing to trade. ${ }^{646}$ Conjoint preference data has been shown in transportation studies to provide a relatively good fit to actual revealed preference data with the added benefit of including psychological predispositions in situations where revealed preferences cannot be reflected in actual market conditions. ${ }^{647}$

The development of conjoint analysis is well documented in a series of reviews in marketing research literature. ${ }^{648}$ However, the criticisms of stated preference surveys are also relevant to conjoint preference surveys. Some authors point out that "even in conjoint analysis, requesting respondents to choose among a finite set of hypothetical neighbourhoods, little is known about which alternatives are really taken into consideration and which are discarded immediately". ${ }^{649}$ Despite these criticisms, combing the three methods of preference analysis, conjoint, stated and revealed, strengthens the methodology and provides a realistic perspective of the decision making process involved in choosing a neighbourhood to live in. As such, a number of conjoint measures were adopted from a study conducted by Levine and Frank (2007). Their study looked at neighbourhood preferences and highlighted an "undersupply of compact, walkable, and transitfriendly neighbourhoods relative to current demand." ${ }^{, 550}$ Their conjoint analysis questions captured a realistic framework for the current housing market, where typical characteristics of conventional neighbourhoods (such as larger lots and newer houses) were traded against traditional

\footnotetext{
${ }^{644}$ Gustafsson et al., 2007

${ }^{645}$ Oppewal \& Timmermans, 1999

${ }^{646}$ Carr, 2008

${ }^{647}$ Louviere, 2001

${ }^{648}$ Green \& Srinivasan, 1990; Böcker, 1986; Huber, 1987; Louviere, 1988

${ }^{649}$ Morrow-Jones et al., 2004

${ }^{650}$ Levine \& Frank, 2007, p255
} 
neighbourhood attributes such as more amenity provision and less reliance on the private automobile. These conjoint decisions were presented with the caveat that either neighbourhood type (conventional or traditional) was equal in cost. Although this may not be the case in the real market, this allowance was made to understand the relative market supply rather than determine what consumers would be willing pay. In this dissertation's survey, equal costs between conjoint choices is maintained, not to determine market supply, but to control for costs so as to focus on the built form elements being considered.

The development of the adopted Levine and Frank (2007) conjoint survey questions underwent considerable design. They were subject to pilot studies and successive post-modifications that ensured the questions reflected the intent of the study and were interpreted correctly. Similarly, the questions were designed to make both neighbourhood types equally desirable and realistically equal in price. A total of seven conjoint neighbourhood preference questions were adopted from the Levine and Frank (2007) study and asked in this dissertation's survey. An example of the type of questions in the current survey is below (Figure 80) and the full survey is included in the Appendix four.

A.

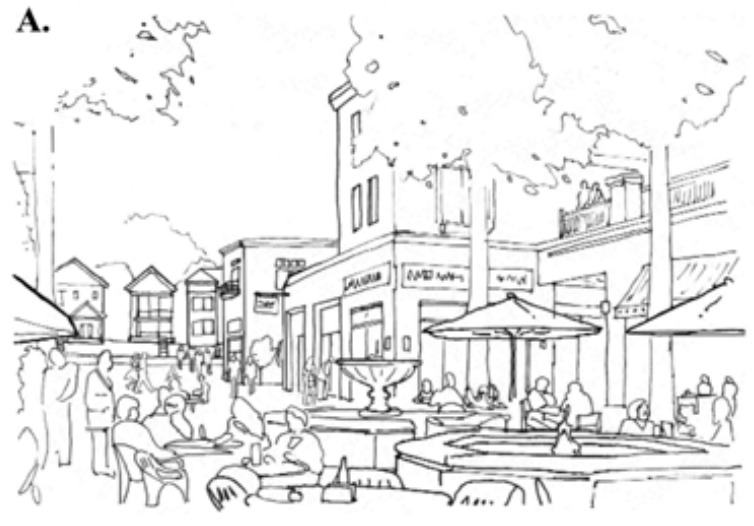

B.

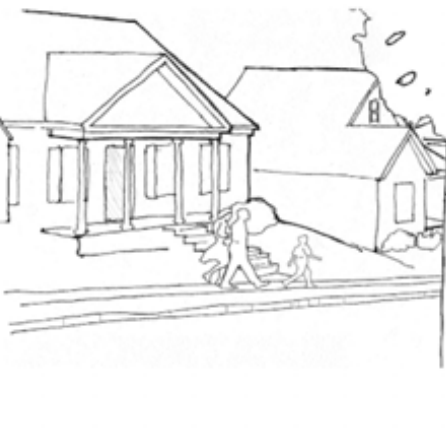

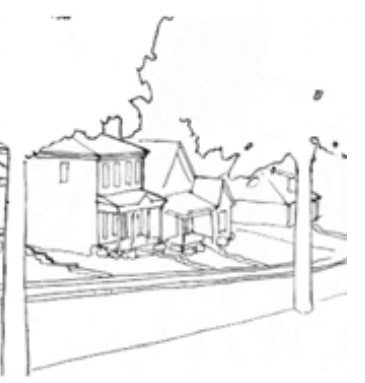

If I were to move, I'd like to find a neighbourhood...

A. that is a lively and active place, even if this means it has a mixture of single family houses, townhouses, and small apartment buildings that are close together on various sized lots
B. with single family houses farther apart-on lots of $1000 \mathrm{~m}^{2}$ or more, even if this means that it is not an especially lively or active place.

1. Your neighbourhood preference is:

\begin{tabular}{|c|c|c|c|c|c|c|c|c|c|}
\hline 1 & 2 & 3 & 4 & 5 & 6 & 7 & 8 & 9 & 10 \\
\hline strongly & \multicolumn{4}{c|}{$\begin{array}{c}\text { somewhat } \\
\text { prefer A }\end{array}$} & \multicolumn{3}{c|}{ Neutral } & $\begin{array}{l}\text { somewhat } \\
\text { prefer B }\end{array}$ & $\begin{array}{c}\text { strongly } \\
\text { prefer B }\end{array}$ \\
\end{tabular}

Figure 80: Example Survey Question 
These questions were posed as a number of trade-offs to survey respondents. These trade-off questions were presented in the context of a hypothetical move and questioned as, "If I were to move, I would like to find a neighborhood:

1. Where I can walk to stores, libraries, or restaurants, even if this means that the houses and commercial areas are within a few blocks $(500 \mathrm{~m})$ of each other

2. Within 5-6 km of work, school, or my other important destinations, even if this means the houses are close together - on lots of [1/4 acre or less $(1000 \mathrm{~m} 2)]$

3. That is a lively and active place, even if this means it has a mixture of single family houses, townhouses, and small apartment buildings that are close together on various sized lots

4. Within 5-6 km of work, school, or my other important destinations, even if this means having mostly connected streets and some through traffic on the street where I live

5. Where I can walk, bicycle, or take public transit for some of my trips, even if this means that the homes and yards are smaller

6. That has more space for walking and biking, even if this means less space for cars

7. Where I can walk, bicycle, or take public transit for some of my trips, even if it has through streets and people from other neighbourhoods walking or driving on them

By employing both stated neighbourhood preference questions from the Schwanen and Mokhtarian (2007) study as well as the conjoint neighbourhood preference questions from the Levine and Frank (2007) study in this dissertation's survey, an accurate measure of neighbourhood preference is gained. Similarly, it is anticipated that the self reported most frequently used travel modes as well as the stated travel mode preferences are accurate and in line with similar studies. Differences between stated and conjoint neighbourhood preferences compared against actual neighbourhood choices are observed, adding to the literature on appropriate neighbourhood preference measures.

Both conjoint and stated preference measures are well established means of eliciting preferences. ${ }^{651}$ With the application of these methods in the present study it is recognized that the true complexity of travel behaviour and residential location choices is higher than the level presented to the respondent in the survey. This simplification is accepted as what is required to maintain survey interest and to obtain sufficient results within the constraints of this study. In addition to caveats regarding the simplification of what is typically a complex issue, there is recognition that even if neighbourhood preferences are stable, which they may very well not be, illuminating them is particularly difficult. ${ }^{652}$ In either case, conjoint or stated, biases from respondents answering

${ }_{652}^{651}$ Green and Rao, 1971

${ }^{652}$ Fujji \& Garling. 2003 
idealistically or strategically to agree with the researcher rather than as per their actual preferences and behaviours are still present. A respondent answering strategically is common to surveys eliciting preferences to hypothetical choices. Another consideration is at the core of this dissertation and suggests that many individuals do not actually know their preferences well and instead infer them from past decisions. ${ }^{653}$ Similarly, consumer preferences may be indicators of other unrevealed preferences "such as a preference for a middle class status, a family centred lifestyle, or a homogeneous residential suburb." 654

Despite the number of considerations surveying for preferences involves, the remainder of this dissertation's survey involves questions focused more on the psychological antecedents to behaviour. Many of these are argued to provide a more useful attribute to the prediction of preferences, and hence behaviours.

\subsection{Problem Awareness}

For both the Norm Activation and Value Belief Norm theories discussed in chapter three, problem awareness plays a key role. In order for pro-environmental behaviours to be initiated, these two normative theories suggest that an awareness of a problem is a prerequisite. Problem awareness is an "important cognitive precondition [] for developing moral norms". ${ }^{655}$ Problem awareness in these theories is more specific rather than general and relates to an actual process as well as its consequences. In this sense, excessive use of the private automobile is considered a process while negative environmental outcomes are the consequence. A direct correlation between problem awareness and the other normative measures (internal attribution, guilt, social norm, and moral norm) in the theories mentioned above has also been observed. ${ }^{656}$ This suggests that increasing problem awareness is an avenue toward changing negative environmental behaviours.

In a study examining the role of awareness on the perceived responsibility for the negative consequences of excessive private automobile use, findings indicate that individuals with a greater awareness for the problems associated with car use both felt more responsible and used their cars less. ${ }^{657}$ In correlational research, problem awareness has been shown to account for variance beyond that of just socio-demographic variables (age, gender, income, educational level). ${ }^{658}$

\footnotetext{
${ }^{653}$ Ariely, 2008

${ }^{654}$ Shlay, 1985, in Churchman 1999 p 406.

${ }^{655}$ Bamberg \& Moser, 2007

${ }^{656}$ Bamberg \& Moser, 2007

${ }^{657}$ Steg \& Vlek, 1997

${ }^{658}$ Steg et al., 2001
}

132 
Problem awareness has also been shown to be correlated with the acceptability of policy directed at travel demand management. Here, the more aware individuals were of the problems linked to caruse, the more receptive they were to incentives to reduce private vehicle use. ${ }^{659}$ In the same vein as problem awareness, awareness of alternatives to car use have also been shown to influence travel behaviour. In a pilot study, driving declined by about $10 \%$ after participants were made aware of alternatives to their current patterns of driving. ${ }^{660}$ " A review of other voluntary travel behaviour change programs in UK found evidence of similar declines in driving" ${ }^{661}$ However, an awareness of problems associated with car use doesn't always result in compensatory behaviours. Car use is a particularly reliant behaviour, and often other pro-environmental behaviours are substituted as justification for continued car use. ${ }^{62}$ Similarly, although many intervention strategies try to get at the antecedents to behaviour, one of which being problem awareness, information campaigns aimed at raising awareness hardly result in behaviour changes. ${ }^{663}$

For the purposes of this dissertation's survey, problem awareness measures were adopted from the Heath and Gifford study (2002) on public transportation use, where they employed an extended version of the Theory of Planned Behaviour (TPB) to predict and explain changes in travel behaviour during a mandatory public transport program at the University of Victoria, B.C. This longitudinal study assessed TPB constructs before and after the introduction of a bus pass program. Here, the TPB constructs predicted the students' use of public transportation accurately. ${ }^{664}$ However, the Heath and Gifford (2002) car-use problem awareness questions focused mainly on negative environmental aspects of car-use, and failed to inquire about the awareness of the many other negative externalities associated with excessive car use. This limited scope is a problem common to travel behaviour research, and also to a greater appreciation of the influence the private vehicle has on a variety of aspects beyond environmental issues. Often, changes to private vehicle travel behaviour is portrayed as an environmental imperative; however, it is well established that for many individuals the primacy of economic concerns will dictate their behaviour. ${ }^{665}$ Factors outside of only environmental concern need to be emphasized in addition to an overall strategy highlighting the links between environmental well being, economic and social well being. As such, in addition to the transportation problem awareness measures used by Heath and Gifford (2002), this dissertation's survey asks questions relating to negative health, economic and social consequences of private vehicle use. These questions relate to the link between car use and the

\footnotetext{
${ }^{659}$ Eriksson et al., 2008

${ }^{660}$ Rose \& Ampt, 2001

${ }^{661}$ Sloman, 2003

${ }^{662}$ Garvell et al., 2003

663 de Groot \& Steg, 2008

${ }^{664}$ Heath \& Gifford 2002, p2154

${ }^{665}$ Cleveland et al., 2005.
} 
obesity epidemic, economic stimulus and infrastructure investment, amenity provision, safety, walking and community development.

There are nine travel behaviour problem awareness questions in total, and each is presented as a statement where survey respondents are asked to rate on a Likert type scale the extent to which they agree or disagree with each of the statements. The statements were presented in a way aimed at obscuring any interpretation of a position the researcher may have. The statements were then reverse coded where necessary to provide a consistent measure of respondents' relative agreement with the problem awareness statements. The average of these nine statements was used as the problem awareness measure. The problem awareness questions can be found in the survey in Appendix four.

\subsection{Moral Norms}

There are three types of norms that are considered for the prediction and explanation of proenvironmental behaviour, and depending on which theory used, TPB, NAT or VBN-theory, the norm emphasis shifts. Within the TPB, external or social norms are associated with behavioural intentions and succeeding actions, whereas in the NAT or the VBN-theory, internal norms are stressed. These alternating propositions for which norms are most important to the explanation of behaviour reflect the larger debate within social sciences on appropriate levels of analysis, (society, the household, the individual or the environment) for the greater understanding of the human condition.

Within the TPB, norms were initially only considered in terms of endorsements from an individual's significant others. ${ }^{666}$ However, because of the weak correlations between these subjective norms ${ }^{667}$ and behaviours, a number of authors have suggested improvements to how norms are utilized. ${ }^{668}$ An initial development is a broader definition of norms that includes injunctive norms (what one ought to do) and descriptive norms (what is typical). ${ }^{669}$ Both of these norms are interpreted from an individual's social context; be it either what he expects significant others think he ought to do, or what the individual interprets as typical amongst his social group.

\footnotetext{
${ }^{666}$ Heath \& Gifford, 2002

${ }^{667}$ Ajzen, 1991 ; Conner \& Armitage, 1998; Godin \& Kok, 1996; Trafimow \& Finlay, 1996

${ }^{668}$ Sheeran \& Orbell, 1999

${ }^{669}$ Heath \& Gifford, 2002
}

134 
Alternatively, some authors stress that the processes through which social norms influence personal norms should be emphasized. ${ }^{670}$ These processes include social categorisation, depersonalisation, conformity and influence. Rather than viewing norms as stimuli that an individual reacts to, this approach underlines the role that group memberships, group norms, social identities, intergroup relations, and ideologies play.

Aside from the injunctive and descriptive external social norms, personal moral norms have also provided an explanation of behaviour. Personal norms (PN) are those considered in the NAT, and rely on the altruistic leanings of individuals to help explain pro-environmental behaviours. ${ }^{671}$ "According to Schwartz, the PN, as opposed to a social norm, can be described as an inner moral conviction that is defended irrespective of the expectations of others. ${ }^{, 672}$ In this sense, moral norms are viewed as more stable compared to social norms, and less context dependent.

Moral norms have been associated with travel behaviour in a number of studies. In a study on driving violations, the addition of a moral norm construct improved the relative predictive power of the model over and above the original TPB variables. ${ }^{673}$ Likewise, moral norms have aided in the explanation of environmentally relevant behaviours, such as the use of public transportation. ${ }^{674}$ Similarly, personal norms have been shown to influence car use intentions. ${ }^{675}$ However, some authors contend that "[b]ecause of the subjective advantages and the social support of car use" it is unlikely that individuals would view car use as a moral endeavour. ${ }^{676}$ Here, they attribute the association between private vehicle use and quality of life aspects promoted by early government initiatives, as well as the general subjective evaluation of private vehicle use as far more advantageous to alternatives, as barriers to interpreting travel behaviour within a moral dimension.

For the purposes of this dissertation's survey, only moral norms were included. Why injunctive or descriptive norms were excluded was in part due to the inclusion of the place attachment construct which effectively captured these social norms in a way more akin to recognizing the processes involved in the formation of norms as discussed previously. This is elaborated on in the section on place attachment. The assumed stable nature of personal norms were also interpreted as more important to the understanding of travel behaviour, and this is reflected in similar studies on

\footnotetext{
${ }^{670}$ Hogg \& Smith, 2007

${ }^{671}$ Schwartz, 1968, 1977

${ }^{672}$ Hunecke et al., 2001, p 832

${ }^{673}$ Parker et al., 1995

${ }^{674}$ Harlan et al., 1999

${ }^{675}$ Choocharukul et al., 2008

${ }^{676}$ Bamberg \& Schmidt, 2003
} 
predicting mode choices. ${ }^{677}$ The moral norm question was adopted from the Heath and Gifford (2002) study and asked respondents to indicate on a five point Likert type scale if they agreed, disagreed or neither agreed nor disagreed with the following statement: "I feel guilty about taking my car when I travel to the destinations I frequent”.

\subsection{Ascribed Responsibility}

Ascribed responsibility is typically employed within the normative theories of behaviour and is a prerequisite that needs to be activated before beliefs are acted on. However, in Heath and Gifford (2002) they expanded on the TPB to include ascribed responsibility, and it is this measure that was adopted for the purposes of this dissertation's survey. Personal responsibility was assessed with a single question that asked respondents to indicate their agreement with the following statement: "I feel personally responsible for the problems resulting from car use when I drive". Survey participants indicated their agreement as strongly agreeing, disagreeing or neither agreeing nor disagreeing with the statement on a five point Likert type scale.

\subsection{Perceived Behavioural Control}

An individual may have altruistic values, may also be aware of environmental problems and potential solutions as well as deem themselves capable of providing solutions and intend to act based on this assessment. However, if there are contextual barriers that restrict them from carrying out pro-environmental behaviours, this must be accounted for in a behavioural explanation. Here, perceived behavioural control (PBC) relates to the perception an individual has over how easy or difficult performing certain behaviours would likely be ${ }^{678}$ This definition of PBC includes internal factors (e.g. knowledge, skills, will-power) as well as external factors (e.g. time, availability, the cooperation of others). ${ }^{679} \mathrm{PBC}$ was discussed previously, however it is expanded upon here in terms of its relation to pro-environmental and travel behaviour.

In a survey of one thousand Ontario resident's, PBC was found to be the greatest impediment to positive environmental action. ${ }^{680}$ This finding is replicated in numerous other studies examining the

\footnotetext{
${ }^{677}$ Hunecke et al., 2001

${ }^{678}$ Ajzen, 2002

${ }^{679}$ Bamberg \& Schmidt, 2003

${ }^{680}$ Comeau, 2008
}

136 
barriers to environmental action. ${ }^{681}$ In another example, PBC can also negatively moderate the relationship between problem awareness and pro-environmental action. An increase in public awareness of environmental problems has been associated not only with increased environmental concern, but also with a growing sense of helplessness. ${ }^{622}$ This loss of self-efficacy relates to PBC and ultimately leads to less pro-environmental behaviour. Physical constraints have been the focus of the majority of research dealing with the influence the built environment may have on travel behaviour. Just as many studies point to increasing land-use densities, mixing land-uses and greater connectivity amongst land-uses, the omission of these qualities is argued to result in a reliance on the private automobile and hence a reduction in PBC. In studies that directly assess the effect of PBC on travel behaviour, Wright et al., (2008) found that individuals intending to reduce their car use perceived more behavioral control than those intending to maintain their car use. In this same study, PBC had the strongest effect on individual's intentions to reduce car use.

Although the TPB and PBC have proved successful in predicting pro-environmental behaviour in the past, some authors question how PBC is conceptualised. It is argued that PBC would be better interpreted as being multidimensional, with two distinct realms. These have been defined as selfefficacy and controllability and relate to an individual's perception of their ability to perform an activity and to their interpretation of control over the particular behaviour respectively. ${ }^{683}$ Other authors suggest that $\mathrm{PBC}$ is too similar a measure to attitudes for it to be considered separately. ${ }^{684}$ Likewise, $\mathrm{PBC}$ is also closely linked to behavioural intentions, which suggests a lack of discriminant validity. ${ }^{655}$ Where the relationships between the TPB variables have been examined, PBC has been treated as independent, and when the two theories are combined, NAT and TPB, "perceived behavioural control partially moderate[s] the relationship between personal normative motives and intentions." ${ }^{\text {" } 686}$ A moderator "is a third variable that affects the zero-order correlation between two other variables". 687

For the purposes of this dissertation's survey, $\mathrm{PBC}$ was assessed with a single measure adopted from Heath and Gifford (2002) that asked respondents to rate how difficult it was for them to take alternatives to the private-vehicle for the majority of trips they make on a weekly basis. This measure was assessed on a Likert type scale from one to five, where one was "very easy", five was "very difficult" and three was "neither easy nor difficult". Two additional measures were also

\footnotetext{
${ }^{681}$ Corraliza \& Berenguer, 2000; Derksen \& Gartell, 1993; Guagnano et al., 1994; Tanner, 1999

${ }^{682}$ Kaplan, 2000

${ }^{683}$ Ajzen, 2002

${ }^{684}$ Leach et al., 2001; Trafimow \& Duran, 1998

${ }^{685}$ Fishbein, 1997; Rhodes \& Courneya, 2003

${ }^{686}$ Wall et al., 2008, p81

${ }^{687}$ Baron \& Kenny, 1986, p. 1174
} 
added to assess the perceived behavioural control over one's ability to relocate. Because preferences can change over the course of an individual's life and particularly over the course of owning a home, a recognition of this must be made. Many self-selection studies make an implicit assumption that re-locating based on desires rather than needs is relatively easy. This is however, not the case, and moving presents one of the most difficult decisions individuals face, as well as one of the most time consuming and stressful. ${ }^{688}$ Similarly, one may not have the financial ability to move, may no longer be willing to invest the effort into relocating, may see the pains involved in a move to outweigh the perceived benefits, may not be willing to or no longer has the capacity for the re-learning involved in a move or may simply feel that the time invested into a location is not worth 'losing'. This relates to the idea of escalated commitment where regardless of negative implications from bad decisions, a tendency to remain with and even further commit time, effort and resources is a way of justifying the initial decision and losses already incurred. For these reasons, two measures aim to assess $\mathrm{PBC}$ over relocating and are measured on the same Likert type scale as that for alternatives to the private automobile PBC. The two re-locating PBC questions were: "Considering the effort involved and financial costs, how difficult would it be for you to move from your current neighbourhood" and "For me, the hassles of moving outweigh the benefits".

\subsection{Place Attachment}

The theoretical background and empirical findings related to place attachment were discussed previously. Key to the hypothesis of the present study, a correlation between place attachment and travel attitudes suggests that attitudes may be subsequent and not just antecedent to behaviours. The concept of place attachment is selected for the present study on this basis and because it specifically links the built environment to psychological phenomena that are likely to occur after a decision has been made. While self-selection studies on travel behaviour rely on the assumption of existing innate preferences, a link between place attachment and travel attitudes would undermine this assumption. The literature suggest that place attachment develops over time, in a local context and in relation to a specific place. Likewise, an association between length of tenure and travel attitudes invoke the same reservations directed at the assumptions of latent travel preferences and attitudes.

\footnotetext{
${ }^{688}$ Munton, 1990; Riad and Norris, 1996 
A number of scales have been developed to assess place attachment and these relate to the different aspects of place attachment, namely: place identity and place dependence. ${ }^{689}$ Similarly, place attachment has been suggested to occur at varying scales of place. ${ }^{690}$ Although place attachment may exist at a greater dimension, the entire dissertation's focus is at a neighbourhood level and as such, place attachment is assessed only at this level. While the varying scales to evaluate place attachment reflect the diversity and multiple interpretations of the concept, the intent of the present study is in essence to cast as wide a net as possible to detect place attachment attributes, whether they be identity or dependent related. While the nature of attachment is surely important, the goal of this study is to establish a relationship between any form of place attachment and travel attitudes. In line with this reasoning, rather than capturing many of the diverse aspects of place attachment, the current survey's initial place attachment question asks residents' agreement with the statement, "I am attached to my neighborhood" and responses were assessed on a five point Likert-type scale indicating strong agreement or disagreement.

The second question utilised to evaluate place attachment relates to Hidalgo and Hernández's (2001) concept of place attachment as a strong desire to maintain closeness to a place. Their nineitem scale asks participants to report how unhappy they would be if various dimensions (social and physical) of their place were lost. Response options ranged from one to five (not at all, to a lot respectively), again on a Likert-type scale. Thus, a question was posed in the present study's survey using the same scale that asked respondents how happy they would be if they had to move from their current neighbourhood to another neighbourhood.

These two question together sufficiently assess place attachment, and theoretically are broad enough to capture all aspects of the concept. While the identity aspect of place attachment relates more to the causal mechanisms proposed to contribute to attitude change, this broader assessment allows for any aspect of place attachment. In previous literature there is a scarcity of studies exploring the identity dimension of attitudes ${ }^{691}$; however, with the inclusion of place attachment variables to the explanation of travel attitudes in the present dissertation, this apparent deficit is addressed. Travel behaviour research potentially may benefit from this wider understanding of attitudes, and place attachment is a well placed concept to initially explore this untapped dimension of travel behaviour.

\footnotetext{
${ }^{689}$ Billig et al., 2006; Twigger, 1992; Giuliani, 2003

${ }^{690}$ Hidalgo \& Hernández, 2001

${ }^{691}$ Hogg \& Smith, 2007, p90
} 
Travel attitude is the dependent variable for this study or for the outcome the previously discussed variables aim to predict. How attitudes are formed was articulated in chapter three and, as such, only the specific measures used to asses travel attitudes are discussed here along with the theoretical basis for selecting these methods.

A study conducted by Schwanen and Moktarian (2007) provided thirty two attitudinal statements that were factor analysed with oblique rotation into six main attitudinal groups. This study was discussed previously in the stated preference section, and two measures from these attitudinal statements were adopted to assess neighbourhood preferences. An issue with these attitudinal statements, beyond some of them reflecting preferences more than attitudes, is the grouping of neighbourhood preference questions with travel attitude questions. This grouping implies that survey participants make a connection between their neighbourhood preferences and travel attitudes (or that there is a connection), whereas previous research has demonstrated that in many cases there is a mismatch between travel attitudes and neighbourhood preferences. As such, travel attitude questions were filtered out of this study and used for the purposes of this dissertation's survey. These questions are as follows, and were assessed again on a five point Likert type scale ranging from strongly agreeing to strongly disagreeing.

1. I would be willing to pay a toll to travel on an uncongested road

2. We need more parking downtown

3. Automobile infrastructure should receive more funding than public transportation, cycling and walking infrastructure because more people drive

4. We should raise the price of fuel to reduce air pollution and congestion

5. To reduce air pollution and congestion we should raise taxes to improve public transportation

6. Getting stuck in traffic doesn't bother me much

7. Narrow roads are preferable to wide ones to reduce the speed of cars

Where necessary, questions were reversed coded to reflect either a travel attitude in favour of the private automobile, or in favour of alternatives to the private automobile. In the Schwanen and Mokhtarian (2005) study this contrast was labelled as a travel freedom factor or a proenvironmental policy factor. The travel freedom factor is associated with views that tend to "disapprove of policies attempting to limit auto travel and value the flexibility a private vehicle 
offers ${ }^{\prime \prime 992}$, whereas the pro-environmental policy factor is associated with a less favourable view of private vehicle travel. Here, attitudes are assessed as opinions "about the individual benefits accruing from auto use and [are contrasted against] the costs involved for society" ${ }^{\prime 693}$ and it is these attitude assessments that are valuable to this study.

\subsection{Quantitative Survey}

All fourteen of the constructs discussed in the preceding sections form the quantitative survey for the present dissertation. These include socio-demographic, psychological (moral norms, perceived behavioural control, ascribed responsibility, problem awareness), and preference factors as well as the added place attachment measures with travel attitudes as the outcome variable. This quantitative survey was administered to the four case study neighbourhoods. Three hundred surveys including pre-paid return envelopes were hand delivered to randomly selected households in each case study. In the two conventional neighbourhoods (Churton Park in New Zealand and Broadmead in Canada) dwellings were clustered into groups of twenty-five and a number was assigned to each cluster. A random number generator then selected twelve clusters in each neighbourhood to deliver the survey to. In Broadmead it was impossible to hand deliver the surveys to some of the identified clusters due to the dwellings not having mail boxes, and in these cases the next cluster of dwellings were used. Similarly Broadmead also contained a number of gated communities within the neighbourhood, and in order to produce a representative sample the survey was mailed to a randomly selected number of these dwellings in the same fashion as was done for the entire neighbourhood. The same random selection system was used for the two traditional neighbourhoods (Newtown in New Zealand, and Fairfield in Canada), however, due to the large number of dwellings that were not single family dwellings, these alternative dwelling forms were randomly selected from a representative proportion separate to the single family dwellings. For the apartments, townhomes and other alternative dwelling types the surveys were also mailed with prepaid return envelopes, rather than hand delivered.

\subsection{Quantitative Survey Analysis Methodology}

Together, the fourteen variables selected provide a parsimonious reflection of all the factors that may influence travel attitudes and are assessed through a multiple regression to account for their

\footnotetext{
${ }^{692}$ Schwanen \& Mokhtarian, 2005, p95

${ }^{693}$ Schwanen \& Mokhtarian, 2005, p95
} 
relative influence. The direction of relationships is less important relative to the main hypothesized correlation between travel attitudes and the post-decision reasoning factors. However, a logical pattern is anticipated. It is estimated that post-decision reasoning will account for travel attitudes to tend toward being pro-private automobile as time in conventional neighbourhoods increases, and a tendency toward alternatives to the private automobile and environmental regard in traditional neighbourhoods as time in them increases. Additionally, greater place attachment in either type of neighbourhood is likely to be associated with a travel attitude in favour of the neighbourhood type norm. To evaluate the influence of post-decision reasoning, data from the survey are analyzed using, initially, a hierarchical multiple regression where constructs were added in order of importance based on past research. A stepwise multiple regression was then utilized due to the exploratory model building involved with the introduction of the new post-decision reasoning variables. Here, a backward stepwise method was used to reduce the risk of making Type II errors from suppressor effects common to the forward method. ${ }^{694}$

In addition, independent sample $t$ - tests were performed to analyze the significance of differences between the traditional and conventional survey participants for each construct. Independent sample t-tests compare the means between two different population samples, and can determine if the differences in means are statistically significant. ${ }^{695}$

Similar studies have employed multiple regressions in a comparable way. While the goal of this study is to explain a greater proportion of travel attitude variance with the addition of post-decision reasoning variables, other studies have likewise sought to explain greater variance with introducing new variables determined through multiple regressions. ${ }^{696}$

Multiple regression is an analysis method typical of a positivist approach and is of an empiricist tradition. As such, this approach suffers the same criticisms leveled at positivism, namely: being reductionist in nature, and suffering from a lack of recognition for the subjectivity of knowledge claims made by counter epistemologies. ${ }^{697}$ Likewise, positivist findings, specifically that of regression analysis, bear semantic issues that serve to elicit undue criticism. Often the explanation of variance is interpreted as the explanation of phenomena, both by practitioners and reviewers alike. "The dividing line between analyses in terms of correlations and in terms of mechanisms, while logically clear, can practically be quite thin." ${ }^{698}$ However, the post-positivist tradition has

\footnotetext{
${ }^{694}$ Field, 2005

${ }^{695}$ Field, 2005

${ }^{696}$ Heath \& Gifford, 2002; Wall et al., 2008; Naess, 2005; Frank et al., 2007; Handy et al., 2005

${ }^{697}$ Creswell, 2003

${ }^{698}$ Mayntz, 2004, p245
}

142 
long given way to claims of absolute objective truth, and despite the seeming certainty associated with a positivist method, correlations and causations are recognized as entirely separate issues. ${ }^{699}$

To determine causation, post-positivist (conventional) scientific practice requires four criteria to be met. ${ }^{700}$ The first is time order. For cause and effect to be ascertained, the cause must precede the effect. The second criterion is non-spuriousness. No external factor or third variable can create an accidental relationship between the cause and the effect under consideration. A statistically established association between the cause and effect is the third criterion and, finally, a known causal mechanism is the fourth. Historically, few studies, if any, on travel behaviour have met all the criteria to establish causation. The direction of causality as well as the non-spuriousness issue, which is often defined as the third variable problem, prohibits multiple regression analysis from making claims of causality. ${ }^{701}$ Instead, multiple regressions are only capable of establishing correlations. Establishing a causal mechanism poses the greatest problem to any causal claims and is commonly referred to as the "black box" problem of social science. ${ }^{702}$

The black box problem refers to the "difficulty analysts have identifying the intervening processes through which an independent variable exerts an effect on a dependent variable" ${ }^{703}$ While theories on these processes can be cautiously validated based on statistical correlation, causation is never really determined. ${ }^{704}$ The majority of correlation research relies on Humean Theory which holds that causation is entirely constituted by facts about empirical regularities among observable variables. ${ }^{705}$ "Whereas correlational analysis consists of specifying antecedents regularly conjoined with outcomes, causal analysis consists of specifying the "mechanism" that underlies and generates empirical regularities and outcomes." ${ }^{, 706}$ In this sense, causation is never identified; but rather the weight of correlational research makes inferences about causation possible. By this logic, it is accepted that only a description of a phenomenon is possible, rather than an understanding of the process that gave rise to such phenomena. Here, process inferences are made by satiating the literature with every intricate detail of the 'what,' rather than the 'how'. Or alternatively stated, researchers are "satisfied with merely establishing systematic co-variation between variables or events" instead of a more robust explanation where "the social 'cogs and wheels' that have brought the relationship into existence" are specified. ${ }^{707}$

\footnotetext{
${ }^{699}$ Maxwell \& Delany, 2004; Field, 2005

${ }^{700}$ Singleton \& Straits, 1999; Baron et al., 1998

${ }^{701}$ Field, 2005

${ }^{702}$ Mayntz, 2004

${ }^{703}$ Mahoney, 2003

${ }^{704}$ Wilson, 1998

705 Mahoney, 2003

${ }^{706}$ Mahoney, 2003, p2

${ }^{707}$ Hedstrom \& Swedberg, 1996; Glennan 1996
} 
Like many conundrums within the social sciences, an agreed definition on causal mechanisms has not been reached. Mahoney (2001) counts twenty four different definitions by twenty one different authors. However, "[m]ost authors agree that mechanism statements are causal generalizations about recurrent processes." ${ }^{, 708}$ This is the definition accepted within this dissertation, and it follows then that a causal mechanism represents a sequence of causally linked events that occur repeatedly in reality if certain conditions are given.

Many studies simply infer a causal mechanism. If mentioned at all, generally the mechanism is that of utility maximization. Utility maximization suggests that people make decisions based on the subjective benefit derived from their decisions, and each individual is supposed to possess an ability to discern the value of each decision relative to all other possible decisions. ${ }^{709}$ Similarly, an innate preference for all commodities is assumed to reside within individuals, even in situations where individuals have no prior experience with similar decisions. Despite the reliance on utility maximization to account for travel behaviour, this causal mechanism has received numerous criticisms.

An initial censure relates to the relative appropriateness of using utility maximization, which is essentially an economic theory, to explain what may not be a market decision, that of travel behaviour. It is argued that "economists should perhaps be a little more modest in [their] 'imperialist ambitions' of explaining non-market behaviour by economic principles". ${ }^{710}$ Other criticisms relate to the over-simplification of human behaviour. Instead of behaviour being driven by self-interest alone, other motivations such as altruism, loyalty, spitefulness and pity should be considered. ${ }^{711}$ Utility maximization also doesn't account for the influence ideologies and normative behaviours have on decision making within business, politics and policy. ${ }^{712}$ Similarly, it fails to recognize the social aspect of decision making. ${ }^{713}$ Here, the term 'social embeddedness' is used to refer to this aspect and is defined as "a state in which an actor is significantly influenced by individual relationships with other actors." 714 In terms of land-use decisions, experimental data demonstrates that a utility maximization causal mechanism fails to account for the diversity of outcomes and decisions made in a simple decision-making context. ${ }^{715}$ Rather than maximizing utility, some commentators argue that consumers create algorithms to cope with the vast amount of

\footnotetext{
${ }^{708}$ Mayntz, 2004

${ }^{709}$ Keen, 2003

${ }^{710}$ Sippel, 1997

${ }^{711}$ Wilson, 1998

${ }^{712}$ Mitchell, 2005

${ }^{713}$ Ebenhöh \& Pahl-Wostl, 2008

${ }^{714}$ Ebenhöh \& Pahl-Wostl, 2008, pp228

${ }^{715}$ Evans et al., 2006

144
} 
decisions prevalent in a saturated market. ${ }^{716}$ These algorithms are similar to habits and can be considered a form of cognitive frugality. Even if travel behaviour is a market decision, some go so far as to suggest that the utility maximization view of consumption is "experimentally falsified, computationally impossible, and distracts scientific attention from the important questions in consumer behaviour, such as how tastes are formed, transmitted and modified". 717

There are, however, other causal mechanisms beyond utility maximization. These can be divided into three main categories; agent-based models (rational choice), structural models (power theories) and social influence models (functionalist). Agent-based models follow the strategy of aggregating the results of individual-level choices into macro-level outcomes. Structural models attempt to demonstrate the causal effects of given social structures or institutions (e.g. the tax collection system) on social outcomes (levels of compliance). And social influence models identify the factors that work behind the backs of agents to influence their choices.

Given that multivariate linear regressions are unable to establish causation on their own ${ }^{718}$, they are still valuable to the study of travel behaviour. They can be used to illuminate the unobservable, to demonstrate postulated theories from abstract theoretical thinking and to partial out the relative influence on behaviour of a number of factors in order to gain an understanding of the individual influence of specific factors. ${ }^{719}$ The latter of these uses is particularly important in determining the relative influence the built form may have on travel behaviour while controlling for the many other factors that influence it. To account for the limitations of a linear regression model, a qualitative exploration of travel behaviour is also employed. This inquiry takes the form of an on-line open ended survey.

\subsection{Qualitative Survey}

From the quantitative survey, participants were asked to leave contact details if they wished to be involved in further research. The same question was posed to survey participants from the pilot study. Interview participants for the qualitative on-line survey were recruited from these contact details.

\footnotetext{
${ }^{716}$ Keen, 2003. p110

${ }^{717}$ Keen, 2003 p 110

${ }^{718}$ Maxwell \& Delany, 2004; Roe, 1998 in Naess, 2006, p31

${ }^{719}$ Naess, 2005
} 
An open ended on-line survey was carried out from this sample of participants. This survey assessed participants' self-generated explanations of travel behaviour and neighbourhood preference. The questions allowed for participants to generate their own narrative, and focused on qualitatively assessing shared positions on travel behaviour through pattern recognition to provide an accurate snapshot of the larger post-decision reasoning phenomenon hypothesized. ${ }^{720}$ The narrative generated by the survey participants can be understood in the same way as a discourse. The varying perspectives individuals' have on different aspects of the world that form the framework for their own personal versions of actions, cognitive processes or other phenomenon represent the meaning of discourse in this dissertation. ${ }^{721}$

Six questions assessed participants' discourse on the main themes of the quantitative survey. The first established from which neighbourhood the participant resided. The next question asked participants to relate the main reasons they had for originally locating in their current neighbourhood. This question was asked as follows:

"If you can remember, what were the most important factors that led you to move to the neighbourhood you live in now?"

The third question examined survey participants' neighbourhood preferences. This was accomplished by having participants list the compromises they made in their neighbourhood as a way to establish preference ranking. A list of examples was added to this question and was generated from the pilot study where survey participants listed both the things they liked and disliked about their neighbourhoods.

"Most neighbourhoods are unable to satisfy all the preferences and desires a person might have and are often a compromise of some preferences for others. Can you list some things (if any) you would like to see improved in your neighbourhood or that are a compromise for you."

The fourth question aimed to elicit behavioural control factors that may limit a person's ability to re-locate. Similarly this question tapped escalated commitment attributes without leading the survey participant.

\footnotetext{
${ }^{720}$ Boyatziz, 1998

${ }^{721}$ Fairclough, 2003 in Wall et al., 2008 146
} 
"What factor(s) most influence you to remain in your neighbourhood (unless you are planning to move in the near future) rather than relocate to a neighbourhood that you feel would realise more of your preferences?"

The fifth question asked for participants' explanations for their travel behaviour. The focus here was to develop a longer narrative where individuals would give some serious thought to their current travel behaviour, and similarly not be limited to the explanations provided in the quantitative survey.

"Can you please tell me how you currently travel for most of the trips you would make in a week (going to work, school, grocery shopping etc.) and why you think you use the mode of travel that you do (drive, bus, walk, cycle etc.)? For example, if you walk for most of your trips- why do you think this is - and why don't you drive instead. Or conversely if you drive for most of your trips why do you think this is and why don't you walk instead or bicycle or take the bus etc."

The final question asked participants if they identified with their neighbourhood. This question aimed to explore a place attachment explanation of travel behaviour and neighbourhood preferences. Instead of asking about place attachment in general as in the quantitative survey, the specific place attachment aspect of place identity was queried. It was felt a precise narrative would be more likely to result from this specific question rather than from a general assessment of place attachment. The question was asked as follows:

\section{"Do you identify with your neighbourhood and/or the people in it? Please explain."}

Qualitative research has been suggested to support causal inferences made from quantitative analysis and better uncover the 'how' and 'why' behind behavioural explanations. ${ }^{722}$ Similarly, mixed method approaches that include qualitative data are stressed as important to the progression of travel behaviour study and necessary to determine causation. ${ }^{723}$ Although qualitative data cannot yield statistically relevant results, they are particularly suited to exploratory study and, when supported by quantitative statistical data, possess greater validity. ${ }^{724}$ Similarly, where quantitative methods require large population samples to elicit small behavioural phenomenon, qualitative explorations may more easily uncover intricacies of behaviour that are difficult to establish

\footnotetext{
${ }^{722}$ Naess, 2005

${ }^{723}$ Clifton \& Handy. 2001; Stopher \& Jones, 2003

${ }^{724}$ Golledge \& Stimson, 1997
} 
quantitatively. ${ }^{725}$ With the phenomenological exploration this dissertation is undertaking, correlational research is also less important to the result. ${ }^{726}$ Similar studies have also employed qualitative data to both support quantitative findings and provide insight into the mechanisms underlying correlational findings. ${ }^{727}$

Fundamentally, qualitative research is interpretive; this includes the interpretation of data and the drawing of conclusions. ${ }^{728}$ The validity of qualitative research is improved upon by comparing the findings against similar studies, which this research does.

Together the fourteen variables used to account for travel attitudes, along with the qualitative survey exploring travel and neighbourhood preferences, provide a strong and in-depth assessment into how travel attitudes are formed. The aim of each survey is to test the post-decision reasoning proposition without leading survey participants or limiting their explanations to a dichotomous agreement with the hypothesis. While this approach makes the interpretation of results far more complex, it also provides a more holistic and thorough assessment for how the built environment interacts with psychological dispositions to influence travel behavior.

\footnotetext{
${ }^{725}$ Poulenez-Donovan \& Ulberg, 2004

${ }^{726}$ Y in in Groat and Wang, 2002, p. 354

${ }^{727}$ Naess, 2005; Wall, et al., 2008

${ }^{728}$ Groat \& Wang, 2002

148
} 


\section{Main Study Survey Results}

A total of two-hundred and sixty seven useable surveys were returned representing a response rate of twenty-two percent. This is similar, although on the low end, to other self administered surveys. ${ }^{729}$ Descriptive statistics for both types of neighbourhoods (traditional and conventional) as well as for each individual case study were computed. The hypothesis that travel attitudes are influenced by post-decision reasoning variables was then tested using multiple regression. The model developed from the multiple regression established the amount of variance each construct explained in travel attitudes, while controlling for the effect of the other contributing variables.

\subsection{Data Screening}

Prior to the main analysis, data were screened for accuracy (i.e., recording errors, or inappropriate values), missing values, and outliers. A missing value analysis revealed that 162 data points were missing, which is $2.4 \%$ of the data. Independent $t$-tests were conducted to assess whether missing data on each variable differed according to travel attitude or neighbourhood type. None of these tests were significant. Missing data was thus replaced with average variable scores for each construct. Although replacing missing data with average scores may suppress the true values of the standard deviation, this was deemed not a serious consideration because of the relatively few missing values. ${ }^{730}$

Finally, data were checked for outliers - extreme values that may increase Type I or Type II errors. Histograms and box-plots were examined, and z-scores were scanned for values greater than three standard deviations from the mean. Two participants from Fairfield and three from Churton Park had tenure lengths far longer than the average, greater than three standard deviations from the mean. As such, these participants' tenure length scores were not included in the analysis.

\section{$\underline{\text { Sample Size }}$}

While the overall fit of the regression model is interesting, the goal of the present study is to establish what link, if any, post-decision reasoning variables have with travel attitudes. For this, the correlations of the individual variables in the model are more important. Green (1991) recommends

\footnotetext{
${ }^{729}$ Handy et al., 2005; Frank et al., 2007

${ }^{730}$ Field, 2005
} 
minimal sample sizes of one hundred and four, plus the number of predictor variables $(104+\mathrm{k})$ when the correlations with individual variables are the focus. With the fourteen variables in the present study, this minimum sample size is achieved in both types of neighbourhoods; traditional ( $\mathrm{n}$ 127) and conventional (n140). Further recommendations, however, suggest larger sample sizes depending on the size of effect anticipated. For small effects, minimum sample sizes are recommended to be greater than five-hundred cases with more than ten predictors. ${ }^{731}$ The size of effect associated with a correlation between post-decision reasoning variables and travel attitudes is, however, largely unknown and here, the limitations of the present study dictate sample sizes.

\subsection{Population Sample}

Descriptive socio-demographic statistics for each type of neighbourhood are presented in Tables 6 to 11 . The relative representativeness of the sample at this level of analysis is less accurate comparative to the individual neighbourhood level.

Table 6: Conventional Neighbourhood Socio-demographics

\begin{tabular}{|c|c|c|c|c|c|c|c|c|}
\hline Level of Analysis & \multicolumn{2}{|c|}{ Age (n136) } & \multicolumn{2}{|c|}{ Gender (n135) } & \multicolumn{2}{c|}{ Income (n122) } & \multicolumn{2}{c|}{ No. Vehicles (n130) } \\
\hline Conventional (n140) & $15-24$ & $2.9 \%$ & Male & $47.4 \%$ & $\$ 25 \mathrm{k}$ or less & $1.6 \%$ & 0 & $0.8 \%$ \\
\hline & $25-34$ & $5.1 \&$ & Female & $52.6 \%$ & $\$ 25 \mathrm{k}$ to $\$ 45 \mathrm{k}$ & $5.7 \%$ & 1 & $25.4 \%$ \\
\hline & $35-49$ & $34.6 \%$ & & & $\$ 45.1 \mathrm{k}$ to $\$ 75 \mathrm{k}$ & $17.2 \%$ & 2 & $55.4 \%$ \\
\hline & $50-64$ & $36.0 \%$ & & & $\$ 75.1 \mathrm{k}$ to $\$ 100 \mathrm{k}$ & $18.9 \%$ & 3 & $13.1 \%$ \\
\hline & $65+$ & $21.3 \%$ & & $\$ 100 \mathrm{k}+$ & $56.6 \%$ & $4+$ & $4.4 \%$ \\
\hline
\end{tabular}

Table 7: Traditional Neighbourhood Socio-demographics

\begin{tabular}{|c|c|c|c|c|c|c|c|c|}
\hline \multirow{2}{*}{$\frac{\text { Level of Analysis }}{\text { Traditional (n127) }}$} & \multicolumn{2}{|c|}{ Age (n126) } & \multicolumn{2}{|c|}{ Gender (n127) } & \multicolumn{2}{|c|}{ Income (n121) } & \multicolumn{2}{|c|}{ No. Vehicles (n127) } \\
\hline & $15-24$ & $6.3 \%$ & Male & $34.6 \%$ & $\$ 25 \mathrm{k}$ or less & $12.4 \%$ & 0 & $15.0 \%$ \\
\hline & $25-34$ & $13.5 \%$ & Female & $65.4 \%$ & $\$ 25 \mathrm{k}$ to $\$ 45 \mathrm{k}$ & $9.1 \%$ & 1 & $55.1 \%$ \\
\hline & $35-49$ & $30.2 \%$ & & & $\$ 45.1 \mathrm{k}$ to $\$ 75 \mathrm{k}$ & $28.1 \%$ & 2 & $26.8 \%$ \\
\hline & $50-64$ & $36.5 \%$ & & & $\$ 75.1 \mathrm{k}$ to $\$ 100 \mathrm{k}$ & $20.7 \%$ & 3 & $1.6 \%$ \\
\hline & $65+$ & $13.5 \%$ & & & $\$ 100 \mathrm{k}+$ & $29.8 \%$ & $4+$ & $1.6 \%$ \\
\hline
\end{tabular}

Table 8: Broadmead Socio-demographics

\begin{tabular}{|c|c|c|c|c|c|c|c|c|}
\hline \multirow{2}{*}{$\begin{array}{c}\text { Level of Analysis } \\
\text { Broadmead (n62) }\end{array}$} & \multicolumn{2}{|c|}{ Age (n59) } & \multicolumn{2}{|c|}{ Gender (n59) } & \multicolumn{2}{|c|}{ Income (n52) } & \multicolumn{2}{|c|}{ No. Vehicles (n56) } \\
\hline & $15-24$ & $1.7 \%$ & Male & $40.7 \%$ & $\$ 25 \mathrm{k}$ or less & $0.0 \%$ & 0 & $0.0 \%$ \\
\hline & $25-34$ & $3.4 \%$ & Female & $59.3 \%$ & $\$ 25 \mathrm{k}$ to $\$ 45 \mathrm{k}$ & $5.8 \%$ & 1 & $30.4 \%$ \\
\hline & $35-49$ & $22.0 \%$ & & & $\$ 45.1 \mathrm{k}$ to $\$ 75 \mathrm{k}$ & $21.2 \%$ & 2 & $50.0 \%$ \\
\hline & $50-64$ & $30.5 \%$ & & & $\$ 75.1 \mathrm{k}$ to $\$ 100 \mathrm{k}$ & $21.2 \%$ & 3 & $16.1 \%$ \\
\hline & $65+$ & $42.4 \%$ & & & $\$ 100 k+$ & $51.9 \%$ & $4+$ & $3.6 \%$ \\
\hline
\end{tabular}

\footnotetext{
${ }^{731}$ Miles and Shevlin, 2001 in Field, 2005 150
} 
Table 9: Churton Park Socio-demographics

\begin{tabular}{|c|c|c|c|c|c|c|c|c|}
\hline Level of Analysis & \multicolumn{2}{|c|}{ Age (n77) } & \multicolumn{2}{|c|}{ Gender (n76) } & \multicolumn{2}{c|}{ Income (n70) } & \multicolumn{2}{c|}{ No. Vehicles (n74) } \\
\hline Churton Park (n78) & $15-24$ & $3.9 \%$ & Male & $\mathbf{5 2 . 6 \%}$ & $\$ 25 \mathrm{k}$ or less & $2.9 \%$ & 0 & $1.4 \%$ \\
\hline & $25-34$ & $6.5 \%$ & Female & $47.4 \%$ & $\$ 25 \mathrm{k}$ to $\$ 45 \mathrm{k}$ & $5.7 \%$ & 1 & $21.6 \%$ \\
\hline & $\mathbf{3 5 - 4 9}$ & $\mathbf{4 4 . 2 \%}$ & & & $\$ 45.1 \mathrm{k}$ to $\$ 75 \mathrm{k}$ & $14.3 \%$ & $\mathbf{2}$ & $\mathbf{5 9 . 5 \%}$ \\
\hline & $50-64$ & $40.3 \%$ & & & $\$ 75.1 \mathrm{k}$ to $\$ 100 \mathrm{k}$ & $17.1 \%$ & 3 & $10.8 \%$ \\
\hline & $65+$ & $5.2 \%$ & & & $\$ 100 \mathrm{k}+$ & $\mathbf{6 0 . 0} \%$ & \multirow{2}{*}{$4+$} & $6.8 \%$ \\
\hline
\end{tabular}

Table 10: Fairfield Socio-demographics

\begin{tabular}{|c|c|c|c|c|c|c|c|c|}
\hline Level of Analysis & \multicolumn{2}{|c|}{ Age (n74) } & \multicolumn{2}{c|}{ Gender (n74) } & \multicolumn{2}{c|}{ Income (n69) } & \multicolumn{2}{c|}{ No. Vehicles (n74) } \\
\hline Fairfield (n74) & $15-24$ & $1.4 \%$ & Male & $35.1 \%$ & $\$ 25 \mathrm{k}$ or less & $10.1 \%$ & 0 & $13.5 \%$ \\
\hline & $25-34$ & $11.0 \%$ & Female & $\mathbf{6 4 . 9 \%}$ & $\$ 25 \mathrm{k}$ to $\$ 45 \mathrm{k}$ & $8.7 \%$ & $\mathbf{1}$ & $\mathbf{5 0 . 0 \%}$ \\
\hline & $35-49$ & $24.7 \%$ & & & $\$ 45.1 \mathrm{k}$ to $\$ 75 \mathrm{k}$ & $\mathbf{3 7 . 7} \%$ & $\mathbf{2}$ & $32.4 \%$ \\
\hline & $\mathbf{5 0 - 6 4}$ & $\mathbf{4 1 . 1 \%}$ & & & $\$ 75.1 \mathrm{k}$ to $\$ 100 \mathrm{k}$ & $14.5 \%$ & 3 & $1.4 \%$ \\
\hline & $65+$ & $21.9 \%$ & & & $\$ 100 \mathrm{k}+$ & $29.0 \%$ & \multirow{2}{*}{$4+$} & $2.7 \%$ \\
\hline
\end{tabular}

Table 11: Newtown Socio-demographics

\begin{tabular}{|c|c|c|c|c|c|c|c|c|}
\hline Level of Analysis & \multicolumn{2}{|c|}{ Age (n53) } & \multicolumn{2}{c|}{ Gender (n53) } & \multicolumn{2}{c|}{ Income (n52) } & \multicolumn{2}{c|}{ No. Vehicles (n53) } \\
\hline Newtown (n53) & $15-24$ & $13.2 \%$ & Male & $34.0 \%$ & $\$ 25 \mathrm{k}$ or less & $15.4 \%$ & 0 & $17.0 \%$ \\
\hline & $25-34$ & $17.0 \%$ & Female & $\mathbf{6 6 . 0} \%$ & $\$ 25 \mathrm{k}$ to $\$ 45 \mathrm{k}$ & $9.6 \%$ & $\mathbf{1}$ & $\mathbf{6 2 . 3} \%$ \\
\hline & $\mathbf{3 5 - 4 9}$ & $\mathbf{3 7 . 7} \%$ & \multicolumn{2}{|c|}{$52.4 \% \mathrm{f}$} & $\$ 45.1 \mathrm{k}$ to $\$ 75 \mathrm{k}$ & $15.4 \%$ & 2 & $18.9 \%$ \\
\hline & $50-64$ & $30.2 \%$ & & $\$ 75.1 \mathrm{k}$ to $\$ 100 \mathrm{k}$ & $28.8 \%$ & 3 & $1.9 \%$ \\
\hline & $65+$ & $1.9 \%$ & & $\$ 100 \mathrm{k}+$ & $\mathbf{3 0 . 8} \%$ & \multirow{2}{*}{$4+$} & $0.0 \%$ \\
\hline
\end{tabular}

The representativeness of the total sample was determined by comparing each case study neighbourhood against available socio-demographic statistics for the relative areas. While neighbourhood level statistics were available for Churton Park, Newtown and Fairfield, Broadmead statistics were compared against a larger local region of Royal Oak. Broadmead contains slightly less than nineteen hundred dwelling units, and Royal Oak has just under thirty two hundred. Anecdotally Broadmead may have higher incomes than the Royal Oak average as well as a slightly older population. This may reflect on the number of vehicles owned data, but it is assumed gender ratios are comparable. Similarly, number of vehicles owned statistics were not available for any of the case study neighbourhoods. However, as stated earlier, the relative representativeness of this factor is less important given the large sample size.

\section{Churton Park}

In Churton Park, the surveyed sample male-to-female ratio and the age profile was representative of the actual population of the neighbourhood, with the exception of people in the sixty-five plus age bracket being slightly under-represented. Those with higher incomes were also slightly overrepresented, as is typical for this type of research. 


\section{Newtown}

In Newtown the age profile was representative, but a greater proportion of females replied to the survey compared to the actual neighbourhood proportion. Similarly, the sample population overrepresented those with higher incomes. With the vast majority of dwelling types being single family dwellings in both Churton Park and Broadmead, differentiating respondents based on dwelling types was unimportant as compared to those in Newtown or Fairfield having relatively greater mixes of dwelling types. However, while surveys were delivered to representative dwelling types in Newtown, on returned surveys it was impossible to determine dwelling types. This oversight was remedied with the sample in the Fairfield case study.

\section{Fairfield}

The sample population was relatively reflective of the actual population in Fairfield in terms of both age and gender. However, again females were slightly overrepresented. More importantly however, the dwelling type sample was somewhat representative. Roughly three quarters of all dwellings in Fairfield are apartments and just under half of all survey responses were from these types of dwellings. Uncharacteristically, middle income earners were slightly overrepresented and higher income earners underrepresented.

\section{Broadmead}

Both females and those in the 65+ age group are slightly overrepresented in Broadmead compared to the statistics for the wider area of Royal Oak. Those in the middle income bracket (45 to $75 \mathrm{k}$ ) were overrepresented while those in the lowest income bracket were underrepresented.

None of the representativeness discrepancies between the sample populations and the actual neighbourhood populations are drastic. From this it is concluded that the population sample is roughly representative, based on census data, to the greater population of each case study but, as is typical for self-administered questionnaires, those with higher incomes and females are overrepresented. ${ }^{732}$ Representativeness, however, is less critical when the elements of study are relationships between variables (as in this research), rather than distributions for variables taken singly. ${ }^{733}$ Similarly in exploratory research, "the premise of much correlation research, that one can only generalize from a representative sample to a larger population, is beside the point". ${ }^{734}$

\footnotetext{
${ }^{732}$ Schwanen \& Mokhtarian, 2004, p763

${ }^{733}$ Babbie, 1998, p237

${ }^{734}$ Yin in Groat and Wang, 2002, p. 354 152
} 


\subsection{Descriptive Statistics}

Descriptive statistics are presented for each variable, and independent sample t-tests are carried out to determine if the differences in reported means are significant between traditional and conventional neighbourhood survey respondents.

\section{Actual and Preferred Travel modes}

Travel preference was measured as a dichotomous variable, either a preference for the private automobile or an alternative to it. Means and standard deviations for dichotomous variables are meaningless, and as such, frequency descriptive statistics only are presented in Table 12. For a dichotomous variable, the closest approximation for a normal distribution would be a 50/50 split. Any situation where group sizes are extremely unequal (95\%-5\%) should be avoided. These types of group divisions should be avoided because the smaller group may be unduly influenced by just a few participants. ${ }^{735}$

Table 12: Travel Modes, Preferred and Actual

\begin{tabular}{|c|c|c|c|c|}
\hline Scale of Analysis & $\begin{array}{c}\text { Typically use } \\
\text { Private } \\
\text { Automobile }\end{array}$ & $\begin{array}{c}\text { Typically use } \\
\text { Alternatives }\end{array}$ & $\begin{array}{c}\text { Prefer Private } \\
\text { Automobile }\end{array}$ & $\begin{array}{c}\text { Prefer Alternative } \\
\text { to private } \\
\text { automobile }\end{array}$ \\
\hline $\begin{array}{c}\text { Total sample (n } \\
\text { 267) }\end{array}$ & 58.1 & 41.5 & $32.9 \%$ & $67.1 \%$ \\
\hline $\begin{array}{c}\text { Conventional } \\
\text { Neighbourhood } \\
\text { (n140) }\end{array}$ & $83.3 \%$ & $15.9 \%$ & $54.0 \%$ & $46.0 \%$ \\
\hline $\begin{array}{c}\text { Traditional } \\
\text { Neighbourhood } \\
\text { (n127) }\end{array}$ & $31.7 \%$ & $61.3 \%$ & $10.8 \%$ & $89.2 \%$ \\
\hline Broadmead (n 62) & $88 \% \%$ & $12 \%$ & & \\
\hline Churton Park (n 78) & $80.3 \%$ & $18.4 \%$ & $57.9 \%$ & $52.0 \%$ \\
\hline Newtown (n 53) & $23.5 \%$ & $76.5 \%$ & $5.9 \%$ & \\
\hline Fairfield (n 74) & $37.7 \%$ & $62.3 \%$ & $14.5 \%$ & $94.1 \%$ \\
\hline
\end{tabular}

\section{Stated Neighbourhood Preference}

On a scale of one to five survey participants indicated their stated neighbourhood preferences. Values above three indicate a preference for a traditional type of neighbourhood while values below three indicate a preference for a conventional type of neighbourhood. The resultant values from the four questions that assessed stated neighbourhood preferences were summed, and the average value was taken as the stated neighbourhood preference. Results are presented in Table 13.

\footnotetext{
${ }^{735}$ Warner, 2007
} 
Table 13: Stated Neighbourhood Preference

\begin{tabular}{|c|c|c|c|c|c|}
\hline $\begin{array}{c}\text { Neighbourhood } \\
\text { Type }\end{array}$ & Mean & $\begin{array}{c}\text { Standard } \\
\text { Deviation }\end{array}$ & $\begin{array}{c}\text { \% Prefer } \\
\text { Conventional }\end{array}$ & $\begin{array}{c}\text { \% prefer } \\
\text { neither }\end{array}$ & $\begin{array}{c}\text { \% Prefer } \\
\text { Traditional }\end{array}$ \\
\hline $\begin{array}{c}\text { Conventional } \\
(\mathrm{n}=139)\end{array}$ & 2.30 & 1.25 & 56.10 & 11.50 & 33.80 \\
\hline $\begin{array}{c}\text { Traditional } \\
(\mathrm{n}=126)\end{array}$ & 3.32 & .64 & 19.50 & 15.90 & 65.08 \\
\hline
\end{tabular}

As expected, the majority of traditional neighbourhood survey participants preferred traditional neighbourhood characteristics, and the majority of conventional neighbourhood survey participants preferred conventional neighbourhood attributes. Although this split was clearer in traditional neighbourhood, the difference between stated neighbourhood preference means was significant: $t(263)=-6.395, p<.001$.

\section{Conjoint Neighbourhood Preference}

Conjoint neighbourhood preferences were assessed on a scale of one to ten, however to make stated and conjoint neighbourhood preferences comparable, values were divided by two. Seven questions gauged conjoint neighbourhood preferences. The average of returned values was used as the conjoint neighbourhood preference measure, presented in Table 14.

Table 14: Conjoint Neighbourhood Preference

\begin{tabular}{|c|c|c|c|c|c|}
\hline $\begin{array}{c}\text { Neighbourhood } \\
\text { Type }\end{array}$ & Mean & $\begin{array}{c}\text { Standard } \\
\text { Deviation }\end{array}$ & $\begin{array}{c}\text { \% Prefer } \\
\text { Conventional }\end{array}$ & $\begin{array}{c}\text { \% prefer } \\
\text { neither }\end{array}$ & $\begin{array}{c}\text { \% Prefer } \\
\text { Traditional }\end{array}$ \\
\hline $\begin{array}{c}\text { Conventional } \\
(\mathrm{n}=139)\end{array}$ & 3.28 & .86 & 30.9 & 5.0 & 64.0 \\
\hline $\begin{array}{c}\text { Traditional } \\
(\mathrm{n}=127)\end{array}$ & 4.35 & .77 & 6.30 & 0.00 & 93.70 \\
\hline
\end{tabular}

Surprisingly, when neighbourhood preferences were presented conjointly, the majority of survey respondents from both neighbourhood types preferred a traditional neighbourhood type. However, the average difference between conjoint neighbourhood type preferences was still significant: $\mathrm{t}(264)=-10.702, \mathrm{p}<.001$.

\section{Problem Awareness}

Nine questions presented statements related to problems associated with private vehicle use that were prevalent in the literature. Respondents indicated their agreement with each of the statements on a five point scale, and the average value of the nine questions was used as the problem awareness measure. The descriptive statistics for the problem awareness measure are presented in Table 15. 
Table 15: Problem Awareness

\begin{tabular}{|c|c|c|c|c|c|}
\hline $\begin{array}{c}\text { Neighbourhood } \\
\text { Type }\end{array}$ & Mean & $\begin{array}{c}\text { Standard } \\
\text { Deviation }\end{array}$ & $\begin{array}{c}\text { \% Disagree } \\
\text { with car-use } \\
\text { problem } \\
\text { statements }\end{array}$ & $\begin{array}{c}\text { \% Neither } \\
\text { agree nor } \\
\text { disagree with } \\
\text { car-use } \\
\text { problem } \\
\text { statements }\end{array}$ & $\begin{array}{c}\text { Agree with } \\
\text { car-use } \\
\text { problem } \\
\text { statements }\end{array}$ \\
\hline $\begin{array}{c}\text { Conventional } \\
(\mathrm{n}=139)\end{array}$ & 3.35 & .54 & 21.60 & 7.9 & 70.5 \\
\hline $\begin{array}{c}\text { Traditional } \\
(\mathrm{n}=127)\end{array}$ & 3.73 & .51 & 7.1 & 0.8 & 92.1 \\
\hline
\end{tabular}

While both traditional $(\mathrm{n} 127, \mathrm{M}=33.60, \mathrm{SE}=.41)$ and conventional $(\mathrm{n} 139, \mathrm{M}=30.12, \mathrm{SE}=.41)$ survey respondents indicated high levels of agreement with car-use problem awareness questions, the traditional neighbourhood survey participants significantly $(\mathrm{t}(264)=-6.02, \mathrm{p}<.001)$ agreed more with the problem awareness statements.

\section{Moral Norm}

Moral norms were assessed with a single question on a five point scale asking survey participants if they felt guilty when they used their private automobiles to travel to the destinations they frequent. Moral norm descriptive statistics are presented in Table 16.

Table 16: Moral Norms

\begin{tabular}{|l|l|l|l|l|l|}
\hline $\begin{array}{l}\text { Neighbourhood } \\
\text { Type }\end{array}$ & Mean & $\begin{array}{l}\text { Standard } \\
\text { Deviation }\end{array}$ & $\begin{array}{l}\text { \% Did not feel } \\
\text { guilty about } \\
\text { using private } \\
\text { vehicle }\end{array}$ & $\begin{array}{l}\text { \% Neither felt } \\
\text { guilty nor not } \\
\text { guilty about } \\
\text { using private } \\
\text { vehicle }\end{array}$ & $\begin{array}{l}\text { Felt guilty } \\
\text { about using } \\
\text { private vehicle }\end{array}$ \\
\hline $\begin{array}{l}\text { Conventional } \\
(\mathrm{n}=135)\end{array}$ & 2.28 & 1.18 & 56.3 & 26.7 & 17.1 \\
\hline $\begin{array}{l}\text { Traditional } \\
(\mathrm{n}=120)\end{array}$ & 3.00 & 1.24 & 32.5 & 30.8 & 36.7 \\
\hline
\end{tabular}

The majority of conventional neighbourhood survey participants did not feel guilty about their private vehicle use compared to traditional neighbourhood survey participants, who almost equally did not feel guilty, neither felt guilty nor not guilty and felt guilty. The average differences between traditional and conventional neighbourhood survey participants were significant: $\mathrm{t}(253)=-4.753$, $\mathrm{p}<.001$. 


\section{Felt Responsibility}

Felt responsibility was calculated with a single question on a five point scale, asking survey participants if they felt personally responsible for the problems resulting from car use when they drive. These results are presented in Table 17.

Table 17: Felt Responsibility

\begin{tabular}{|l|l|l|l|l|l|}
\hline $\begin{array}{l}\text { Neighbourhood } \\
\text { Type }\end{array}$ & Mean & $\begin{array}{l}\text { Standard } \\
\text { Deviation }\end{array}$ & $\begin{array}{l}\text { \% Did not } \\
\text { feel guilty } \\
\text { about using } \\
\text { private } \\
\text { vehicle }\end{array}$ & $\begin{array}{l}\text { \% Neither } \\
\text { felt guilty } \\
\text { nor not guilty } \\
\text { about using } \\
\text { private } \\
\text { vehicle }\end{array}$ & $\begin{array}{l}\text { \% Felt guilty } \\
\text { about using } \\
\text { private } \\
\text { vehicle }\end{array}$ \\
\hline $\begin{array}{l}\text { Conventional } \\
(\mathrm{n}=137)\end{array}$ & 2.62 & 1.09 & 41.6 & 38.7 & 19.7 \\
\hline $\begin{array}{l}\text { Traditional } \\
(\mathrm{n}=122)\end{array}$ & 3.02 & 1.22 & 30.33 & 31.1 & 38.52 \\
\hline
\end{tabular}

A significant difference was observed: $\mathrm{t}(257)=-2.765, \mathrm{p}<.05$, between traditional and conventional survey participants average felt responsibility.

\section{Perceived Behavioural Control (travel mode)}

One question assessed, on a five point scale, survey participants' perceived behavioural control over using alternatives to the private automobile. Participants were asked to rate how difficult it would be for them to use an alternative. Results are presented in Table 18.

Table 18: Perceived Behavioural Control (private vehicle)

\begin{tabular}{|l|l|l|l|l|l|}
\hline $\begin{array}{l}\text { Neighbourhood } \\
\text { Type }\end{array}$ & Mean & $\begin{array}{l}\text { Standard } \\
\text { Deviation }\end{array}$ & $\begin{array}{l}\text { \% that would } \\
\text { find it } \\
\text { difficult to } \\
\text { take } \\
\text { alternatives } \\
\text { to the private } \\
\text { vehicle }\end{array}$ & $\begin{array}{l}\text { \% finding it } \\
\text { neither easy } \\
\text { nor difficult } \\
\text { to take } \\
\text { alternatives } \\
\text { to the private } \\
\text { vehicle }\end{array}$ & $\begin{array}{l}\text { \% that would } \\
\text { find it easy to } \\
\text { take } \\
\text { alternatives } \\
\text { to the private } \\
\text { vehicle }\end{array}$ \\
\hline $\begin{array}{l}\text { Conventional } \\
(\mathrm{n}=137)\end{array}$ & 3.25 & 1.45 & 35.8 & 12.4 & 51.8 \\
\hline $\begin{array}{l}\text { Traditional } \\
(\mathrm{n}=126)\end{array}$ & 4.26 & 1.15 & 10.3 & 12.7 & 77.0 \\
\hline
\end{tabular}

On average, traditional neighbourhood survey respondents found it easier to take alternatives to the private vehicle than conventional neighbourhood survey respondents, and this difference was significant: $\mathrm{t}(261)=-6.26, \mathrm{p}<.001$. 


\section{Perceived Behavioural Control (moving)}

Moving perceived behavioural control was assessed with two questions asking about the financial effort as well as the hassles involved in moving. Both were assessed on a five point scale and the hassles of moving were reverse-coded to make the scales agree in terms of perceived behavioural control. Results are presented in Table 19.

Table 19: Perceived Behavioural Control (moving)

\begin{tabular}{|l|l|l|l|l|l|}
\hline $\begin{array}{l}\text { Neighbourhood } \\
\text { Type }\end{array}$ & Mean & $\begin{array}{l}\text { Standard } \\
\text { Deviation }\end{array}$ & $\begin{array}{l}\text { \% that found } \\
\text { moving both } \\
\text { financially } \\
\text { difficult (A) } \\
\text { and the } \\
\text { hassles to } \\
\text { outweigh the } \\
\text { benefits (B) }\end{array}$ & $\begin{array}{l}\text { \% that found } \\
\text { it neither easy } \\
\text { nor difficult } \\
\text { to relocate }\end{array}$ & $\begin{array}{l}\text { \% that found } \\
\text { moving both } \\
\text { financially } \\
\text { easy (A) and } \\
\text { the benefits to } \\
\text { outweigh the } \\
\text { hassles (B) }\end{array}$ \\
\hline $\begin{array}{l}\text { Conventional } \\
(\mathrm{n}=139)(\mathrm{A})\end{array}$ & 2.96 & 1.07 & 35.3 & 32.4 & 32.4 \\
\hline $\begin{array}{l}\text { Traditional } \\
(\mathrm{n}=127)(\mathrm{A})\end{array}$ & 2.51 & 1.12 & 51.2 & 31.5 & 17.3 \\
\hline $\begin{array}{l}\text { Conventional } \\
(\mathrm{n}=139)(\mathrm{B})\end{array}$ & 2.78 & 1.08 & 42.4 & 32.4 & 25.2 \\
\hline $\begin{array}{l}\text { Traditional } \\
(\mathrm{n}=127)(\mathrm{B})\end{array}$ & 2.63 & 1.21 & 46.46 & 33.86 & 19.69 \\
\hline
\end{tabular}

On average, traditional neighbourhood survey participants identified less behavioural control over their ability to relocate for financial reasons than their conventional counterparts. This difference was also significant: $\mathrm{t}(264)=3.354, \mathrm{p}<.001$. However, survey participants from both neighbourhoods equally found the hassles to outweigh the benefits of moving, and as such no statistically significant difference between these means is apparent.

\section{Place Attachment}

Place attachment was measured with two questions asking participants to indicate how they would feel if they had to move from their current neighbourhood, and if they were attached to their neighbourhood. Both questions were asked on a five point scale, and the average value was used for the place attachment appraisal. Descriptive statistics are presented in Table 20. 
Table 20: Place Attachment

\begin{tabular}{|l|l|l|l|l|l|}
\hline Place Attachment & Meighbourhood \\
Type & Mean & $\begin{array}{l}\text { Standard } \\
\text { Deviation }\end{array}$ & $\begin{array}{l}\text { \% Not } \\
\text { attached to } \\
\text { their } \\
\text { neighbourhood }\end{array}$ & $\begin{array}{l}\text { \% Neither } \\
\text { attached nor } \\
\text { detached to } \\
\text { their } \\
\text { neighbourhood }\end{array}$ & $\begin{array}{l}\text { \% Attached to } \\
\text { their } \\
\text { neighbourhood }\end{array}$ \\
\hline $\begin{array}{l}\text { Conventional } \\
(\mathrm{n}=139)\end{array}$ & 3.31 & .906 & 23.0 & 27.3 & 49.6 \\
\hline $\begin{array}{l}\text { Traditional } \\
(\mathrm{n}=127)\end{array}$ & 3.87 & .92 & 11.0 & 18.9 & 70.1 \\
\hline
\end{tabular}

On average there is a significant difference between conventional and traditional levels of place attachment: $\mathrm{t}(264)=-5.031, \mathrm{p}<.001$, and traditional neighbourhood survey participants are more attached to their neighbourhood.

\section{Tenure}

Tenure was assessed as length of residency. Results are presented in Table 21, and divided into three categories of residents who have resided for three or fewer years, between four and ten years and more than ten years in their current neighbourhood.

Table 21: Tenure

\begin{tabular}{|l|l|l|l|l|l|}
\hline Tenure & Mean & $\begin{array}{l}\text { Standard } \\
\text { Deviation } \\
\text { Type }\end{array}$ & $\begin{array}{l}\text { \% residing } \\
\text { for 3 years or } \\
\text { less }\end{array}$ & $\begin{array}{l}\text { \% residing } \\
\text { between 4 } \\
\text { and 10 years }\end{array}$ & $\begin{array}{l}\text { \% residing } \\
\text { for greater } \\
\text { than 10 years }\end{array}$ \\
\hline $\begin{array}{l}\text { Conventional } \\
(\mathrm{n}=139)\end{array}$ & 12.18 & 8.05 & 10.8 & 39.6 & 49.5 \\
\hline $\begin{array}{l}\text { Traditional } \\
(\mathrm{n}=127)\end{array}$ & 11.13 & 7.59 & 10.0 & 50.0 & 40.0 \\
\hline
\end{tabular}

Surprisingly, lengths of tenure are very similar between both the traditional and conventional neighbourhood survey participants, and there is no statistically significant difference.

\section{Travel Attitude}

Travel attitudes were assessed with seven questions garnered from the literature that asked survey participants to indicate if they agreed with a number of statements relating to their travel attitude, on a five point scale. The average of these questions was used as the travel attitude measure. Descriptive results are presented in Table 22. 
Table 22: Travel Attitudes

\begin{tabular}{|l|l|l|l|l|l|}
\hline \multicolumn{2}{|l|}{ Travel Attitudes } & Seighbourhood \\
Type & Mean & $\begin{array}{l}\text { Standard } \\
\text { Deviation }\end{array}$ & $\begin{array}{l}\text { \% with } \\
\text { auto- } \\
\text { orientated } \\
\text { travel } \\
\text { attitudes }\end{array}$ & $\begin{array}{l}\text { \% with neither } \\
\text { auto nor } \\
\text { alternative } \\
\text { orientated travel } \\
\text { attitudes }\end{array}$ & $\begin{array}{l}\text { \% with } \\
\text { alternative } \\
\text { orientated } \\
\text { travel } \\
\text { attitudes }\end{array}$ \\
\hline $\begin{array}{l}\text { Conventional } \\
(\mathrm{n}=138)\end{array}$ & 3.12 & .64 & 42.0 & 9.4 & 48.6 \\
\hline $\begin{array}{l}\text { Traditional } \\
(\mathrm{n}=124)\end{array}$ & 3.53 & .56 & 13.7 & 11.3 & 75.0 \\
\hline
\end{tabular}

On average, traditional neighbourhood participants $(\mathrm{n} 124, \mathrm{M}=24.70, \mathrm{SE}=.349)$ expressed travel attitudes more in favour of alternatives to the car than conventional neighbourhood survey participants $(\mathrm{n} 138, \mathrm{M}=21.84, \mathrm{SE}=.381)$. This difference in travel attitudes was significant: $\mathrm{t}(260)=$ $-5.499, \mathrm{p}<.001$ (two tailed), and represents a medium effect, $\mathrm{r}=.32$.

\subsection{Dependent Variable Normality Tests}

Prior to testing hypotheses, the normality of the data was checked. Normality is the assumption that variables are normally distributed, and can be evaluated through histograms as well as through examinations of skew and kurtosis.

Travel attitude data were symmetrical and non-kurtotic both for the total sample, and when examined separately for each type of neighbourhood, traditional or conventional. When broken down further into each case study, travel attitudes again were neither skewed nor kurtotic. However, Fairfield travel attitude data tended to be slightly negatively skewed (i.e. the majority of travel attitudes tended toward being strongly being anti-auto orientated). This skew is not considered to be significant however, because the converted skew $\mathrm{z}$-score is less than the upper threshold of 1.96 at $\mathrm{p}<.05(\mathrm{z}=-1.83)$.

\section{Model Simplification}

To obtain a parsimonious regression model, independent sample t-tests were carried out with socio demographic data and travel attitudes. If significant differences remain in travel attitudes when comparing identical socio-demographic cohorts between the traditional and conventional neighbourhoods, then it can be deduced that factors outside of socio-demographics are influencing 
travel attitudes, and the relevant socio-demographic variables can be excluded from the regression model.

\section{$\underline{\text { Age and Travel Attitudes }}$}

Significant differences in travel attitude means existed when comparing identical sociodemographic cohorts between conventional and traditional neighbourhood survey participants, for all socio-demographic variables except the sixty-five plus age bracket (see Table 23). Means and standard errors are presented to correspond to a scale from one to five. The sixty-five plus age bracket was thus included in the regression model.

Table 23: Age and Travel Attitude t-test

\begin{tabular}{|c|l|c|}
\hline $\begin{array}{l}\text { Age bracket } \\
\text { (years) }\end{array}$ & \multicolumn{1}{|c|}{ Mean and Standard Error } & \multicolumn{1}{c|}{ t-test } \\
\hline $18-24$ & $\begin{array}{l}\text { Conv (n4), M=3.46, SE .46 } \\
\operatorname{Trad}(\mathrm{n} 8), \mathrm{M}=3.25, \mathrm{SE} .07\end{array}$ & $\mathrm{t}(3.14)=.46 \mathrm{p}<.05$ \\
\hline $25-34$ & $\begin{array}{l}\operatorname{Conv}(\mathrm{n} 7), \mathrm{M}=3.24, \mathrm{SE}=.26 \\
\operatorname{Trad}(\mathrm{n} 17), \mathrm{M}=3.69, \mathrm{SE}=.11\end{array}$ & $\mathrm{t}(22)=-1.85, \mathrm{p}<.05$ \\
\hline $35-49$ & $\begin{array}{l}\operatorname{Conv}(47), \mathrm{M}=3.06 \mathrm{SE}=.08 \\
\operatorname{Trad}(37), \mathrm{M}=3.5, \mathrm{SE}=.09\end{array}$ & $\mathrm{t}(82)=-3.485, \mathrm{p}<.001$ \\
\hline $50-64$ & $\begin{array}{l}\text { Conv (n48), } \mathrm{M}=3.16, \mathrm{SE}=.55 \\
\operatorname{Trad}(\mathrm{n} 46), \mathrm{M}=3.6 \mathrm{SE}=.09\end{array}$ & $\mathrm{t}(92)=-3.70, \mathrm{p}<.001$ \\
\hline 65 plus & $\begin{array}{l}\text { Conv (n29), } \mathrm{M}=3.04, \mathrm{SE}=.13 \\
\operatorname{Trad}(\mathrm{n} 15), \mathrm{M}=3.34, \mathrm{SE}=.19\end{array}$ & $\mathrm{t}(42)=-1.30, \mathrm{p}>.05$ \\
\hline
\end{tabular}

\section{Gender and Travel Attitudes}

For gender, there are significant differences between mean travel attitudes for males in traditional compared to conventional neighbourhoods: $\mathrm{t}(105)=-3.96, \mathrm{p}<.001$. On average, traditional neighbourhood males are more in favour of alternatives to the car $(\mathrm{n} 43, \mathrm{M}=24.33, \mathrm{SE}=.61)$ than conventional neighbourhood males ( $\mathrm{n} 64, \mathrm{M}=21.06, \mathrm{SE}=.54)$. On average, females in traditional neighbourhoods (n81, $\mathrm{M}=24.89, \mathrm{SE}=.42)$ also expressed travel attitudes more in favour of alternatives to the private automobile compared to their conventional neighbourhood counterparts $(\mathrm{n} 70, \mathrm{M}=22.59, \mathrm{SE}=.51)$. This difference was also significant $\mathrm{t}(149)=-3.49, \mathrm{p}<.001$, and represented a small effect: $r=.29$. Significant travel attitude differences remain between neighbourhood types for both genders; therefore, gender is not important in terms of predicting travel attitudes, and thus is not included in the regression model. 


\section{Income and Travel Attitudes}

In all income brackets there were significant differences between travel attitude means when comparing participants with identical incomes. This suggests that income does not play a role on influencing travel attitudes. See Tables 24-26 for a breakdown of this analysis.

Table 24: Income Descriptive Statistics 1

\begin{tabular}{|c|c|c|c|c|c|c|c|c|c|}
\hline Neighbourhood & \multicolumn{3}{|c|}{ Less than \$24K } & \multicolumn{3}{c|}{ \$25-44K } & \multicolumn{3}{c|}{ \$45-74K } \\
\hline & no & M & SE & no & M & SE & no & M & SE \\
\hline Conventional & 2 & 17.5 & .50 & 7 & 21.29 & 2.31 & 21 & 21.90 & .89 \\
\hline Traditional & 14 & 23.93 & .57 & 11 & 24.45 & 1.66 & 34 & 25.09 & .77 \\
\hline
\end{tabular}

Table 25: Income Descriptive Statistics 2

\begin{tabular}{|c|c|c|c|c|c|c|}
\hline Neighbourhood & \multicolumn{3}{|c|}{$\$ 75-100 \mathrm{~K}$} & \multicolumn{3}{c|}{ \$100K Plus } \\
\hline & no & M & SE & no & M & SE \\
\hline Conventional & 22 & 20.95 & .80 & 69 & 21.97 & .55 \\
\hline Traditional & 25 & 24.89 & .63 & 35 & 24.86 & .61 \\
\hline
\end{tabular}

Table 26: Income Descriptive Statistics 3

\begin{tabular}{|c|c|c|c|}
\hline Income & df & t-statistic & significance \\
\hline Less than $\$ 24 \mathrm{~K}$ & 14 & -4.13 & $\mathrm{p}<.001$ \\
\hline$\$ 25-44 \mathrm{~K}$ & 16 & -1.14 & $\mathrm{p}<.05$ \\
\hline$\$ 45-74 \mathrm{~K}$ & 53 & -2.64 & $\mathrm{p}<.05$ \\
\hline$\$ 75-100 \mathrm{~K}$ & 45 & -3.84 & $\mathrm{p}<.001$ \\
\hline$\$ 100 \mathrm{~K}$ Plus & 102 & -3.26 & $\mathrm{p}<.001$ \\
\hline
\end{tabular}

\section{$\underline{\text { Summary independent sample t-tests }}$}

When comparing identical socio-demographic segments of the sample population, significant differences in travel attitudes between neighbourhood types were evident for all factors except between the sixty-five plus age bracket cohort and for car ownership. Significant travel attitudes existed between neighbourhood types for income and gender which suggests that these sociodemographic factors do not influence travel attitudes. For travel attitudes, only the 65 plus year old age segment of the sample population and number of cars owned are included in the regression model. For all other socio demographics, significant travel attitudes differences were observed between identical socio-demographic segments in either the traditional or conventional neighbourhood types.

\subsection{Regression Model Results}

Having determined that the difference in travel attitudes between conventional and traditional neighbourhoods is significant, the next step is to conduct a hierarchical multiple regression to test hypothesises and see which independent variables best predict travel attitude. For this, previous 
research was used to both select the predictor variables and the order in which they were entered into the model. Previous literature suggests entering the socio-demographic variables first, the psychological variables second, the preference variables third and the new variables (place attachment, tenure, perceived relocation behavioural control) fourth. ${ }^{736}$ Once the most salient variables have been determined, variables that had little or no effect on travel attitudes were excluded from the model, and an analysis was run again in a forward stepwise multiple regression to determine the individual contribution of each variable to the explanation of travel attitude variance. Similar scores on certain measures are anticipated to affect travel attitudes differently between traditional and conventional survey respondents and as such the sample population was split into either neighbourhood category. For example, strong place attachment in traditional neighbourhoods was anticipated to correspond to high alternative travel attitude scores, whereas strong place attachment scores in conventional neighbourhoods were expected to correlate with low alternative oriented travel attitudes. Similarly, a combined regression model generalized poorly. Confidence interval boundaries tended to cross zero, indicating that in some instances, living in a neighbourhood for a long time (long term tenure) would result in anti-auto travel attitudes, while for other instances, long tenure would result in pro-auto travel attitudes. Regression results are presented in Tables 27 and 28 for either neighbourhood type.

\footnotetext{
${ }^{736}$ Heath \& Gifford, 2002; Cao et al., 2007 
Table 27: Conventional Neighbourhood Travel Attitude Regression

\begin{tabular}{|c|c|c|c|c|c|c|c|}
\hline \multicolumn{7}{|c|}{ Hierarchical Regression of Travel Attitudes, Conventional Neighbourhoods } & \\
\hline Step & Variable & $\mathrm{R}^{2}$ & $\Delta \mathrm{R}^{2}$ & & $\beta$ & $t$ & \\
\hline \multirow[t]{3}{*}{1} & & .059 & .059 & & & & \\
\hline & No_cars & & & & -.245 & -2.321 & * \\
\hline & $65+$ & & & & -.066 & & \\
\hline \multirow[t]{7}{*}{2} & & .538 & .480 & $* * *$ & & & \\
\hline & No_cars & & & & -.170 & -2.225 & * \\
\hline & $65+$ & & & & -.107 & & \\
\hline & PBC auto alternatives & & & & -.161 & -2.112 & * \\
\hline & moral norm (guilt) & & & & .321 & 3.615 & ** \\
\hline & problem awareness & & & & .472 & 5.236 & $* * *$ \\
\hline & personal responsibilty & & & & .051 & & \\
\hline \multirow[t]{11}{*}{3} & & .587 & .048 & & & & \\
\hline & No_cars & & & & -.132 & & \\
\hline & $65+$ & & & & -.073 & & \\
\hline & PBC auto alternatives & & & & -.157 & -2.037 & * \\
\hline & moral norm (guilt) & & & & .236 & 2.564 & * \\
\hline & problem awareness & & & & .413 & 4.550 & $* * *$ \\
\hline & personal responsibilty & & & & .081 & & \\
\hline & mode prefered & & & & .050 & & \\
\hline & $\begin{array}{l}\text { neighborhood preference } \\
\text { (stated) }\end{array}$ & & & & .007 & & \\
\hline & $\begin{array}{l}\text { neighborhood preference } \\
\text { (conjoint) }\end{array}$ & & & & .221 & 2.353 & * \\
\hline & mode typical & & & & .045 & & \\
\hline \multirow[t]{15}{*}{4} & & .591 & .005 & & & & \\
\hline & No_cars & & & & -.149 & & \\
\hline & $65+$ & & & & -.061 & & \\
\hline & PBC auto alternatives & & & & -.166 & -2.079 & * \\
\hline & moral norm (guilt) & & & & .233 & 2.448 & * \\
\hline & problem awareness & & & & .427 & 4.427 & $* * *$ \\
\hline & personal responsibilty & & & & .078 & & \\
\hline & mode prefered & & & & .054 & & \\
\hline & $\begin{array}{l}\text { neighborhood preference } \\
\text { (stated) }\end{array}$ & & & & .003 & & \\
\hline & $\begin{array}{l}\text { neighborhood preference } \\
\text { (conjoint) }\end{array}$ & & & & .231 & 2.359 & * \\
\hline & mode typical & & & & .040 & & \\
\hline & tenure & & & & -.061 & & \\
\hline & place attachment & & & & .053 & & \\
\hline & ease of moving & & & & -.008 & & \\
\hline & hassle of moving & & & & -.015 & & \\
\hline \multicolumn{7}{|c|}{ note: only significant t-values are shown. ${ }^{*} p<.05 .{ }^{* *} p<.01 .{ }^{* \star *} p<.001}$. & \\
\hline
\end{tabular}

For conventional neighbourhoods, the initial regression step with the socio-demographic variables (65+ age bracket and number of vehicles owned) correlated with $5.9 \%$ of the variance in travel attitudes, and this was insignificant. The second step in the model with the psychological variables (perceived behavioural automobile use control, moral norm, problem awareness and personal responsibly) correlated with an additional $48 \%$ travel attitude variance. This association was significant. The third step in the regression that included the preference variables (stated and conjoint neighbourhood preferences, preferred and typical travel modes) added an additional $4.8 \%$ variance explanation; however, this was not significant. The final step in the conventional neighbourhood regression included the new variables (place attachment, tenure and perceived relocation behavioural control). Their addition added half a percent more variance explanation, and 
this was not significant. When all variables were entered into the model, a total of $59.2 \%\left(\mathrm{R}^{2}=\right.$ $.059)$ of the variance in travel attitudes was accounted for with the fourteen variables. The initial psychological variables (perceived behavioural automobile use control, moral norm, problem awareness and personal responsibly) explained the majority of variance in travel attitudes, and when all the variables in the model were included, perceived behavioural automobile use control, moral norm, problem awareness and conjoint neighbourhood preferences were the only significant variables for the prediction of travel attitudes.

The betas indicate the direction of the relationships observed. Higher problem awareness, an increased sense of guilt and conjoint neighbourhood preferences for traditional type neighbourhoods all correspond to alternative orientated travel attitudes. A reduced sense of behavioural control over the use of private vehicles, on the other hand, corresponds to less alternative orientated travel attitudes as can be seen in Tables 27 and 28. 
Table 28: Traditional Neighbourhood Travel Attitude Regression

\begin{tabular}{|c|c|c|c|c|c|c|c|}
\hline \multicolumn{7}{|c|}{ Hierarchical Regression of Travel Attitudes, Traditional Neighbourhoods } & \\
\hline Step & Variable & $\mathrm{R}^{2}$ & $\Delta \mathrm{R}^{2}$ & & $\beta$ & $t$ & \\
\hline \multirow[t]{3}{*}{1} & & .037 & .037 & & & & \\
\hline & No_cars & & & & -.010 & & \\
\hline & $65+$ & & & & -.195 & & \\
\hline \multirow[t]{7}{*}{2} & & .365 & .328 & *** & & & \\
\hline & No_cars & & & & -.013 & & \\
\hline & $65+$ & & & & -.087 & & \\
\hline & PBC auto alternatives & & & & .054 & & \\
\hline & moral norm (guilt) & & & & -.173 & & \\
\hline & problem awareness & & & & .461 & 3.460 & ** \\
\hline & personal & & & & .302 & 2.077 & * \\
\hline \multirow[t]{11}{*}{3} & & .412 & .047 & & & & \\
\hline & No_cars & & & & .019 & & \\
\hline & $65+$ & & & & -.119 & & \\
\hline & PBC auto alternatives & & & & -.012 & & \\
\hline & moral norm (guilt) & & & & -.205 & & \\
\hline & problem awareness & & & & .445 & 3.097 & ** \\
\hline & personal & & & & .366 & 2.413 & * \\
\hline & mode prefered & & & & -.131 & & \\
\hline & $\begin{array}{l}\text { neighborhood } \\
\text { preference (stated) }\end{array}$ & & & & -.104 & & \\
\hline & $\begin{array}{l}\text { neighborhood } \\
\text { preference (conjoint) }\end{array}$ & & & & .038 & & \\
\hline & mode typical & & & & .227 & & \\
\hline \multirow[t]{15}{*}{$\overline{4}$} & & .503 & .091 & * & & & \\
\hline & No_cars & & & & -.021 & & \\
\hline & $65+$ & & & & .006 & & \\
\hline & PBC auto alternatives & & & & .035 & & \\
\hline & moral norm (guilt) & & & & -.152 & & \\
\hline & problem awareness & & & & .510 & 3.529 & ** \\
\hline & personal & & & & .297 & 1.994 & * \\
\hline & mode prefered & & & & -.137 & & \\
\hline & $\begin{array}{l}\text { neighborhood } \\
\text { preference (stated) }\end{array}$ & & & & -.163 & & \\
\hline & $\begin{array}{l}\text { neighborhood } \\
\text { preference (conjoint) }\end{array}$ & & & & .029 & & \\
\hline & mode typical & & & & .216 & & \\
\hline & tenure & & & & -.006 & & \\
\hline & place attachment & & & & -.073 & & \\
\hline & ease of moving & & & & .136 & & \\
\hline & hassle of moving & & & & -.189 & & \\
\hline \multicolumn{7}{|c|}{ note: only significant t-values are shown. ${ }^{*} \mathrm{p}<.05 .{ }^{* *} \mathrm{p}<.01 .{ }^{* * *} \mathrm{p}<.001}$. & \\
\hline
\end{tabular}

For traditional neighbourhoods, the initial socio-demographic variables (65+ age bracket and number of vehicles owned) accounted for $3.7 \%$ of the variance in travel attitudes, and this was not significant. The addition of the first set of psychological variables in the second step of the regression improved the accuracy of the model to correlate with $36.5 \%$ of the variance in travel attitudes. This improvement in prediction was significant. The third step of the regression added the remaining psychological variables, and added a further insignificant $4.7 \%$ explanation. The fourth and final step of the regression for traditional neighbourhood travel attitudes examined the influence of the new variables. Here, an additional $9.1 \%$ of the variance in travel attitudes was accounted for, and this additional explanation was significant. 
The model correlated with a total of $50.3 \%$ of the variance in travel attitudes. Only two variables were significant in the prediction of travel attitudes. These were problem awareness and personal responsibility. Similar to conventional neighbourhood case studies, higher problem awareness and personal responsibility values are associated with alternative orientated travel attitudes.

From this regression it cannot be concluded that the new variables of place attachment, tenure or perceived relocation behavioural control contribute to or explain travel attitudes.

\subsection{Qualitative Survey Results}

A total of forty-eight email addresses were obtained from the quantitative hand delivered survey. An additional seventeen email addresses were garnered from the initial pilot study. The online survey was emailed to these sixty-five email addresses and a total of fifty-one responses were gained for a response rate of seventy-eight percent (78\%). This was relatively high considering the elapsed time between surveys; however, as each of the respondents indicated that they would be interested in further research, the response rate is unremarkable. Traditional neighbourhood survey participants were however, overrepresented $(n=37)$ necessitating an additional hand delivered flyer to be distributed randomly to a conventional neighbourhood (Broadmead). The delivery of the additional flyer was restricted to Broadmead, instead of to both conventional neighbourhoods, due to both logistic and time constraints; the neighbourhoods are located on either side of the world. The flyer drop gained another fourteen responses, for a response rate of fourteen percent. In all, a total of seventy two on-line surveys were completed (traditional $n=37$, conventional $n=35$ ). Only those responses that developed into frequent patterns are reported (greater than seven thematically matching responses) and presented in order of highest to lowest response rates. Results are presented in Table 29.

Table 29: Conventional Qualitative Survey Responses

\begin{tabular}{|c|c|}
\hline Question & Conventional $(n=35)$ \\
\hline $\begin{array}{l}\text { What were the most important factors } \\
\text { that led you to move to the } \\
\text { neighbourhood you live in now? }\end{array}$ & $\begin{array}{l}\text { (20)Access to green space (parks, the } \\
\text { view, trees; (16)Dwelling features } \\
\text { (maintenance free, clean, large house, } \\
\text { large yards, parking); (11)General } \\
\text { neighbourhood appeal; (9) Safe; } \\
\text { (7)Quiet; (7)The people }\end{array}$ \\
\hline $\begin{array}{l}\text { 2. List some things (if any) you would like } \\
\text { to see improved in your neighbourhood } \\
\text { or that are a compromise for you? }\end{array}$ & $\begin{array}{l}\text { (20) Lack of amenity; (18) Reliance on } \\
\text { car; (11) Lack of community; (11) } \\
\text { Speeding cars; (7) Boring } \\
\text { (monoculture, nothing going on, } \\
\text { nothing to do) }\end{array}$ \\
\hline
\end{tabular}




\begin{tabular}{|c|c|c|}
\hline & $\begin{array}{l}\text { What factor(s) most influence you to } \\
\text { remain in your neighbourhood? }\end{array}$ & $\begin{array}{l}\text { (18) Familiarity; (14) Potential for } \\
\text { change; (14)This is our home; (12) } \\
\text { Investment (in dwelling or social); } \\
\text { (10) Access to green space; (7) Safe } \\
\text { (7) nostalgia }\end{array}$ \\
\hline & $\begin{array}{l}\text { Why you think you use the mode of } \\
\text { travel that you do? }\end{array}$ & $\begin{array}{l}\text { (28) drive, lack of choice; (18) drive } \\
\text { out of necessity; (11) drive, work } \\
\text { requirement; (9) drive, to haul large } \\
\text { loads; (7) Kids; (7) To meet } \\
\text { commitments; (7) drive, convenience }\end{array}$ \\
\hline & $\begin{array}{l}\text { Do you identify with your } \\
\text { neighbourhood and/or the people in it? }\end{array}$ & $\begin{array}{l}\text { (15) yes with the natural aspect; } \\
\text { (11)Yes similar people: ( } 8 \text { ) yes similar } \\
\text { values; (14) no don't know many } \\
\text { people }\end{array}$ \\
\hline
\end{tabular}

Table 30 presents the traditional neighbourhood survey respondent responses.

Table 30: Traditional Neighbourhood Qualitative Survey Responses

\begin{tabular}{|c|c|}
\hline Question & Traditional $(n=37)$ \\
\hline $\begin{array}{l}\text { What were the most important factors } \\
\text { that led you to move to the } \\
\text { neighbourhood you live in now? }\end{array}$ & $\begin{array}{l}\text { (31) Proximity to amenity/ work; } \\
\text { (12)Trees/ natural landscape/ beauty; } \\
\text { (10)Rental prices; (7) Diversity/ } \\
\text { multiculturalism }\end{array}$ \\
\hline $\begin{array}{l}\text { 2. List some things (if any) you would like } \\
\text { to see improved in your neighbourhood } \\
\text { or that are a compromise for you? }\end{array}$ & $\begin{array}{l}\text { (12) Traffic Problems; (9) Parking } \\
\text { problems; (9) Property Prices/ taxes }\end{array}$ \\
\hline $\begin{array}{l}\text { 3. What factor(s) most influence you to } \\
\text { remain in your neighbourhood? }\end{array}$ & $\begin{array}{l}\text { (29) Location factors; (13) } \\
\text { Neighbours, family close by; (12) } \\
\text { Same reasons for moving (11) Sense } \\
\text { of community }\end{array}$ \\
\hline $\begin{array}{l}\text { 4. Why you think you use the mode of } \\
\text { travel that you do? }\end{array}$ & $\begin{array}{l}\text { 18) W/C/B to avoid parking; (12) W/C } \\
\text { easiest most convenient; (10)W/C } \\
\text { dislike traffic; (8) W/C for heath; (8) } \\
\text { Drive to transport things; (7) W/C bus } \\
\text { is terrible; (7) Drive at night }\end{array}$ \\
\hline $\begin{array}{l}\text { 5. Do you identify with your } \\
\text { neighbourhood and/or the people in it? }\end{array}$ & $\begin{array}{l}\text { (27) Yes, with the diversity; (16) } \\
\text { Yes with the community feel; }\end{array}$ \\
\hline
\end{tabular}

W/C/ B walk, cycle or bus for commute mode

Reasons given by survey participants for initially locating in either traditional or conventional neighbourhoods differed significantly. While the most salient explanations related to location factors, these factors differed between neighbourhood types. Conventional neighbourhood survey participants identified access to green-space as an important determinant for their residential location choices; whereas traditional neighbourhood survey participants listed proximity to employment and more consumer orientated amenity. Likewise, other explanations given for residential location choices differed. Conventional neighbourhood survey participants highlighted 
dwelling attributes, while these did not register for traditional neighbourhood survey participants. A salient discrepancy between the two neighbourhood types was also the language used. Traditional survey respondents typically cited "proximity" to certain features as their location consideration while conventional survey respondents cited "access" to certain features, namely green space. While both proximity and access can be interpreted as location considerations, it is more likely that proximity refers to a location factor and access refers to a design feature.

An indicative response given as the reason for initially locating in the conventional survey respondents' respective neighbourhood was:

"A maintenance free home with lots of access to parks and in a quiet neighbourhood."

For traditional neighbourhood survey participants, a typical response provided for their initial neighbourhood selection was:

"Proximity to work and city; cost of rental properties; interesting suburb due to cultural diversity"

Although explanations for moving are based on retrospective assessments, which some authors argue are inaccurate ${ }^{737}$, these data closely match reasons given for remaining in the neighbourhood. Some survey respondents explicitly referred to their earlier responses as per the example below;

"The same ones which made me choose to live in Fairfield. No interest in moving elsewhere."

Compromises in both types of neighbourhoods formed salient patterns. For conventional neighbourhood survey participants, the lack of consumer amenity was paramount, along with both a reliance on the private automobile and problems such as speeding associated with this reliance. Some common responses were:

"It is a somewhat boring neighbourhood-once you get home from work you have to get back into the car to do anything in the evening."

"Improved walking and cycling that is safe, access to the local shops and amenity."

\footnotetext{
${ }^{737}$ Handy et al., 2005
} 
For traditional neighbourhood survey participants, compromises related mostly to parking issues and traffic issues, but this was for Newtown only. The other traditional neighbourhood, Fairfield, mainly cited gentrification issues such as high property prices and taxes. Typical responses from the traditional neighbourhood survey participants are as follows:

"Noisy cars are an issue - unnecessarily stereos and loud exhausts."

"The neighborhood is getting kind of expensive. Taxes are going up and the dynamic of the neighbourhood is turning more high end."

Factors survey participants listed for remaining in their chosen neighbourhoods despite their expressed compromises reflected many of the same reasons for initially locating in each neighbourhood. However, other reasons related to investments survey participants had made in their neighbourhoods, such as dwelling improvements, social associations and a general familiarity with the area. A typical example given by traditional neighbourhood survey respondents is:

"We have renovated our house so that it really meets our current needs. - There are not too many alternative places that meet our social and environmental aspirations. - Because of the planning it is a very beautiful place to live and is hard to leave."

Although both conventional and traditional neighbourhood survey respondents gave explanations for their use of the private automobile that were similar, conventional survey respondents only gave explanations for driving, and not for when they used alternatives. In conventional neighbourhoods, residents mainly explained their driving behaviour as a result of a lack of volition, similar to comparable findings in the literature. ${ }^{738}$ Responses ranged from having a lack of alternative and employment expectations or out of necessity, hauling large loads as well as for convenience.

Typical responses included:

"In my job I carry computer gear and go to Johnsonville most days which means I take the car to work."

"Drive mostly, not many other realistic options."

\footnotetext{
${ }^{738}$ Wall et al., 2008
} 
A lack of volition did not appear to be a factor for traditional survey respondents' driving behaviour. Instead they cited the time of day to influence the use of the private motor vehicle, and this was during evenings. Similar to conventional neighbourhood survey responses, hauling large loads was also cited for traditional residents as a motivating factor for using the private automobile. Common travel attitude explanations given by traditional neighbourhood survey participants were:

"Walk for most trips - most things are close enough that I don't need to drive, and doing so would be more hassle and stress than just walking (getting the car out, driving through often fiddly one-way street system, the hell of parking, and then the second ring of parking hell when I come back home and can't find a park near my house and have to circle/park somewhere else/attempt a difficult park which stresses me out...). Also I enjoy the exercise and getting out and about."

"Walk, I hate driving. I feel the roads are too crowded and that people drive too fast."

For traditional neighbourhood survey respondents who travel by alternative means, their travel explanations included avoiding traffic and parking issues, enjoyment and providing exercise.

Rather than the qualitative survey asking general questions about place attachment, the unique aspect of place identification was explored. Identification relates to place attachment as an aspect of it and, more importantly, as a closer proxy to the process theorized for the formation of place attachment. Survey responses indicated that place identification was a factor for only about half the survey respondents in the conventional neighbourhoods. Similarities were stressed as influencing place identification and these included similar people, values or a similar appreciation for the natural environment. The only explanation given for not identifying with place that developed into a theme, related to not knowing many other residents or neighbours. Indicative responses for traditional neighbourhood survey participants were:

"Yes[I identify] - a similar socio economic group with I would argue similar values."

"The problem with no effective village center is that we have only moderate contact with the neighbourhood. This results in a lack of local social interaction. - We identify with our neighbourhood mostly through a common interest in the natural setting and parks."

Traditional neighbourhood survey respondents' responses on the other hand, demonstrated a strong place identity and, counter to the conventional neighbourhood survey participants, they identified 170 
with the diversity of place. This included the multi-cultural aspect, the diversity of incomes and age groups and the diversity of values. In addition, the community feel of the traditional neighbourhood was cited as a reason for place identification. Typical response examples include;

"I identify with the neighbourhood. It has the right kind of "feel" - energetic without being loud and noisy (like town), but not as sleepy as many other suburbs. There is a mixed age group, families, seniors, local business people. I am part of this neighbourhood."

"Yes \{I identify]. There is a strong sense of community, working together for each other. The wide diversity of people in close proximity leads to valuing of each other's identity, culture, and "otherness." 


\section{Discussion}

This section discusses the quantitative and qualitative findings from the main study as well as how these findings relate to the initial pilot study and physical form assessments of the four case studies. First, the discussion centres on the hypothesised relationship that the post-decision reasoning variables of place attachment and tenure have with travel attitudes. Next, the discussion concentrates on other findings that relate to the hypothesis but were not the posited phenomena under direct investigation. This includes the insight into the role perceived behavioural control has on informing travel attitudes rather than just travel behaviours. The chapter concludes with a discussion on the results that relate to the way preferences are interpreted and perceived.

\subsection{Post-Decision Reasoning Variables}

Neither the quantitative nor the qualitative survey provides results consistent with the hypothesis that the post-decision reasoning factors of place attachment or tenure influence travel attitudes. Given that this hypothesised correlation is the foundation to the premise of this dissertation, that actions influence attitudes, this assertion cannot be made from the observed quantitative relationships between place attachment, tenure and travel attitudes. While the qualitative survey probed survey participants' responses for both travel attitudes and place attachment, the nature of qualitative research does not allow responses for either measure to be correlated to one another. Unless survey participants specifically alluded to the hypothesised process of post-decision reasoning, linking their place attachment to travel attitudes, the qualitative survey was unlikely to make this association. A lack of volition was the most salient explanation for auto-orientated travel attitudes and although this relates to dwelling location choices, this connection was not made by the survey participants. Citing barriers to pro-environmental behaviour as well as perceiving such behaviour as beyond the control of the survey participants is a common theme within the travel behaviour literature, ${ }^{739}$ and is reflected in the present study. This lack of volition is further discussed as it relates to perceived behavioural control later in this chapter.

Survey participants from both neighbourhood types reported relatively high place attachment, in line with the view that place attachment is a common person-environment experience ${ }^{740}$. Place attachment in both neighbourhood types may be a factor of the many theories on why place attachment develops, the most convincing of which relates to a learned familiarity of place. Within

\footnotetext{
${ }^{739}$ Wall et al., 2008

${ }^{740}$ Mesch \& Manor, 1998; Relph, 1976
}

172 
a familiar, comfortable place, an individual can relax, problem-solve, self-reflect and carry out day to day activities with ease. ${ }^{741}$

Traditional survey participants expressed a significantly greater level of place attachment ${ }^{742}$ with their neighbourhood than conventional survey participants. This may have been a factor of traditional neighbourhoods' better meeting the expressed neighbourhood preferences of the residents. The conjoint neighbourhood preference evaluation revealed that the majority of both traditional and conventional survey participants preferred traditional neighbourhood characteristics: ninety-four and sixty-four percent respectively. However, stated preferences were more in line with actual neighbourhood choices, and here only thirty-four percent (34\%) of conventional neighbourhood survey participants preferred traditional neighbourhood characteristics, and sixtyfive percent $(65 \%)$ of traditional survey participants preferred traditional neighbourhood characteristics. Interestingly, how preferences were presented, either stated or conjoint, had a large effect on how preferences were interpreted. To add to this conundrum, conjoint neighbourhood preferences were correlated to travel attitudes in the conventional case study neighbourhoods. As preferences tended toward preferring traditional neighbourhood characteristics, travel attitudes tended toward preferring alternatives to the private automobile.

The greater place attachment reported in traditional neighbourhoods may reflect the greater match between actual travel modes commonly used and preferred travel modes. Seventy-five percent of survey participants in the traditional case studies had travel preferences that matched their preferred travel modes, compared to sixty seven percent in the conventional case studies. This finding is in line with other studies that demonstrate a percentage (approximately a quarter) of residents within the two neighbourhood types whose travel preferences do not match their travel behaviours. ${ }^{743}$

The slightly lower rate of survey participants expressing an attachment for place in conventional neighborhoods may relate to recent associations between conventional land-use patterns and a lack of sustainability. Place attachment is postulated to develop for places that are favorable to identify with, ${ }^{744}$ and when a place is perceived as unsustainable, place attachment may diminish. That said however, previous empirical findings have associated place attachment with access to natural $\operatorname{areas}^{745}$ and with residents residing in cul-de-sacs. ${ }^{746}$ These two associations may be relevant to the place attachment observed in the conventional case study neighbourhoods, as access to natural

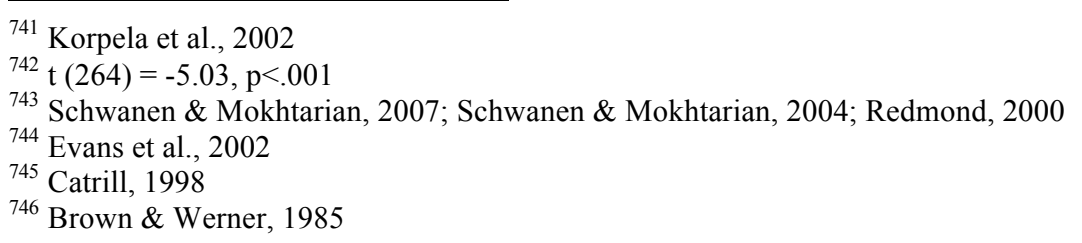


areas was a salient dwelling location consideration for conventional neighbourhood qualitative survey participants and, arguably, many of these participants may also reside in cul-de-sacs, given the high proportion of cul-de-sacs in conventional neighbourhoods found in the GIS neighbourhood assessment. The high levels of place attachment observed in the traditional case study neighbourhoods may also reflect place attachment correlations found in the literature. High levels of place attachment have been observed in village type residential settings ${ }^{747}$ and in New Urbanist communities or neighbourhoods with traditional land-use patterns. ${ }^{748}$

High levels of place attachment in the traditional case studies potentially reflect a perceived inability to relocate. The extant literature identifies a correlation between older individuals and greater attachment to place, ${ }^{749}$ which suggests a tenure length association but also a capability aspect. The quantitative survey identified a greater proportion of traditional neighbourhood survey participants (51\% compared to $35 \%$ for the conventional case study) for whom moving posed both a financial as well as an effort hurdle.

The descriptive statistics for place attachment and the qualitative responses for place identity are also similar in their distribution: PA 50\% conventional and 70\% traditional, PI $60 \%$ conventional and $73 \%$ traditional. This lends weight to the overall interpretation of the concept to include both facets of place attachment as a multidimensional issue. Likewise, the ability to generalize place attachment findings in either form of neighborhood is strengthened by the congruency between quantitative and qualitative responses. Still, however, the relative distributions of place attachment do not support the hypothesized correlation between it and travel attitudes.

Like place attachment, tenure also did not correlate to travel attitudes. Despite the disparate relative ages of the case study neighbourhoods, tenure lengths were remarkably similar. However, survey participants with tenure lengths of three or fewer years may reflect differing aspects of either neighbourhood type. In conventional neighbourhoods, those residing for three or fewer years may be new home owners who have recently purchased a newly built home. In the traditional case study neighbourhoods, however, those residing for three or fewer years are less likely to be new home owners and more likely to be renters, due to the relatively few new homes being built and large number of rental properties.

\footnotetext{
${ }^{747}$ Kim \& Kaplan, 2004

${ }^{748}$ Kim \& Kaplan, 2004

${ }^{749}$ Brown, 1987; Varady, 1986; Brown \& Perkins, 1996 
Tenure is correlated to place attachment for the total sample, ${ }^{750}$ and this corresponds with previous findings that demonstrate place attachment to develop over time. ${ }^{751}$ However, at the neighbourhood scale, tenure is correlated to place attachment in traditional neighbourhoods ( $\mathrm{r}=.273$, p (one tailed) $<.05)$ but not in conventional neighbourhoods. This discrepancy in the associations between length of tenure and place attachment has been reported in the literature, ${ }^{752}$ but has not been related to neighbourhood type. Perhaps neighbourhood type plays a role in this observed inconsistency of associations.

While the hypothesized correlations were not observed in either the quantitative or qualitative surveys, the premise of this dissertation, that travel attitudes may be subsequent to neighbourhood location decisions rather than antecedent is supported by findings related to perceived behavioural control.

\subsection{Perceived Behavioural Control}

Perceived behavioural control (PBC) was a significant variable related to travel attitudes in both the quantitative and qualitative surveys. However, this association was salient only for conventional neighbourhood survey participants. From the quantitative survey, PBC was correlated with travel attitudes for conventional but not traditional neighbourhood survey respondents. Presumably this limited correlation reflects objective travel mode constraints in conventional as compared to traditional neighbourhoods. Likewise, lack of volition claims were more pronounced in the conventional compared to the traditional neighbourhood case studies from the qualitative survey. For traditional neighbourhood qualitative survey participants, use of the private automobile reflected a utilitarian aspect rather than one of limited choice. This included evening driving and driving to haul large items or loads. Similarly, for these same participants the use of alternative travel modes were a response to constraints associated with driving, such as a lack of parking and traffic problems. In both neighbourhood types for the qualitative survey, what is perceived as the easiest option in terms of travel mode is the selected preference. Although environmental concern was mentioned by a few traditional neighbourhood survey participants, this pro-environmental regard did not materialize into a response pattern. These qualitative findings suggest that travel attitudes, regardless of neighbourhood type, are influenced by a situational tally of benefits and detriments and not existing innate values or beliefs. While it is likely that participants from either

\footnotetext{
${ }^{750} \mathrm{r}=.15$, $\mathrm{p}$ (one tailed) $<.05$

${ }^{751}$ Hay, 1998; Tuan, 1977, Relph, 1976; Moore and Graefe, 1994

752 Stedman, 2002
} 
neighbourhood type would express different values and beliefs, the present study's findings suggest that each individual's context provides allowances that permit individuals to afford to hold certain values and beliefs without contradicting their previous choices and decisions.

These findings provide an empirical example for the earlier criticism ${ }^{753}$ of the limited consideration for context within environmental psychology's behaviour theories. Instead of accepting values as the nucleus to behaviours, a wider interpretation of context to evaluate the factors which permit individuals to hold certain values provides a greater insight into the general causality behind proenvironmental behaviour, and specifically, travel behaviour. Context can include political and international factors such as globalization as some authors suggest, ${ }^{754}$ or a more detailed account of physical form factors, as the present study suggests. Just as Upton Sinclair once said, "it is difficult to get a man to understand something when his salary depends upon his not understanding it." So too then, might it be true that you cannot expect to find pro-environmental values when both identities and previous decisions run counter to having them. This position is buttressed by a previous study that found pro-environmental behaviours to be situation specific. ${ }^{755}$

While some findings from the present study suggest a post-decision evaluation of beliefs and values, as mentioned above; the quantitative survey shows that this may differ with neighbourhood type. Here, findings from the quantitative survey correlate travel attitudes with variables associated with value positions, but only for traditional neighbourhood survey respondents. Both problem awareness and personal responsibility factors were the only variables correlated with travel attitudes in the regression model for these respondents. This suggests that for traditional neighbourhood survey participants, existing beliefs and values may inform their travel attitudes. However, while this has been the accepted interpretation of the data in previous research ${ }^{756}$, it is just as plausible that the relationship goes the other way. Here the limitations of multiple regressions are exposed, because of the nature of correlation and its lack of accounting for the direction of causality. The qualitative survey, though, provides some indication that this relationship may go from behaviours to beliefs, rather than from beliefs to behaviours. Traditional neighbourhood respondents failed to cite pro-environmental values or beliefs as informing their travel behaviour or their neighbourhood location considerations. Instead, these were assessed as decisions made to maximize utility. However, the qualitative study also demonstrated that proximity to local amenities and employment was an important determinant for neighbourhood location choices both initially and as a reason for remaining in the neighbourhood, for traditional

\footnotetext{
${ }^{753}$ Steg, 2009; Hamnett \& Randolph, 1988

${ }^{754}$ Van Kempen 2007

${ }^{755}$ Cleveland et al., 2005

${ }^{756}$ Schwanen \& Mokhtarian, 2005

176
} 
neighbourhood survey participants. This qualitative finding, together with the quantitative correlations between values and travel attitudes, could be interpreted as in line with the existing literature and supporting the view that values and beliefs are antecedents to behaviour for this group of survey participants. For conventional neighbourhood survey participants, however, evidence points more strongly toward travel attitudes being a post-decision or subsequent evaluation in-line with this dissertation's hypothesis.

Residential location considerations guided by existing travel preference were not apparent from the qualitative survey for conventional neighbourhood survey participants; nor were mode preferences correlated to travel attitudes. Additionally, PBC was correlated with travel attitudes in the regression model. These three factors from the qualitative and quantitative surveys suggest that for conventional neighbourhood survey participants, travel attitudes reflect the post-decision hypothesis. It is logical to associate PBC with actual travel behaviours, but the correlation to travel attitudes implies an alternative causal direction. While correlations alone cannot determine causation, the qualitative findings support this possibility. Travel attitudes were explained mostly as a lack of volition in the qualitative survey, and this finding reflects the extant literature. In numerous studies, a reoccurring discourse is prevalent that points to a lack of personal volition as a salient constraint to both environmentally supportive behaviour and travel behaviour specifically. ${ }^{757}$ This narrative reflects a denial of responsibility and a lack of blameworthiness on the part of the respondents, who view themselves as "victim[s] of forces over which they had little or no control." ${ }^{, 758}$ Beyond a perceived lack of behavioural control, a lack of knowledge or information has been cited as a deterrent to pro-environmental behaviour as well. ${ }^{759}$ The difference in problem awareness between the two neighbourhood types was significant, however, all problem awareness measures were well above the scale midpoint. While a lack of public transport, employment commitments or time constraints may all be valid travel constraints to the survey participants in the present study as in other studies, these constraints should not inform travel attitudes unless some measure of cognitive dissonance mitigation is occurring. Here, the hypothesized effects of postdecision reasoning as described in this dissertation's methodology appear somewhat supported by the qualitative and quantitative findings, and add to the literature on the role behavioural control plays on both environmentally significant behaviour in general and travel behaviour specifically.

\footnotetext{
${ }^{757}$ Wall et al., 2008; Kennedy et al., 2009; Cleveland et al., 2005; Guagano 1995

${ }^{758}$ Bickerstaff and Walker, 2002, p 2184

${ }^{759}$ Kennedy et al., 2009
} 
Given the observed divergence between stated and conjoint neighbourhood preferences in the present study and the unique results showing a conjoint preference for traditional neighbourhood characteristics regardless of neighbourhood type, it is worth considering both how preferences are determined, and the separation of travel preferences from neighbourhood preferences. Previous studies have demonstrated a relative level of mismatch between actual choices, in terms of both neighbourhood and travel modes, and preferences. ${ }^{760}$ These studies, however, fail to distinguish neighbourhood preferences from travel preferences, and as such, the relative levels of mismatch may be inaccurate. Separating travel and neighbourhood related preferences is also suggested in the literature. Here, studies that aggregate travel and neighbourhood preferences to classify residents as either dissonant or consonant with their neighbourhood may categorize individuals as dissonant however, they "may still be consonant as far as their travel preferences are concerned". ${ }^{761}$ Similarly, the bundling of neighbourhood characteristics into stereotypical examples has been criticised as doing more to obscure actual neighbourhood preferences than illuminate them. ${ }^{762}$ Likewise, unearthing precise neighbourhood qualities that both traditional and conventional neighbourhood residents prefer is vague. A clearer picture of what neighbourhood attributes traditional and conventional neighbourhood residents prefer is necessary to guide planners, policy and urban designers. And the findings from this dissertation, at least in part, suggest traditional neighbourhood characteristics have a wider appeal than previous aggregated preference measures have indicated.

Congruent with arguing that neighbourhood and travel preferences should be separated in studies rather than aggregated, it is more important to discover if the survey participant rather than the researcher sees travel behaviour and neighbourhood preferences as linked. Survey participants may very well not perceive the connection and therefore would not experience any inconsistency between their attitudes and behaviours. Previous experimental research documents that cognitive dissonance is not produced if inconsistency can be attributed to external forces. ${ }^{763}$ The failure by survey participants to make this association in the present study reiterates this point. Both traditional and conventional survey participants reported a discrepancy between their stated and conjoint neighbourhood preferences. While the stated preference questions simply listed certain features such as a large yard that respondents then indicated a preference for, the conjoint

\footnotetext{
${ }^{760}$ Schwanen \& Mokhtarian, 2005; Levine \& Frank, 2007

${ }^{761}$ Bohte et al., 2009

${ }^{762}$ Myers \& Gearin, 2001

763 Thogersen, 2004

178
} 
preference questions asked respondents to trade-off certain preferences for others. Typically the trade was predicated on an increased need to use the private automobile, or land-uses geared more toward the private automobile. Thus the mismatch between stated and conjoint preferences indicates that survey participants were not automatically making the compromise connection. The role of descriptive norms (i.e. the greater social context) may also suggest that wider normative observations take primacy over moral considerations. ${ }^{764}$

The idea that individuals locate into neighbourhoods that match their travel preferences was found to be only partly true in the present dissertation. It appeared that traditional neighbourhood respondents did so, with their reference to proximity to certain amenities; however, conventional neighbourhood residents did not. This limitation, when considering the influence travel mode preferences have on neighbourhood selection, was also apparent in a study by Van Wee et al, (2002) where they found that self selection was important particularly for those that preferred public transportation, and not for private automobile orientated individuals. Rather than suggesting that individuals locate in neighbourhoods where travel preferences are met, findings from this study suggest that there are individuals who possess distinct travel preferences (they dislike driving) and hence locate in neighbourhoods where alternatives are available. There are also other individuals who value factors outside travel preferences when they select neighbourhoods to reside in. Typically conventional neighbourhoods provide the factors they value. Removing the implicit assumption that survey participants are cognizant of the ramifications of their neighbourhood choices, both elicits a clearer picture of actual preferences and provides an insight into how and what physical features are accrued value for varying subgroups. This is a unique finding to the study of travel behaviour in the context of self-selection research with measured physical assessments.

From the present dissertation's findings it may not be as hard as first imagined to simultaneously meet the preferences of both conventional and traditional residents within the same local. These two groups are potentially more similar than they are different.

\subsection{Preference Thresholds}

Both the quantitative and qualitative studies indicate that the differences between traditional and conventional neighbourhood survey participants' travel and neighbourhood preferences, while

\footnotetext{
${ }^{764}$ Bamberg \& Schmidt, 2003
} 
statistically significant, are not actually all that different. Instead preferences generally agree between the two groups. It is their hierarchical rank that differs, and this difference is not diametrically opposed, but rather preferences fall on the same side of the balance. This finding gives confidence for policy and design toward their aim of reconciling the differences between the perceived opposing preferences of either traditional and conventional neighbourhood residents. More sustainable land-uses that meet the desires of a wider population without separating groups by larger distances appears realistic in view of the present study's findings. While some studies emphasize the differences between traditional and conventional neighbourhood residents to tailor policy toward these divergent groups, ${ }^{765}$ it may serve sustainability objectives better to stress the similarities. This recommendation is congruent with those found in the study of place identity and the negative role of out-group discrimination. Hogg (2007) reiterates this point and implores researchers to not "emphasize the differences between places in order to explain certain negative behaviours". This may also be true for the different values and beliefs held by different people.

The differences in preferences between the survey participants from the two neighbourhood types reflects, at least to some degree, the varying values and meanings survey participants place on certain aspects of their environment. While the intention of the present study was to explore neighbourhood and travel preferences, without simultaneously evaluating all the factors that influence residential location choices, it is difficult to determine an accurate preference hierarchy. In this respect, "a dwelling is an individual's primary anchor in the environment" and serves functions beyond just shelter, privacy and security. ${ }^{766}$ Given the meaning-laden aspect of dwellings, a greater explication of dwelling factors would have benefited the overall description of a preference hierarchy. This value hierarchy has seldom been addressed in the existing literature. However, in an empirical study that examined the sale value of certain neighbourhood characteristics, salient submarkets surfaced that valued neighbourhood design features differently by neighbourhood type ${ }^{767}$ Neighbourhood characteristics, such as proximity to bus stops, homogeneity of single family residential uses, diversity or enhanced pedestrian access, were all ascribed different values depending on what type of neighbourhood these features were located in: traditional or conventional. Separating prices paid for dwellings into neighbourhood features begins to describe the value hierarchy placed on certain neighbourhood characteristics. Likewise, there is evidence that shows that consumers prefer certain aspects of traditional neighbourhoods but not others: particularly higher density. ${ }^{768}$ A shorter commute is also widely appealing. ${ }^{769}$ Consumers have indicated a preference for newer dwellings in neighbourhoods that were, or appeared older as

\footnotetext{
${ }^{765}$ Schwanen \& Mokhtarian, 2007; Schwanen \& Mokhtarian, 2004; Anabel, 2005

${ }^{766}$ Coolen, 2006, p186

${ }^{767}$ Song \& Quercia, 2008

${ }^{768}$ Rybczynski, 1998

${ }^{769}$ Bradford, 1993

180
} 
well. ${ }^{770}$ Knowing which pieces consumers prefer, and how those preferences interact, along with what tradeoffs consumers are willing to make is important. Combining this understanding with well defined value positions on the NEP or QOL scale may start to establish what mixes of neighbourhood design features can accommodate the most preferences. However, how meanings are assigned to certain design elements, and if these meanings change in different combinations of design features, pose the ultimate hurdle. Whether or not accommodating all preferences is even possible, or is desirable, has yet to be established.

While planning for preferences may, in general, be commendable, it may not be entirely well advised. Given the well documented unsustainable direction of current consumption patterns ${ }^{771}$, accommodating preferences is worth careful consideration. Collective consumption has even outpaced personal incomes, and this trend in North America is suggested to be the underlying factor that contributed to the recent near global economic collapse. ${ }^{772}$ The supply of mortgages to those that can't afford them is a clear example of where supplying to meet preferences can go wrong. While home ownership is a preference held by many, this preference must be weighed against an individual's financial context. Likewise, if preferences reflect trends, the rising obesity epidemic adds scepticism to preference orientated planning. ${ }^{773}$

Preference planning may also limit the diversity of solutions available to modern planning problems. It is difficult to determine preferences for land-uses that may not currently exist or that residents may have little experience with. ${ }^{774}$ Similarly, relying on previous preferences to inform future land-uses, to a large degree, ensures that future land-uses will not drastically vary from the orthodox or a business-as-usual approach. Drastic changes from the conventional, or at least experimentation with vastly different land-uses, appears to be what is required to progress planning and urban design to a state capable of actually responding to the pressures they face. While planning may be criticised for overly relying on past preferences some suggest that developers perceive consumer demand as highly conservative, and tend to avoid innovations in their product. ${ }^{775}$ However, it is hard to decipher whether developers interpret the market as conservative or if they view planning regulations as barriers to innovation, either constraint limits change.

\footnotetext{
${ }^{770}$ Bradford, 1993

${ }^{771}$ Schor, 2005

${ }^{772}$ Cynamon \& Fazzari, 2008

${ }^{773}$ Frank, 2004

${ }^{774}$ Morrow-Jones et al., 2004

${ }^{775}$ Rydin, 2007
} 
Preferences may also reflect socially undesirable tendencies. Theories of the role self-congruency plays with informing neighbourhood choices purport to explain a need by individuals to seek to reside in neighbourhoods that reflect their self image. This includes racial identities resulting in racially segregated communities. Several studies by Clark $(1991,1992)$ have shown the preference of white Americans for predominantly white neighbourhoods. Likewise, European neighbourhood preferences reflect ethnicity as well as racial neighbourhood segregation. ${ }^{776}$ The tendency to reside in ethnically homogeneous neighborhoods is indicative of the effect of the need for selfconsistency, i.e. individuals seek to live in neighbourhoods with other individuals similar to them. ${ }^{777}$

Other socially undesirable preferences include a growing trend to withdraw from community exchanges or the public realm. ${ }^{778}$ As technology improves and mobility increases, individuals no longer appear to rely on a local community, but instead have access to a much broader diversity of communities that they are able to be a part of. This withdrawal from community may potentially exacerbate conflict in commons dilemmas, and this has been found even when preservation is preferred to exploitation. ${ }^{779}$ The conflicting goals of public and private ownership, and community and private interests suggest that simply meeting demand does little for sustainability objectives or realistic housing programmes.

A preference for the untenable appears to be a common finding in neighbourhood preference studies too. Studies have found both a dislike for sprawl as well as density, ${ }^{780}$ and similarly a preference for single family dwellings as well as short commutes ${ }^{781}$. The findings from the current dissertation support this view and provide empirical evidence to the widely held opinion that a proportion of consumers wish to realize the benefits of suburban living without the perceived drawbacks $^{782}$.

Injudicious urban renewal programmes and Robert Moses' highway blitzkrieg in the middle of the twentieth century has left the planning profession and urban design forever branded in the public eye as misguided disciplines. Now, heavy reliance on public input and mandated participatory planning are modern day reflections of the latter disciplines' early mistakes. However, there is much misinterpretation as to who is at fault for the ill advised social reform by design folly, and

\footnotetext{
${ }^{776}$ Semyonov et al., 2007

${ }^{777}$ Lindstrom \& Bartling, 2003

${ }^{778}$ Kintrea, 2007

${ }^{779}$ Bimonte, 2008

${ }^{780}$ Danielson et al, 1999

${ }^{781}$ Molin et al., 2001

${ }^{782}$ Danielson et al, 1999; Samuels, 2005
}

182 
likewise for the extent public input should play a role. Given that preferences may only be a reflection of trade policy, bylaws, government regulation and advertising rather than actual market responses, public input must be weighed against this possibility. Some claim that unsustainable consumption patterns may be an outcome of income increases, widening consumer choice, falling retail prices, and taste preferences in an expanding global marketplace. However, implicit here is the belief that markets for all kinds of items are naturally developing mechanisms for managing consumption and production. The driving force in this approach is the sovereign consumer motivated by subjective preferences and limited by personal budget constraints and market choice. ${ }^{783}$ However, the market view ignores the effect of cultural and political influences as well as any regard for managing the commons.

The position of preferences as sacrosanct must be challenged. This is especially true given the possibility that they may only reflect government regulation that ensures the conventional or existing unsustainable practice. Likewise allowing preferences to guide planning and urban design may perpetuate socially undesirable tendencies, may also limit future solution options as well as give the false impression that untenable desires can be had. Ideally, personal responsibility should remain just that: personal. However, in light of recent financial events, there appears to be a case for regulating responsibility. Next to perhaps the global warming debate, the vested interests in maintaining a business-as-usual approach to land-use patterns will likely be almost as contentious.

\section{Recommendations}

While the present study established a number of relevant findings in support of the hypothesis, it did not prove the hypothesis, nor establish a clear relationship between post-decision reasoning variables and travel attitudes. At the same time, the null hypothesis also cannot be accepted: that travel attitudes exist prior to residential location choices. A number of recommendations are relevant to future studies that aim to explore the contextual factors that inform attitudes after decisions have been made, and not prior.

A more in-depth qualitative survey that explored participants' interpretations and motivations for both their travel as well as residential location choice behaviours may have provided richer results. Here, an interview technique would have better suited. However, the risk of leading survey

${ }^{783}$ Kasa, 2008 
participants in the pursuit of a very specific phenomenon remains. Differentiating between travel attitudes and travel behaviours also posed a problem. The qualitative survey asked "why" survey participants thought they travelled the way they did, instead of a more accurate inquiry into travel attitudes. However, eliciting travel attitudes would have necessitated inquiring about travel preferences which still misses the specificity sought to elicit actual travel attitudes.

Respondents' explanations for travel attitudes given in the qualitative survey and their place identification responses did not translate into observable associations with travel attitudes. Without leading the survey participants, it proved difficult to ask this double barrelled question (do you identify with place and does this influence your travel attitudes?). Again, a more in-depth survey may have helped. Similarly, a greater differentiation of place attachment in both the quantitative and qualitative surveys may have clarified the relationship between place attachment and travel attitudes.

Given that the hypothesis rested on observing place attachment indicators to develop over time instead of existing prior to deciding to reside in a particular neighbourhood, a greater explication of the multi dimensionality of place attachment may have been beneficial. While some forms of place attachment may have developed prior to locating in a particular neighbourhood another form may be more likely to develop over time. Along these lines, Twigger-Ross and Uzzell (1996) propose that there are different types of place identity, place referent and place congruent continuity. Place referent continuity suggests an attachment to a place itself, whereas place congruent continuity proposes an attachment to place because it fits with an individual's "schema" or mental representation of what types of places they usually are attached to. Determining which type of place attachment was observed may have aided in establishing the hypothesised relation. Length of residency also indicates what type of place attachment is occurring, and here, for participants that resided in their neighbourhoods longer, place attachment was stronger for them, indicating a place referent form of place attachment.

While the hypothesis relied on place attachment variables to explore the possibility that attitudes formed after residential location choices, the observed relationship with perceived behavioural control (PBC) provided an unanticipated supportive finding. Further studies could examine the type of PBC observed. Kraft et al., ( 2005) break PBC into the elements of three separate but interrelated factors (perceived control, perceived confidence and perceived difficulty), or as two separate but interrelated factors representing self-efficacy (measured by perceived difficulty and perceived confidence or by just perceived confidence) and perceived control. This further division of PBC may provide greater insight. 
Perceived behavioural control also relates to scale. For the present study this scale is the neighbourhood; however, locus of control studies have indicated that there are many scales to perceived behavioural control, and a greater consideration of the magnitude or at what scale perceived behavioural control diminishes is applicable. ${ }^{784}$ In terms of pro-environmental behaviours, household behaviours are generally easily controllable, such as composting or providing natural ventilation as well as sealing drafts. However, the provision of recycling services as well as public transport is less immediately under an individual's control and because of this the relationship with moral norms and personal responsibility may be affected. Where these latter factors are relevant to cognitive dissonance, the scale then of perceived behavioural control must also be relevant.

Personality as well as value indicators were not included in the present study because of a perceived lack of relation to the built environment and due to the overall purpose to explore links between the built form and attitudes. Similarly, the concentration of the present study was on the role context, specifically past decisions, plays on travel attitudes. However, in line with personality factors, consumer researchers often include three aspects of self concept that may have benefited the current study. These are the actual self-image, the ideal self-image, and the social self-image. ${ }^{785}$ The actual self-image is defined as how consumers see themselves. The ideal self-image is defined as how consumers would like to see themselves, and the social self-image is defined as how consumers would like to be seen by significant others. Significant others are those people that an individual cares to impress, such as friends, relatives, associates, co-workers, and others. These three divisions of self-concept relate to the overall wider context of an individuals' cultural and social influences and to self identification which, as discussed earlier, relates to place attachment. This connection to place attachment and self-identification helps to place personality factors back into a realm relevant to the built form, and as such, perhaps these factors should have been considered in the present study.

\footnotetext{
${ }^{784}$ Kennedy et al., 2009

${ }^{785}$ Sirgy \& Su, 2000
} 
The aim of the dissertation was to explore the potential for attitudes to be a factor of previous decisions rather than an attribute informing them. This potential relationship was explored through the hypothesis of post-decision reasoning and the mediating influence of place attachment and length of tenure on travel attitudes. While being somewhat counter to the logical subsequent evaluation of the extent and generalizability of the mismatch between travel attitudes and travel behaviour identified in the pilot study, this direction was due in part to the literature which demonstrated a fairly consistent mismatch of about a quarter of residents whose travel and neighbourhood preferences did not match their actual behaviours. ${ }^{786}$ However, an initial finding from the present study indicates that the extent of mismatch may be more than what has previously been found. Here, the separation of travel from neighbourhood preferences provides this insight. About a third of all survey participants' stated neighbourhood preferences did not match the current neighbourhood they resided in. However, conjoint neighbourhood preferences, where a trade between certain neighbourhood features was evaluated, indicated slightly more than a third of conventional neighbourhood survey participants to be mismatched with their neighbourhood, and only six percent of traditional neighbourhood survey participants to be mismatched. Travel mode preferences, when separated from neighbourhood preferences, are congruent with the extent of mismatch observed for neighbourhood preferences. Here, twenty four percent and thirty-three percent of traditional and conventional neighbourhood survey participants respectively expressed travel mode preferences counter to their actual travel behaviours. The mismatch between travel and neighbourhood preferences indicates a slightly greater appeal for traditional neighbourhood features above what has previously been found.

While the hypothesized relations between place attachment, tenure and travel attitudes were not observed, the premise that past decisions influence current preferences, beliefs and attitudes is supported by the findings related to perceived behavioural control. Perceived behavioural control (PBC) was a significant variable related to travel attitudes in both the quantitative and qualitative surveys. PBC was correlated with travel attitudes in the regression model and, similar to the literature, ${ }^{787}$ a lack of volition was the most salient explanation for auto-orientated travel attitudes in the qualitative survey. However, perceived behavioural control could be assumed to be a potential pre-existing condition (i.e. those that have low perceived behavioural control tend to locate in neighbourhoods that effectively limit their behavioural control). As identified in chapter

\footnotetext{
${ }^{786}$ Schwanen \& Mokhtarian, 2007; Schwanen \& Mokhtarian, 2004; Redmond, 2000

${ }^{787}$ Wall et al., 2008; Kennedy et al., 2009; Cleveland et al., 2005; Guagano, 1995 186
} 
seven, the problems of self-selection apply to the PBC variable because it, unlike tenure or place attachment, is not supported by the extant literature to form only after an individual chooses to reside in a neighbourhood. While this is statistically possible and the research design does not account for this possibility, it would seem implausible from a logically augmented position.

Residential location considerations guided by existing travel preferences were also not apparent from the qualitative survey for conventional neighbourhood survey participants, nor were mode preferences correlated to travel attitudes. These factors suggest that for some survey participants, travel attitudes reflect a post-decision hypothesis. Typical behavioural theories are hierarchical in nature, and end with pro-environmental behavior linked to values through a causal chain of intermediate variables. Here associations between PBC and actual travel behaviours are well founded, ${ }^{788}$ but the correlation to travel attitudes implies an alternative causal direction. This is further supported with the qualitative findings.

This study takes a much different direction to both travel behaviour research, with its focus on selfselection, and environmental psychology, with its aim of segmenting descriptive personality cohorts. It is not, however, entirely without theoretical precedent. Past decisions have been shown to influence future decisions in an escalated commitment study, ${ }^{789}$ and the counter proposition to residents' self-selecting neighbourhoods that meet their travel preferences is recognized. ${ }^{790}$ Similarly, context has been found to influence preferences "based on information available at the time of preference elicitation". ${ }^{791}$ The extant literature also identifies preferences to be more stable after choices are made and when effort is involved. ${ }^{792}$ Other studies demonstrate that after a decision is made, relatively unrelated attributes resulting from that decision are prescribed varying valuations and this includes stated travel preferences. ${ }^{793}$ The corollary of this suggests that choosing a neighbourhood to reside in for whatever reason (be it a newer dwelling, proximity to relatives, new carpet or more space) can result in shifting preferences for other seemingly unrelated but consequential attributes, such as travel preferences.

The present dissertation adds evidence to similar studies within behavioural economics, which as a discipline is making inroads into a more realistic view of utility and economic thinking. Unlike the assumptions of environmental psychology, preferences may very well not be the expression of selfinterested or collective-interested innate deep seated values and beliefs. Instead, preferences appear

\footnotetext{
788 Steg \& Vlek, 2009

${ }^{789}$ Karlsson et al., 2005

790 Mokhtarian \& Schwanen, 2005

${ }^{791}$ Hoeffler et al., 2006, p 4

${ }^{792}$ Hoeffler \& Ariely, 2006

${ }^{793}$ Simon et al., 2004
} 
to be more transient and dynamic, and it is the understanding of this progression that is a better focus for realizing the key to behavioural change and action toward greater sustainability. Here, the present study uniquely expands the literature on constructed preferences and attitudes into the realm of travel behaviour and neighbourhood choices, and provides an exciting avenue for future research as well as evidence to the other side of the causal equation.

The emerging literature on constructive preferences also questions the existence of innate preferences, as assumed in self selection studies. From this theoretical perspective, preference reversals have been demonstrated, ${ }^{794}$ contingent valuations have been shown ${ }^{795}$ as well as the endowment effect, ${ }^{796}$ which illustrates the volatility of preferences depending on ownership. Individuals tend to prefer what they presently own far more than prior to ownership. ${ }^{797}$ These studies point to the possibility that preferences may be invented rather than found, ${ }^{798}$ and as such, adapting attitudes, beliefs and values to correspond to previous decisions seems as plausible as preferences being a result of underlying values, beliefs and attitudes. Even previously assumed deep seated values have been shown to be flexible. In a study that assessed survey participants' values on the New Environmental Paradigm (NEP) scale, values were shown to change over time with the introduction of a recycling program. ${ }^{799}$ Not only did recycling activity increase, but also attitudes towards recycling and relative NEP scores changed to be more favourable toward proenvironmental values. This suggests that the context individuals find themselves within may afford opportunities to hold positive environmental beliefs and values, and the findings from the present study support this view. The evidence from this dissertation, along with similar studies that encourage a greater consideration of context, implore future research to look beyond defining population sub-groups who hold certain values. Instead, the context within which those values are found needs greater explication in order to determine what context affords individuals or households to have positive environmental values and beliefs. This approach provides a much more efficient means of closing the gap between well intentioned attitudes and continued unsustainable behaviours. From the starting point articulated at the beginning of this dissertation, the analogy of the serenity prayer; it is not a matter of some individuals being more environmentally responsible than others, but more a matter of some individuals' situations affording them the opportunity to be more environmentally conscientious. An understanding of the limitations individuals face is a far sounder platform to preach environmental regard, than from one buttressed by artificial laurels of superior values and beliefs.

\footnotetext{
794 Fischer \& Hawkins, 1993

${ }^{795}$ Schkade \& Payne, 1994

${ }^{796}$ Medvec et al., 1995

${ }^{797}$ Van Bovan et al., 2003

798 Johnson et al., 2005

${ }^{799}$ Vining \& Ebreo, 1992 


\section{References}

AARTS, H., VERPLANKEN, B. \& VAN KNIPPENBERG, A. (1998) Predicting behavior from actions in the past: repeated decision making or a matter of habit? . Journal of Applied Social Psychology, 28, 1355-1374.

AGUILIAR, M. A. (2002) Identity and daily space in two municipalities in Mexico City. Environment and Behavior, 34, 111-121.

AJZEN, I. (1985) From intentions to actions: a theory of planned behavior. IN KUHL, J. \& BECKMANN, J. (Eds.) Action- Control: from Cognition to Behavior. Heidelberg, Germany, Springer.

AJZEN, I. (1991) The theory of planned behavior. Organizational Behavior and Human Decision Processes, 50, 179-221.

AJZEN, I. (2002) Perceived behavioral control, self-efficacy, locus of control, and the theory of planned behavior. Journal of Applied Social Psychology, 32, 665-683.

AJZEN, I. \& FISHBEIN, M. (1980) Understanding attitudes and predicting social behavior, Englewood Cliffs, N.J., Prentice Hall.

ALLENCONSULTINGGROUP (2004) Benefits of Investing in New Zealand's Road Infrastructure. Sydney, Allen Consulting Group.

ALtMAN, I. \& LOW, S. (1992) Place Attachment, New York, Plenum Press

AMPT, E. (2003) Understanding voluntary travel behaviour change. 26th Australasian Transport Research Forum. Wellington, NZ.

ANABLE, J. (2005) 'Complacent car addicts' or 'aspiring environmentalists'? Identifying travel behaviour segments using attitude theory. Transport Policy, 12, 65-78.

ANDREWS, G. \& PHILlIPS, D. (2005) Ageing and Place: Perspectives, Policy, Practice, London, Routledge.

ARC (1998) Regional Growth Forum. IN INFRASTRUCTURE, S. (Ed.), Auckland Regional Council.

ARC (2003) The Demand and Supply of Housing In the Auckland Region 1991-2001. Auckland, Auckland Regional Council.

AREFI, M. \& TRIANTAFILLOU, M. (2005) Reflections on the Pedagogy of Place in Planning and Urban Design. Journal of Planning Education and Research, 25, 75-88.

ARIELY, D. (2008) Predictably Irrational, New York, Harper Collins.

ARIELY, D. \& NORTON, M. (2008) How actions create - not just reveal - preferences. Trends in Cognitive Sciences, 12.

ASSITER, A. (1984) Althusser and structuralism. The British journal of sociology, 35, 272-296. 
ATKINSON, R. (2002) Does Gentrification Help or Harm Urban Neighbourhoods? An Assessment of the Evidence-Base in the Context of the New Urban Agenda. CNR Summary 5. London, Economic and Social Research Council.

AXELROD, L. S. \& LEHMAN, D. R. (1993) Responding to environmental concerns: What factors guide individual action? Journal of Environmental Psychology, 13, 149-159.

BABBIE, E. (1998) The Practice of Social Research, Stamford, CT., Wadsworth Publishing Company.

BACKHOUSE, R. (2002) The Penguin History of Economics, London, Penguin Books Ltd

BAGLEY, M. N. \& MOKHTARIAN, P. (2002) The impact of residential neighborhood type on travel behaviour: A structural equation modelling approach. Annals of Regional Science, $36,279-297$.

BALE, J. (2002) Lassitude and Latitude International Review for the Sociology of Sport 37, 147 158.

BALL, D. \& TASAKI, L. (1992) The Role and Measurement of Attachment in Consumer Behavior. Journal of Consumer Psychology, 1, 155-172.

BAMBERG, S. (2006) Is residential relocation a good opportunity to change people's travel behavior? Results from a theory-driven intervention study. Environment and Behavior, 38, 820-840.

BAMBERG, S., AJZEN, I. \& SCHMIDT, P. (2003) Choice of travel mode in the theory of planned behavior: The roles of past behavior, habit, and reasoned action. Basic and Applied Social Psychology, 25, 175-187.

BAMBERG, S. \& MÖSER, G. (2007) Twenty years after Hines, Hungerford, and Tomera: A new meta-analysis of psycho-social determinants of pro-environmental behaviour. Journal of Environmental Psychology, 27, 14-25.

BAMBERG, S., RÖLLE, D. \& WEBER, C. (2003) Does habitual car use not lead to more resistance to change of travel mode? Transportation, 30, 97-108.

BAMBERG, S. \& SCHMIDT, P. (2003) Incentives, morality, or habit? Predicting students' car use for university routes with the models of Ajzen, Schwartz, and Triandis. Environment and Behavior, 35, 264-285.

BARNES, T. J. (2001) 'In the beginning was economic geography' - a science studies approach to disciplinary history. Progress in Human Geography 25,4 (2001) pp. 521-544, 25, 521-544.

BARNETT, J. (1995) Suburban Sprawl: Its Prevention and Cure. The Fractured Metropolis Improving the New City, Restoring the Old City, Reshaping the Region. New York, HarperCollins.

BARON, J. (1997) Biases in the qualitative measurement of values for public decisions. Psychological Bulletin 122, 72-88. 
BARON, R. \& KENNY, D. (1986) The moderator-mediator variable distinction in social psychological research: Conceptual, strategic and statistical considerations. Journal of Personality and Social Psychology, 51, 1173-1182.

BARON, R. A., EARHARD, B. \& OZIER, M. (1998) Psychology, Scarborough, Canada, Allyn \& Bacon.

BARTLETT, R. (2005) Testing the 'Popsicle Test': Realities of Retail Shopping in New Traditional Neighbourhood Developments. Urban Studies, 40, 1471-1485.

BARTLETTE, J. (2002) Bartlett's Familiar Quotations: A Collection of Passages, Phrases, and Proverbs Traced to Their Sources in Ancient and Modern Literature Boston, New York, London, Little, Brown and Company.

BATES, J. (1988) Econometric issues in stated preference analysis. Journal of Transport Economics and Policy, 22.

BAUMEISTER, R. F. (1998) The self. IN GILBERT, D. T., FISKE, S. T. \& G. LINDZEY, G. (Eds.) Handbook of social psychology. New York, McGraw-Hill.

BAUSCH, K. (2001) The emerging consensus in social systems theory, New York, Kluwer Academic/ Plenum Publishers.

BECHTEL, R. B. \& CHURCHMAN, A. (Eds.) (2002) Handbook of environmental psychology, New York, Wiley.

BEN-AKIVA, M., MORIKAWA, T. \& SHIROISHI, F. (1989) Analysis of the reliability of stated preference data in estimating mode choice models. Transport Policy, Management \& Technology Towards 2001, 4, 263-277.

BESSER, L., MARCUS, M. \& FRUMKIN, H. (2008) Commute Time and Social Capital in the U.S. American Journal of Preventive Medicine, 34.

BETANZO, D. (2007) Pros and Cons of High-Density Urban Development. Build, 99, 39-40.

BETSCH, T., SUSANNE, H. \& HOHLE, C. (2002) Explaining Routinized Decision Making: A Review of Theories and. Theory and Psychology 2002; 12; 453, 12, 453-488.

BHAT, C. R. \& GUO, J. (2007) A comprehensive analysis of built environment characteristics on household residential choice and auto ownership levels. Transportation Research Part B: Methodological, 41, 506-526.

BICKERSTAFF, K. \& WALKER, G. (2002) Risk, responsibility, and blame: analysing vocabularies of motive in air pollution(ing) discourses. Environment and Planning A, 31, 2175-2192.

BIGCITIES (2003) Quality of Life in New Zealand's Eight Largest Cities

BILLIG, M., KOHN, R. \& LEVAV, I. (2006) Anticipatory stress in the population facing forced removal from the Gaza Strip. Journal of Nervous and Mental Disease, 194, 195-200.

BIMONTE, S. (2008) The "tragedy of tourism resources" as the outcome of a strategic game: A new analytical framework. Ecological Economics 67, 457-467. 
BLUME, L.E.\& DURLAUF, S.N., (2006) Identifying social interactions: a review. In: Oakes, M. and Kaufman, J., editors, Methods in Social Epidemiology, pp. 287-315. Jossey Bass, San Francisco.

BOARNET, M. \& CRANE, R. (2001) Travel by Design: The Influence of Urban Form on Travel, New York, Oxford University Press.

BOARNET, M. G. \& SARMIENTO, S. (1998) Can land use policy really affect travel behaviour? A study of the link between non-work travel and land-use characteristics. Urban Studies, $35,1155-1169$.

BÖCKER, F. (1986) Präferenzforschung als Mittel marktorientierter Unternehmensführung. Zeitschrift für betriebswissenschaftliche Forschung, 38, 543-574.

BOGERS, E., VITI, F. \& HOOGENDOORN, S. P. (2005) Joint Modelling of Advanced Travel Information Service, Habit, and Learning Impacts on Route Choice by Laboratory Simulator Experiments. Transportation Research Record, 1926, 189-197.

BOHTE, W., MAAT, K. \& WEE, B. V. (2009) Measuring Attitudes in Research on Residential Self-Selection and Travel Behaviour: A Review of Theories and Empirical Research. Transport Reviews, 29, 325-357.

BONAIUTO, M., AIELlO, A., PERUGINI, M., BONNES, M. \& ERCOLANI, A. P. (1999) Multidimensional perception of residential environment quality and neighbourhood attachment in the urban environment. Journal of Environmental Psychology, 19, 331-352.

BONAIUTO, M., BILOTTA, E., BONNES, M., CECCARELLI, M., MARTORELLA, H. \& CARRUS, G. (2008) Local Identity and the Role of Individual Differences in the Use of Natural Resources: The Case of Water Consumption1. Journal of Applied Social Psychology, 2008, 38, 4, pp. 947-967., 38, 947-967.

BONNES, M., BONAIUTO, M. \& ERCOLANI, A. P. (1991) Crowding and residential satisfaction in the urban environment: a contextual approach. Environment and behavior, $23,531-552$.

BONSALL, P., SHIRES, J., MAULE, J., MATTHEWS, B. \& BEALE, J. (2007) Responses to complex pricing signals: Theory, evidence and implications for road pricing. Transportation Research A, 41, 672-683.

BOYATZIZ, R. (1998) Transforming Qualitative Information, Beverly Hills, CA, Sage.

BOYER, M. (1978) A habit forming optimal growth model. International Economic Review, 19, 585-609.

BRADFORD, S. (1993) Are TNDs selling better? Builder, August, 76-79.

BRAY, R., VAKIL, C. \& ELLIOTT, D. (2005) Report on Public Health and Urban Sprawl in Ontario: A review of the pertinent literature. Environmental Health Committee, College of Family Physicians.

BREHENY, M. J. (2001) Densities and Sustainable Cities: The UK Experience. IN SAINT, A. \& ECHENIQUE, M. (Eds.) Cities for the New Millennium. London, Spoon. 
BROCKNER, J. \& RUBIN, J. Z. (1985) Entrapment in Escalating Conflicts, New York, Springer.

BROWN, B. \& CROPPER, V. (2001) New Urban and Standard Suburban Sub divisions:

Evaluating Psychological and Social Goals. Journal of American Planning Association, 67, 402.

BROWN, B. B. (1987) Territoriality. IN STOKOLS, D. \& ALTMAN, I. (Eds.) Handbook of environmental psychology. New York, Wiley.

BROWN, B. B. \& PERKINS, D. D. (1996) Neighborhood revitalization: Socio-environmental indicators and needs. 14th Conference of the International Association for PeopleEnvironment Studies. Stockholm, Sweden.

BROWN, B. B., PERKINS, D. D. \& BROWN, G. (2004) Incivilities, place attachment and crime: Block and individual effects. Journal of Environmental Psychology 24, 359-371.

BROWN, B. B. \& WERNER, C. M. (1985) Social cohesiveness, territoriality, and holiday decorations: The influence of cul-de-sacs. Environment and behavior, 17, 539-565.

BROWN, G. \& RAYMOND, C. (2007) The relationship between place attachment and landscape values: Toward mapping place attachment. Applied Geography 27, 89-111.

BURCHELL, R. \& LISTOKIN, D. (1995) Development Patterns and Infrastructure Costs, New Brunswick, NJ, Rutgers University.

BURTON, E. (2002) Measuring urban compactness in UK towns and cities. Environment and Planning B: Planning and Design, 29, 219-250.

CABE (2005) Making Higher Densities Work. London, Commission for Architecture and the Build Environment.

CABE (2005) Physical Capital. Commission for Architecture \& the Built Environment.

CALTHORPE, P. (1993) The Next American Metropolis, New York, Princeton Architectural Press.

CAMPBELL, J. D. (1999) Self Esteem and Clarity of the Self-Concept. IN BAUMEISTER, R. F. (Ed.) The Self in Social Psychology. New York, Psychology Press.

CAO, X. (2008) Exploring causal effects of neighborhood design on travel behavior using stratification on the propensity score, Transportation Research Board 88th Annual Meeting Washington, DC.

CAO, X., HANDY, S. \& MOKHTARIAN, P. (2006) The influences of the built environment and residential self-selection on pedestrian behavior: evidence from Austin, TX. Transportation, 33, 1-20.

CAO, X., MOKHTARIAN, P. \& HANDY, S. (2005) The impacts of the built environment and residential self-selection on non-work travel: a seemingly unrelated regression approach. 85th Transportation Research Board Annual Meeting. Washington, DC.

CAO, X., MOKHTARIAN, P. \& HANDY, S. (2006) Neighborhood design and vehicle type choice: evidence from Northern California. Transportation Research Part D: Transport and Environment, 12. 
CAO, X., MOKHTARIAN, P. \& HANDY, S. (2007) Cross-sectional and quasi-panel explorations of the connection between the built environment and auto ownership. Environment and Planning A, 39, 830-847.

CAO, X., MOKHTARIAN, P. \& HANDY, S. (2009) Examining the Impacts of Residential SelfSelection on Travel Behaviour: A Focus on Empirical Findings. Transport Reviews, 29, 359-395.

CARR, K. (2008) Qualitative Research to Assess Interest in Public Transportation for Work Commute. Journal of Public Transportation, 11.

CARRUTHERS, J. (2003) Urban Sprawl and the Cost of Public Services. Environment and planning B, planning \& design, 30, 503-522.

CASAKIN, H. \& BILLIG, M. (2009) Effect of Settlement Size and Religiosity on Sense of Place in Communal Settlements. Environment and Behavior, 41, 821-835.

CATRILL, J. G. (1998) The environmental self and sense of place: Communication foundations for regional ecosystem management. Journal of Applied Communication Research, 26, 301318.

CERA (2006) Peak Oil Theory- "World Running out of Oil Soon" - Is Faulty. Cambridge, Mass., Cambridge Energy Research Associates

CERVERO, R. \& DUNCAN, M. (2002) Transit's Value-Added Effects: Light and Commuter Rail Services and Commercial Land Values. Transportation Research Record, 1805, 8-15.

CERVERO, R. \& GORHAM, R. (1995) Commuting in Transit Versus Automobile Neighborhoods. Journal of the American Planning Association, 61, 210-225.

CHA, E.-S., KIM, K. \& PATRICK, T. (2008) Predictors of Intention to Practice Safer Sex Among Korean College Students. Arch Sex Behavior 37, 641-651.

CHAMBERLAIN (2004) The G-Word. Metropolis, 23, 28-29.

CHAPMAN, R. (2005) Urban design and physical activity- a context for cycling. New Zealand Cycling Conference NZ.

CHAVIS, D. M. \& PRETTY, G. M. H. (1999) Sense of Community: Advances in measurement and application. Journal of Community Psychology, 27, 635-642.

CHEN, C., GARLING, T. \& KITAMURA, R. (2004) Activity rescheduling: reasoned or habitual? Transportation Research Part F 7, 351-370.

CHEN, C., GONG, H. \& PAASWELL, R. (2008) Role of the built environment on mode choice decisions: additional evidence on the impact of density. Transportation, 35, 285-299.

CHOOCHARUKUL, K., VAN, H. T. \& FUJII, S. (2008) Psychological effects of travel behavior on preference of residential location choice. Transportation Research Part A 42, 116-124.

CHRANZ (2006) Affordable Housing in New Zealand. National Summit-Affordable Housing. Wellington, Centre for Housing Research Aotearoa New Zealand. 
CHURCHMAN, A. (1999) Disentangling the Concept of Density. Journal of Planning Literature, 13.

CITYOFVICTORIA (2001) Neighbourhood Profiles. Victoria, Victoria City Council.

CLEVELAND, M., KALAMAS, M. \& LAROCHE, M. (2005) Shades of green: linking environmental locus of control and pro-environmental behaviors. Journal of Consumer Marketing, 22, 198-212.

CLIFTON, K. J. \& HANDY, S. L. (2001) Qualitative methods in travel behaviour research. International Conference on Transport Survey Quality and Innovation. Kruger National Park, South Africa.

COMEAU, L. A. (2008) Effects of framing on Ontarians' perceived competence to act on climate change. Environmental Education and Communication Program. Victoria, B.C., Royal Roads University

CONNER, M. \& ARMITAGE, C. J. (1998) Extending the theory of planned behavior: A review and avenues for further research. Journal of Applied Social Psychology, 28, 1429-1464.

COOLEN, H. (2003) The Meaning of Dwellings: an Ecological Perspective. Housing, Theory and Society, 23, 185-201.

CORRALIZA, J. A. \& BERENGUER, J. (2000) Environmental values, beliefs and actions: A situational approach. Environment and Behavior, 32, 832-848.

CORTRIGHT, J. (2005) The Young and the Restless in a Knowledge Economy CEOs for Cities. Portland, Joseph Cortright Consulting.

COX, K. \& GOLLEDGE, R. (Eds.) (1981) Behavioral problems in geography revisited, London, Methuen and Co. Ltd.

COX, W. (1996) Urban Transport: From Theory to Reality. The Public Purpose.

COX, W. (2004) Smart Growth Threatening the Quality of Urban Life. Winnipeg, Frontier Centre.

CRAIG, S. C., MARTINEZ, M. D., KANE, J. G. \& GAINOUS, J. (2005) Core Values, Value Conflict, and Citizens' Ambivalence about Gay Rights. Political Research Quarterly, 58, 5-17.

CRANE, R. \& CREPEAU, R. (1998) Does Neighborhood Design Influence Travel?: A Behavioral Analysis of Travel Diary and GIS Data. Transportation Research Part D: Transport and Environment, 3, 225-238.

CRANO, W. D. \& PRISLIN, R. (Eds.) (2008) Attitudes and Attitude Change, London, Psychology Press.

CRD (2007) Regional Housing Affordability Strategy. Victoria, Capital Regional District.

CRESWELL, J. W. (2003) Research Design; Qualitative, Quantitative, and Mixed Methods Approaches, Thousand Oaks, CA, Sage Publications. 
CROTTY, M. (1998) The Foundations of Social Research: Meaning and Perspective in the Research Process, London, Sage Publications Ltd

CYNAMON, B. Z. \& FAZZARI, S. M. (2008) Household Debt in the Consumer Age: Source of Growth-Risk of Collapse. Capitalism and Society, 3.

DANIELSON, K. A., LANG, R. \& FULTON, W. (1999) What Does Smart Growth Mean for Housing. Housing Facts and Findings, 1.

DARGAY, J. M. \& M, H. (2007) Volatility of car ownership, commuting mode and time in the UK Transportation Research. Part A: Policy \& Practice, 41, 934-948.

DAVIDOV (2007) Explaining habits in a new context. The case of travel-mode choice. Rationality and Society, 19, 315-334.

DAVIDSON, K. (2005) Will the concept of 'sustainable development' provide any solutions for the 21C. Social Change in the 21st Century Conference. Queensland University of Technology, QUT.

DE GROOT, J. I. M. \& STEG, L. (2008) Value Orientations to Explain Beliefs Related to Environmental Significant Behavior How to Measure Egoistic, Altruistic, and Biospheric Value Orientations. Environment and Behavior, 40, 330-354.

DE ROO, G. (2000) Environmental conflicts in compact cities: complexity, decision making, and policy approaches. Environment and planning B, planning \& design, 27, 151-162.

DE ROO , G. (2003) Environmental Planning in the Netherlands: Too Good to be True. From Command-and-Control Planning to Shared Governance, Aldershot, Ashgate.

DE ROO , G. \& MILLER, D. (2000) Compact Cities and Sustainable Urban Development: A Critical Assessment of policies and plans from an international perspective, London, Ashgate Publishing Ltd.

DERKSEN, I. \& GARTELL, J. (1993) The social context of recycling. American Sociological Review, 58.

DEUTSCH, M. \& GERARD, H. B. (1955) A study of normative and informative social influences upon individual judgment. Journal of Abnormal. Social Psychology, 51, 629-636.

DIEKMANN, A. \& PREISENDÖRFER, P. (2003) Green and greenback: The behavioral effects of environmental attitudes in low-cost and high-cost situations. Rationality and Society, 15, 441-472.

DIELEMAN, F. \& WEGENER, M. (2004) Compact city and urban sprawl. Built environment, 30, 308-323.

DIELEMAN, F. M., CLARK, W. A. V. \& DEURLOO, M. C. (2000) The Geography of Residential Turnover in Twenty-seven Large US Metropolitan Housing Markets, 1985-95. $37,223-245$.

DIETZ, R.D. (2002) The estimation of neighbourhood effects in the social sciences: an interdisciplinary approach. Social Science Research, 31: 539-575 
DIXON, J. \& DURRHEIM, K. (2000) Displacing place-identity: A discursive approach to locating

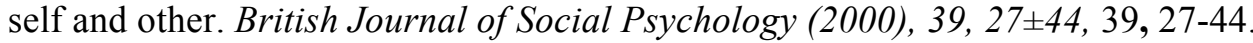

DOVEY, K. (1998) Safety and Danger in Urban Design. Safer Communities: Strategic Directions in Urban Planning. Melbourne.

DTZ, N. Z. (2004) Changes in the Structure of the New Zealand Housing Market Executive Summary. Wellington, Centre for Housing Research.

DTZ, N. Z. (2004) Housing Costs and Affordability. Wellington, Centre for Housing Research.

DTZ, N. Z. (2005) Housing Tenure Aspirations and Attainment. IN BRANZ (Ed.), The Centre for Housing Research.

DUANY, A. (2000) The Rise of Sprawl and the Decline of the American Dream, New York, North Point Press.

DUNLAP, R. E., VAN LIERE, K. D., MERTIG, A. G. \& JONES, R. E. (2000) Measuring endorsement of the new ecological paradigm: a revised NEP scale. Journal of Social Issues, 56, 425-442.

DURKHEIM, E. \& MAUSS, M. (1998), 'Between Sociology and Anthropology I, notes on the notion of civilization (1913)', pp. 151-154, in Classical Readings in Culture and Civilization, J. Rundell and S. Mennell (eds), London and New York: Routledge.

EAGLY, A. H. \& CHAIKEN, S. (1993) The Psychology of Attitudes, Fort Worth, TX, Harcourt Brace Jovanovich College Publishers

EAGLY, A. H. \& KULESA, P. (1997) Attitudes, Attitude Structure, and Resistance to Change: Implications for Persuasion on Environmental Issues. IN BAZERMAN, M. \& H., M., D M., TENBRUNSEL, A E. \& WADE-BENZONI, K A. (Eds.) Environment, Ethics, \& Behavior: The Psychology of Environmental Valuation \& Degradation. San Francisco, The New Lexington Press.

EBENHÖH, E. \& PAHL-WOSTL, C. (2008) Agent Based Behavior Between Maximization and Cooperation Rationality and Society, 20, 24-252.

ECHENIQUE, M. \& SAINT, A. (2001) Cities for the New Millennium, London, Spon.

ENGLES, F. (1845). The Condition of the Working Class in England. City Reader, The. R. T. Le Gates and F. Stout. London, Routledge. 1996.

ERIKSSON, L., GARVILL, J. \& NORDLUND, A. M. (2008) Acceptability of single and combined transport policy measures: The importance of environmental and policy specific beliefs. Transportation Research Part A: Policy and Practice, 42, 1117-1128.

EVANS, G. W., KANTROWITZ, E. \& ESHELMAN, P. (2002) Housing Quality and Psychological Well-Being Among the Elderly Population. Journal of Gerontology: Psychological Sciences, 57(B), 381-383.

EVANS, G. W., SAEGERT, S. \& HARRIS, R. (2001) Residential Density and Psychological Health Among Children in Low-Income Families. Environment and behavior, 33, 165-180. 
EVANS, T. P., SUN, W. \& KELLEY, H. (2006) Spatially explicit experiments for the exploration of land-use decision-making dynamics. International Journal of Geographical Information Science, 20, 1013-1037.

EWING, R. (1997) Is Los Angeles Style Sprawl Desirable? American Planning Association, 63, 107-126.

EWING, R. (2005) Can the Physical Environment Determine Physical Activity Levels? Exercise and Sport Sciences Reviews, 33, 69-75.

EWING, R., BARTHOLOMEW, K., WINKELMAN, S., WALTERS, J. \& CHEN, D. (2007) Growing Cooler: The evidence on urban development and climate change, Chicago, Urban Land Institute.

EWING, R., KILLINGSWORTH, R., SCHMID, T., ZLOT, A. \& RAUDENBUSH, S. (2003) Relationship Between Urban Sprawl and Physical Activity, Obesity, and Morbidity. American Journal of Health Promotion, 18.

EWING, R., PENDALL, R. \& CHEN, D. (2002) Measuring Sprawl and Its Impact. Washington DC, Smart Growth America.

EWING, R., PENDALL, R. \& CHEN, D. (2003) Measuring Sprawl and its Impact. Smart Growth America.

FARRELL, A. \& BRANDT, A. (2006) Risks of the Oil Transition. Environmental Research Letters.

FESTINGER, L. (1957) Theory of Cognitive Dissonance, Stanford, CA, Stanford University Press.

FIELD, A. (2005) Discovering Statistics Using SPSS, London, Sage Publications.

FINA, S. \& SIEDENTOP, S. (2008) Urban sprawl in Europe - identifying the challenge. Urban Planning and Regional Development Information Society.

FISCHEL, W. (1990) Do Growth Controls Matter? A Review of Empirical Evidence on the Effectiveness and Efficiency of Local Government Land Use Regulation. Cambridge, MA, Lincoln Institute of Land Policy.

FISCHER, G. W. \& HAWKINS, S. A. (1993) Strategy compatibility, scale compatibility, and the prominence effect. Journal of Experimental Psychology: Human Perception and Performance, 19, 580-597.

FISHBEIN, M. (1997) Predicting, understanding, and changing socially relevant behaviors: Lessons learned. IN MCGARTY, C. \& HASLAM, S. A. (Eds.) The message of social psychology Oxford, Blackwell.

FISHBEIN, M. \& AJZEN, I. (1975) Belief, attitude, intention, and behavior: An introduction to theory and research, Reading, MA., Addison-Wesley.

FISHMAN, R. (1977) Urban Utopias in the Twentieth Century: Ebenezer Howard, Frank Lloyd Wright, and Le Corbusier, NY, Basic Books Inc. 
FLEMING, M. A. \& PETTY, R. E. (2000) Identity and Persuasion: An Elaboration Likelihood Approach. IN TERRY, D. J. \& HOGG, M. A. (Eds.) Attitudes, Behavior, and Social Context: The Role of Norms and Group Membership. London, Lawrence Erlbaum

FLEURE, H. J. (1919) Human regions. Scottish Geographical Magazine, 35, 94-105.

FLORIDA, R. (2003) The Rise of the Creative Class: And How It's Transforming Work, Leisure, Community, and Everyday Life, New York, Basic Books.

FORAN, M. F. (1973) An Experimental Study of the Effects of Organizational Structure, Authoritarianism, and Feedback on Cognitive Dissonance in the Budgeting Process. Seattle, University of Washington.

FORSTER, C. (2006) The Challenge of Change: Australian Cities and Urban Planning in the New Millennium. Geographical Research, 44, 173-182.

FORSYTH, A. (2003) Measuring Density: Working Definitions for Residential and Building Intensity. IN LANDSCAPE, D. C. F. A. U. (Ed.), University of Minnesota.

FOWLER, E. (1992) Building Cities that Work, London, McGill-Queen's University Press.

FRANCK, K. (1984) Exorcising the Ghost of Physical Determinism. Environment and Behavior, $16,411-435$.

FRANK, L., ANDRESEN, M. \& SCHMID, T. (2004) Obesity Relationships with Community Design, Physical Activity, and Time Spent in Cars. American Journal of Preventive Medicine, 27, 87-96.

FRANK, L. \& PIVO, G. (1994) Relationships Between Land Use and Travel Behaviour in the Puget Sound Region. . Seattle, WA, Washington State Department of Transportation.

FRANK, L. \& PIVO, G. (1995) Impacts of Mixed Use and Density on Utilization of Three Modes of Travel: Single-Occupant Vehicle, Transit, and Walking. Transportation Research Record 1466, 44-55.

FRANK, L. D., SALENS, B. E., POWELL, K. E. \& CHAPMAN, J. E. (2007) Stepping towards causation: Do built environments or neighbourhood and travel preferences explain physical activity, driving, and obesity? . Social Science and Medicine, 65, 1898-1914.

FRENKEL, A. (2004) The Determinants of Urban Density - The Israeli Case. 42nd Congress of the European Regional Science Association. Dortmund.

FRIED, M. (2000) Continuities and discontinuities of place. Journal of Environmental Psychology, 20, 193-205.

FRUMKIN, H., FRANK, L. \& JACKSON, R. (2004) Urban Sprawl and Public Health: Designing, Planning, and Building for Healthy Communities, Washington DC USA, Island Press.

FUJII, S. \& GARLING, T. (2003) Development of script-based travel mode choice after forced change. Transportation Research Part F 6, 117-124. 
FUJII, S., GARLING, T. \& KITAMURA, R. (2001) Changes in Drivers' Perceptions and Use of Public Transport During a Freeway Closure: Effects of Temporary Structural Change on Cooperation in a Real-Life Social Dilemma. Environment and Behavior, 33, 796-808.

FULLILOVE, M. T. (1996) Psychiatric implications of displacement: Contributions from the psychology of place. American Journal of Psychiatry, 153, 1516-1523.

GALSTER, G., HANSON, R., RATCLIFF, M. R. \& WOLLMOND, H. (2001) Wrestling Sprawl To The Ground: Defining and measuring the elusive concept. Housing Policy Debate, 12.

GARLING, T. \& AXHAUSEN, K. W. (2003) Introduction: Habitual travel choice. Transportation, $30,1-11$.

GÄRLING, T. \& GARVILL, J. (1993) Psychological explanations of participation in everyday activities. IN GÄRLING, T. \& GOLLEDGE, R. (Eds.) Behaviour and Environment: Psychological and Geographical Approaches. Amsterdam, Elsevier/North-Holland.

GARLING, T. \& GOLLEDGE, R. G. (Eds.) (1993) Behavior and Environment: Psychological and Geographical Approaches (Advances in Psychology) New York, Elesvier Science Publishers.

GARLING, T., KARLSSON, N., ROMANUS, J. \& SELART, M. (1997) Influences of the past on choices of the future. IN RANYARD, R., CROZIER, R. \& SVENSON, O. (Eds.) Decision Making: Cognitive Models and Explanations London, Routledge.

GARLING, T. \& SCHUITEMA, G. (2007) Travel Demand Management Targeting Reduced Private Car Use: Effectiveness, Public Acceptability and Political Feasibility. Journal of Social Issues, 63, 139-153.

GARREAU, J. (1991) Edge City: Life on the New Frontier:, NY, NY Anchor Books Doubleday.

GARVILL, J., MARELL, A. \& NORDLUND, A. M. (2003) Effects of increased awareness of choice of travel mode. Transportation, 30, 63-79.

GHOSH, S., VALE, R. J. D. \& VALE, B. A. (2007) Metrics of local environmental sustainability—a case study of Auckland, New Zealand. Local Environment, 12, 1-23.

GIFFORD, R. (2007) Environmental Psychology and Sustainable Development: Expansion, Maturation, and Challenges. Journal of Social Issues, 63, 199--212.

GIGERENZER, G., TODD, P. \& GROUP, A. R. (1999) Simple Heuristics that Make us Smart, New York, Oxford University Press.

GIRLING, C. \& HELPHANK, K. (1996) Yard, Street, Park: The Design of Suburban Open Space, Wiley; New Ed edition.

GIRLING, C. \& KELLETT, R. (2002) Comparing stormwater impacts and costs on three neighborhood plan types. Landscape journal, 21, 100-109.

GIULIANI, M. V. (2003) Theory of attachment and place attachment. IN M. BONNES, T. L., \& M. BONAIUTO (Ed.) Psychological theories for environmental issues. Aldershot, U.K., Ashgate. 
GIULIANI, M. V. \& FELDMAN, R. (1993) Place attachment in a developmental and cultural context. Journal of Environmental Psychology, 13, 267-274.

GIULIANO, G. \& DARGAY, J. (2006) Car ownership, travel and land use: a comparison of the US and Great Britain. Transportation Research Part A: Policy and Practice, 40, 106-124.

GLAESER, E. \& SACERDOTE, B. (1999) Why is There More Crime in Cities? Journal of political economy, 107.

GLAESER, E. \& SACERDOTE, B. (2000) The Social Consequence of Housing. National Bureau of Economic Research.

GLENNAN, S. (1996) Mechanisms and the nature of causation. Erkenntnis 4, 49-71.

GODIN, G. \& KOK, G. (1996) The theory of planned behavior: A review of its applications to health-related behaviors. American Journal of Health Promotion, 11, 87-89.

GOLDMANN, L. (1987) Towards a Sociology of the Novel, London, Tavistock Publications.

GOLDSTONE, R. L., JONES, A. \& ROBERTS, M. E. (2006) Group Path Formation. IEEE Transaction on Systems, Man, and Cybernetics- Part A: Systems and Humans 36, 611-620.

GOLLEDGE, R. G. \& STIMSON, R. J. (1997) Spatial behavior: a geographical perspective, New York, Guilford Publications Inc.

GORDON, P. \& RICHARDSON, H. (1997) Are Compact Cities a Desirable Planning Goal? American Planning Association, 63, 95-96.

GRAY, A. (2001) Definitions of Crowding and the Effects of Crowding on Health: A Literature Review. Wellington, Ministry of Social Policy.

GREEN, P. \& SRINIVASAN, V. (1990) Conjoint analysis in marketing: New developments with implication for research and practice. Journal of Marketing 54, 3-19.

GREEN, P. E. \& RAO, V. R. (1971) Conjoint measurement for quantifying judgmental data. Journal of Marketing Research, 8, 355-363.

GREENE, R. \& GREENE, M. (2003) Urban safety in residential areas: Global spatial impact and local self-organising processes. 4th International Space Syntax Symposium London.

GREENWALD, M. J. \& BOARNET, M. G. (2001) Built environment as determinant of walking behavior: analysing non-work pedestrian travel in Portland, Oregon. Transportation Research Record, 1780, 33-42.

GRIMES, A., KERR, S. \& AITKEN, A. (2004) Bi-Directional Impacts of Economic, Social and Environmental Changes and the New Zealand Housing Market. IN MOTU (Ed.) Wellington, Centre for Housing Research.

GROAT, L. \& WANG, D. (2002) Architectural research methods, New York, John Wiley and Son.

GUAGNANO, G. A., DIETZ, T. \& STERN, P. C. (1994) Willingness to pay for public goods: A test of the contribution model. Psychological Science 5, 411-415. 
GUAGNANO, G. A., STERN, P. C. \& DIETZ, T. (1995) Influences on attitude-behavior relationships. A natural experiment with curbside recycling. Environment and Behavior, $27,699-718$.

GUINTHER, J. (1997) Direction of Cities, New York, Penguin.

GUSTAFSSON, A., HERRMANN, A. \& HUBER, F. (2007) Conjoint Measurement: Methods and Applications, Berlin, Springer.

GUZMAN, C. \& BHATIA, R. (2005) Anticipated Effects of Residential Displacement on Health: Results from Qualitative Research. Program on Health Equity and Sustainability. San Francisco, San Francisco Department of Public Health.

HAGIHARA, G. \& FUJII, S. (2005) The psychological effects of car use on place attachment. Infrastructure Planning Review, 22, 461-466.

HALAWI, L., ARONSON, J. \& MCCARTHY, R. (2005) Resource-Based View of Knowledge Management for Competitive Advantage. The Electronic Journal of Knowledge Management, 3, 75-86.

HAMMOND, D. (2005) Residential location and commute mode choice. Cardiff, University of Wales.

HAMNETT, C. \& RANDOLPH, B. (1988) Cities, housing and profits: Flat break-ups and the decline of private renting, London, Hutchinson.

HANDY, S. (2005) Smart Growth and the Transportation-Land Use Connection: What Does the Research Tell Us? International Regional Science Review, 28, 146-167.

HANDY, S., CAO, X. \& MOKHTARIAN, P. (2005) Correlation or causality between the built environment and travel behaviour? Evidence from Northern California. Transportation Research Part D, 10, 427-444.

HANDY, S. \& NIEMEIER, D. A. (1997) Measuring accessibility: an exploration of issues and alternatives. Environment and Planning A 29, 1175-1194.

HANSON, S. \& HANSON, P. (1993) The geography of everyday life. IN T, G. \& GOLLEDGE, R. G. (Eds.) Behavior and Environment: Psychological and Geographical Approaches. Amsterdam, North-Holland.

HARGREAVES, R. \& DAVIES, K. (2003) Urban Sustainability in New Zealand: An Information Resource for Urban Practitioners. IN ENVIRONMENT, M. F. T. (Ed.), Ministry for the Environment

HARLAND, P., STAATS, H. \& WILKE, H. A. M. (1999) Explaining pro-environmental intention and behavior by personal norms and the theory of planned behavior. Journal of Applied Social Psychology, 29, 2505-2528.

HARMON-JONES, E. \& MILLS, J. (Eds.) (1999) Cognitive Dissonance: Progress on a Pivotal Theory in Social Psychology, Washington, D.C, APA Books. 
HARRIES, K. (2006) Property Crimes and Violence in United States: An Analysis of the influence of Population density. International Journal of Criminal Justice Sciences, 1, 24-34.

HARTMAN, C. (2002) Between Eminence and Notoriety: Four decades of radical urban planning, New Jersey, Center for Urban Policy Research.

HAY, R. (1998) Sense of place in developmental context. Journal of Environmental Psychology, $18,5-29$.

HAYES, N. (1996) Principles of Social Psychology, Est Sussex, UK, Lawrence Erlbaum and Associates.

HEATH, Y. \& GIFFORD, R. (2002) Extending the Theory of Planned Behavior: Predicting the Use of Public Transportation. Journal of Applied Social Psychology, 32, 2154-2189.

HEDMAN, R. \& JASZEWSKI, A. (1984) Fundamentals Of Urban Design, Chicago, Illinois, American Planning Association.

HEDSTRÖM, P. \& SWEDBERG, R. (Eds.) (1996) Social mechanisms. An Analytical Approach to Social Theory, Cambridge, U.K., Cambridge University Press.

HENSHER, D. A. \& BRADLEY, M. (1993) Using stated response choice data to enrich revealed preference discrete choice models. Business and Economics, 4.

HENSHER, D. A. \& PUCKETT, S. (2007) Congestion and variable user charging as an effective travel demand management instrument. Transportation Research A, 41, 615-626.

HERNANDEZ, B., HIDALGO, M. C., SALAZAR-LAPLACEA, M. E. \& HESS, S. (2007) Place attachment and place identity in natives and non-natives. Journal of Environmental Psychology 27, 310-319.

HIDALGO, M. C. \& HERNÁNDEZ, B. (2001) Place attachment: Conceptual and empirical questions. Journal of Environmental Psychology, 21, 273-281.

HILLIER, B. (2004) Can Streets Be Made Safe? . Urban Design International, 9, 31-45.

HILLIER, B. \& SAHBAZ, O. (2005) High Resolution Analysis of Crime Patterns in Urban Street Networks: an initial statistical sketch from an ongoing study of a London borough. Fifth Space Syntax International Symposium. Delft University of Technology, Delft.

HILLIER, B. \& SHU, S. (2000) Crime and Urban Layout: The Need for Evidence. IN BALLINTYNE, S., PEASE, K. \& MCLAREN, V. (Eds.) Secure Foundations: Key Issues in Crime Prevention, Crime Reduction and Community Safety London, Institute of Public Policy Research.

HIPPS, J. A. (1993) Trustworthiness and authenticity: Alternate ways to judge authentic assessments. Atlanta, GA., Paper presented at the annual meeting of the American Educational Research Association.

HNZC (2005) Auckland Regional Housing Strategy. Wellington, Housing New Zealand Corporation. 
HODSON, G., MAIO, G. R. \& ESSES, V. M. (2001) The role of attitudinal ambivalence in susceptibility to consensus information. Basic and Applied Social Psychology, 23, 197-205.

HOEFFLER, S. \& ARIELY, D. (1999) Constructing Stable Preferences: A Look Into Dimensions of Experience and Their Impact on Preference Stability. Journal of Consumer Psychology, $8,113-139$.

HOEFFLER, S., ARIELY, D. \& WEST, P. (2006) Path Dependent Preferences: The Role of Early Experience and Biased Search in Preference Development. Organizational Behavior and Human Decision Processes, 101, 215-229.

HOGG, M. A. \& HAINS, S. C. (1996) Intergroup relations and group solidarity: Effects of group identification and social beliefs on depersonalised attraction. Social Psychology, 70, 290309.

HOGG, M. A. \& SMITH, J. R. (2007) Attitudes in social context: A social identity perspective. European Review of Social Psychology, 18, 89-131.

HOGG, M. A. \& VAUGHAN, G. M. (2008) Social Psychology, Essex, U.K., Pearson Education Ltd.

HOWES, Y. \& GIFFORD, R. (2009) Stable or Dynamic Value Importance? The Interaction Between Value Endorsement Level and Situational Differences on Decision-Making in Environmental Issues. Environment and Behavior, 41, 549-582.

HOYLE, R. H. (Ed.) (1995) Structural equation modelling: concepts, issues, and applications, California, Sage.

HUBBERT, M. (1949) Energy from Fossil Fuels. Science, 109.

HUBER, J. (1987) Conjoint analysis: how we got here and where we are. Sawtooth Software Conference. Evanston.

HUCHTING, K., LAC, A. \& LABRIE, J. W. (2008) An application of the Theory of Planned Behavior to sorority alcohol consumption. Addictive Behaviors 33, 538-551.

HUDDY, L. (2001) From Social to Political Identity: A Critical Examination of Social Identity Theory. Political Psychology, 22.

HUDSON, S. (2005) Corunna Avenue the History of a Victoria Street: Newtown Wellington Wellington.

HUNECKE, M., BLÖBAUM, A., MATTHIES, E. \& HÖGER, R. (2001) Responsibility and Environment: Ecological Norm Orientation and External Factors in the Domain of Travel Mode Choice Behavior. Environment and Behavior 33, 830-852.

HUNECKE, M., HAUSTEIN, S., GRISCHKAT, S. \& BÖHLER, S. (2007) Psychological, sociodemographic, and infrastructural factors as determinants of ecological impact caused by mobility behavior, Journal of Environmental Psychology, 27, 277-292.

HUNTER, L. M. (1998) The association between environmental risk and internal migration flows. Population and Environment: A Journal of Interdisciplinary Studies, 19, 247-277. 
HUNTINGTON, E. (1915) Civilization and climate, New Haven, Yale University Press.

HUSOCK, H. (2003) America's Trillion-Dollar Housing Mistake: The Failure of American Housing Policy, New York, Ivan R. Dee.

IPCC (2007) Climate Change 2007 - The Physical Science Basis. United Nations.

JABAREEN, Y. (2005) Culture and Housing Preferences in a Developing City. Environment and behavior, 37, 134.

JACOBS, J. (1984) Cities and the Wealth of Nations: Principles of Economic Life, New York, Random House.

JENKS, M. \& DEMPSEY, N. (2005) Future Forms and Design for Sustainable Cities, Oxford, Architectural Press.

JOHNSON, B. R. (1997) Examining the validity structure of qualitative research. Education, 118, 282-292.

JOHNSON, E. J., STEFFEL, M. \& GOLDSTEIN, D. G. (2005) Making Better Decisions: From Measuring to Constructing Preferences. Health Psychology, 24, S17-S22.

JOHNSON, P. A. (1994) The Theory of Architecture: Concepts, Themes and Practices, Ney York, John Wiley and Sons Inc.

JOHNSON, S. D. (1995) Will our research hold up under scrutiny? Journal of Industrial Teacher Education, 32, 3-6.

JOIREMAN, J. A., LANGE, P. A. M. V. \& VUGT, M. V. (2004) Who cares about the environmental impact of cars? Those With an Eye Toward the Future. Environment and Behavior, 36, 187-206.

JOLANDA MAAS, R., VERHEIJ, R., GROENEWEGEN, P., DE VRIES, S. \& SPREEUWENBERG, P. (2006) EVIDENCE BASED PUBLIC HEALTH POLICY AND PRACTICE: Green space, urbanity, and health: how strong is the relation? Journal of Epidemiology Community Health, 60, 587-592.

JORGENSEN, B. S. \& STEDMAN, R. C. (2006) A comparative analysis of predictors of sense of place dimensions: Attachment to, dependence on, and identification with lakeshore properties. Journal of Environmental Management 79, 316-327.

JUDKINS, G., SMITH, M. \& KEYS, E. (2008) Determinism within human-environment research and the rediscovery of environmental causation. Geographical Journal, 174, 17-29.

KAISER, F., WOLFING, S. \& FUHRER, U. (1999) Environmental Attitude and Ecological Behaviour Journal of Environmental Psychology, 19, 1-9.

KAISER, F. G. \& GUTSCHER, H. (2003) The proposition of a general version of the theory of planned behavior: Predicting ecological behavior. Journal of Applied Social Psychology, 33, 586-603. 
KALTENBORN, B. P. \& BJERKE, T. (2002) Associations between landscape preferences and place attachment: A study in Røros, southern Norway. Landscape Research, 27, 381-396.

KAPLAN, R. (2001) The Nature of the View From Home: Psychological Benefits. Environment and behavior, 33, 507-542.

KAPLAN, R., AUSTIN, M. \& KAPLAN, S. (2004) Open space communities—Resident perceptions, nature benefits, and problems with terminology. Journal of American Planning Association, 70, 300-312.

KAPLAN, R., KAPLAN, S. \& AUSTIN, M. E. (2005) Factors shaping local land use decisions: Citizen planners' perceptions and challenges. Environment and Behavior, 40, 46-71.

KAPLAN, S. (2000) Human nature and environmentally responsible behavior. Journal of Social Issues, 56, 491-508.

KARLSSON, N., JULIUSSON, E. A. \& GÄRLING, T. (2005) A conceptualization of task dimensions affecting escalation of commitment. European Journal of Cognitive Psychology, 17, 835-858.

KARP, D. G. (1996) Values and their Effect on Pro-Environmental Behavior. Environment and Behavior, 28, 111-133.

KASA, S. (2008) Globalizing Unsustainable Food Consumption: Trade Policies, Producer Lobbies, Consumer Preferences, and Beef Consumption in Northeast Asia. Globalizations, 5, 151163.

KATZ, P. (1994) The New Urbanism Toward an Architecture of Community, New York, McGraw Hill.

KEARNEY, A. (2006) Residential Development Patterns and Neighbourhood Satisfaction: Impacts of Density and Nearby Nature. Environment and behavior, 38, 112-139.

KEEN, S. (2003) Standing on the toes of pygmies: Why econophysics must be careful of economic foundations on which it builds. Physica A, 324, 108-116.

KEKÄLE, J. (2002) Psychological sense of community. Tertiary Education and Management, 8, 65-80.

KENNEDY, E. H., BECKLEY, T. M., MCFARLANE, B. L. \& NADEAU, S. (2009) Why We Don't "Walk the Talk": Understanding the Environmental Values/Behaviour Gap in Canada. Research in Human Ecology, Vol. 16, No. 2, 2009.

KENNY, C. (2007) A Note on the Ethical Implications of the Stern Review on the Economics of Climate Change. The Journal of Environment and Development, 16, 432-440.

KENWORTHY, J. \& NEWMAN, K. (1999) Sustainability and Cities: overcoming automobile dependence, Washington DC, Island Press.

KHATTAK, A. J. \& RODRIGUEZ, D. (2005) Travel behavior in neo-traditional neighborhood developments: a case study in USA. Transportation Research Part A: Policy and Practice, 39, 481-500. 
KIM, H.-K. \& SOHN, D. W. (2002) An analysis of the relationship between land use density of office buildings and urban street configuration: case studies of two areas in Seoul by space syntax analysis. Cities, 19, 409-418.

KIM, J. \& KAPLAN, R. (2004) Physical and Psychological Factors in Sense of Community: New Urbanist Kentlands and Nearby Orchard Village. Environment and behavior, 36, 313-340.

KINTREA, K. (2007) Housing aspirations and obsolescence: understanding the relationship. Journal Housing and the Built Environment 22, 321-338.

KITAMURA, R. \& HOORN, T. V. D. (1987) Regularity and irreversibility of weekly travel behavior. Transportation, 14, 227-251.

KITAMURA, R., MOKHTARIAN, P. \& LAIDET, L. (1995) A Micro-Analysis of Land Use and Travel in Five Neighbourhoods in the San Francisco Bay Area. 75th Annual Meeting, Transportation Research Board. Washington, DC.

KITAMURA, R., MOKHTARIAN, P. \& LAIDET, L. (1997) A micro-analysis of land use and travel in five neighborhoods in the San Francisco Bay Area. Transportation, 24, 125-158.

KITCHEN, P. (2006) Exploring the Link between Crime and Socio-Economic Status in Ottawa and Saskatoon: A Small-Area Geographical Analysis. IN DIVISION, R. A. S. (Ed.), Department of Justice Canada

KNACK, R. E. \& BELMONT, S. (2002) Dense, denser, denser still: perceptions can mislead when it comes to units per acre. Planning, 68, 4-9.

KOOREY, G. (2003) Sustainable Urban Transport Policies- New Zealand and Overseas. IPENZ Transportation Group Technical Conference. IPENZ.

KORPELA, K. M., M, K. \& HARTIG, T. (2002) Children's Favourite Places: Restorative Experience, Self-Regulation and Children's Place Preferences. Journal of Environmental Psychology, 22, 387-398.

KRAFT, P., RISE, J., SUTTON, S. \& RØYSAMB, E. (2005) Perceived difficulty in the theory of planned behaviour: Perceived behavioural control or affective attitude? British Journal of Social Psychology, 44, 479-496.

KUNSTLER, J. (1994) Geography of Nowhere: The Rise and Decline of America's Man-Made Landscape, New York, Free Press.

KYLE, G. T., GRAEFE, A. \& MANNING, R. E. (2005) Testing the dimensionality of place attachment in recreational settings. Environment and Behavior, 37, 153-177.

KYLE, G. T., GRAEFE, A., MANNING, R. E. \& BACON, J. (2004) Effect of involvement and place attachment on recreationists' perceptions of setting density. Journal of Leisure Research, 36, 209-231.

KYLE, G. T., MOWEN, A. J. \& TARRANT, M. (2004) Linking place preferences with place meaning: An examination of the relationship between place motivation and place attachment. Journal of Environmental Psychology, 24, 439-454. 
LALLI, M. (1992) Urban-related identity: Theory, measurement and empirical findings. Journal of Environmental Psychology, 12, 285-303.

LANDHÄUßER, S. \& ZIEGLER, H. (2006) Social capital. Social Work and Society, 4.

LANDSBURG, S. (2001) Why Are We Getting So Fat? A few theories on America's weight problem. Slate.

LASH, H. (2007) The Liveable City. Vancouver Working Group Discussion Paper. Vancouver.

LAUDENSLAGER, M. S. \& HOLT, D. T. (2004) Understanding Air Force Members' Intentions to participate in Pro-Environmental Behaviors: An application for the theory of planned behavior. Perceptual and Motor Skills 98, 1162-1170.

LAVE, C. (1992) Cars and Demographics. Access, 1, 4-8.

LEACH, M., HENNESY, M. \& FISHBEIN, M. (2001) Perception of easy-difficulty: Attitude or self efficacy? Journal of Applied Social Psychology, 31, 1-20.

LEPORE, S. J., EVANS, G. W. \& SCHEIDER, M. L. (1992) Role of control and social support in explaining the stress of hassles and crowding. Environment and behavior, 24, 795-811.

LEVINE, J. (2006) Zoned Out: Regulation, Markets, and Choices in Transportation and Metropolitan Land Use., Washington, D.C., Resources for the Future.

LEVINE, J. \& FRANK, L. (2007) Transportation and land-use preferences and residents' neighborhood choices: the sufficiency of compact development in the Atlanta region. Transportation 34, 255-274.

LINDSTROM, M. J. \& BARTLING, H. (Eds.) (2003) Suburban Sprawl: Culture, Theory, and Politics, New York, Rowman \& Littlefield Publishers, Inc.

LITMAN, T. (2004) Economic Value of Walkability. Victoria, Victoria Transport Policy Institute.

LITMAN, T. (2005) Land Use Impacts on Transport. Canada, Victoria Transport Policy Institute.

LIU, R. \& LI, G. (2003) Dynamic travel behaviour analyses based on stochastic decision-making styles. 10th International conference on travel behaviour research. Lucerne, Switzerland.

LOUVIERE, J. J. (1988) Analyzing decision making: Metric Conjoint Analysis, Newbury Park, Sage.

LOUVIERE, J. J. (2001) What If Consumer Experiments Impact Variances as Well as Means? Response Variability as a Behavioral Phenomenon. Journal of Consumer Research, 28, 506-511.

LOUVIERE, J. J., HENSHER, D. A. \& SWAIT, J. D. (2000) Stated Choice Methods: Analysis and Application, Cambridge Cambridge University Press.

LYNE, M. (2004) The Potential Health Impacts of Residential Intensification in Auckland City. Auckland, University of Auckland. 
MAHONEY, J. (2003) Tentative Answers to Questions about Causal Mechanisms. Paper presented at the annual meetings of the American Political Science Association. Philadelphia, PA.

MANSKI, C. (1993). Identification of endogenous social effects: the reflection problem. Review of Economic Studies, 60, 531-542

MANZO, L. C. (2003) Beyond house and haven: toward a re-visioning of emotional relationships with places. Journal of Environmental Psychology 23, 47-61.

MANZO, L. C. (2005) For better or worse: Exploring multiple dimensions of place meaning. Journal of Environmental Psychology, 25, 67-86.

MARK, T. L. \& SWAIT, J. (2003) Using stated preference and revealed preference modelling to evaluate prescribing decisions. Health Economics, 13, 563-573.

MATHISON, S. (1998) Why triangulate? Educational Researcher, 17, 13-17.

MATTHIES, E., KLÖCKNER, C. A. \& PREISSNER, C. L. (2006) Applying a modified moral decision making model to change habitual car use: How can commitment be effective? Applied Psychology: An International Review, 55, 91-106.

MATTHIES, E., KUHN, S. \& KLOCKNER, C. A. (2002) Travel mode choice of women: The result of limitation, ecological norm, or weak habit? Environment and Behavior, 34, 163177.

MAXWELL, S. E. \& DELANY, H. D. (2003) Designing Experiments and Analyzing Data: A Model Comparison Perspective, New York, Routledge Academic.

MAYNTZ, R. (2004) Mechanisms in the Analysis of Social Macro-Phenomena. Philosophy of the Social Sciences, 34, 237-259.

MCFADDEN, D. (1998) Measuring willingness-to-pay for transportation improvement. IN GARLING, T., LAITILA, T. \& WESTIN, K. (Eds.) Theoretical Foundations of Travel Choice Modelling. Amsterdam, Elsevier.

MCFADDEN, D. (1999) Rationality for economists? Journal of Risk and Uncertainty 19, 73-105.

MCFADDEN, D. \& DOMENCICH, T. (1975) Urban travel demand: A behavioral analysis, New York, American Elsevier.

MCINDOE, G., CHAPMAN, R., MCDONALD, C., HOLDEN, G., HOWDEN-CHAPMAN, P. \& SHARPIN, A. (2005) The Value of Urban Design. Wellington, Ministry for the Environment.

MCINDOE, G. \& POPOVA, D. (1999) Wellington Inner City Residential Areas: Urban Design Evaluation. Wellington City Council.

MCKAY, H. (2005) Social disengagement: a breeding ground for fundamentalism Annual Manning Clark lecture.

MCSHANE, O. (2003) Pollution, congestion will leave city empty. The New Zealand Herald. Auckland. 
MEDVEC, V. H., MADEY, S. F. \& GILOVICH, T. (1995) When less in more: Counterfactual thinking and satisfaction among Olympic medalists. Journal of Personality and Social Psychology, 69, 603-610.

MESCH, G. S. \& MANOR, O. (1998) Social ties, environmental perception, and local attachment. Environment and Behavior, 30, 227-245.

MESJASZ, C. (1988) Applications of Systems Modelling in Peace Research. Journal of Peace Research, 25.

MEYER, M. \& MILLER, E. (2000) Urban Transportation Planning, Toronto, McGraw-Hill Science.

MFE (1999) Summary of proposed indicators of the environmental effects of transport. IN BELL, K. (Ed.) Environmental Performance Indicators. Wellington, Ministry for the Environment.

MFE (2000) Technical Paper no.63, Urban Amenity indicators: The liveability of our environments. Ministry for the Environment.

MFE (2002) Creating great places to live work and play. Ministry for the Environment.

MFE (2003) Streamlining RMA Approvals, a study of delays in major roading projects. Wellington, NZ Ministry for the Environment.

MFE (2005) Urban Design Protocol. Wellington, Ministry for the Environment.

MITCHELL, D. (2000) Cultural geography: a critical introduction, Cornwall, U.K., Blackwell.

MITCHELL, N. J. (2005) Calculating and Believing: Ideological Norms in the Cradle of Utility Maximization. Social Justice Research, 18, 243-256.

MOH (2004) Tracking the Obesity Epidemic: New Zealand 1977-2003. Ministry of Health.

MOJ (2005) Part 1: Seven Qualities of Safer Places. Ministry of Justice.

MOKDAD, A., BOWMAN, B., FORD, E. \& AL., E. (2001) The continuing epidemics of obesity and diabetes in the United States. Journal of the American Medical Association, 286, $1195-$ 1200 . .

MOKHTARIAN, P. \& SALOMON, I. (2001) How derived is the demand for travel: Some conceptual and measurement considerations. Transportation research Part A, 35.

MOKHTARIAN, P. \& SCHWANEN, T. (2005) Attitudes toward travel and land use choice of residential neighbourhood type: Evidence from the San Francisco Bay Area. Housing Policy Debate, 18, 171-207.

MOLIN, E., OPPEWAL, H. \& TIMMERMANS, H. J. P. (2001) Analyzing heterogeneity in conjoint estimates of residential preferences. Journal of Housing and the Built Environment, 16, 267-284. 
MONTGOMERY, C. \& BARNES, J. H. (1993) POSTDIS: A short rating scale for measuring postpurchase dissonance. Journal of Consumer Satisfaction, Dissatisfaction and Complaining Behavior, 6, 204-216.

MOORE, R. L. \& GRAEFE, A. R. (1994) Attachments to recreation settings. Leisure Sciences, 16, 17-31.

MORRIS, N. (2003) Health, Well-Being and Open Space: Literature Review. OPEN space Research Centre.

MORRISON, P. \& MCMURRAY, S. (1999) The Inner-city Apartment versus the Suburb: Housing Sub-markets in a New Zealand City. Urban Studies, 36, 377.

MORROW-JONES, H. A., IRWIN, E. G. \& ROE, B. (2004) Consumer Preference for Neotraditional Neighborhood Characteristics. Housing Policy Debate, 15, 171-202.

MOTLOCH, J. L. (2000) Introduction to Landscape Design, Austin, TX., Wiley.

MSP (2006) Social Report. NZ Ministry of Social Development.

MUNTON, A. G. (1990) Job relocation, stress and the family. Journal of Organizational Behavior 11, 401-406.

MYERS, D. \& GEARIN, E. (2001) Current Preferences and Future Demand for Denser Residential Environments. Housing Policy Debate, 12, 633-659.

NAESS, P. (2005) Residential location affects travel behavior-but how and why? The case of Copenhagen metropolitan area. Progress in Planning, 63, 167-257.

NAESS, P. (2006) Urban Structure Matters: Residential Location, Car Dependence and Travel Behaviour, New York, Routledge.

NAJAFI, M., MOHAMED, R., TAYEBI, A. \& LAKE, M. (2006) The Fiscal Impacts of Alternative Single Family Housing Densities: Infrastructure Costs. Michigan, Michigan State University Land Policy Institute.

NASAR, J. \& JULIAN, D. (1995) The psychological sense of community in the neighbourhood. American Planning Association, 61, 178(7).

NELSON, A., PENDAL, R., DAWKINS, C. \& KNAAP, G. J. (2002) The Link Between Growth Management and Housing Affordability: The Academic Evidence. The Brookings Institute Centre on Urban and Metropolitan Policy.

NEWMAN, K. \& WYLY, E. (2006) The Right to Stay Put, Revisited: Gentrification and Resistance to Displacement in New York City. Urban Studies, 43, 23-57.

NEWMAN, M. (2005) The compact city fallacy. Journal of planning education and research, 25, 11-26.

NEWMAN, P. \& KENWORTHY, J. (1989) Gasoline Consumption and cities: A comparison of U.S. cities with a global survey. Journal of the American Planning Association, 55, 24-37. 
NEWMAN, P. D. (1992) The compact city: an Australian perspective. Built environment, 18, 285300 .

NIEBOER, N. (2005) The Disputable Role of the Built Environment in Liveability. ENHRHousing: New Challenges and Innovations in Tomorrow's Cities. Reykjavik.

NIEBOER, N. (2005) How strategic is housing asset management of institutional real estate investors? . Property Management, 23, 22-32(11).

NORDLUND, A. \& GARVILL, J. (2003) Effects of values, problem awareness, and personal norm on willingness to reduce personal car use. Journal of Environmental Psychology, 23, 339347.

NORMAN, P. \& SMITH, L. (1995) The theory of planned behavior and exercise: an investigation into the roles of prior behavior, behavior intentions, and attitude variability. European Journal of Social Psychology, 25, 403-415.

OHLIN, J. (2003) A Suburb Too Far? Urban Consolidation in Sydney. Briefing Paper 4/2003. Sydney, NSW Parliamentary Library.

OPPEWAL, M. E. \& TIMMERMANS, H. (1999) Group-based versus individual-based conjoint preference models of residential preferences: a comparative test. Environment and Planning A 31, 1935-1947.

OREG, S. \& KATZ-GERRO, T. (2006) Predicting Proenvironmental Behavior Cross-Nationally: Values, the Theory of Planned Behavior, and Value-Belief-Norm Theory. Environment and Behavior, 38, 462-483.

O'TOOLE, R. (2001) The Folly of "Smart Growth". Portland, Thoreau Institute.

OWEN, N. \& HUMPEL, N. (2004) Understanding the Environmental Influences on Walking: Review and Research Agenda. American Journal of Preventive Medicine, 27, 67-76.

PARKER, D., MANSTEAD, A. S. R. \& STRADLING, S. G. (1995) Extending the theory of planned behavior: The role of personal norm. British Journal of Social Psychology, 34, 127- 137.

PARKS, C. D. \& SANNA, L. J. (1999) Group Performance and Interaction, Boulder, CO., Westview.

PATTERSON, M. E. \& WILLIAMS, D. R. (2005) Maintaining research traditions on place: Diversity of thought and scientific progress. Journal of Environmental Psychology, 25, 361-380.

PAYNE, J., BETTMAN, J. \& SCHKADE, D. (1999) Measuring constructed preferences: towards a building code. Journal of Risk and Uncertainty 19, 243-270.

PAYNE, M. (2002) The Politics of Systems Theory within Social Work. Journal of Social Work, 2, 269-292.

PEET, R. (1985) The Social Origins of Environmental Determinism. Annals of the Association of American Geography, 75, 309-333. 
PEET, R. (1998) Modern Geographical Thought Oxford, Wiley-Blackwell.

PENDALL, R. (2000) Local land-use regulation and the chain of exclusion. Journal of the American Planning Association, 66, 125-142.

PERKINS, H. \& THORNS, D. (1998) Urban planning in New Zealand: the influences of the Resource Management Act and the Local Government Act. In Urban Sustainability in New Zealand. Wellington, Royal Society of New Zealand.

PETERS, A. (2002) Is your community child-friendly? Canadian Social Trends, 11.

PICKRELL, D. H. (1989) Urban Rail Transit Projects: Forecast vs. Actual Ridership and Costs. Urban Mass Transportation Administration Report. IN OFFICE, U. S. G. P. (Ed.) Washington, DC, United States Department of Transportation.

PIMENTEL, D., XUEWEN, H. \& PIMENTEL, M. (1996) Impact of Population Growth on Food Supplies and Environment. Population and Development Review. Baltimore.

PINJARI, A. R., PENDYALA, R. M., BHAT, C. R. \& WADDELL, P. (2007) Modelling residential sorting effects to understand the impact of the built environment on commute mode choice. Transportation, 34, 557-573.

PINJARI, A. R., PENDYALA, R. M., BHAT, C. R. \& WADDELL, P. A. (2007) Modelling Residential Sorting Effects to Understand the Impact of the Built Environment on Commute Mode Choice. Transportation, 34, 557-573.

PLAS, J. M. \& LEWIS, S. E. (1996) Environmental factors and sense of community in a planned town. American Journal of Community Psychology, 24, 109-143.

PLATINGA, A. \& BERNELL, S. (2005) A Spatial Economic Analysis of Urban Land Use and Obesity. Journal of Regional Science, 45, 473-492.

PODOBNIK, B. (2002) The Social and Environmental Achievements of New Urbanism: Evidence from Orenco Station. Portland, Department of Sociology: Lewis and Clark College.

PORRITT, J. (2006) Capitalism: As If the World Matters London, Earthscan Publications

POSTMES, T., TANIS, M. \& WIT, B. D. (2001) Communication and Commitment in Organizations: A Social Identity Approach. Group Processes \& Intergroup Relations, 4, 227-246.

POTWOROWSKI, J. A. (2009) Making it Happen -The Transition to a Sustainable Society. Ottawa, Telfer School of Management, University of Ottawa.

POULENEZ-DONOVAN, C. \& ULBERG, C. (2004) Seeing the trees and missing the forest: Qualitative versus quantitative research findings in a model transportation demand management program evaluation. Transportation Research Record, 1459, 1-6.

POWER, M. (2003) Development of a Common Instrument for Quality of Life. IN NOSIKOV, A. \& GUDEX, C. (Eds.) EUROHIS. IOS Press.

POZDENA, R. J. (2003) Smart Growth and its Effects on Housing Markets: The New Segregation. Portland QuantEcon. 
PROSHANSKY, H. M. (1978) The city and self-identity. Environment and Behavior, 10, 147-169.

PROSHANSKY, H. M., FABIAN, A. K. \& KAMINOFF, R. (1983) Place-identity. Journal of Environmental Psychology, 3, 57-83.

PUTNAM, P. (2000) Bowling Alone, New York, Simon and Shuster.

RANDOLPH, B. (2006) Delivering the Compact City in Australia: Current Trends and Future Implications Urban Policy and Research, 24, 473-490.

REDMOND, L. (2000) Identifying and Analyzing Travel-Related Attitudinal, Personality, and Lifestyle Clusters in the San Francisco Bay Area. Institute of Transportation Studies. Davis, University of California, Davis.

RELPH, E. (1976) Place and Placelessness, London, Pion.

RHODES, R. E. \& COURNEYA, K. S. (2003) Self-efficacy, controllability and intention in the theory of planned behavior: Measurement redundancy or causal independence? Psychology and Health 18, 79-92.

RIAD, J. K. \& NORRIS, F. H. (1996) The Influence of Relocation on the Environmental, Social, and Psychological Stress Experienced by Disaster Victims. Environment and Behavior 28, 163-182.

ROBERTS, J. A. (1996) Green consumers in the 1990s: Profile and implications for advertising. Journal of Business Research, 36, 217-231.

ROE, P. G. (2000) Qualitative research on intra-urban travel: an alternative approach. Journal of Transport Geography, 8, 99-106.

ROGERS, R. (1999) Towards and Urban Renaissance, London, Spon.

RONIS, D. L., YATES, J. F. \& KIRSCHT, J. P. (1989) Attitudes, decisions, and habits as determinants of repeated behavior. IN PRATKANIS, A. R., BRECKLER, S. J. \& GREENWALD, A. G. (Eds.) Attitude Structure and Function. Hillsdale, NJ., Erlbaum.

ROOS, M. W. M. (2008) Willingness to consume and ability to consume. Journal of economic behaviour and organization, 66, 387-402.

ROSE, G. \& AMPT, E. (2001) Travel Blending: an Australian travel awareness initiative. Transportation research part $D, 6,95-110$.

ROSELAND, M., HENDRICKSON, D., CONNELLY, S. \& BRUGMANN, J. (1998) Toward Sustainable Communities: Resources for Citizens and Their Governments, Gabriola Island, BC, New Society Publishers.

ROSENZWEIG, C., PARRY, M., FISCHER, G. \& FROHBERG, K. (1993) Climate Change and World Food Supply. Oxford, University of Oxford, Environmental Change Unit.

ROUECHE, K. (2005) Fairfield History, Victoria, BC, Trafford Publishing. 
RYAN, M., WATSON, V. \& ENTWISTLE, V. (2009) Rationalising the irrational: a think aloud study of discrete choice experiment responses. Health Economics, 18, 321 - 336.

RYBCZYNSKI, W. (1998) (Some) People Like New Urbanism. Wharton Real Estate Review, 2, 49-53.

RYBCZYNSKI, W. (2001) The Look of Architecture, Oxford, Oxford University Press.

RYDIN, Y. (2007) Re-Examining the Role of Knowledge Within Planning Theory. Planning Theory, 6, 52-68.

SACK, R. D. (1997) Homo geographicus: A framework for action, awareness and moral concern, London, John Hopkins University Press.

SAKANO, R. \& BENJAMIN, J. M. (2008) A Structural equations analysis of revealed and stated travel mode and activity choices. Transport America, 4, 97-115.

SALEH, W. (2005) Congestion charging: theory and practice. Transport Policy, 12, 377-383.

SAMUELS, I. (2005) Streetsweeper: In praise of wider streets ... and other things. Urban Design International, 10, 137-141(5).

SAMUELS, I. (2005a) What Homebuyers Want: Attitudes and Decision Making among Consumers. London, CABE.

SANDERSON, K. (2005) Housing Affordability and Urban Density. Wellington, Business and Economic Research Ltd. .

SAUER, C. (1925) The Morphology of Landscape, Berkeley, University of California Press.

SAUL, J. R. (1999) The Unconscious Civilization, New York, Free Press

SCHEINER, J. \& HOLZ-RAU, C. (2007) Travel mode choice: affected by objective or subjective determinants? . Transportation, 34, 487-511.

SCHEYVENS, R. \& STOREY, D. (2003) Development Fieldwork: a Practical Guide, Sage Publications.

SCHKADE, D. A. \& PAYNE, J. W. (1994) How people respond to contingent valuation questions: A verbal protocol analysis of willingness to pay for environmental regulation. Journal of Environmental Economics and Management, 26, 88-109.

SCHLEGEL, R. P., D'AVERNAS, J. R., ZANNA, M. P., DECOURVILLE , N. H. \& MANSKE, S. R. (1992) Problem drinking: A problem for the theory of reasoned action? Journal of Applied Social Psychology, 22, 358-385.

SCHNEIDER A, C. E. W. (2008) Compact, Dispersed, Fragmented, Extensive? A Comparison of Urban Growth in Twenty-five Global Cities using Remotely Sensed Data, Pattern Metrics and Census Information. Urban Studies, 45, 659-692.

SCHOR, J. B. (2005) Prices and quantities: Unsustainable consumption and the global economy. Ecological Economics 55, 309-320. 
SCHWANEN, T., P (2005) What affects commute mode choice: neighbourhood physical structure or preferences toward neighbourhoods? Journal of Transport and Geography, 13, 83-99.

SCHWANEN, T. \& MOKHTARIAN, P. (2003) Does dissonance between desired and current neighborhood type affect individual travel behaviour? An empirical assessment from the San Francisco Bay Area. Proceedings of the European Transport Conference (ETC). Strasbourg.

SCHWANEN, T. \& MOKHTARIAN, P. (2005b) What if you live in the wrong neighborhood? The impact of residential neighborhood type dissonance on distance travelled. Transportation Research Part D: Transport and Environment, 10, 127-151.

SCHWANEN, T. \& MOKHTARIAN, P. (2004) The extent and determinants of dissonance between actual and preferred residential neighborhood type. Environment and Planning B: Planning and Design, 31, 759-784.

SCHWANEN, T., P \& MOKHTARIAN, P. (2005) What affects commute mode choice: neighborhood physical structure or preferences toward neighborhoods? Journal of Transport Geography, 13, 83-99.

SCHWANEN, T., P \& MOKHTARIAN, P. (2007) Attitudes toward Travel and Land Use and Choice of Residential Neighborhood Type: Evidence from the San Francisco Bay Area. Housing Policy Debate, 18.

SCHWARTZ, S. (1977) Normative influences on altruism. IN BERKOWITZ, L. (Ed.) Advances in experimental social psychology. New York, Academic Press.

SCHWARTZ, S. H. (1968) Words, deeds, and the perception of consequences and responsibility in action situation. Journal of Personality and Social Psychology, 10, 232-242.

SCHWARTZ, S. H. (1992) Universals in the content and structure of values: Theory and empirical tests in 20 countries. IN ZANNA, M. (Ed.) Advances in experimental social psychology. New York, New York: Academic Press

SCION (2006) The Future of Housing in New Zealand. IN BRANZ (Ed.) Wellington, Centre for Housing Research.

SEMPLE, E. C. (1911) Influences of the Geographic Environment: on the basis of Ratzel's system of Anthropo-Geography, New York, Henry Holt.

SEMYONOV, M., GLIKMAN, A. \& KRYSAN, M. (2007) Europeans' Preference for Ethnic Residential Homogeneity: Cross-National Analysis of Response to Neighborhood Ethnic Composition. Social Problems, 54, 434-453.

SHAMAI, S. (1991) Sense of place: an empirical measurement. Geoforum 22, 347-358.

SHEERAN, I. \& ORBELL, S. (1999) Augmenting the theory of planned behavior: Roles of anticipated regret and descriptive norms. Journal of Applied Social Psychology, 29, $2107-$ 2142 .

SHOUP, D. C. (2005) The High Cost of Parking. Journal of American Planning Association. 
SHUMAKER, S. A. \& TAYLOR, R. B. (1983) Toward a clarification of people-place relationships: A model of attachment to place. IN FEIMER, N. R. \& GELLER, E. S. (Eds.) Environmental psychology: Directions and perspectives. New York, Praeger.

SIMON, D., KRAWCZYK, D. C. \& HOLYOAK, K. J. (2004) Construction of Preferences by Constraint Satisfaction. Psychological Science 15.

SINGLETON, R. A. \& STRAITS, B. C. (1999) Approaches to Social Research, New York and Oxford, Oxford University Press.

SIPPEL, R. (1997) An Experiment on the Pure Theory of Consumer's Behaviour. The Economic Journal, 107, 1431-1444.

SIRGY, J. \& SU, C. (2000) Destination Image, Self-Congruity, and Travel Behavior: Toward an Integrative Model. Journal of Travel Research, 38, 340-352.

SLOMAN, L. (2003) Less traffic where people live: how local transport schemes can help cut traffic. Royal Commission for the Exhibition of 1851. Westminister, University of Westminster and Transport 2000 Trust.

SLUYTER, A. (2003) Neo-Environmental Determinism, Intellectual Damage Control and Nature/ Society Science. Antipode, 813-817.

SMITH, V. K. (1992) Arbitrary values, good causes, and premature verdicts. Journal of Environmental Economics and Management 22, 71-89.

SNELLEN, D., BORGERS, A. \& TIMMERMANS, H. (1998) The Relationship Between Urban Form and Activity Patterns Preliminary Conclusions from an Activity Survey. European Transport. Loughborough University, Loughborough

SOLO, R. (1975) What Is Structuralism? Piaget's Genetic Epistemology and the Varieties of Structuralist Thought. Journal of Economic Issues, 9, 605-625.

SONG, Y. \& KNAAP, G. J. (2004) Measuring urban form: is Portland winning the war on sprawl? Journal of the American Planning Association, 70, 210-225.

SONG, Y. \& QUERCIA, R. G. (2008) How are neighbourhood design features valued across different neighbourhood types? Journal Housing and the Built Environment, 23, 297-316.

SPARC (2007) Activity Friendly Environments - Benefits. Wellington.

SPEARS, R., LEA, M. \& LEE, S. (1990) De-individualization and group polarization in computermediated communication. British Journal of Social Psychology 29, 121-134.

SPEIR, C. \& STEPHENSON, K. (2002) Does sprawl cost us all? Isolating the effects of housing patterns on public water and sewer costs. . American Planning Association, 68, 56(15).

STATISTICS NZ (2001) Community Profiles. Statistics New Zealand.

STAUFFACHER, M., SCHLICH, R., AXHAUSEN, K. W. \& SCHOLZ, R. W. (2005) The diversity of travel behaviour: motives and social interactions in leisure time activities. Arbeitsberichte Verkr- und Raumplanung, 30. 
STAW, B. M. \& ROSS, J. (1989) Understanding behaviour in escalation situations. Science, 246, 216-220.

STEAD, D. (2001) Relationships between land use, socioeconomic factors, and travel patterns in Britain. Environment and planning B, planning \& design, 28, 499-528.

STEDMAN, R. (2003) Is it really just a social construction? The contribution of the physical environment to sense of place. Society and Natural Resources, 16, 671-685.

STEDMAN, R. C. (2002) Toward a social psychology of place. Predicting behavior from placebased cognitions, attitude, and identity. Environment and Behavior, 34, 561-581.

STEG, L., GEURS, K. \& RAS, M. (2001) The effects of motivational factors on car use: A multidisciplinary modelling approach. Transportation research Part A, 35, 789-806.

STEG, L. \& VLEK, C. (1997) The role of problem awareness in willingness-to-change car use and in evaluating relevant policy measures. IN ROTHENGATTER, T. \& VAYA, E. C. (Eds.) Traffic and transport psychology. Theory and application Oxford, Pergamon.

STEG, L. \& VLEK, C. (2009) Encouraging pro-environmental behaviour: An integrative review and research agenda. Journal of Environmental Psychology, 29, 309-317.

STEIN, C. S. (1957) Toward New Towns for America, MIT Press.

STENBACKA, C. (2001) Qualitative research requires quality concepts of its own. Management Decision, 39, 551-555.

STERN, N. (2006) The Economics of Climate Change. Cambridge, Cabinet Office - HM Treasury.

STERN, P. (2000) Toward a coherent theory of environmentally significant behavior. Journal of Social Issues, 56, 407-424.

STERN, P. C. (2000) Toward a coherent theory of environmentally significant behaviour. Journal of social issues, $56,407-427$.

STERN, P. C. \& DIETZ, T. (1994) The value basis of environmental concern. Journal of Social Issues, 50, 65-84.

STERN, P. C., DIETZ, T., ABEL, T., GUAGNANO, G. A. \& KALOF, L. (1999) A value-beliefnorm theory of support for social movements: The case of environmentalism. Human Ecology Review, 6, 91-97.

STERN, P. C., DIETZ, T. \& KALOF, L. (1993) Value orientations, gender, and environmental concern. Environment and Behavior, 322-348.

STONE, M. (1994) Whose Shortage of Affordable Housing? IN 4 (Ed.) Comment Housing Policy Debate 5.

STOPHER, P. \& JONES, P. (Eds.) (2003) Transport Survey Quality and Innovation, New York, Pergamon.

STRAUGHAN, R. D. \& ROBERTS, J. A. (1999) Environmental segmentation alternatives: A look at green consumer behavior in the new millennium. Journal of Consumer Marketing, 16, $558-575$. 
SUTTON, S. (1998) Predicting and explaining intentions and behavior: How well are we doing? Journal of Applied Social Psychology, 28, 1317-1338.

SUZUKI, D. F. (2004) Smart Generation: Powering Ontario With Renewable Energy. Vancouver, David Suzuki Foundation.

SWEENEY, J. C., HAUSKNECHT, D. \& SOUTAR, G. N. (2000) Cognitive Dissonance after Purchase: A Multidimensional Scale. Psychology \& Marketing, 17, 369-385.

SYME, C., MCGREGOR, V. \& MEAD, D. (2005) Social Implications of Housing Intensification in the Auckland Region: analysis and review of media reports, surveys and literature. Auckland Sustainable Cities Programme (Urban Form, Design and Development Work Strand). Auckland.

TALEN, E. (2001) Traditional urbanism meets residential affluence: An analysis of the variability of suburban preference. Journal of American Planning Association, 67, 199-216.

TALEN, E. (2003) Measuring Urbanism: Issues in Smart Growth Research. Journal of Urban Design, 8, 195-215.

TANIGUCHI, A. \& FUJII, S. (2007) Process model of voluntary behavior modification and effects of travel feedback programs. Transportation Research Record, 45.52.

TANNER, C. (1999) Constraints on Environmental Behaviour Journal of Environmental Psychology 19, 145-157.

TAYLOR, B. D. (2006) Putting a price on mobility. Journal of the American Planning Association, $72,279-284$.

THIEBAUD, W. (2002) Rational Choice Theory. IN FOXALL, G. R. (Ed.) Consumer Behaviour Analysis: Critical Perspectives on Business and Management London, Routledge.

THILL, J.-C. \& KIM, M. (2005) Trip making, induced travel demand, and accessibility Journal of Geographical Systems, 7.

THØGERSEN, J. (2004) A cognitive dissonance interpretation of consistencies and inconsistencies in environmentally responsible behavior. Journal of Environmental Psychology, 24, 93103.

THOMPSON-FAWCETT, M. \& BOND, S. (2003) Urbanist intentions for the built landscape: examples of concept and practice in England, Canada and New Zealand. Progress in Planning, 60, 147-234.

TIESDELL, S. (2004) Integrating affordable housing within market-rate developments: the design dimension. Environment and Planning B: Planning and Design, 31, 195-212.

TIMMERMANS, H., MOLIN, E. \& NOORTWIJK, L. V. (1994) Housing choice processes: Stated versus revealed modelling approaches. Netherlands Journal of Housing and the Built Environment, 9. 
TIMMINS, P., GALLOIS, C., TERRY, D. \& KASHIMA, Y. (1993) Theory of reasoned action and the role of perceived risk In the study of safer sex. IN TERRY, D. J., GALLOIS, C. \& MCCAMISH, M. M. (Eds.) the theory of reasoned action: Its application to safe sex behaviour. U.K., Pergamon.

TOWN, S. \& O'TOOLE, R. (2005) Crime-Friendly Neighborhoods.

TRAFIMOW, D. \& DURAN, A. (1998) Some tests of the distinction between attitude and perceived behavioural control. British Journal of Social Psychology, 37, 1-14.

TRAFIMOW, D. \& FINLAY, K. (1996) The importance of subjective norms for a minority of people. Personality and Social Psychology Bulletin, 22, 820-828.

TROY, P. (1996) The Perils of Urban Consolidation, Annandale, NSW, The Federation Press.

TSAI, Y.-H. (2005) Quantifying Urban Form: Compactness versus 'Sprawl. Urban Studies, 42, $141-161$.

TUAN, Y. (1974) Topophilia: A study of environmental perception, attitudes, and values, Englewood Cliffs, N.J., Prentice-Hall.

TUAN, Y. (1977) Space and Place: the Perspective of Experience, Minneapolis, University of Minnesota Press.

TURNBULL, C. M. (1987) The forest people, New York, Touchstone.

TURNER, D., HEWITT, J., WAGNER, C., SU, B. \& DAVIES, K. (2004) Best practice in medium density housing design. Wellington, Housing New Zealand Corporation.

TURNER, J. C. (1987) The analysis of social influence. IN TURNER, J. C., M. A. HOGG, OAKES, P. J., REICHER, S. D. \& WETHERELL, M. S. (Eds.) Rediscovering the social group: A self-categorization theory. Oxford, Blackwell.

TWIGGER, C. (1992) Psychological attachment to place: London Docklands-a case study. Annual British Psychological Society Conference. Scarborough, U.K.

UNFPA (2007) State of World Population 2007. United Nations Population Fund. New York.

UZZELL, D., POL, E. \& BADENAS, D. (2002) Place identification, social cohesion, and environmental sustainability. Environment and Behavior, 34, 26-53.

VAN ASSCHE, K. \& VERSCHRAEGEN, G. (2008) The Limits of Planning: Niklas Luhmann's Systems Theory and the Analysis of Planning and Planning Ambitions. Planning Theory 7, 263-283.

VAN BOVEN, L., LOEWENSTEIN, G. \& DUNNING, D. (2003) Mispredicting the endowment effect: underestimation of owners' selling prices by buyer's agents. Journal of Economic Behavior \& Organization, 51, 351-365.

VAN INWAGEN, P. (1999) An Essay on Free Will, Oxford, Oxford University Press.

VAN KEMPEN, R. (2007) Divided cities in the 21st century: challenging the importance of globalisation. Journal Housing and the Built Environment, 22, 13-31. 
VAN ROON, M., DIXON, J. \& VAN ROON, H. (2005) Reformulating Planning Tools to promote Low Impact Urban Design and Development. New Zealand Water and Waste Association 4th South Pacific Conference on Stormwater and Aquatic Resource Protection. Auckland.

VAN VUGT, M. (2001) Community identification moderating the impact of financial incentives in a natural social dilemma: Water conservation. Personality and Social Psychology Bulletin, $11,1440-1449$.

VANCE, C. \& HEDEL, R. (2007) The impact of urban form on automobile travel: disentangling causation from correlation. Transportation, 34, 575-588.

VARADY, D. P. (1986) Neighborhood confidence: A critical factor in neighborhood revitalization? Environment and Behavior, 18, 480-501.

VERPLANKEN, B. \& AARTS, H. (1999) Habit, attitude, and planned behaviour: Is habit an empty construct or an interesting case of goal-directed automaticity. IN STROEBE, W. \& HEWSTONE, M. (Eds.) European Review of Social Psychology. Chichester, England, Wiley.

VERPLANKEN, B., WALKER, I., DAVIS, A. \& JURASEK, M. (2008) Context change and travel mode choice: Combining the habit discontinuity and self-activation hypotheses. Journal of Environmental Psychology 28, 121-127.

VINING, J. \& EBREO, A. (1992) Predicting recycling behavior from global and specific environmental attitudes and changes in recycling opportunities. Journal of Applied Social Psychology, 22, 1580-1607.

VISION2020 (2005) Information Paper on the Cost of Sprawl. Portland, Puget Sound Regional Council.

VISSER, P. \& KROSNICK, J. (1998) Development of Attitude Strength Over the Life Cycle: Surge and Decline. Journal of Personality and Social Psychology, 75, 1389-1410.

VON HOFFMAN, A. \& HARRIGAN, L. (2004) Happy to Grow: Development and Planning in Fairfax County, Virginia. Boston, Joint Center for Housing Studies, Harvard University.

WALL, R., DEVINE-WRIGHT, P. \& MILL, G. A. (2007) Comparing and combining theories to explain proenvironmental intentions: The case of commuting-mode choice. Environment and behavior, 39, 731-753

WALL, R., DEVINE-WRIGHT, P. \& MILL, G. A. (2008) Interactions Between Perceived Behavioral Control and Personal Motives: Qualitative and Quantitative Evidence From a study of Commuting Mode Choice. Journal of Mixed Methods Research, 2, 63-86.

WARNER, R. M. (2007) Applied Statistics From Bivariate Through Multivariate Techniques, Thousand Oaks, CA., Sage Publications.

WCC (2006) A Heart for Churton Park. Wellington, Wellington City Council.

WCED (1987) Report of the World Commission on Environment and Development United Nations. 
WEBBER, R. (2004) The relative power of type of neighbourhood vis a vis person and household demographic variables as discriminators of consumer behaviour. IN RESEARCH, E. C. F. N. (Ed.) CNR Paper 22. UCL \& ESRC.

WERNER, I. (2006) The Role of Social Capital in Housing Management - Pilot Studies in Four Swedish Housing Areas. Housing in an expanding Europe: theory, policy, participation and implementation. Ljubljana, Slovenia.

WHEELER, S. M. (2003) The Evolution of Urban Form in Portland and Toronto: implications for sustainability planning. Local Environment, 8, 317-336.

WHITE, R. (2002) Building the Ecological City, Cambridge, Woodhead.

WILLIAMS, D. R., PATTERSON, M. E., ROGGENBUCK, J. W. \& WATSON, A. E. (1992) Beyond the commodity metaphor-examining emotional and symbolic attachment to place. Leisure Sciences, 14, 29-46.

WILLIAMS, K., BURTON, E. \& JENKS, M. (2000) Achieving Sustainable Urban Form, London, E \& FN Spon.

WILLIAMS, M. (2005) The End of Oil?, MIT Technology Review.

WILSON, E. O. (1998) Consilience: The Unity of Knowledge, New York, Random House.

WILSON, K., ELLIOTT, S., LAW, M., EYLES, J., JERRETT, M. \& KELLER-OLAMAN, S. (2004) Linking perceptions of neighbourhood to health in Hamilton, Canada. Journal of Epidemiol. Community Health, 58, 192-198.

WISH, N. B. (1986) Are We Really Measuring the Quality of Life? Well-being Has Subjective Dimensions, As Well As Objective Ones. American Journal of Economics and Sociology, 45 . 
Appendix 1- Pilot Survey 
VICTORIA UNIVERSITY OF WELLINGTON

Te Whare Wananga o te Upoko o te Ika a Maui

\section{RESEARCH INTO NEIGHBOURHOOD QUALITY}

I am a Masters student in urban design at Victoria University of Wellington, School of Architecture and Design. The research I am conducting seeks resident's opinions and experiences about the positives and negatives of their neighbourhood's design.

The information you provide will contribute to my thesis and, in the future, help guide planning and design professionals to build more liveable communities that represent the views of residents.

The survey is aimed at discovering what makes your neighbourhood liveable. For this research the 'what' refers to the physical setting, the things that designers and planners can change such as; road layouts and traffic volumes, building types and uses, amount and type of green space, the look and feel of the streetscape, connections to other neighbourhoods, types of transportation supported as well as amenities and activities provided. Liveability is about how your neighbourhood performs in terms of providing convenience for the function of your day to day activities. This means having your needs met, feeling safe, having choices, being able to stay healthy and being free of unnecessary financial hardships caused by your environment.

The survey involves a series of tick boxes and short answer questions and should only take about 20 minutes to complete. Please feel free to add additional comments.

Please submit your completed survey by April 13th for me to include your views in my research.

I hope you will be able to help with this research by highlighting the good and the bad of your neighbourhood.

Thank you for your participation: 


\section{Neighbourhood Quality Survey:}

Thank you for taking part in this survey. The survey should take approximately 20 minutes and you are free to write your answers long hand or in point form or just check the box where indicated. You can mail this survey back to me in the pre-paid envelope provided or if you prefer you can email me and I will send you a link to complete the survey on-line. When emailing please quote that you are emailing from Churton Park.

If you have any questions please feel free to contact me at miko_betanzo@yahoo.com

\section{Survey:}

\section{Demographic:}

1. Sex: Male $\square$ Female

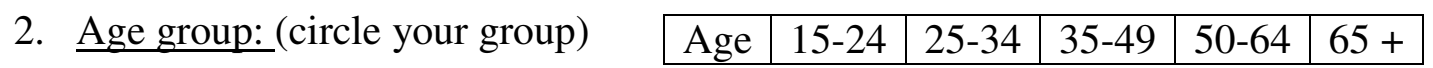

3. Churton Park is where I: Live in my own home $\square \quad$ Live in a rented home $\square \quad$ Work $\square$ Have a vested interest in (as a professional or business owner).

\section{General Neighbourhood Questions:}

1. List some of the things you dislike about your neighbourhood in terms of its liveability.

\begin{tabular}{|l|}
\hline \\
\hline \\
\hline
\end{tabular}

2. List some of the things you like about your neighbourhood in terms of its liveability.

3. What contributes to your feeling of safety and/or lack of safety in your neighbourhood?

\begin{tabular}{|l|}
\hline \\
\hline \\
\hline
\end{tabular}

4. When you are not home, do you feel that your property is safe? Why or why not?

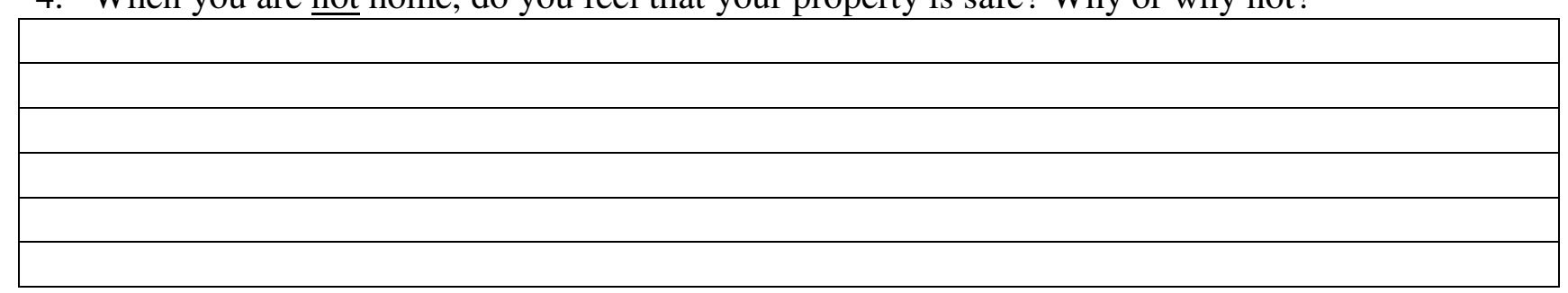

$\mathrm{S} \mathrm{CH}$ O O L O F A R C H I T E C T U R E

Victoria University of Wellington, PO Box 600, Wellington, New Zealand.

Webpage: http://www.vuw.ac.nz/architecture/ Phone: +64-4463-6200, Email: architecture@vuw.ac.nz 
5. Is there anything about the design of your neighbourhood that you feel hinders your weekly routine? Please explain.

6. While carrying out your day to day activities, do you have opportunities to get to know your neighbours? Please explain why or why not?

7. Are you satisfied with the amount of green space and/ or open space in your neighbourhood? Please explain why or why not.

8. Are you satisfied with the amount of privacy you have in your neighbourhood? Please explain.

9. Describe/ discuss what encourages or discourages you to walk in your neighbourhood. 
10. How many vehicles are owned by your household? $\quad 0 \square \quad 1 \square \quad 2 \square \quad$ more than $2 \square$

Transportation Tables

\begin{tabular}{|c|c|c|c|c|c|c|c|}
\hline $\begin{array}{l}\text { Please tick which } \\
\text { transport option } \\
\text { you use MOST for } \\
\text { each destination. }\end{array}$ & 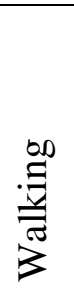 & $\begin{array}{l}\frac{0}{0} \\
\text { de } \\
\end{array}$ & 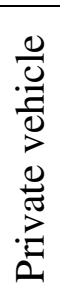 & 瓬 & 禀 & $\frac{\bar{\Xi}}{\overline{0}}$ & $\frac{\mathbb{Z}}{\mathrm{Z}}$ \\
\hline Work / Employmen & & & & & & & \\
\hline Education/ school & & & & & & & \\
\hline Supermarket & & & & & & & \\
\hline Restaurant/ café/ ba & & & & & & & \\
\hline Shopping mall, retai & & & & & & & \\
\hline Bank/ ATM & & & & & & & \\
\hline Entertainment/ mov & & & & & & & \\
\hline Doctor/ health care & & & & & & & \\
\hline Park/ Reserve & & & & & & & \\
\hline Church & & & & & & & \\
\hline Corner store/ Dairy & & & & & & & \\
\hline Bakery/ butcher & & & & & & & \\
\hline Day-care/ Crèche & & & & & & & \\
\hline Hairdresser & & & & & & & \\
\hline Library & & & & & & & \\
\hline Sport Participation & & & & & & & \\
\hline
\end{tabular}

\begin{tabular}{|c|c|c|c|c|c|c|c|}
\hline $\begin{array}{l}\text { Please tick which } \\
\text { transport option } \\
\text { you would prefer to use } \\
\text { for each destination }\end{array}$ & $\frac{\infty}{\stackrel{\infty}{\#}}$ & $\frac{0}{0}$ & $\begin{array}{l}\frac{0}{0} \\
.0 \\
0 \\
0 \\
0 \\
0 \\
0 \\
0\end{array}$ & 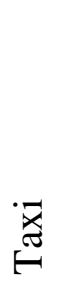 & 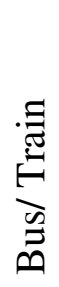 & $\frac{\overline{\bar{D}}}{\overline{0}}$ & $\frac{\mathbb{Z}}{\mathrm{Z}}$ \\
\hline \multicolumn{8}{|l|}{ Work / Employment } \\
\hline \multicolumn{8}{|l|}{ Education/ school } \\
\hline \multicolumn{8}{|l|}{ Supermarket } \\
\hline \multicolumn{8}{|l|}{ Restaurant/ café/ bar/ } \\
\hline \multicolumn{8}{|l|}{ Shopping mall, retail district } \\
\hline \multicolumn{8}{|l|}{ Bank/ ATM } \\
\hline \multicolumn{8}{|l|}{ Entertainment/ movie } \\
\hline \multicolumn{8}{|l|}{ Doctor/ health care } \\
\hline \multicolumn{8}{|l|}{ Park/ Reserve } \\
\hline \multicolumn{8}{|l|}{ Church } \\
\hline \multicolumn{8}{|l|}{ Corner store/ Dairy } \\
\hline \multicolumn{8}{|l|}{ Bakery/ butcher } \\
\hline \multicolumn{8}{|l|}{ Day-care/ Crèche } \\
\hline \multicolumn{8}{|l|}{ Hairdresser } \\
\hline \multicolumn{8}{|l|}{ Library } \\
\hline Sport Participation & & & & & & & \\
\hline
\end{tabular}


11. If you could, what changes would you make to your neighbourhood to make it more liveable

\begin{tabular}{|l|}
\hline \\
\hline \\
\hline \\
\hline \\
\hline \\
\hline \\
\hline \\
\hline
\end{tabular}

Comments:

Write your email here

if you wish to be notified about the completion of this research and where it will be available.

Again, thank you for your time in filling out this survey. By submitting a completed survey your informed Submit and consent to survey consent has been implied.

Your thoughts on what makes your neighbourhood liveable will make a difference to the way neighbourhoods are designed.

Your responses to this survey will be confidential and summarised in the thesis on an anonymous basis. It will not be possible for you to be identified personally. All material collected will only be available to myself and my supervisor and will be permanently deleted one year after the completion of this research.

If you have any queries or would like to receive more information about this survey please feel free to contact myself, Domenico Betanzo at miko_betanzo@yahoo.com, or my supervisor, Graeme McIndoe at Victoria University, PO Box 600, Wellington, 04-463-6234, Graeme.McIndoe@vuw.ac.nz. 
Appendix 2- Flyer 


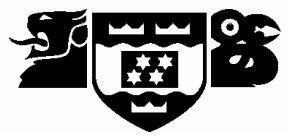

\section{RESEARCH INTO NEIGHBOURHOOD QUALITY}

Hello,

Would you be interested in taking part in an on-line survey on the quality of your neighbourhood? The survey is part of my research for the Victoria University of Wellington, School of Architecture and Design and will go towards my thesis.

If you are interested please e-mail me at: newtownsurvey@yahoo.co.nz and I will e-mail you back with a link to the on-line survey.

If you have any queries or would like to receive more information about this survey please feel free to contact myself, Domenico Betanzo at miko_betanzo@yahoo.com, or my supervisor, Graeme McIndoe at Victoria University, PO Box 600, Wellington, 04-463-6234,

Graeme.McIndoe@vuw.ac.nz.

This survey is to be completed by April 10th for me to include your views in my research

Thank you for your participation: 
Appendix 3- Pilot Ethics Approval 


\begin{tabular}{l|l}
\hline TO & Domenica Betanzo \\
\hline COPY TO & Graeme Mclndoe, Supervisor \\
\hline FROM & Dr Allison Kirkman, Convener, Human Ethics Committee \\
\hline
\end{tabular}

\begin{tabular}{l|l}
\hline DATE & 16 December 2006 \\
\hline PAGES & 1 \\
\hline
\end{tabular}

SUBJECT

Ethics Approval: No 143/2006, A loom for our urban tapestry: exploring the relationships between liveability and density.

Thank you for your application for ethical approval, which has now been considered by the Standing Committee of the Human Ethics Committee.

Your application has been approved and this approval continues until 30 March 2007. If your data collection is not completed by this date you should apply to the Human Ethics Committee for an extension to this approval.

Best wishes with the research.

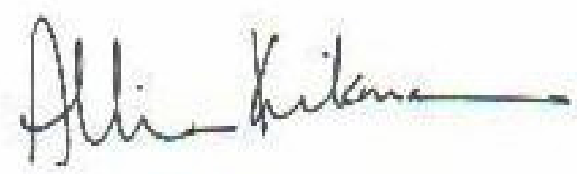

Allison Kirkman

Convener 
Appendix 4- Quantitative Survey 


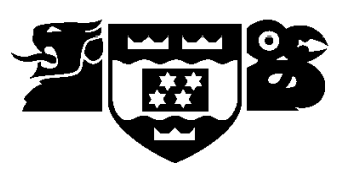

\section{FAIRFIELD Travel Preference Survey}

This survey asks questions about your opinion on a number of day-to-day transportation issues. The survey also asks questions about your preferences concerning transportation options and neighbourhood types. The information you provide will contribute to a $\mathrm{PhD}$ dissertation and is independently funded with the help of Building Research New Zealand.

The survey involves a series of scales or boxes where you can circle or use a check-mark to indicate your answer. It should only take about 10 minutes to complete.

Once you have completed the survey please return it to the researcher in the pre-paid envelope provided.

Thank you for your time in filling out this survey. By submitting a completed survey your informed consent has been implied. Your responses to this survey will be confidential and summarised in a thesis on an anonymous basis.

If you have any questions please contact Domenico Betanzo at:

miko_betanzo@yahoo.com

Thank you for your participation. 


\begin{tabular}{|c|c|c|c|c|c|c|c|}
\hline $\begin{array}{l}\text { Please tick which } \\
\text { transport option } \\
\text { you use MOST }\end{array}$ & 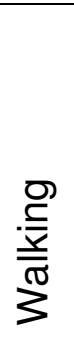 & $\frac{0}{\frac{0}{0}}$ & 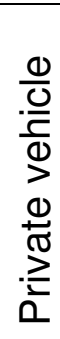 & $\begin{array}{l}\bar{x} \\
\stackrel{\varpi}{\circ}\end{array}$ & 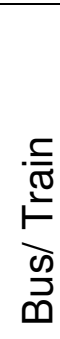 & $\frac{\grave{\Phi}}{\stackrel{Ð}{\Xi}}$ & $\frac{\nwarrow}{Z}$ \\
\hline Tick only one & & & & & & & \\
\hline
\end{tabular}

\begin{tabular}{|c|c|c|c|c|c|c|c|}
\hline $\begin{array}{l}\text { Please tick which } \\
\text { transport option } \\
\text { you WOULD PREFER to } \\
\text { use most }\end{array}$ & 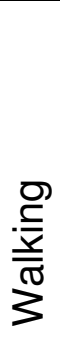 & $\frac{0}{0}$ & 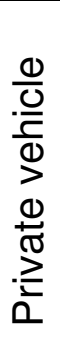 & 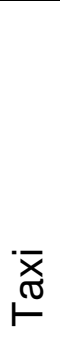 & 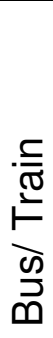 & 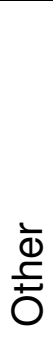 & $\frac{\nwarrow}{z}$ \\
\hline Tick only one & & & & & & & \\
\hline
\end{tabular}

On a scale from 1 to 5 , please rate if you strongly agree, strongly disagree or neither agree nor disagree with the following statements:

1. I like to have a large yard at my home

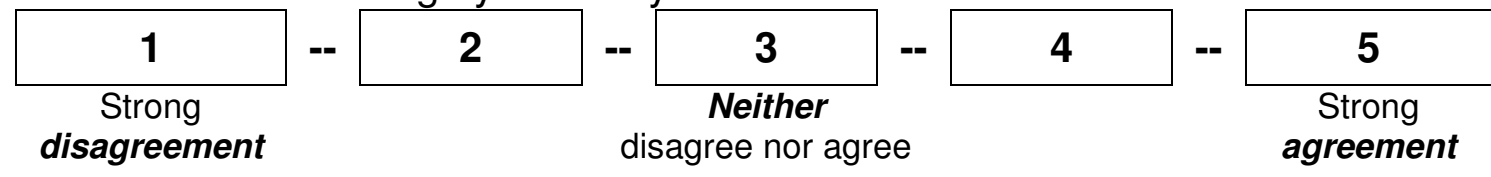

2. I like living in a neighbourhood where there is a lot going on

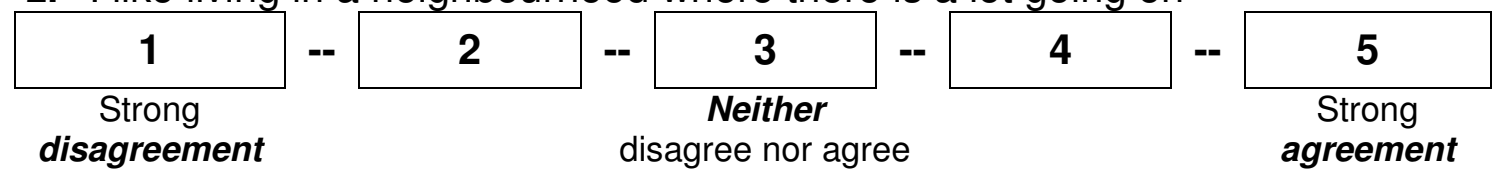

3. Living in a multi family unit wouldn't give me enough privacy

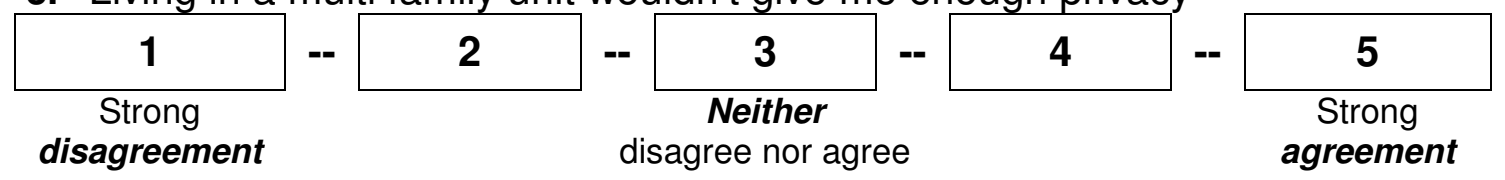

4. Having shops and services within walking distance of my home is important to me

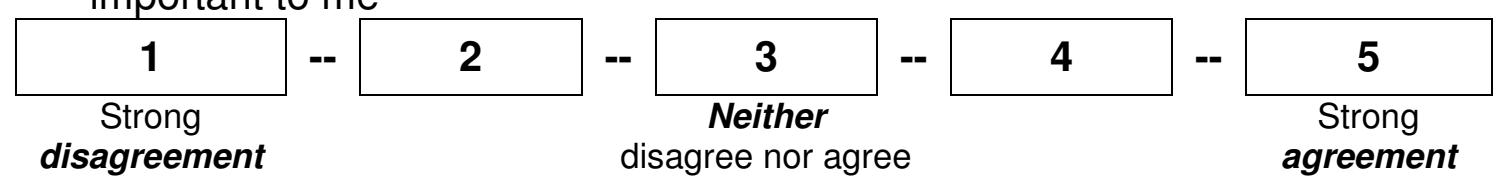


For the following questions, please imagine moving to a different neighbourhood. These questions ask about the kind of neighbourhood you'd hope to find. Please look at the following images and read their neighbourhood descriptions, then circle the appropriate number to indicate your answer. Keep in mind that anything we do not refer to in a question such as school quality, public safety, or house cost - is exactly the same between the two choices presented.

A.

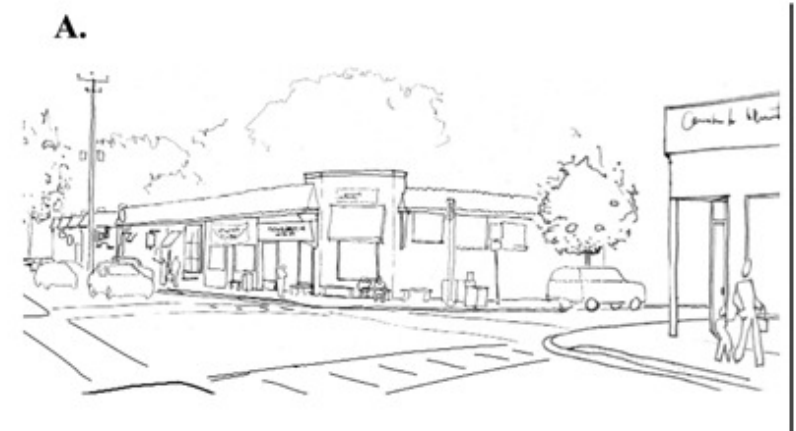

B.

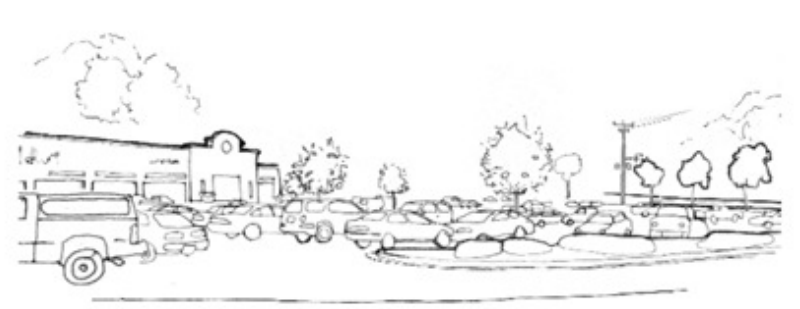

If I were to move, l'd like to find a neighbourhood...

A. Where I can walk to stores, libraries or restaraunts, even if this means that the houses and commercial areas are within a few blocks $(500 \mathrm{~m})$ of each other.
B. Where the commercial areas are kept separate (over 2 kilometres) from the houses, even if this means that I can't walk to stores, libraries or restaraunts.

5. Your neighbourhood preference is:

\begin{tabular}{|c|c|c|c|c|c|c|c|c|c|c|}
\hline 0 & 1 & 2 & 3 & 4 & 5 & 6 & 7 & 8 & 9 & 10 \\
\hline $\begin{array}{c}\text { strongly } \\
\text { prefer A }\end{array}$ & $\begin{array}{c}\text { somewhat } \\
\text { prefer A }\end{array}$ & & neutral & \multicolumn{1}{c|}{$\begin{array}{c}\text { somewhat } \\
\text { prefer B }\end{array}$} & $\begin{array}{c}\text { strongly } \\
\text { prefer B }\end{array}$ \\
\end{tabular}

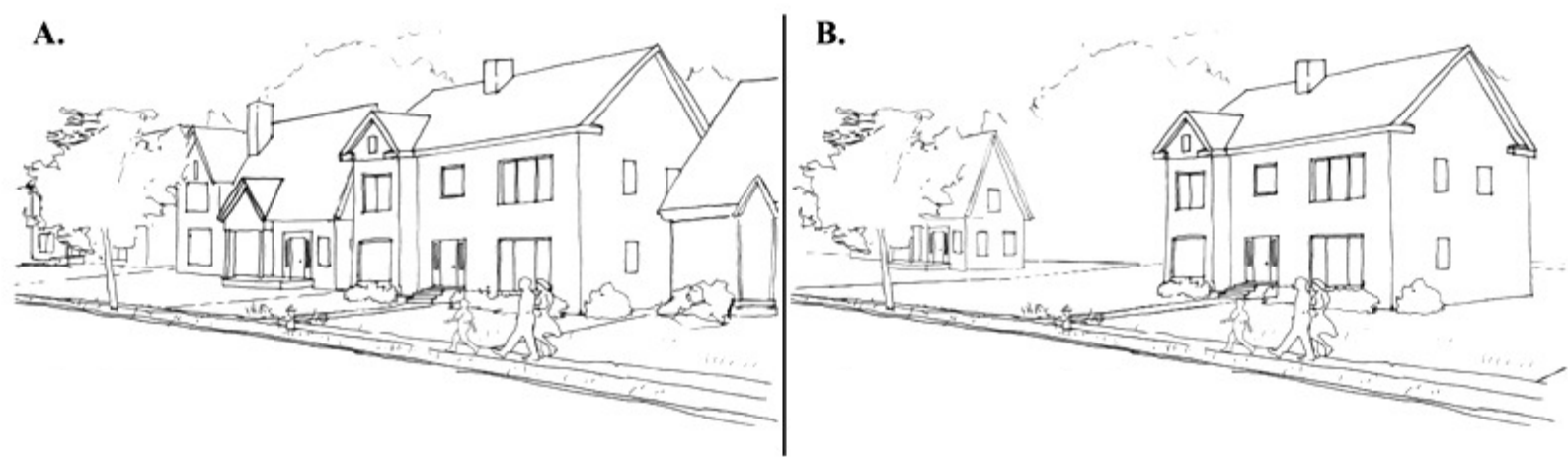

If I were to move, I'd like to find a neighbourhood...

A. within 5-6 km of work, school, or my other important destinations, even if this means the houses are close together - on lots of $1000 \mathrm{~m}^{2}$ or less.
B. with houses farther apart-on lots of $4000 \mathrm{~m}^{2}$ or more, even if this means travelling 25 to 30 kilometers to work, school or my other important destinations.

6. Your neighbourhood preference is:

\begin{tabular}{|c|c|c|c|c|c|c|c|c|c|c|}
\hline 0 & 1 & 2 & 3 & 4 & 5 & 6 & 7 & 8 & 9 & 10 \\
\hline $\begin{array}{c}\text { strongly } \\
\text { prefer A }\end{array}$ & $\begin{array}{c}\text { somewhat } \\
\text { prefer A }\end{array}$ & neutral & \multicolumn{1}{c|}{$\begin{array}{c}\text { somewhat } \\
\text { prefer B }\end{array}$} & $\begin{array}{c}\text { strongly } \\
\text { prefer B }\end{array}$ \\
\end{tabular}

S C H O O L O F A R C H I T E C T U R E

Victoria University of Wellington, PO Box 600, Wellington, New Zealand.

Webpage: http://www.vuw.ac.nz/architecture/ Phone: +64-4463-6200, Email: 


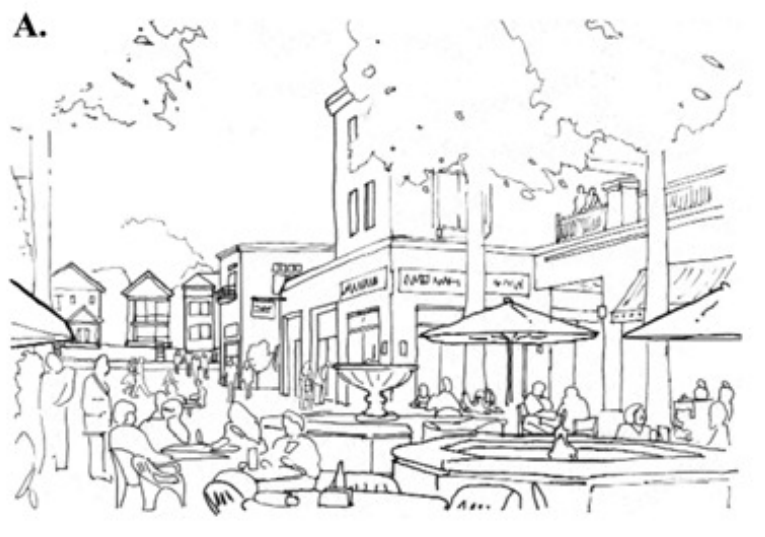

B.

If I were to move, l'd like to find a neighbourhood...

A. that is a lively and active place, even if this means it has a mixture of single family houses, townhouses, and small apartment buildings that are close together on various sized lots

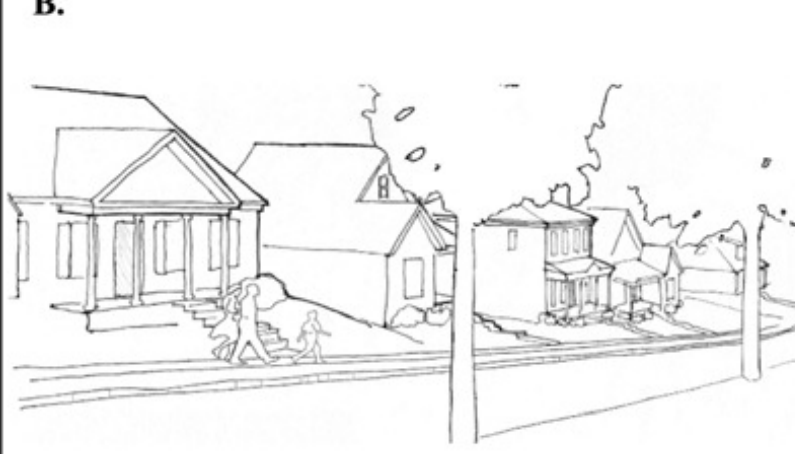

7. Your neighbourhood preference is:

\begin{tabular}{|c|c|c|c|c|c|c|c|c|c|c|}
\hline 0 & 1 & 2 & 3 & 4 & 5 & 6 & 7 & 8 & 9 & 10 \\
\hline $\begin{array}{l}\text { stro } \\
\text { pref }\end{array}$ & & $\begin{array}{c}\text { sor } \\
\mathrm{pr}\end{array}$ & $\begin{array}{l}\text { hat } \\
\text { A }\end{array}$ & & neu & & & $\begin{array}{l}\text { vhat } \\
\text { r B }\end{array}$ & & $\begin{array}{l}\text { rongl } \\
\text { efer } \mathrm{E}\end{array}$ \\
\hline
\end{tabular}

A.

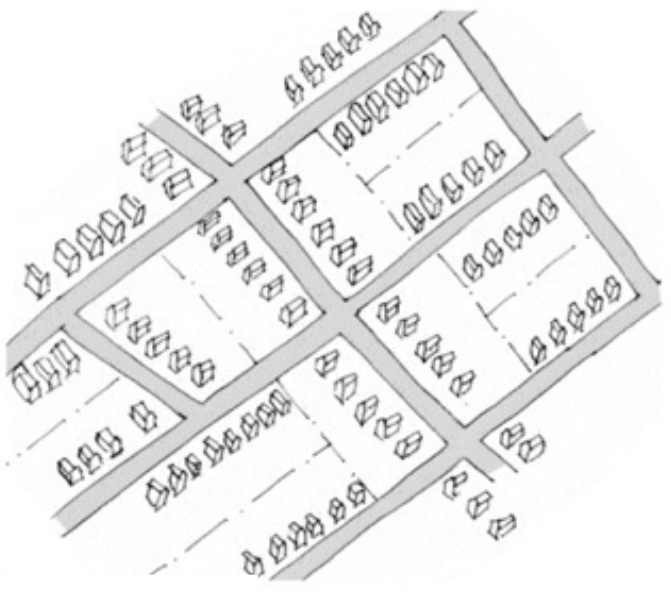

B. with single family houses farther apart-on lots of $1000 \mathrm{~m}^{2}$ or more, even if this means that it is not an especially lively or active place.
B.

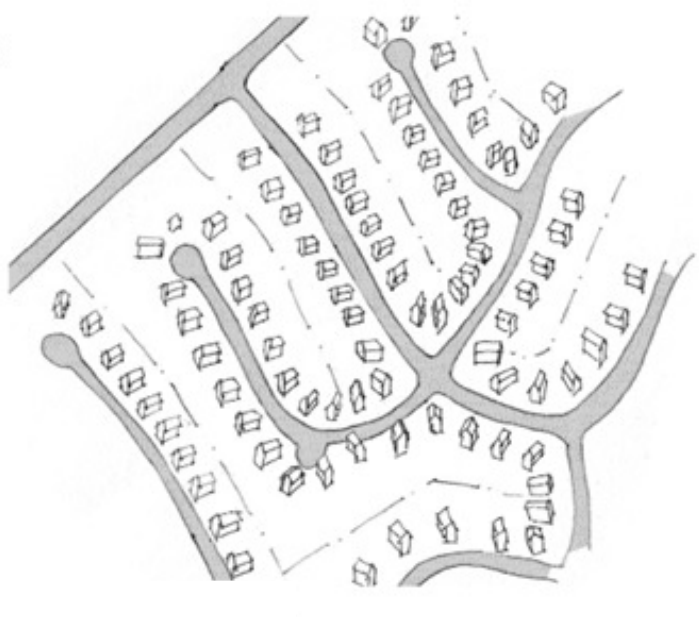

If I were to move, l'd like to find a neighbourhood...

A. within 5-6 km of work, school, or my other important destinations, even if this means having mostly connected streets and some through traffic on the street where I live.
B. with mostly cul-de-sacs and no through traffic, even if this means travelling 25 to 30 kilometers to work, school or my other important destinations.

8. Your neighbourhood preference is:

\begin{tabular}{|c|c|c|c|c|c|c|c|c|c|c|}
\hline 0 & 1 & 2 & 3 & 4 & 5 & 6 & 7 & 8 & 9 & 10 \\
\hline $\begin{array}{l}\text { strc } \\
\text { pre }\end{array}$ & & & & & neu & & & $\begin{array}{l}\text { hat } \\
\text { B }\end{array}$ & & $\begin{array}{l}\text { strongly } \\
\text { orefer B }\end{array}$ \\
\hline
\end{tabular}

S C H O O L O F A R C H I T E C T U R E

Victoria University of Wellington, PO Box 600, Wellington, New Zealand.

Webpage: http://www.vuw.ac.nz/architecture/ Phone: +64-4463-6200, Email: 

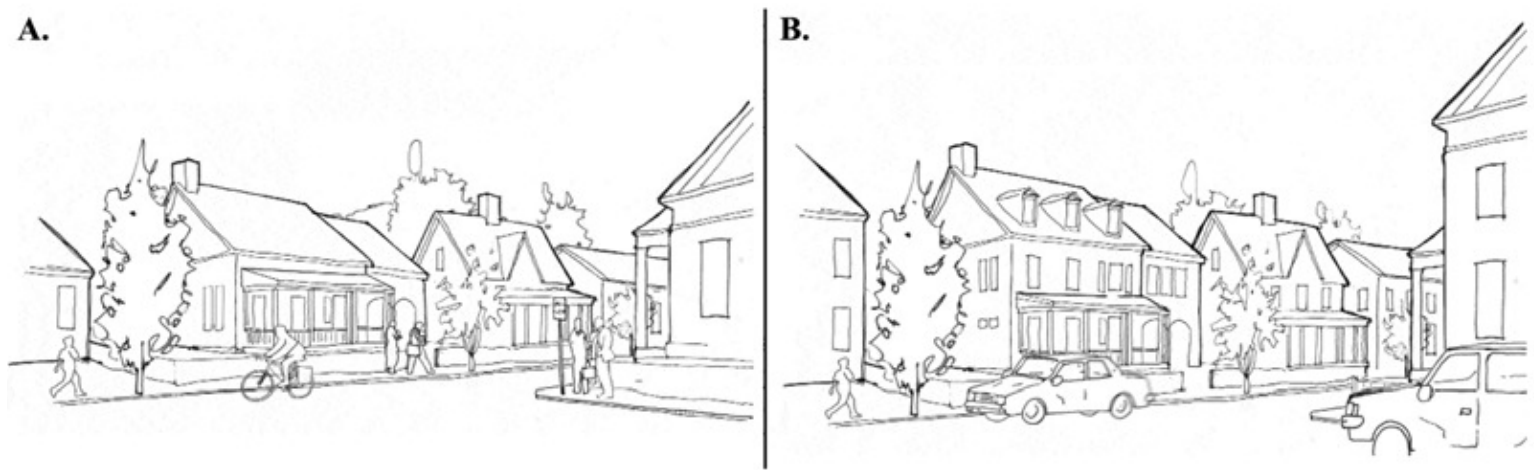

If I were to move, l'd like to find a neighbourhood...

A. where I can walk, bicycle, or take public transit for some of my trips, even if this means that the homes and yards are smaller
B. with larger homes, even if this means I have to drive for all of my trips.

9. Your neighbourhood preference is:

\begin{tabular}{|c|c|c|c|c|c|c|c|c|c|c|}
\hline 0 & 1 & 2 & 3 & 4 & 5 & 6 & 7 & 8 & 9 & 10 \\
\hline $\begin{array}{c}\text { strongly } \\
\text { prefer A }\end{array}$ & $\begin{array}{c}\text { somewhat } \\
\text { prefer A }\end{array}$ & neutral & \multicolumn{1}{c|}{$\begin{array}{c}\text { somewhat } \\
\text { prefer B }\end{array}$} & $\begin{array}{c}\text { strongly } \\
\text { prefer B }\end{array}$ \\
\end{tabular}

A.

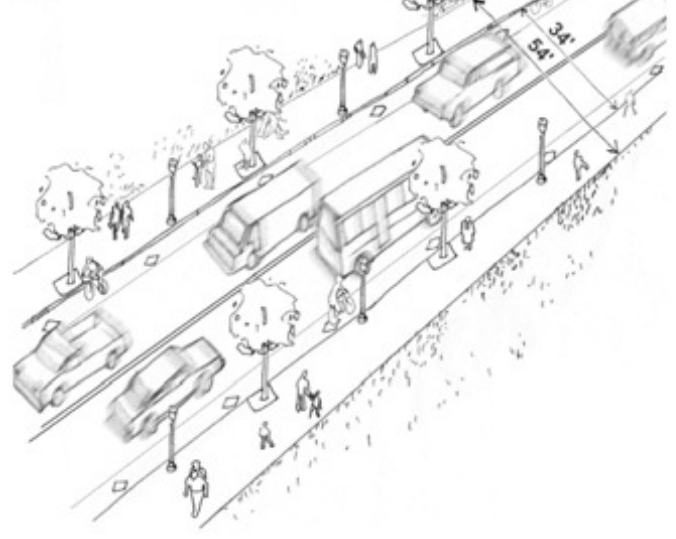

B.

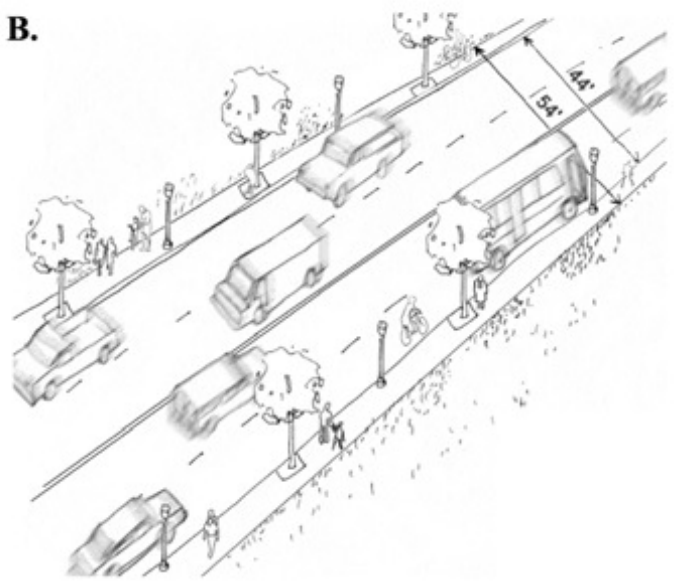

If I were to move, l'd like to find a neighbourhood...

A. that has more space for walking and biking, even if this means less space for cars.
B. that has more space for cars, even if this means less space for walking and biking.

10. Your neighbourhood preference is:

\begin{tabular}{|c|c|c|c|c|c|c|c|c|c|c|}
\hline 0 & 1 & 2 & 3 & 4 & 5 & 6 & 7 & 8 & 9 & 10 \\
\hline $\begin{array}{l}\text { strol } \\
\text { pref }\end{array}$ & & & $\begin{array}{l}\text { hat } \\
\text { A }\end{array}$ & & neut & & $\begin{array}{r}\text { son } \\
\text { pr }\end{array}$ & $\begin{array}{l}\text { hat } \\
\text { B }\end{array}$ & & $\begin{array}{l}\text { trongly } \\
\text { refer } B\end{array}$ \\
\hline
\end{tabular}




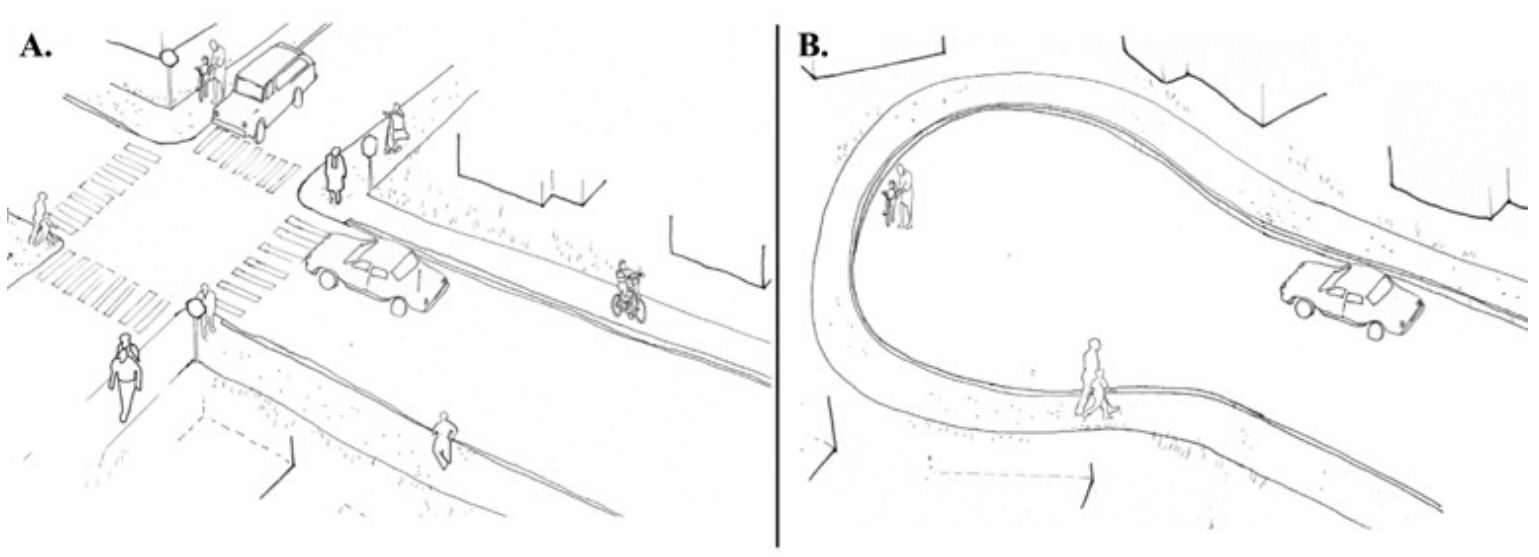

If I were to move, l'd like to find a neighbourhood...

A. where I can walk, bicycle, or take public transit for some of my trips, even if the neighborhood has through streets and people from other neighborhoods walking or driving on them
B. with cul-de-sacs and few people from other neighbourhoods walking or driving on them, even if this means I must drive for all my trips.

11. Your neighbourhood preference is:

\begin{tabular}{|c|c|c|c|c|c|c|c|c|c|c|}
\hline 0 & 1 & 2 & 3 & 4 & 5 & 6 & 7 & 8 & 9 & 10 \\
\hline $\begin{array}{l}\text { stro } \\
\text { pref }\end{array}$ & & $\begin{array}{r}\text { so } \\
\text { p }\end{array}$ & $\begin{array}{l}\text { vhat } \\
\text { r }\end{array}$ & & neu & & $\begin{array}{c}\text { sor } \\
\text { pr }\end{array}$ & $\begin{array}{l}\text { vhat } \\
r \text { B }\end{array}$ & & $\begin{array}{l}\text { trongly } \\
\text { refer } \mathrm{B}\end{array}$ \\
\hline
\end{tabular}

12. How long have you lived at your current address?

Number of years

Number of months

13. If you have moved in the last 3 years, what was the name of the previous neighbourhood/area you lived in and where was it?

\begin{tabular}{|c|c|}
\hline neighbourhood name & \\
\hline what city and country & \\
\hline
\end{tabular}

14. How would you feel if you had to move to another neighbourhood?

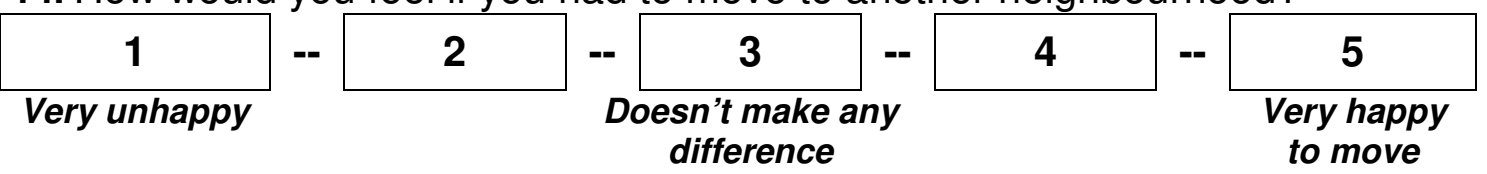

15. I feel strongly attached to my neighborhood?

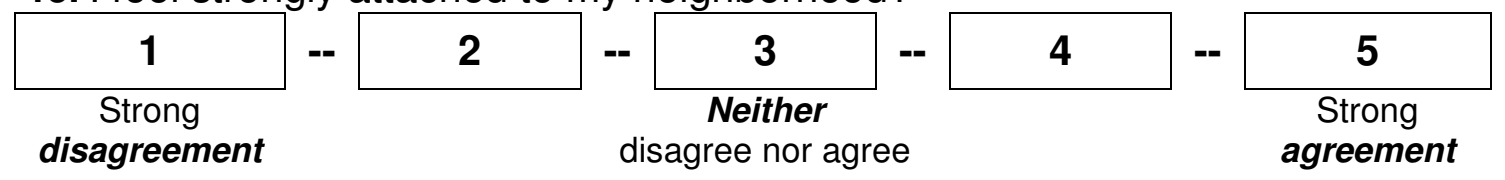


16. My neighbourhood reflects the type of person I am

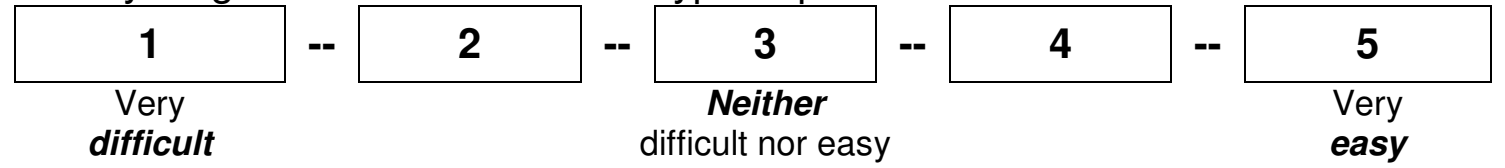

17. People like me live in my neighbourhood

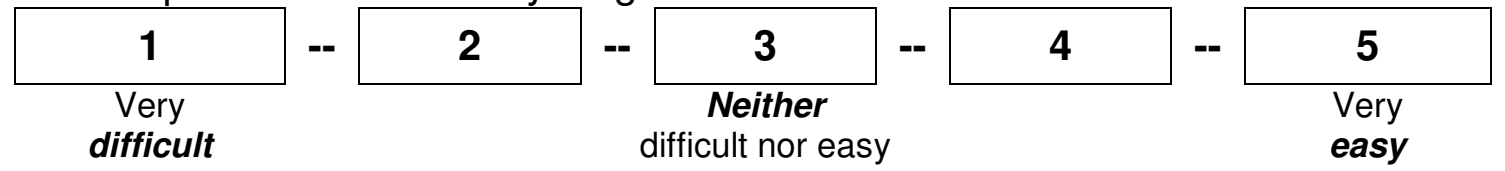

18. Considering the effort involved and financial costs, how difficult would it be for you to move from your current neighbourhood

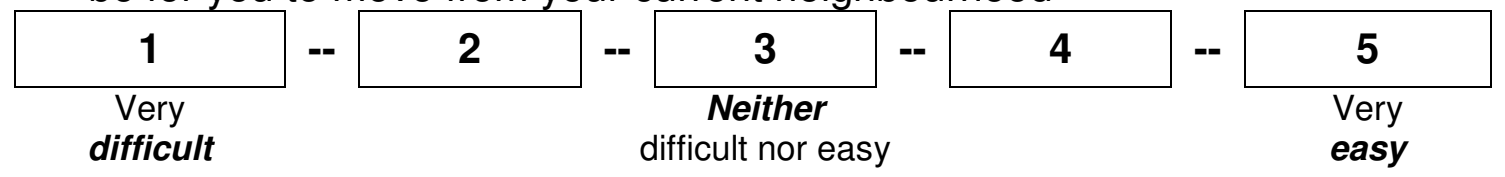

19. For me, the hassles of moving outweigh the benefits

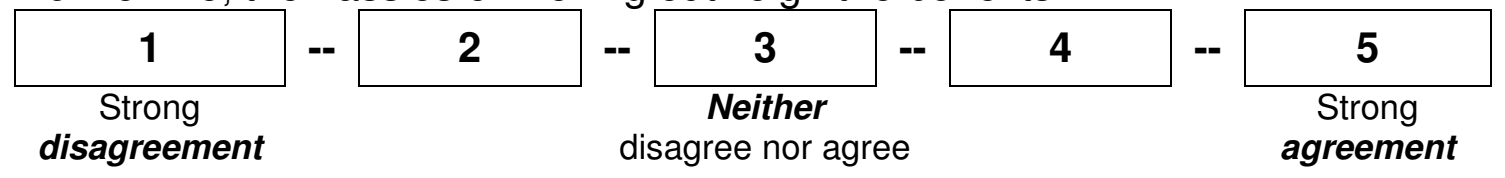

20. In your neighbourhood, how difficult would it be for you to take alternatives to the car to work or school

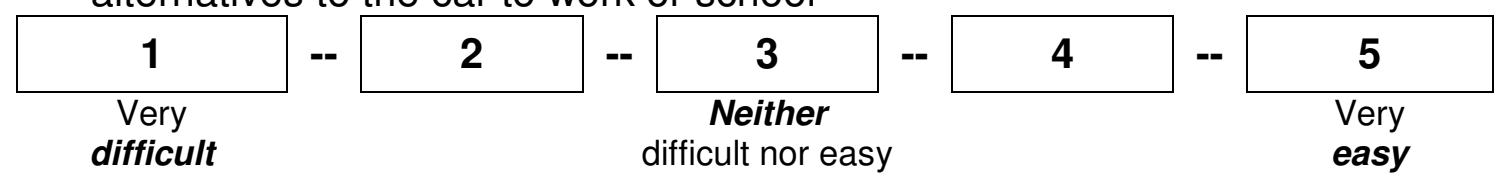

Please indicate if you agree or disagree with the following statements.

21. Car use doesn't significantly contribute to the depletion of energy sources

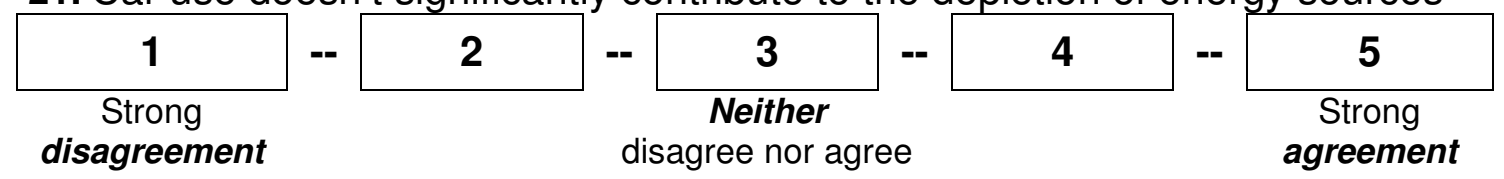

22. Car use requires paving over more natural areas than would be required by other modes of transport (bus, rail, walking, cycling)

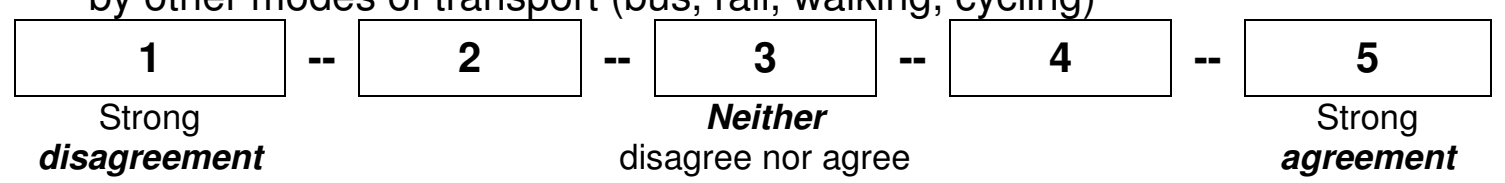

23. Commuting by private car is bad for the environment

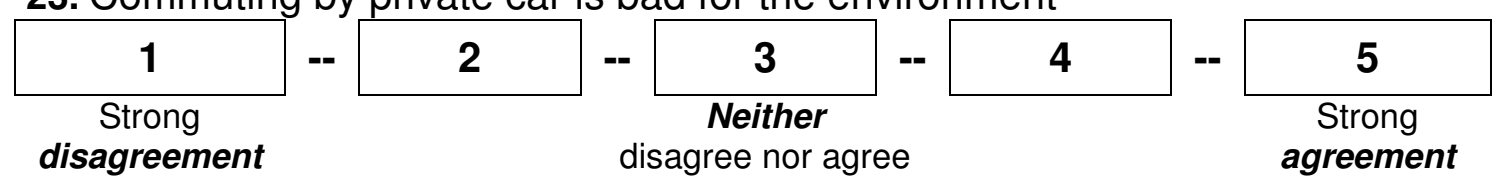


24. Car use and traffic make it difficult and undesirable to walk in some neighbourhoods

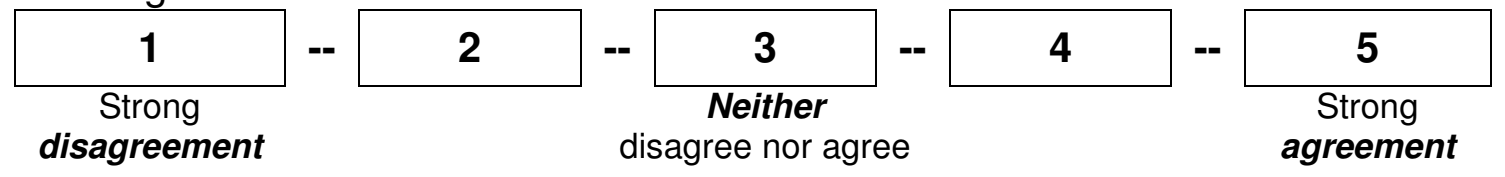

25. People that drive most of the time are just as likely to get as much day to day exercise as people who normally walk or take public transportation

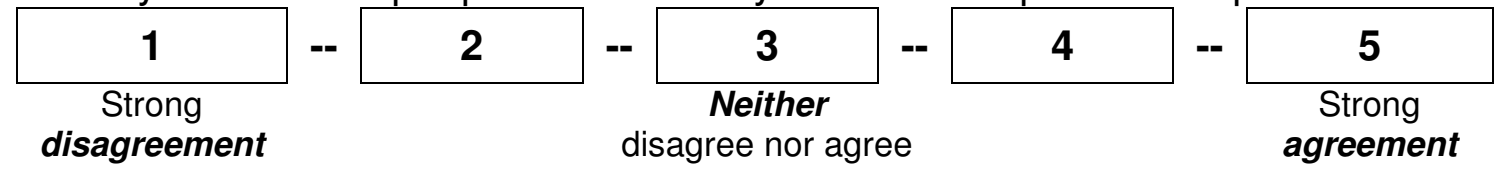

26. The obesity epidemic is linked to excessive dependence on the private automobile

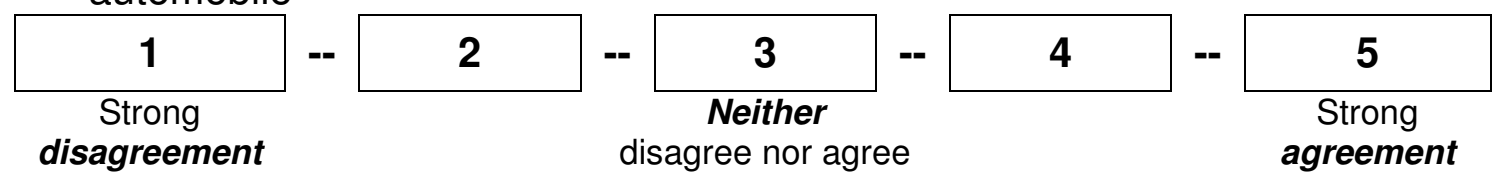

27. Long car commutes DO NOT affect opportunities to get to know neighbours

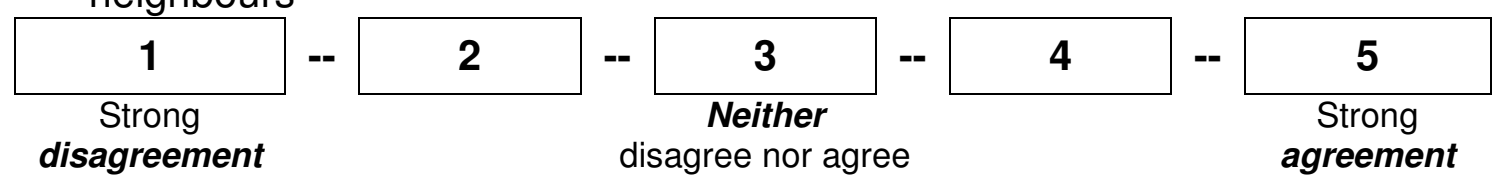

28. Walking to the destinations people frequent would help them to get to know their neighbours

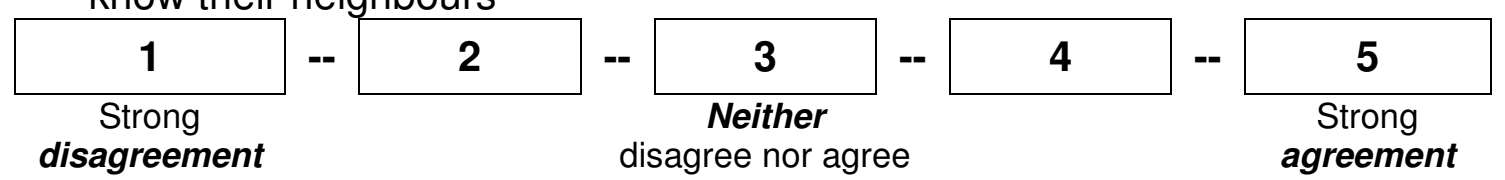

29. The best way to stimulate the economy is by building more roads and highways

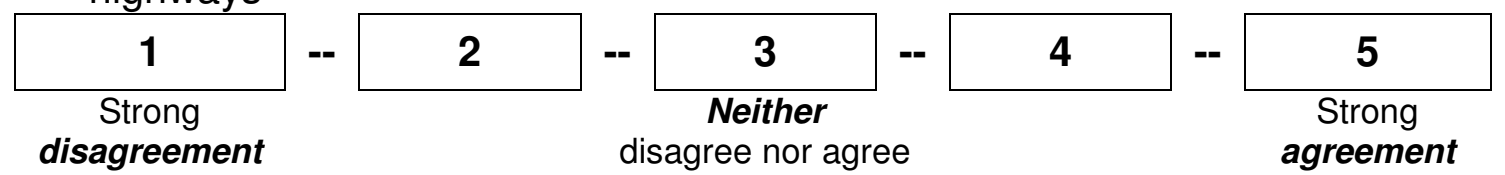

30. I would be willing to pay a toll to travel on an uncongested road

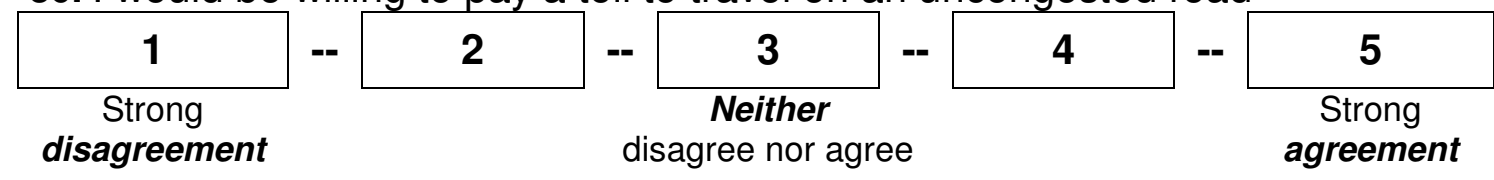

31. We need more parking downtown

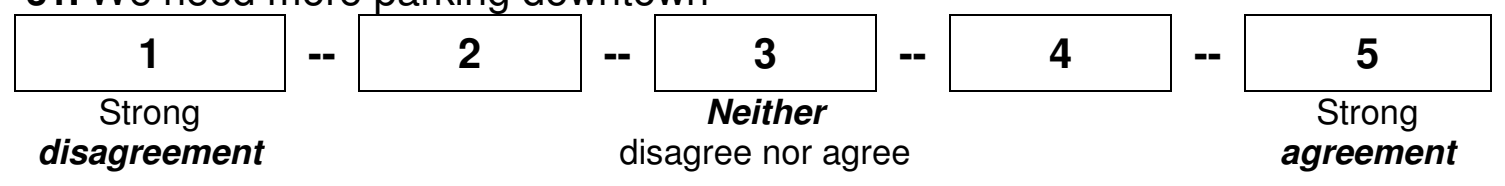


32. Automobile infrastructure should receive more funding than public transportation, cycling and walking infrastructure because more people drive

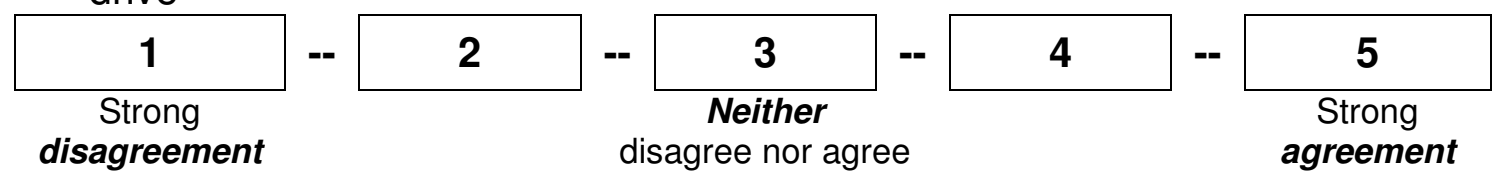

33. We should raise the price of fuel to reduce air pollution and congestion

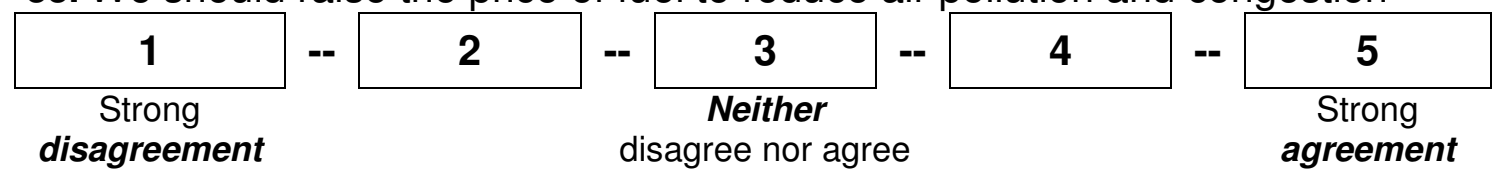

34. To reduce air pollution and congestion we should raise taxes to improve public transportation

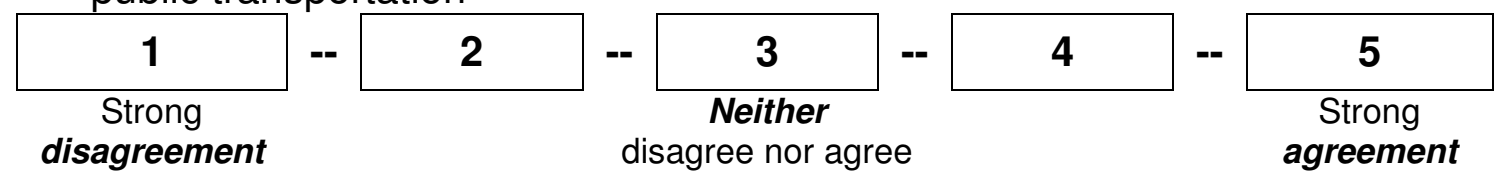

35. Getting stuck in traffic doesn't bother me much

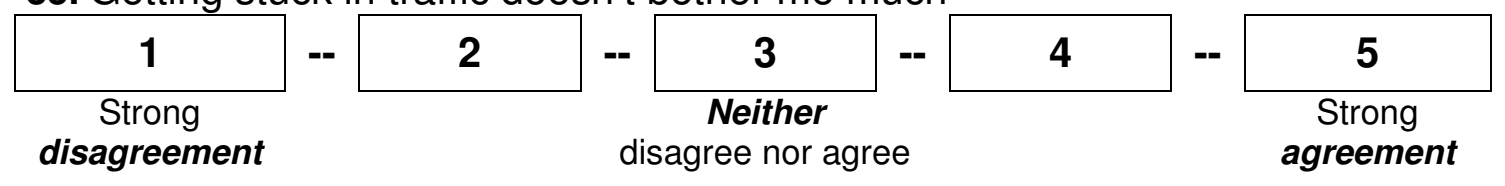

36. Narrow roads are preferable to wide ones to reduce the speed of cars

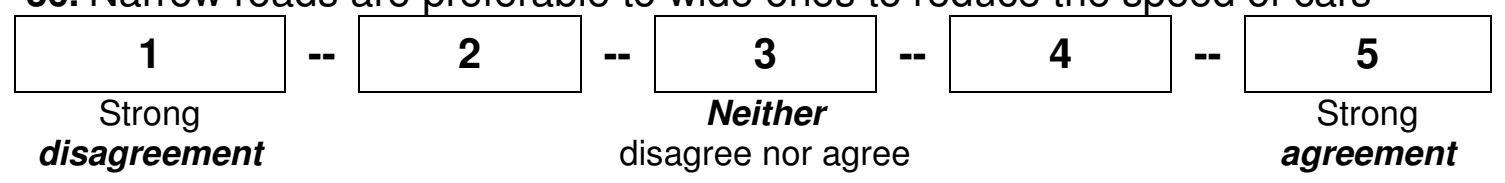

37. I feel personally responsible for the problems resulting from car use when I drive

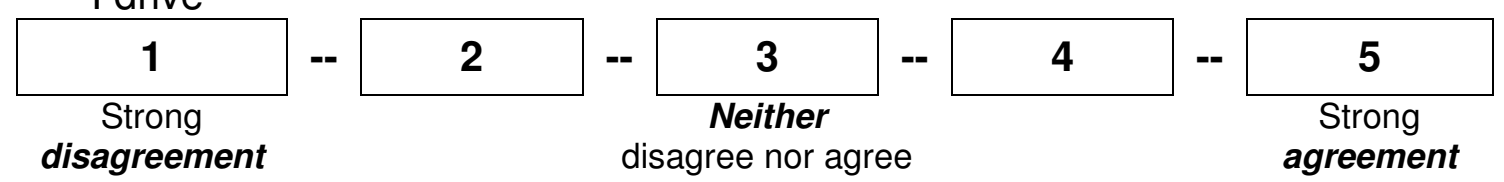

38. I feel guilty about taking my car when I go to work/school

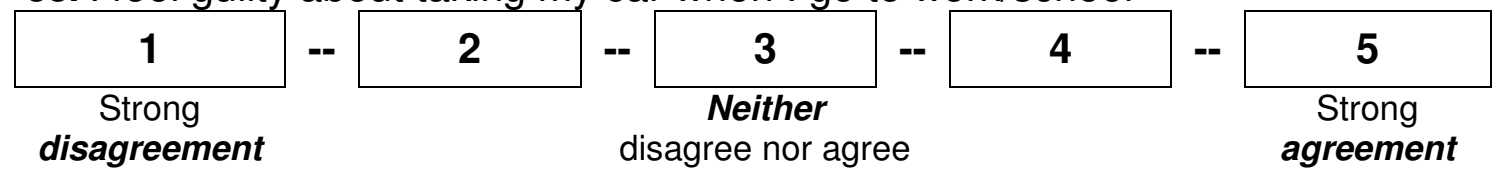




\section{Demographics:}

1. Sex:

Male

Female

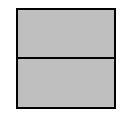

2. Age group: (circle your group)

\begin{tabular}{|l|c|c|c|c|c|}
\hline Age & $15-24$ & $25-34$ & $35-49$ & $50-64$ & $65+$ \\
\hline
\end{tabular}

3. Number of vehicles in your household?

4. Please indicate your gross household income per year [before tax].

$\square \$ 25,000$ or less

$\square$ Between $\$ 25,001$ \& $\$ 45,000$

$\square$ Between $\$ 45,001 \& \$ 75,000$

$\square$ Between $\$ 75,001 \& \$ 100,000$

$\square 100,001$ or more

\section{Thank you- You have completed the survey!}

If you'd like to participate in future research or to know where this research will be available please include your email address below (or other contact details):

Please feel free to email me if you wish to add any comments to any of your answers. None of the information you provide will be used for any other purpose other than this dissertation or for publications as summaries of this study. 
Appendix 5- On-Line Qualitative Survey 


\section{VICTORIA UNIVERSITY OF WELLINGTON}

Te Whare Wananga o te Upoko o te Ika a Maui

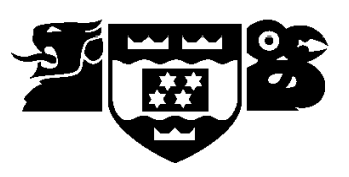

\section{Qualitative Survey Questions}

Neighbourhood and Travel Preference Survey

Recently you may have completed a mailed out survey that asked questions about your transportation and neighbourhood preferences and you indicated that you would like to be involved in further research. This survey is a follow up to that initial survey and asks a number of open ended questions about your preferences. There are just 6 written answer questions that allow you to write long answers or just provide point form notes.

Click the link below to get to the survey.

\section{http://www.surveymonkey.com/s.aspx?sm=GC6L19Z407eXPUhH5gtu4Q} 3d $3 d$

If you were emailed this message but haven't done the mailed out survey, you may still be interested in sharing your opinions about your preferences and your help would be greatly appreciated.

Thank you very much for your input and participation! Please feel free to pass this email along to other people in your neighbourhood.

Thank you for the time you've taken to fill out this survey. Your neighbourhood and travel preferences are important to this research and to help design better neighbourhoods.

Your responses to this survey will be confidential and summarised in a dissertation and subsequent publications on an anonymous basis. It will not be possible for you to be identified personally.

If you have any queries or would like to receive more information about this survey please feel free to contact myself, Domenico Betanzo at miko_betanzo@yahoo.com, or my supervisor, Gordon Holden at Victoria University, PO Box 600, Wellington, 0-4-463 6230, gordon.holden@vuw.ac.nz

A. What is the name of the neighbourhood you live in?

1. If you can remember, what were the most important factors that led you to move to the neighbourhood you live in now? 
2. Most neighbourhoods are unable to satisfy all the preferences and desires a person might have and are often a compromise of some preferences for others. Can you list some things (if any) you would like to see improved in your neighbourhood or that are a compromise for you. (Some typical examples are; local amenities within walking distance, more trees, more/ better off-street parking, less traffic, less noise, better neighbours, lower property prices, slower traffic, shorter commutes and less crime-but please add whatever factors you think of)

3. What factor(s) most influence you to remain in your neighbourhood (unless you are planning to move in the near future) rather than relocate to a neighbourhood that you feel would realise more of your preferences.

4. Can you please tell me how you currently travel for most of the trips you would make in a week (going to work, school, grocery shopping etc.) and why you think you use the mode of travel that you do most frequently(drive, bus, walk, cycle etc.). (I.E. If you walk for most of your trips- why do you think this is - and why don't you drive instead. Or conversely if you drive for most of your trips why do you think this is and why don't you walk instead or bicycle or take the bus etc.)

5. Do you identify with your neighbourhood and/or the people in it, please explain? 
Appendix 6- Ethics Approval 


\section{MEMORANDUM \\ Phone $\quad 0-4-4635676$ \\ Fax 0-4-4635209 \\ Email_Allison.kirkman@vuw.ac.nz}

\begin{tabular}{l|l}
\hline TO & Domenico Betanzo \\
\hline COPY TO & Professor Gordon Holden, Supervisor \\
\hline FROM & Dr Allison Kirkman, Convener, Human Ethics Committee \\
\hline
\end{tabular}

\begin{tabular}{l|l}
\hline DATE & April 8, 2009 \\
\hline PAGES & 1 \\
\hline
\end{tabular}

\begin{tabular}{l|l}
\hline SUBJECT & $\begin{array}{l}\text { Ethics Approval: No 16457, Commuting travel behaviour: } \\
\text { measuring a moving target. }\end{array}$ \\
\hline
\end{tabular}

Thank you for your application for ethical approval, which has now been considered by the Standing Committee of the Human Ethics Committee.

Your application has been approved from the above date and this approval continues until 30 May 2009. If your data collection is not completed by this date you should apply to the Human Ethics Committee for an extension to this approval.

Best wishes with the research.

\section{Allison Kirkman}

Convener 